UNIVERSIDAD POLITÉCNICA DE VALENCIA

INSTITUTO DE INGENIERÍA ENERGÉTICA

DEPARTAMENTO DE INGENIERÍA MECÁNICA Y MATERIALES

Doctoral program "Ingeniería y Producción Industrial"

\title{
Modelling and analysis of a metal hydride cooling system
}

\section{PhD candidate: Jorge Payá Herrero}

PhD director: Dr. J.M. Corberán Salvador

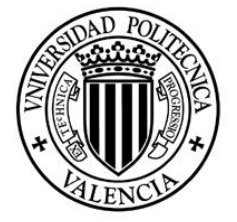

UNIVERSIDAD POLITECNICA DE VALENCIA Energética

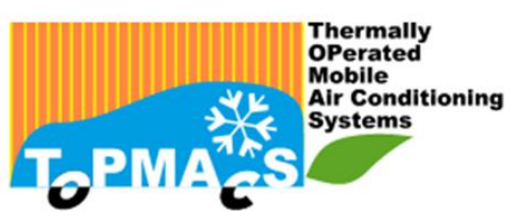

Valencia, September 2010 


\section{UNIVERSIDAD POLITÉCNICA DE VALENCIA}

INSTITUTO DE INGENIERÍA ENERGÉTICA

UNIVERSIDAD Instituto

POLITECNICA Ingeniería

DE VALENCIA Energética

José Miguel Corberán, Dr. from the Polytechnic University of Valencia and head of the Institute for Energy Engineering,

\section{CERTIFIES THAT}

The work which is presented by J. Payá Herrero, titled "Modelling and analysis of a metal hydride cooling system" has been carried out at the Institute for Energy Engineering under my supervision and assessment.

As the modelling and experimental objectives have been reached, I authorise the submission of this $\mathrm{PhD}$ work for its evaluation by the corresponding examination board.

Valencia, September 2010

José Miguel Corberán Salvador 


\section{ACKNOWLEDGEMENTS}

This PhD project is the final result of 4 intensive years dealing with metal hydrides, a field which was initially not the expertise of our department. Thus, I had to overcome several obstacles during this time such as the lack of documentation or of an experimental installation. Nevertheless, I am very pleased with the results and I would like to thank the director of my PhD, José Miguel Corberán, for his comments and fruitful guidance during this project.

Working in the European project TOPMACS provided me a great opportunity to collaborate with the research institute IKE from Stuttgart, one of the few places in the world with an experimental metal hydride cooling system. I would like to thank Rainer Mertz, Rudy Kulenovich and Laurien Eckhart for encouraging me to stay at their institute during 5 months with a grant from the DAAD. Working at IKE improved substantially the quality of my $P h D$ in both experimental and theoretical aspects.

A special mention for Marc Linder from IKE, it has been a pleasure working with him throughout both of our PhD's. I will always be grateful for his help during my 5 months' stay in Stuttgart.

During the development of my research, which I mostly did at the institute IIE, on a daily basis, the friendly relationship with all of the staff made it very easy to work. I will always remember many of the students or staff with whom I have shared more than one laugh; Javi, Max, Paula, Teo, Jose, Joan, Dani, Pablo, Emmanuel, Oliver, Christian, Alex, Israel, Carla, Pepe and many more...Special thanks for Rafa for always helping me with any software problems and for everything we've shared during this time.

As in any other long-term research project, I had to face many problems or small disappointments in which I always had the help from my family. I will always be grateful to my parents and my sister for all of their love and support no matter when. Finally, on a more personal scale I would like to thank my beloved girlfriend Aurore who has constantly helped me and motivated me both at work and on my life. 
This $\mathrm{PhD}$ has been supported by the following research grants and projects:

- European project TOPMACS (Thermally Operated Mobile AirConditioning Systems), funded by the European Commission under the $6^{\text {th }}$ European Community framework program (Contract Ref. TST4-CT2005-012471). The TOPMACS project aims to apply different sorption technologies for the cooling in automotive applications with heat recovery from the engine.

- J. Payá has received a Research Fellowship from the FPU program of the Spanish Science and Innovation Ministry (Ministerio de Ciencia e Innovación, Ref. AP2007-04556).

- Part of the contents of the experimental campaign of this PhD work has been performed at IKE (Stuttgart). The 5 months stay (October 2009February 2010) was financed by the German institution DAAD (Ref. $\mathrm{A} / 09 / 95083)$. 
This $\mathrm{PhD}$ work has been partially published in:

- Paya, J., Linder, M., Mertz, R., and Corberan, J. M., Analysis and optimisation of a metal hydride cooling system, International Journal of Hydrogen Energy, In Press, doi: 10.1016/j.ijhydene.2010.08.112

- Paya, J., Linder, M., Laurien, E., and Corberan, J. M., Dynamic model an experimental results of a thermally driven metal hydride cooling system, International Journal of Hydrogen Energy 34 (7) (2009), pp. 3173-3184

- Paya, J., Linder, M., Laurien, E., and Corberan, J. M., Mathematical models for the P-C-T characterization of hydrogen absorbing alloys, Journal of Alloys and Compounds 484 (1-2) (2009), pp. 190-195

- Paya, J., Corberan, J. M., Linder, M., and Mertz, R., Thermally driven metal hydride cooling systems: Experimental and numerical results of a 400W system, $3^{\text {rd }}$ International Conference on Solar Air-Conditioning (Palermo) (2009), pp. 222-229

- Paya, J., Corberan, J. M., Linder, M., and Mertz, R., Dynamical model of a metal hydride cooling system driven by waste heat, Proceedings of the $2^{\text {nd }}$ International Conference on Solar Air-Conditioning, Tarragona (2007), pp. 529-534

- Paya, J. and Corberan, J. M., Theoretical model of the effective thermal conductivity of sorption materials, Proceedings of the $2^{\text {nd }}$ International Conference on Solar Air-Conditioning, Tarragona (2007), pp. 322-327 


\section{SUMMARY}

The following PhD thesis has been carried out in the Institute for Energy Engineering of the Polytechnic University of Valencia. Part of the PhD has been realised in Stuttgart (Germany) at the Institüt für Kernenergetik und Energiesysteme (IKE).

This $\mathrm{PhD}$ thesis consists in the modelling and validation of a metal hydride cooling system. The experimental prototype is located in the institute IKE.

In the first place, the hydrogen absorbing materials have been characterized in terms of the static P-C-T properties and of the intrinsic reaction kinetics. In the second place, after this first characterization phase, a completely dynamic model has been developed based on the heat and mass transfer processes which take place in the reactors. The results have been validated with an exhaustive experimental campaign of dynamic cooling tests and the adjustment of the model is very good.

Finally, the cooling performance of the system has been improved by means of the model which has enabled the optimization of the operating conditions and of the sorption materials. 


\section{RESUMEN}

La tesis doctoral que se presenta a continuación ha sido realizado en el Instituto de Ingeniería Energética de la Universidad Politécnica de Valencia, y parcialmente en el instituto de Stuttgart (Alemania) "Institüt für Kernenergetik und Energiesysteme" (IKE).

El presente estudio consiste en el modelado y validación de un sistema de producción de frío basado en la absorción/desorción de hidrógeno en metales. La instalación experimental que se ha modelado se halla en el instituto IKE.

En primer lugar, los materiales utilizados se han caracterizado tanto desde el punto de vista de las curvas P-C-T de equilibrio como de la cinética de absorción/desorción de cada aleación. En segundo lugar, se ha desarrollado un modelo completamente dinámico basado en las reacciones de transferencia de calor y masa que ocurren en los reactores. Los resultados se han validado con una amplia gama de medidas de IKE en régimen transitorio, obteniendo un ajuste muy bueno para diferentes ensayos.

Finalmente, mediante la utilización del modelo, se han optimizado las condiciones de operación y las propiedades de los materiales, alcanzando así mejores prestaciones en refrigeración. 


\section{RESUM}

La tesi doctoral que es presenta a continuació s'ha realitzat a l'Institut d'Enginyeria Energètica de la Universitat Politècnica de València, i parcialment a l'institut de Stuttgart (Alemanya) "Institut für Kernenergetik und Energiesysteme" (IKE).

Aquest estudi consisteix en el modelatge i validació d'un sistema de producció de fred basat en la absorció/desorció d'hidrogen en metalls. La instal.lació experimental que s'ha modelat es troba a l'institut IKE.

En primer lloc, els materials utilitzats s'han caracteritzat tant des del punt de vista de les corbes P-C-T d'equilibri com de la cinètica de absorció/desorció de cada aliatge. En segon Iloc, s'ha desenvolupat un model completament dinàmic basat en les reaccions de transferència de calor i massa que ocorren en els reactors. Els resultats s'han validat amb una àmplia gamma de mesures de IKE en règim transitori, obtenint un ajust molt bo per diferents assaigs. Finalment, mitjançant la utilització del model, s'han optimitzat les condicions d'operació i les propietats dels materials, aconseguint així millorar les prestacions en refrigeració. 


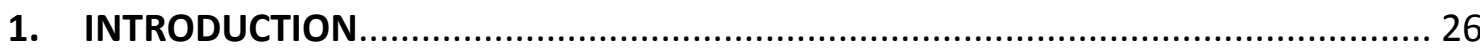

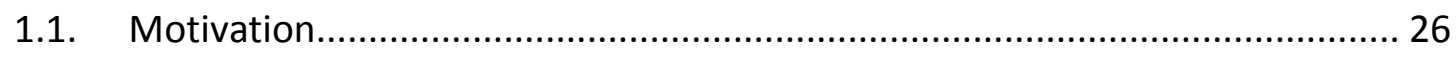

1.2. Introduction on metal hydride cooling systems ......................................... 28

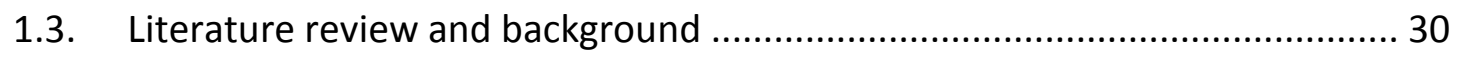

1.3.1. State of the art of the technology ...................................................... 30

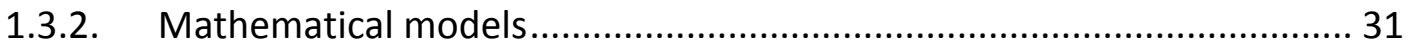

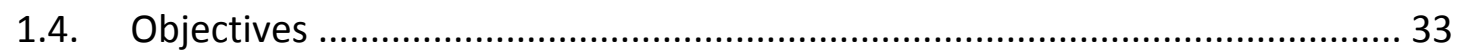

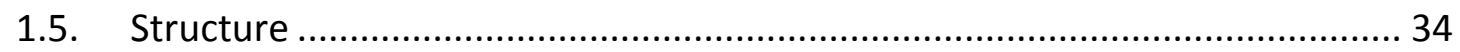

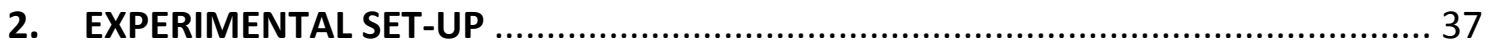

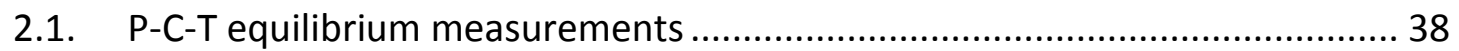

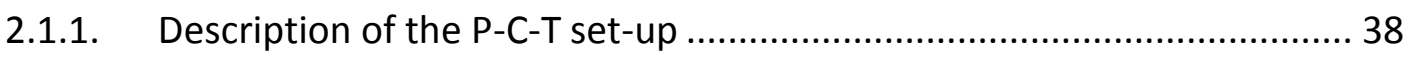

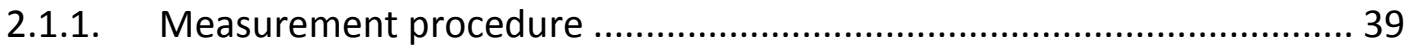

2.1.1. Uncertainty of the measurements ....................................................... 42

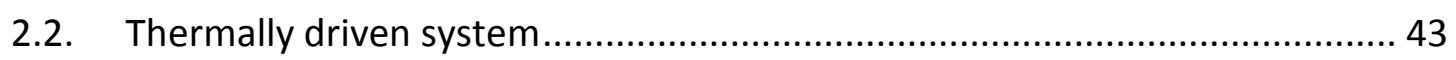

2.2.1. Description and technical specifications ............................................. 43

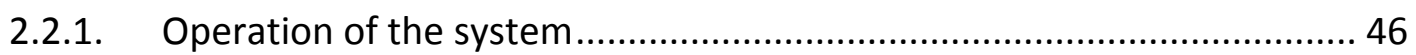

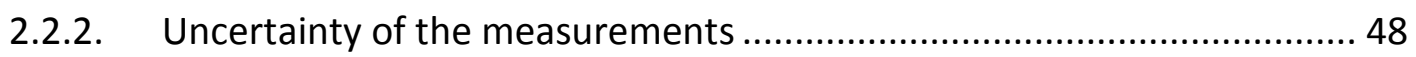

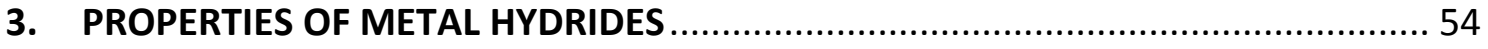

3.1. Brief description of the sorption reaction ................................................... 54

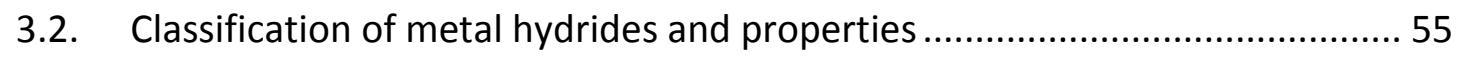

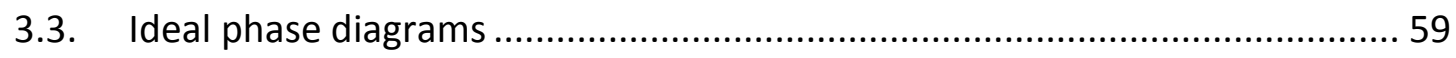

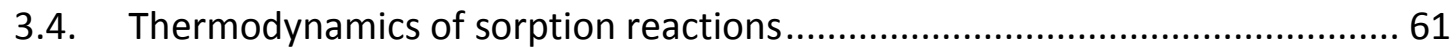

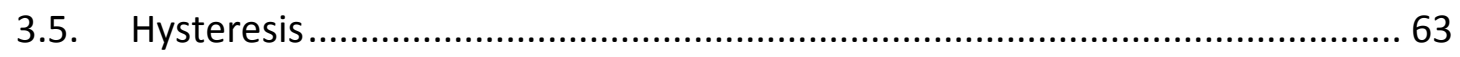

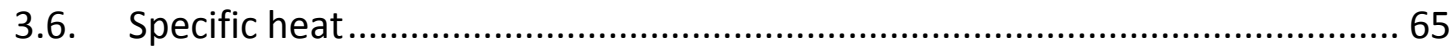

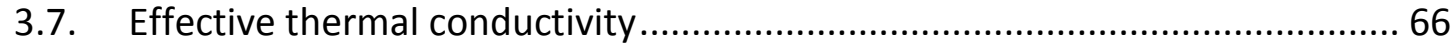

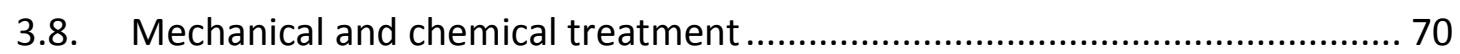

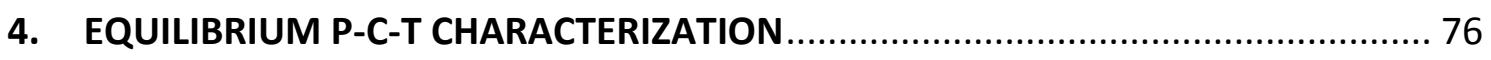

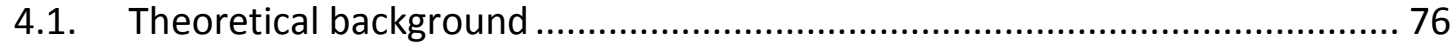

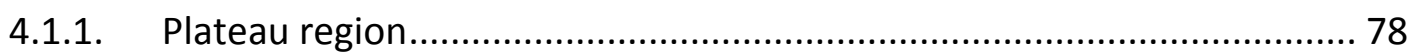

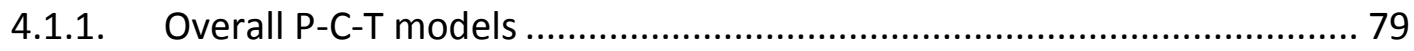




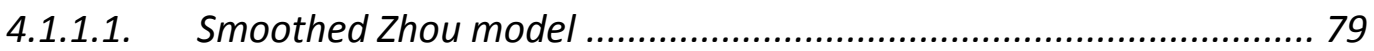

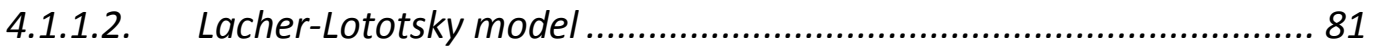

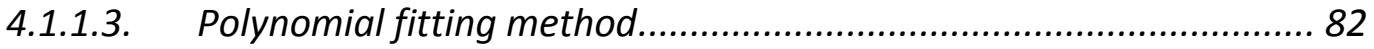

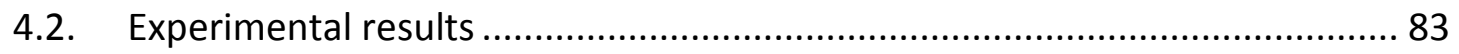

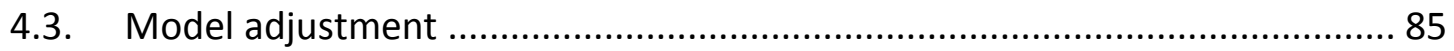

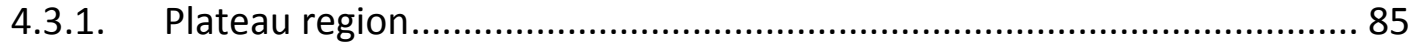

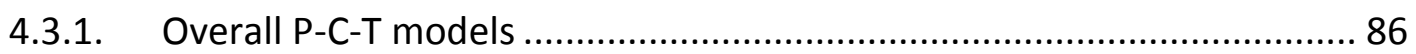

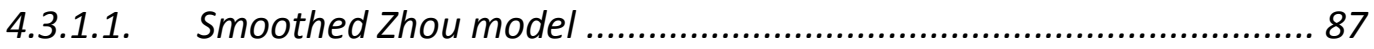

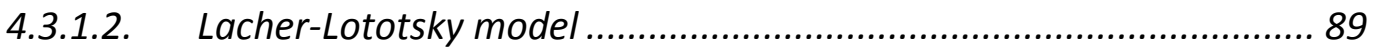

4.3.1.3. Polynomial fitting method........................................................... 91

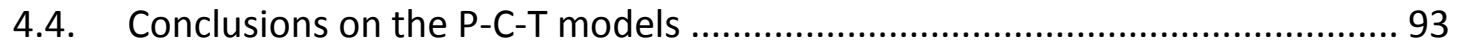

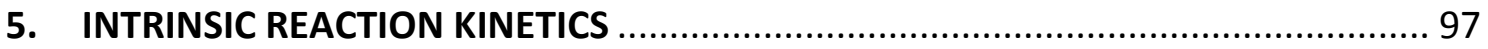

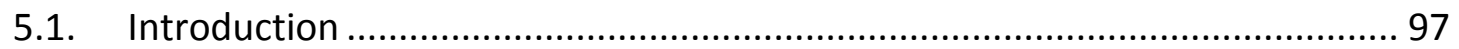

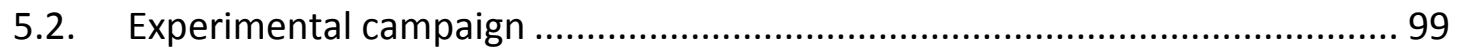

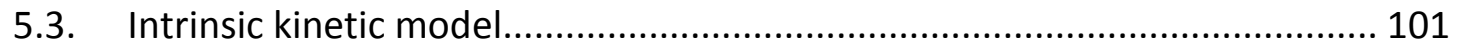

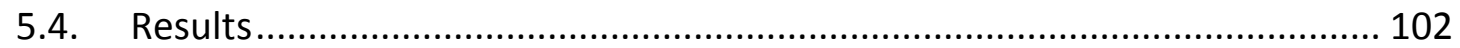

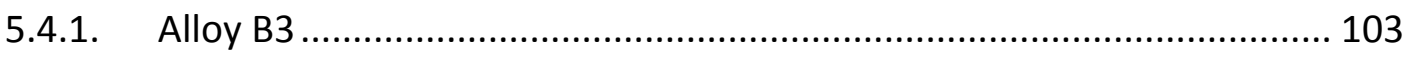

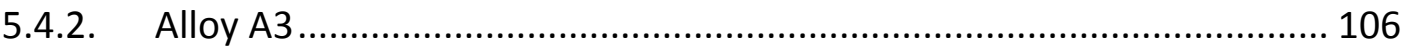

5.5. Conclusions on the intrinsic reaction kinetics ........................................... 109

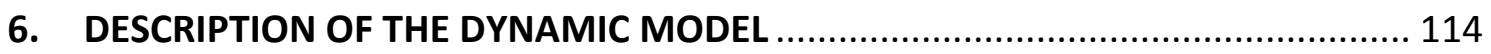

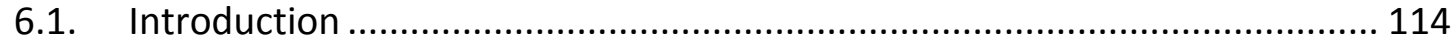

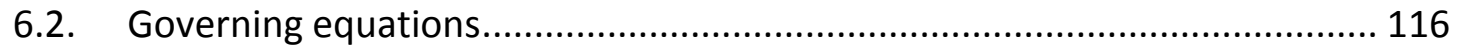

6.2.1. Heat and mass transfer equations ................................................. 117

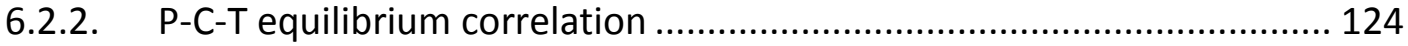

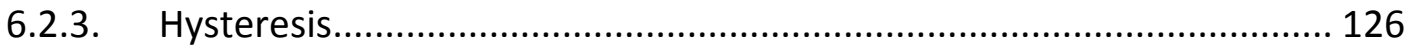

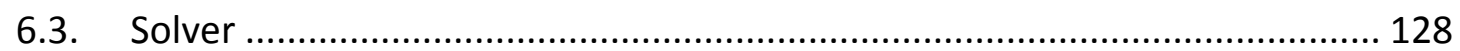

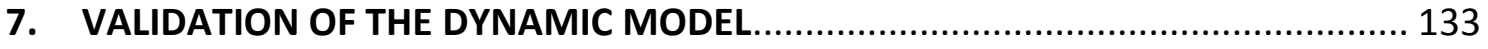

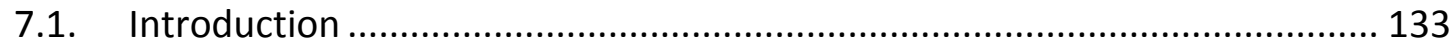

7.2. Validation of the model with experimental tests ...................................... 135

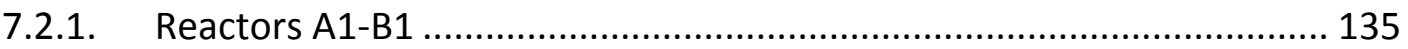

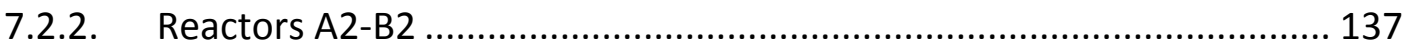




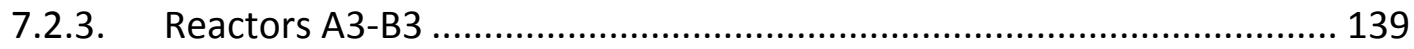

7.2.3.1. Maximum cooling power tests.................................................. 139

7.2.3.2. Dynamic cooling tests ................................................................ 144

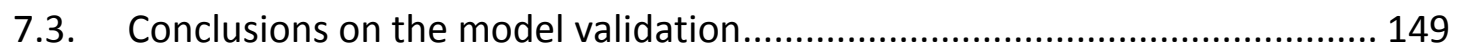

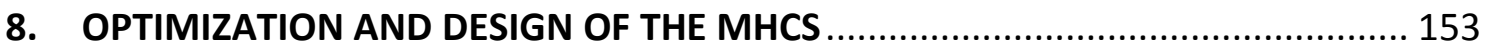

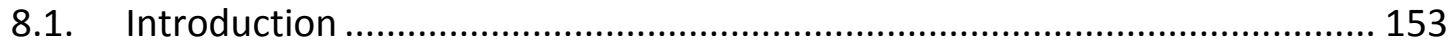

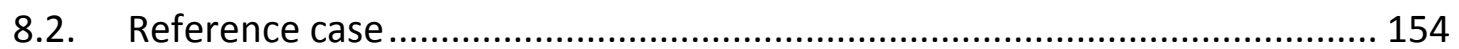

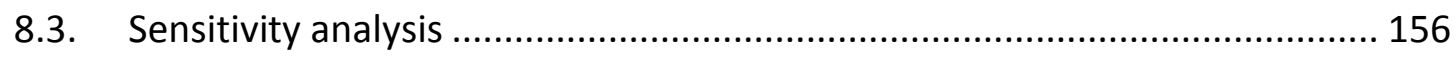

8.3.1. Regeneration temperature .............................................................. 156

8.3.2. Chilled water temperature .................................................................. 159

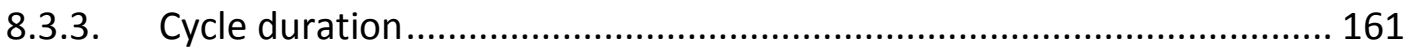

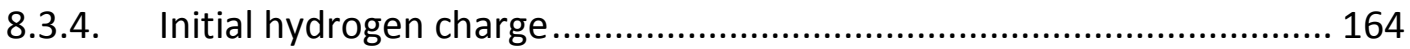

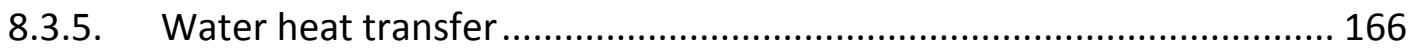

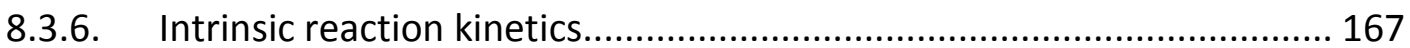

8.3.7. Effective thermal conductivity ........................................................ 168

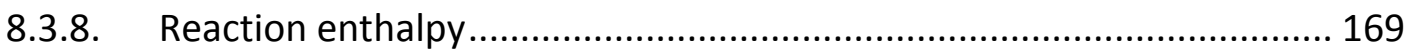

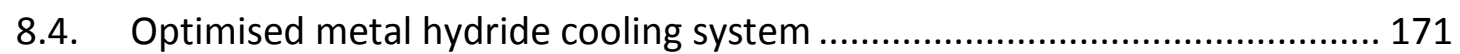

8.4.1. Optimal operating conditions........................................................... 172

8.4.2. Modification of the alloy properties ................................................ 174

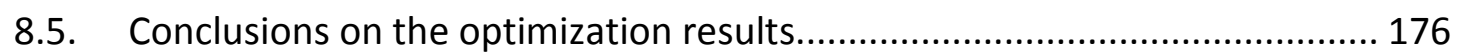

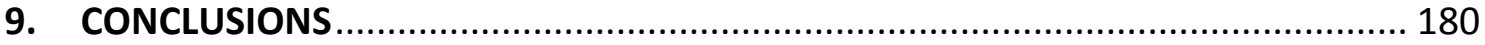

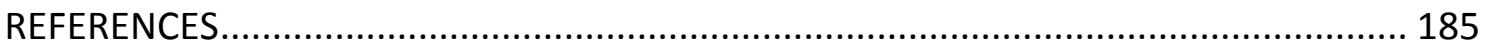


GENERAL INDEX 


\section{Figure captions}

Fig. 1. Working principle of a MHCS 28

Fig. 2. Experimental set-up for the measurement of P-C-T curves ............................................ 38

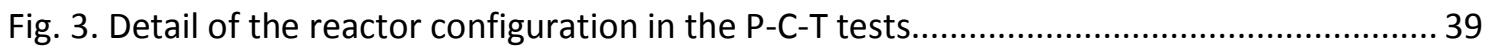

Fig. 4. Uncertainty in the calculation of the metal hydride concentration................................ 43

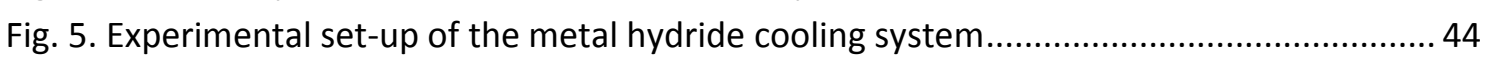

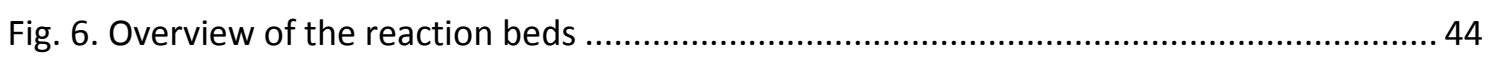

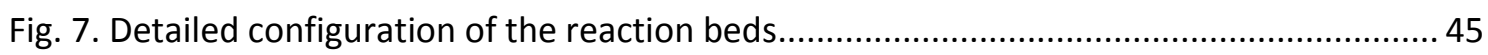

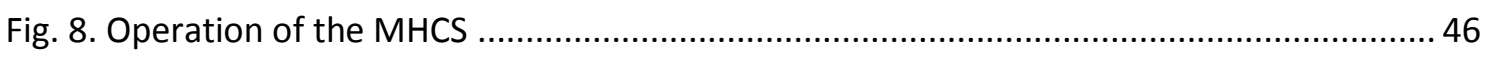

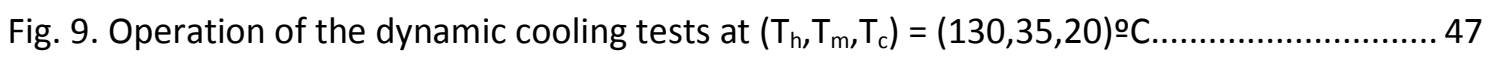

Fig. 10. Uncertainty in the measurements of the water mass flow rate. .................................. 49

Fig. 11. Uncertainty in the measurements of the reactor outlet temperature (bed A). Tests: $T_{h}=130 \circ \mathrm{C}, T_{m}=35 \circ C, T_{c}=20 \circ C$

Fig. 12. Uncertainty in the measurements of the hydrogen exchange rate. Tests: $T_{h}=130 \circ \mathrm{C}$,

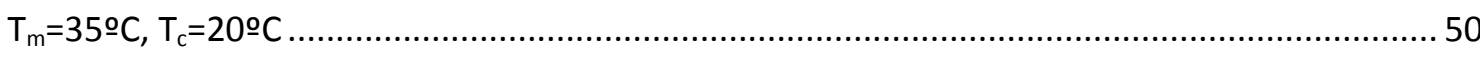

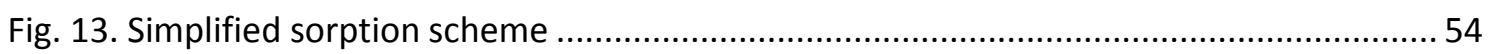

Fig. 14. Operating temperature and pressure range of different alloys ..................................... 56

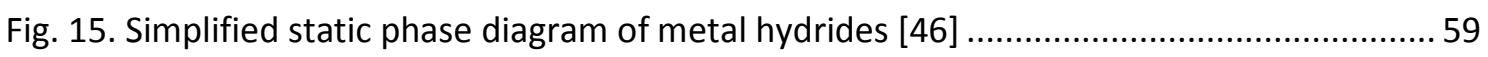

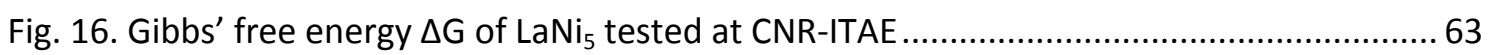

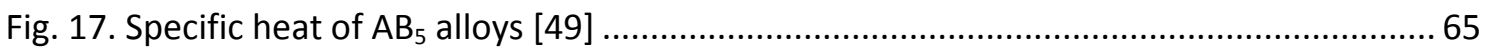

Fig. 18. Effective thermal conductivity of a metal hydride powder at $20{ }^{\circ} \mathrm{C} \ldots \ldots . . . . . . . . . . . . . . . . . . . . . .69$

Fig. 19. Extension of the Zhou model to include smooth phase transitions................................ 81

Fig. 20. Equilibrium P-C-T measurements of the cold reaction bed (A3) ................................... 84

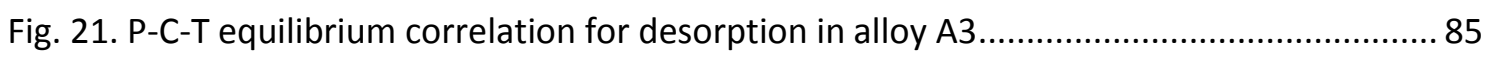

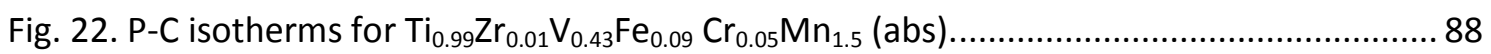

Fig. 23. P-C isotherms for $\mathrm{LmNi}_{4.91} \mathrm{Sn}_{0.15}$ (des). Smoothed Zhou model ..................................... 89

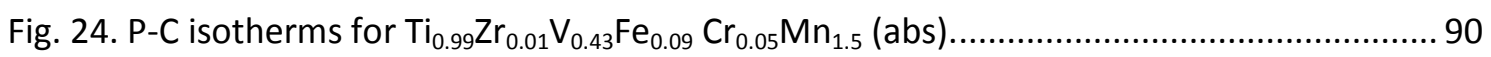

Fig. 25. P-C isotherms for $\mathrm{LmNi}_{4.91} \mathrm{Sn}_{0.15}$ (abs). Lacher-Lototsky model .................................... 91

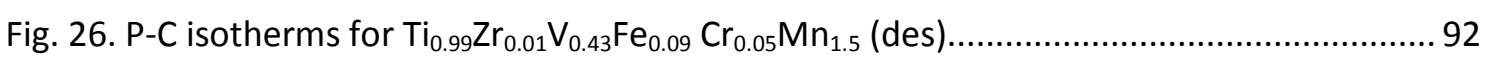

Fig. 27. P-C isotherms for $\mathrm{LmNi}_{4.91} \mathrm{Sn}_{0.15}$ (abs). Polynomial fitting method ................................ 93

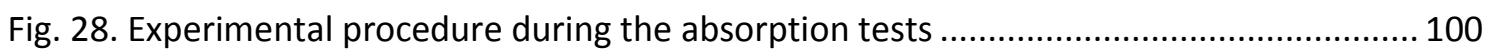

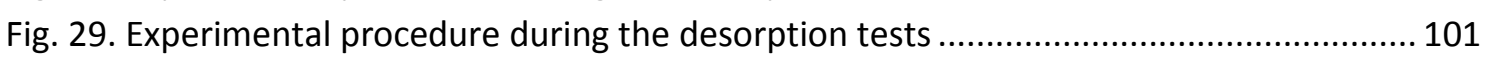

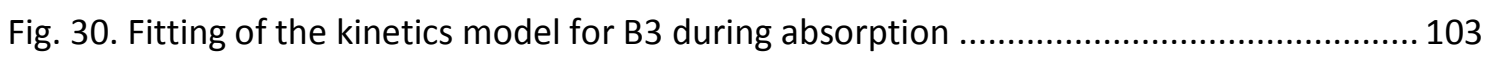

Fig. 31. Arrhenius plot of the reaction rate of B3 during absorption........................................ 104

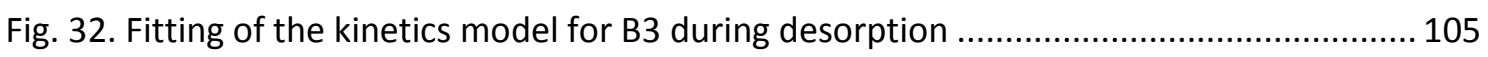

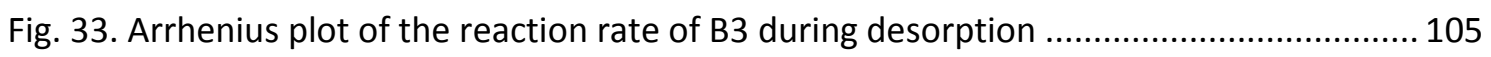

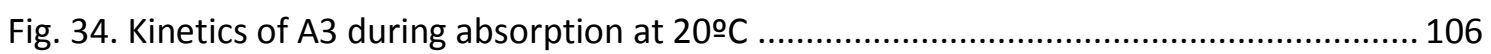

Fig. 35. Intrinsic absorption kinetics of A3 in the plateau region (model) ............................... 107

Fig. 36. Intrinsic desorption kinetics of A3 in the plateau region (model) ............................... 108

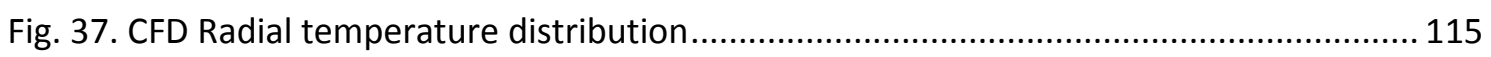

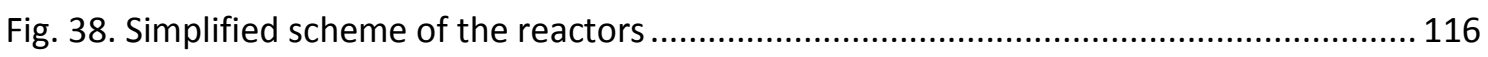

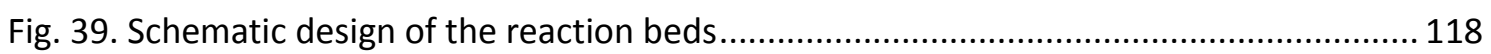


Fig. 40. Heat transfer within the metal hydride powder 118

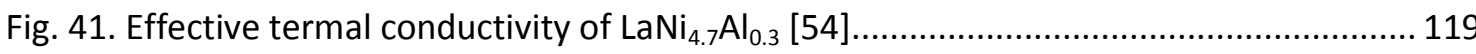

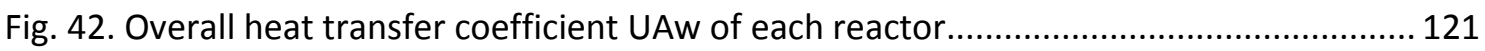

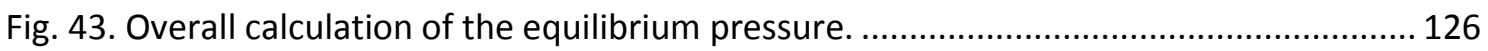

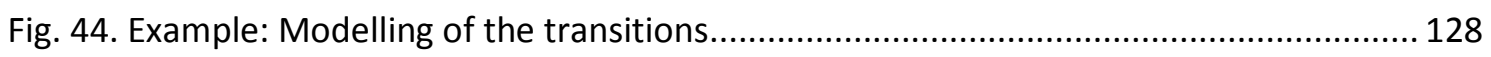

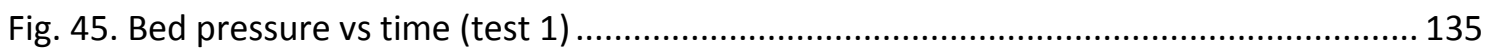

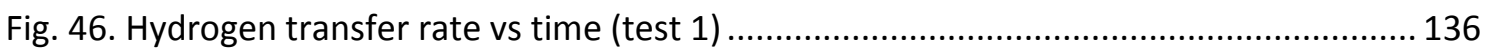

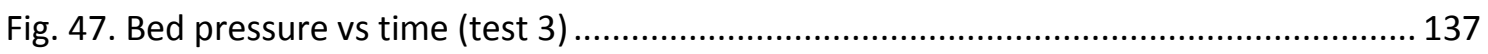

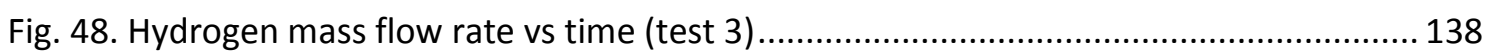

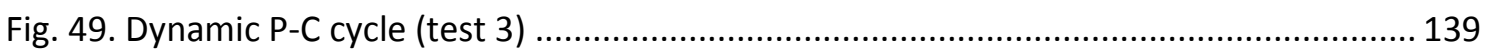

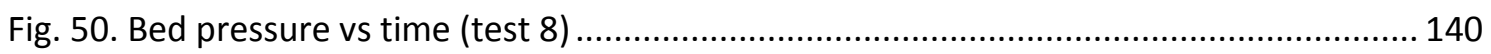

Fig. 51. Metal hydride concentration in the alloys vs time (test 8) ....................................... 141

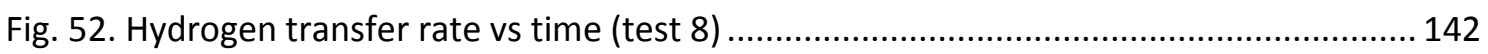

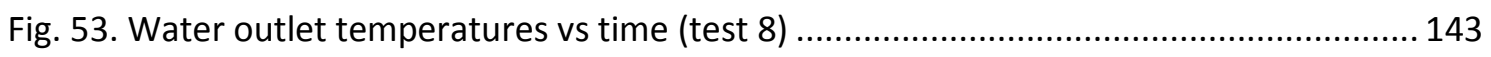

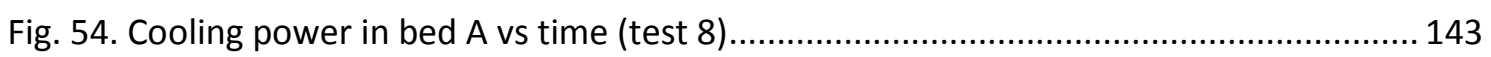

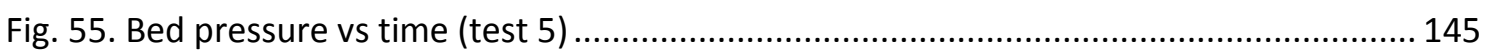

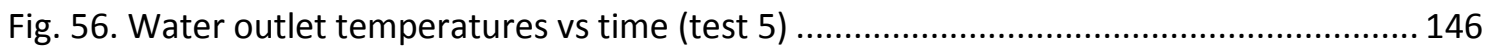

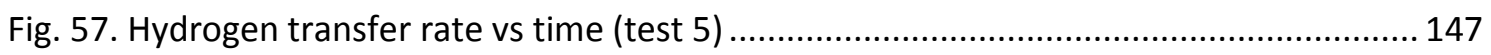

Fig. 58. Metal hydride concentration in the alloys vs time (test 5) ....................................... 147

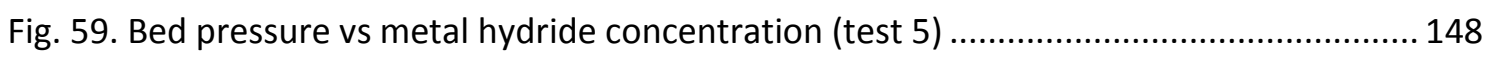

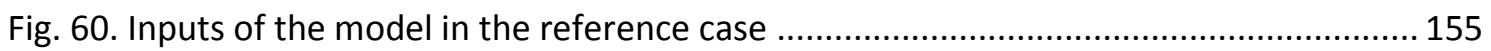

Fig. 61. Performance of the MHCS under different regeneration temperatures $T_{h} \ldots \ldots \ldots \ldots \ldots . . . . .156$

Fig. 62. Effect of the regeneration temperature on the operating conditions of $A 3 \ldots \ldots \ldots \ldots \ldots . . . .158$

Fig. 63. Effect of the regeneration temperature on the operating conditions of B3............... 158

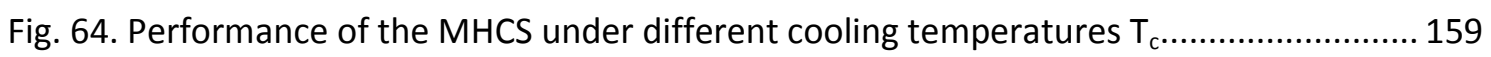

Fig. 65. Effect of the cooling temperature on the operating conditions of $A 3$.......................... 160

Fig. 66. Effect of the cooling temperature on the operating conditions of B3 .......................... 161

Fig. 67. Performance of the MHCS under different cycle durations $\Delta t_{\text {cycle }} \ldots \ldots \ldots \ldots \ldots \ldots \ldots \ldots \ldots . . . . . . . . . . . . . . . . .162$

Fig. 68. Effect of the cycle duration on the operating conditions of $A 3$.................................. 163

Fig. 69. Effect of the cycle duration on the operating conditions of B3 ................................... 163

Fig. 70. Performance of the MHCS for different initial metal hydride concentrations in B3.... 164

Fig. 71. Effect of the hydrogen charge on the operating conditions of $A 3$............................... 165

Fig. 72. Effect of the hydrogen charge on the operating conditions of B3 ................................. 165

Fig. 73. Effect of the reaction enthalpy in B3 on the performance of the MHCS ...................... 170

Fig. 74. Effect of the reaction enthalpy in $B 3$ on the operating conditions of $A 3 \ldots \ldots \ldots \ldots \ldots \ldots . . . . . . .170$

Fig. 75. Effect of the reaction enthalpy in $B 3$ on the operating conditions of $B 3$...................... 171

Fig. 76. Operating conditions in A3 with an optimised operation ........................................ 173

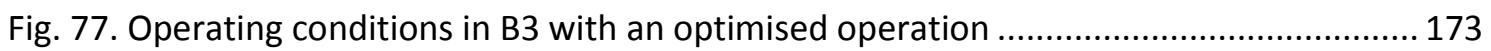

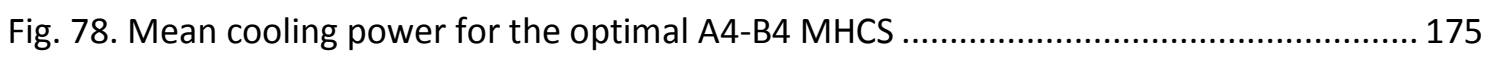

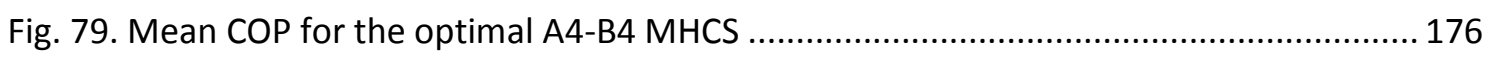

Fig. 80. Overall performance of the MHCS with different operation strategies....................... 177 


\section{Table captions}

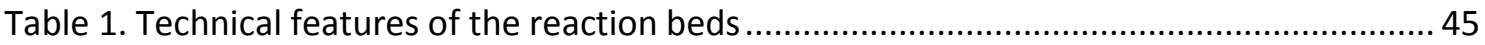

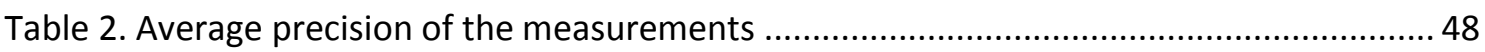

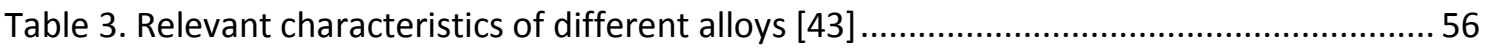

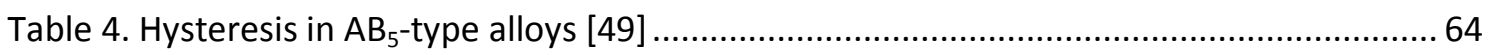

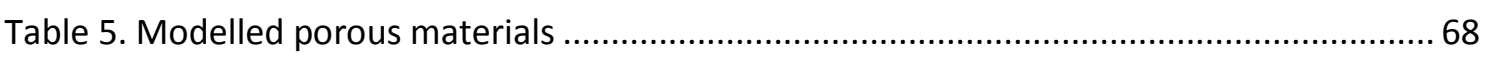

Table 6. Parameters of the ZBS model for a metal hydride powder..........................................69

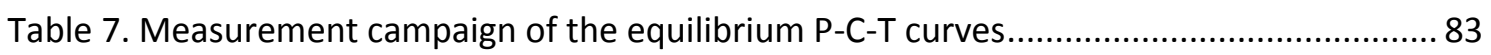

Table 8. Fitting parameters of the modified Van't Hoff model.................................................... 86

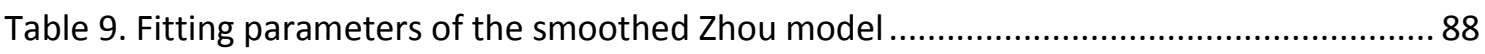

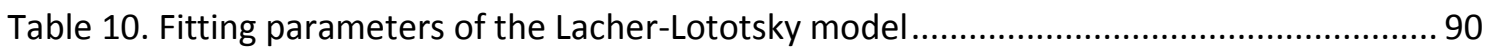

Table 11. Fitting parameters of the polynomial fitting method ................................................ 92

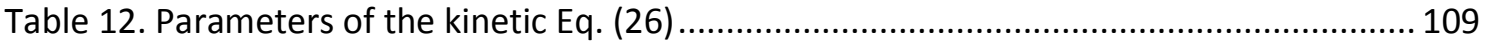

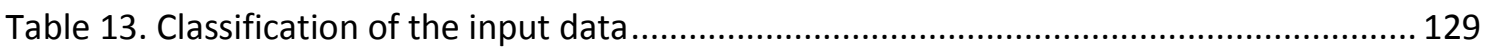

Table 14. Experimental tests which have been validated with the model .............................. 133

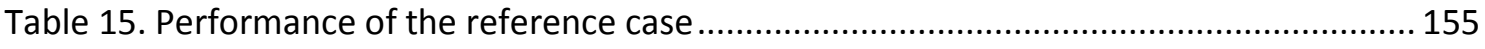

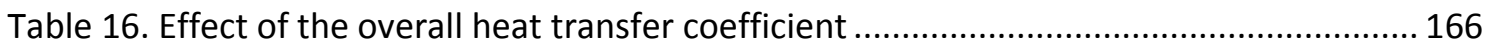

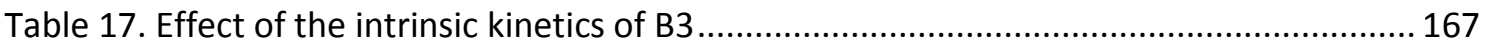

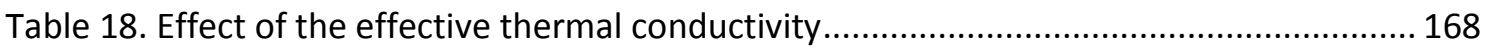

Table 19. Optimal operation parameters with reactors A3-B3............................................. 172

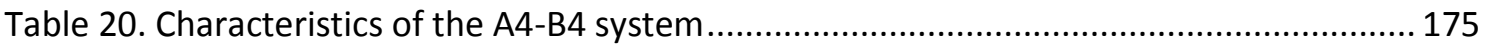


Chapter 1:

Introduction 


\section{INTRODUCTION}

\subsection{Motivation}

Metal hydride cooling systems (MHCS) have been studied from the 1970s onwards. An increasing interest has been recently observed [1] in the field of refrigeration since the restriction on the use of chlorofluorocarbons. MHCS are compact, environmentally friendly and can be thermally driven by waste heat or with solar energy, on the contrary to conventional cooling systems with mechanical compression.

Many metal hydrides have been studied, and recently more compounds are being analyzed. Each alloy presents a different behaviour (pressuretemperature-concentration) and hereby it is possible to obtain a large temperature range of operation with a proper selection of the hydrogen absorbing materials.

Several MHCS have already been built and tested [2-9], showing encouraging results, but this technology still has to be improved. In the actual state of development, MHCS have not reached a commercial status yet [3]. The main reason for this is the high initial cost of the alloys, and the poor heat and mass transfer of the reactors.

In some cases, material problems such as severe activation characteristics and pyrophoricity have been observed. In order to be commercially viable, the metal hydride systems must be able to compete with conventional systems in terms of coefficient of performance (COP), second law efficiency, operational reliability and costs. The COP and second law efficiencies of MHCS can be theoretically equal or even higher to those of other sorption systems.

In order to improve the efficiency and achieve an economic viability, it is important to minimize the amount of alloys and the thermal mass of the reactors [10]. An accurate simulation tool is essential to understand the controlling mechanisms and to optimize the cooling performance of these systems. 
MHCS require at least two coupled metal hydride beds, each of them working at different temperature levels. The thermodynamic cooling cycle which is described is completely transient and therefore dynamic models are needed to predict the performance of the reactors. Adequate knowledge of these systems implies modelling coupled heat and mass transfer processes.

Heat and mass transfer aspects of single reactors have been studied by many authors [11-15], particularly for hydrogen storage applications. Many studies have been recently published by Jemni et al. on this matter using spatial models to define the reactions which take place inside the reactors [16-20]. However, literature on models of coupled MHCS is more limited, and very often the developed models are not validated with experimental measurements during dynamic cooling tests.

As pointed out by Gambini [21], the major determinants of the behaviour are the heat transfer characteristics of the heat exchangers (design, layout, thermophysical properties of the hydrides) and the operational parameters of the system (fluid flow rates and inlet temperatures, cycle duration, etc.). These are some of the key aspects which should be studied with a reliable simulation tool.

This PhD study focuses on two main objectives: on the one hand, to reach a better knowledge on the modelling of MHCS with respect to the actual state of art. These systems are very complex and hence it is essential to validate the developed models with experimental measurements.

On the other hand, once the model has been validated, the simulations will allow for an optimization of the system in order to increase the cooling power. 


\subsection{Introduction on metal hydride cooling systems}

The MHCS consists of two coupled reactors $A$ and $B$ containing different metallic alloys which respond to the equilibrium pressure-concentrationtemperature (P-C-T) curves which are shown in Fig. 1. The reactors can exchange heat with two heat sources (cold temperature $T_{c}$, high temperature $T_{h}$ ) and one heat sink (ambient, $T_{m}$ ). The working principle of this MHCS is illustrated in Fig. 1 and consists of a cooling phase (1-2) followed by a regeneration phase (3-4).

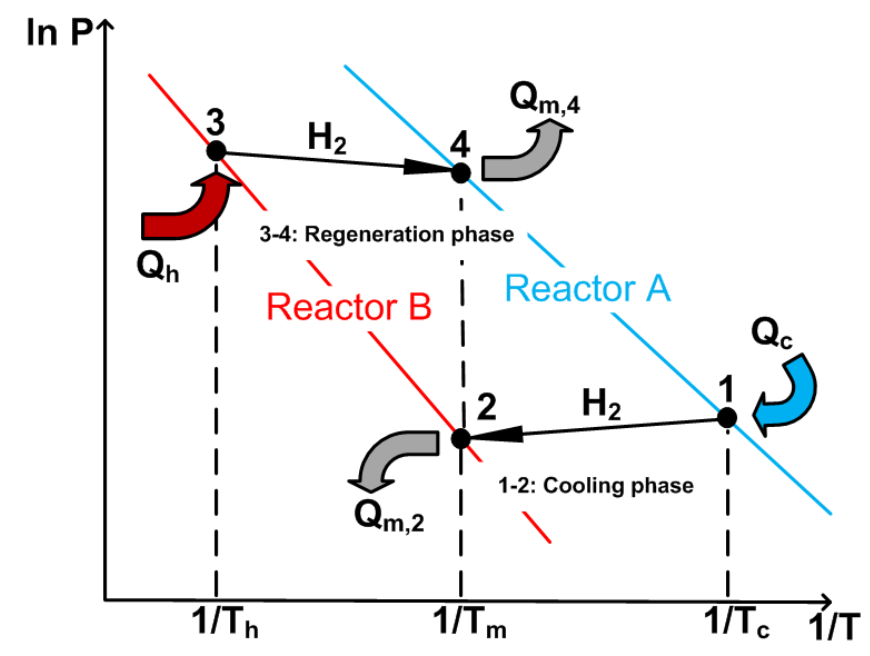

Fig. 1. Working principle of a MHCS

The cooling phase starts ideally when the cold temperature reactor $A$ is fully charged with metal hydride. As the pressure in this bed is higher than in bed $B$, hydrogen flows through the connection line from $A$ towards $B$. In bed $A$, the desorption enthalpy is responsible for the cooling of the chilled water $T_{c}$ which circulates through the reactor.

Meanwhile, bed $B$ absorbs the hydrogen which is released from bed $A$. Absorption is an exothermic reaction and therefore, this bed must be cooled in order to keep it at $T_{m}$. This is necessary to keep the equilibrium pressure in bed $B$ below the equilibrium pressure in bed $A$. 
At the end of the cooling phase, bed A contains almost no hydrogen under metal hydride phase. For the regeneration of reactor $A$, the pressure of bed $B$ is increased by pumping hot water at $T_{h}$ through the reactor. This increases the equilibrium pressure in bed $B$, and enables hydrogen transfer from reactor $B$ towards $A$. The hot water provides the enthalpy which is required in bed $B$ for the dehydriding reaction. Hydrogen is then desorbed from bed $B$ and absorbed in bed A. The hydriding process is exothermic and the heat is rejected to the heat sink at $T_{m}$.

With respect to Fig. 1, which is completely ideal, real systems present relevant differences:

- In each alloy, the absorption equilibrium pressures are higher than the desorption pressures. This phenomenon is known as hysteresis, and is very frequent in metallic alloys.

- The cooling phase and the regeneration phase are not isotherm processes. During each of these phases, the reactors are being cooled down or heated up and thus, the sorption reactions do not take place at constant temperature.

- In Fig. 1, the working principle has been illustrated on a static pressureconcentration-temperature (P-C-T) characterization of the alloys. It has been proved in literature that the equilibrium pressure is very sensible to the hydrogen exchange rate [22]. In a real MHCS, hydrogen is being transferred between both reactors, and hence, the pressures which are observed dynamically in a MHCS may differ significantly from the static P-C-T pressures. 


\subsection{Literature review and background}

\subsubsection{State of the art of the technology}

In recent years, metal hydride systems have attracted an increasing attention for cooling applications. Although many studies have focused in predicting the performance of these systems, the number of experimental installations remains rather scarce. Several metal hydride cooling prototypes have been developed and tested in Germany [2], China [23], India [3] and Japan [8]. Very recently, two interesting review articles [1,24] have been published giving an overview of the experimental systems which have been developed up to now.

One of the most promising features of MHCS is their high specific and volumetric cooling power in comparison with other sorption heat pumps [25]. In fact, MHCSs are pressurized and do not need condensers and evaporators as in many other heat pumps ( $\mathrm{LiBr}$ absorption chillers, water/silica-gel adsorption systems, ammonia/water chillers...). Thus, the latter two features make MHCSs rather compact in comparison with other sorption chillers.

In previous experimental installations [5-7] the hydrogen transfer rate between the coupled reactors is fairly low, hereby leading to a poor cooling performance. The experimental work has indicated several key aspects which can limit the performance of a MHCS:

- Hydrogen mass transfer and diffusivity

- Intrinsic reaction kinetics of the alloys

- External heat transfer and internal heat conduction

Among the latter characteristics, the experimental systems have shown that most often, the cooling performance is limited by the heat conduction of the metal powder and/or by the external heat transfer to the heat carrier.

The internal heat transfer is often deteriorated because of the low thermal conductivity of the alloy powder. In MHCSs, after sufficient cycling, the metal hydride powders usually have grain sizes of around $1 \mu \mathrm{m}$ or less [1] resulting in an effective thermal conductivity of approximately $1 \mathrm{~W} /(\mathrm{m} \mathrm{K})$. In order to 
enhance the thermal conductivity several techniques have been used, such as the introduction of high conduction matrices (e.g. porous aluminium foams [8]) or the fabrication of highly compacted pellets [26]. However, the latter present a low diffusivity (around $10^{-11} \mathrm{~cm}^{2}$ ) and they may lead to hydrogen mass transfer limitations. Additionally, it has been shown that an increase of the effective thermal conductivity of the powder bed is only beneficial as long as the external heat transfer to the heat carrier fluid does not limit the overall heat transfer [27]. In former systems, the operation of the reactors involved intermediate preheating and pre-cooling phases $[6,10,23]$. Gambini [21] showed that these phases can theoretically be included in the regeneration and cooling phase, hereby simplifying the operation of the system.

Finally, it has to be pointed out that the cycle duration of former experimental systems $[3,6]$ are much higher (around 1000s or more) than the ones employed in this PhD work. However, according to studies on the intrinsic kinetics of fast metal hydrides, it seems that theoretically the hydrogen transfer can be much faster and hence, that the cycle duration can be shortened.

All of the authors agree that there are still many improvements to be done, particularly in order to increase the hydrogen transfer rate, reduce the cycle durations and achieve higher cooling powers per mass of alloy.

\subsubsection{Mathematical models}

In respect to the dynamic models of MHCSs, many models have been developed in recent years, among others by Gambini [13,28], Gopal and coworkers $[3,10]$, Satheesh et al. $[29,30]$.

Most of the published models of metal hydride reactors involve a spatial and time discretization in the reactors and are solved by finite volume methods. Aldas K. et al. [11] presented a full three dimensional model, whereas most of the authors have employed two dimensional models [12,15,18,31-34]. Groll [5], 
Isselhorst [35] and Murthy [3,10,36,37] among other authors have presented one dimensional models. However, in practice, the model validation is done under a global perspective, based on the overall performance of the MHCS. The use of spatial models involves higher computational times, and it is also hard to validate the temperature distribution inside the reactors with measurement data.

Several dynamical models have already been validated with experimental data for single reactors $[11,13,18,19]$ during an absorption or desorption. In the case of MHCSs, several experimental systems have been presented [6,9], but they have only been compared with model results occasionally [3]. Usually, only temperature profiles are validated with measurements. In particular, an accurate prediction of the exchanged flow rate of hydrogen is not simple, as it involves many different aspects such as the intrinsic reaction kinetics of each reactor, as well as heat and mass transfer dynamics.

Gambini presented a similar one dimensional model of a MHCS [28], but in this case the model was only compared with experimental results with one desorbing bed and a coupled absorbing reactor. However, in a continuous cooling system a regeneration phase is needed, and the model has to reproduce the behaviour in both the cooling and the regeneration phase. In a second article from Gambini [21], the simulation results of a continuous cooling system were presented but they were not validated with experimental results.

Murthy [3] presented a dynamic one dimensional model which was validated with measurements during one cycle test. The simulation results were compared with experimental results during 20 cycles of a dynamic cooling test. Pressure and temperature measurements were also presented and compared in this study, but not the hydrogen exchange rate between the reactors.

The metal hydride powders which are used in MHCS often present an important difference between the absorption and desorption equilibrium pressures. Many authors have already reported the importance of hysteresis in the modelling of MHCS $[13,14,21,28]$. However, the transitions between absorption and desorption have not been treated yet. 


\subsection{Objectives}

As mentioned in the introduction, a dynamic model is required to reproduce the behaviour of coupled metal hydride reactors, and hence to employ it as a tool to assist in their design. The final objective of this $\mathrm{PhD}$ is to develop an accurate model for metal hydride cooling systems, and to validate it with experimental results of coupled reactors working under different operating conditions.

In first place, the $\mathrm{PhD}$ focuses on the static properties of metal hydride powders: thermal conductivity, P-C-T correlation, etc. Nevertheless, coupled metal hydride reactors work under non equilibrium conditions and thus, the dynamic model requires a proper modelling of the reaction kinetics. One of this PhD's targets is to analyze the kinetics of these alloys and to develop adequate models for the sorption reaction.

Based on these previous studies on the static characterization of the alloys, and on the intrinsic reaction kinetics, the main aim of this $\mathrm{PhD}$ is to develop a dynamic model able to reproduce the dynamic behaviour of metal hydride cooling systems. The model has been validated with experimental measurements obtained at the research institute IKE (Institut für Kernenergetik und Energiesysteme, Stuttgart, Germany). Part of this work has been realised at the Institute IKE, where the $\mathrm{PhD}$ candidate has performed the necessary tests and acquired knowledge on measurement procedures.

Finally, the model has been used to optimize the design and to maximize the performance of a MHCS prototype. This research will determine the key factors in the design of MHCS. 


\subsection{Structure}

This PhD work has been structured according to the previous objectives. Chapter one provides a literature review and background on metal hydride cooling systems, and defines the objectives of the project.

The second chapter of the PhD describes the installations, the equipment and the methodology which has been followed in the experimental part of this PhD study and which was carried out at the research institute IKE.

In chapters $\mathbf{3}$ to $\mathbf{5}$, the behaviour of single metal hydride reactors is studied. Chapter 3 provides information on thermo-physical properties of powders, such as the effective thermal conductivity. One of the key points in any MHCS is the equilibrium correlation between the pressure, temperature and metal hydride concentration. This aspect is analyzed thoroughly in Chapter 4. In any MHCS, the behaviour is completely dynamic and the reactors work under non equilibrium conditions. Hence, in chapter 5 , the behaviour of the alloys under non equilibrium conditions (intrinsic reaction kinetics) is analyzed.

The final part of the thesis (chapters 6 to 9) deals with the development of a model for a MHCS. This model derives from the static characterization of the materials (Chapters 3 and 4 ) and assumes non equilibrium conditions (Chapter $5)$. The main equations of the model are explained in chapter 6 , whereas the simulation results are validated with experimental measurements in chapter 7.

Finally, with the use of the model, in chapter $\mathbf{8}$ an optimization of the system is presented focusing on improving the cooling power by means of an optimised operation and of a more adequate selection of the alloys. 


\section{Chapter 2:}

\section{Experimental set-up}




\section{Nomenclature}

\begin{tabular}{|ll}
\hline P & Pressure, bar \\
C & Metal hydride concentration, g MH/g alloy (\%) \\
T & Temperature, K \\
V & Valve \\
$\dot{Q}$ & Heat transfer rate, W \\
FS & Full scale \\
$\epsilon$ & Error \\
& \\
Subscripts & \\
max & Maximum hydrogen storage capacity \\
h & Hot temperature level \\
m & Medium temperature level \\
c & Cold temperature level \\
w & Water \\
in & Inlet of the reactor \\
out & Outlet of the reactor
\end{tabular}




\section{EXPERIMENTAL SET-UP}

In this chapter of the $\mathrm{PhD}$ work, the experimental installations used during this $\mathrm{PhD}$ work are presented. The experimental campaign has been realised in the Institüt für Kernenergetik und Energiesysteme (IKE), located in Stuttgart (Germany).

Two different installations have been tested in the hydrogen laboratory of IKE. Subsection 2.1 deals with the first set-up, which enables the measurement of the P-C-T equilibrium curves of metal alloys. The second installation is described in subsection 2.2 and involves two coupled metal hydride reactors. As in other experimental MHCSs from literature $[3,4,6,8,10,23,29,35]$, the sorption alloys which are used are based on a combination of lanthanum and mischmetal-based alloys.

In order to develop an accurate model of the MHCS, it is essential to first characterize the behaviour of the alloys before inserting them in the reaction beds, in other words, before involving any additional heat and mass transfer processes.

The characterization of the alloys has been done by means of dynamic P-C-T measurements. In these tests, it is essential to guarantee that the generated or absorbed heat can be transferred to a fluid in order to maintain isothermal conditions in the alloy. Hereby, these tests are done for small alloy samples (around $10 \mathrm{~g}$ ).

The metal hydride cooling system consists of two coupled reactors, each of them containing around $900 \mathrm{~g}$ of hydrogen absorbing alloys. The main components are described in this chapter, with a special emphasis on the operation and technical specifications of the measurement equipment. 


\subsection{P-C-T equilibrium measurements}

2.1.1. Description of the P-C-T set-up

The experimental set-up is represented in Fig. 2 and is based on the volumetric method to measure dynamically the amount of dissolved (or released) hydrogen (Sieverts method). A detailed description of the experimental set-up has been recently published in literature $[38,39]$.

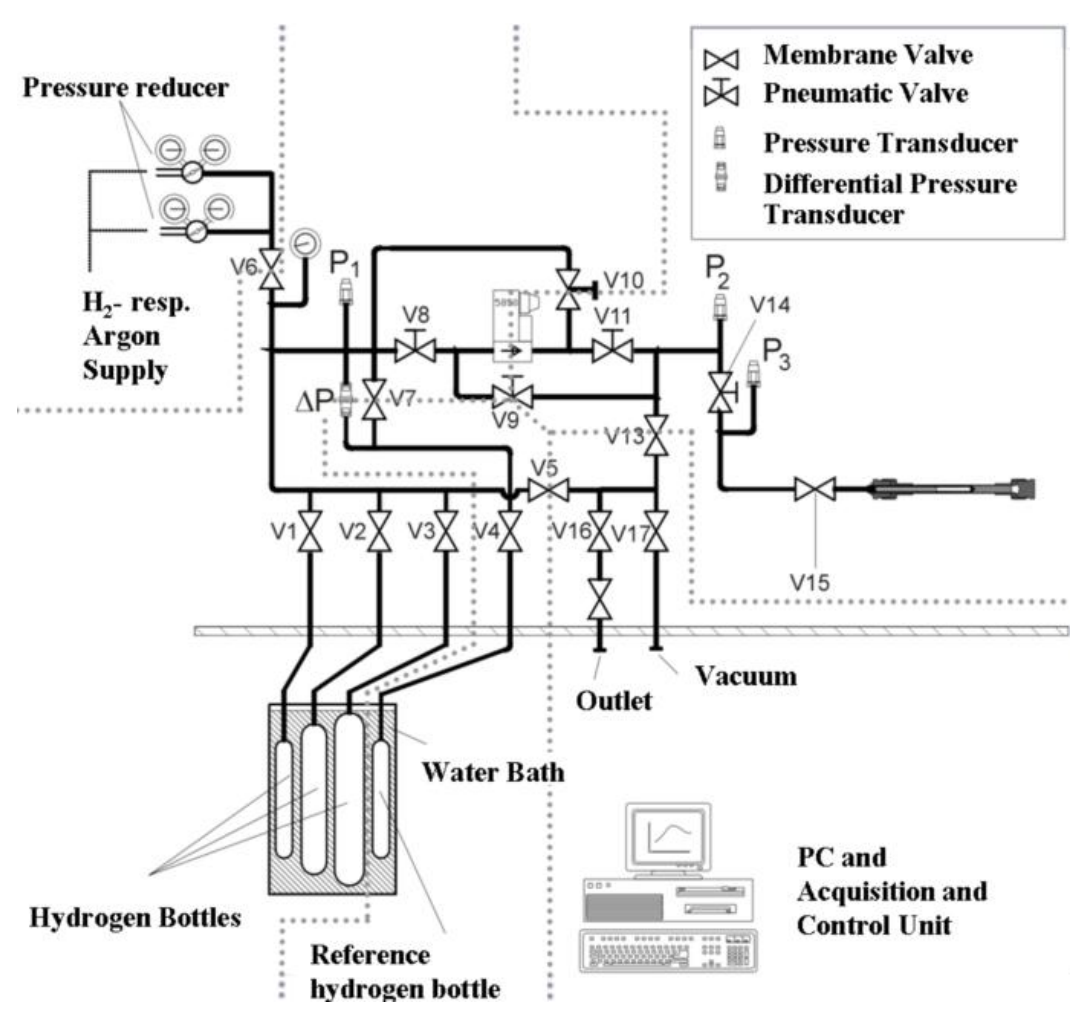

Fig. 2. Experimental set-up for the measurement of P-C-T curves

During the tests, a sample of around $10 \mathrm{~g}$ is located in the reaction bed which is represented in Fig. 3. The reactor guarantees a sufficient heat and mass transfer. The sample temperature is continuously measured by a K-type thermocouple $( \pm 1.5 \mathrm{~K})$ inserted into the reaction bed. After the activation of the sample, the whole set-up is evacuated. A mass flow controller separates the 
reaction bed containing the sample from the known reference volumes of the set-up.

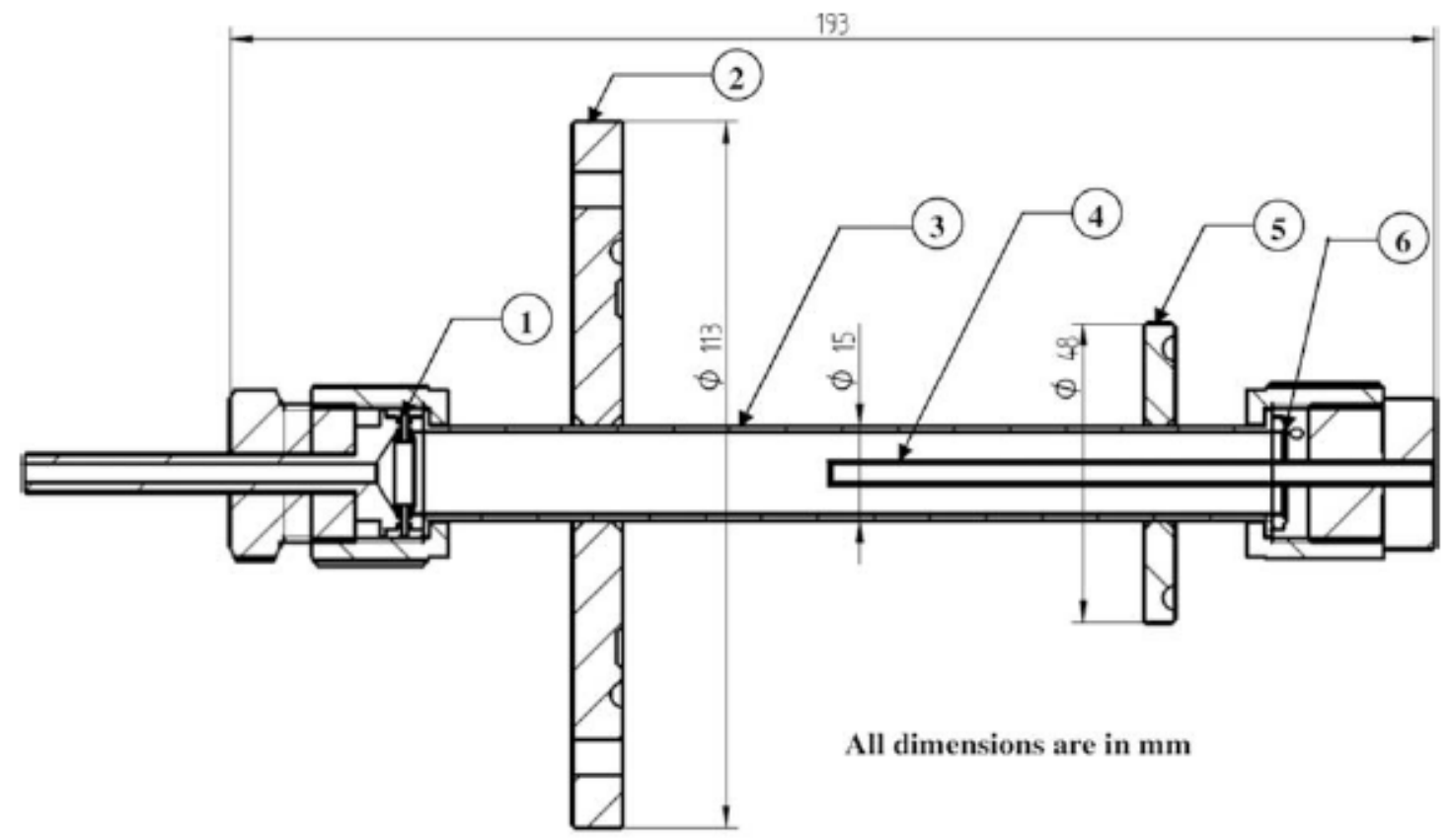

1. Filter $2 \& 5$ Flanges for water jacket 3 . Reactor tube

4. Thermocouple 6. Leak proof teflon seal

Fig. 3. Detail of the reactor configuration in the P-C-T tests

Although the temperature of the reaction bed is controlled by a thermostat, the metal hydride temperature increases inevitably during absorption and desorption (due to the dynamic measurement principle). The flow rate was set to a small value $(10 \mathrm{Nml} / \mathrm{min})$. For this flow rate, the observed temperature increase during absorption was less than $1.5 \mathrm{~K}$. Hence, it can be considered reasonably well that the measured $\mathrm{P}-\mathrm{C}$ curves are isotherms.

\subsubsection{Measurement procedure}

The measurement procedure is based on the principle that a closed, sealed system contains hydrogen either in gas state or in metal hydride state. If the 
volume is known, the mass of gas can be calculated by measuring the respective temperatures and pressures and using a real gas equation. The experimental set-up used for measuring the dynamic P-C-T curves of the metal hydride alloys has been illustrated in Fig. 2. The experimental set-up can be divided into two main sections: area 1 (left part of set-up) and area 2 (right part), which are separated during absorption through $\mathrm{V} 10$ (during desorption through V11), mass flow controller, V9 (during desorption V8), V5 and V13. Valves V8, V9, V10, V11 and V14 are pneumatic valves; this allows an automatic operation of the experiment. Through V6 and the pressure reducer, the system can be filled with hydrogen for P-C-T measurement and activation or with argon for volume determination. Through V1, V2 and V3 hydrogen bottles are connected and provide the necessary hydrogen for the measurements.

The gas bottles (total volume $3.5 \mathrm{I}$ ) are maintained at a constant temperature with a water bath. Valves V5 and V13 are the junctions to the outlet and the vacuum pump. The whole system can be evacuated via V17 with the help of a vacuum pump. The reactor containing the metal hydride is connected to the setup through V14 and V15. P1, P2 and P3 are absolute pressure transducers (resolution: 0.01 bar). Additionally, a differential pressure transducer (DP) measures the pressure difference between area 1 and a reference hydrogen bottle. The differential pressure transducer can be bypassed via V7. The transducer works up to the differential pressure of 2 bar. All measured values are recorded using a PC with a data logging system. A high temperature oven (heating) and a thermostat (heating and cooling) are used to keep the reactor at constant temperature.

Fig. 3 shows construction details of the reactor used in the dynamic P-C-T measurements. The reactor is made of a SS-316 tube with a $15 \mathrm{~mm}$ diameter. The sorption alloy is filled inside the tube within its free volume $(16.6 \mathrm{ml})$. The right side of the reactor contains a metal sheathed K-type thermocouple which enables the measurement of the sample temperature with a time constant of 0.2 $s$ (resolution: $0.1^{\circ} \mathrm{C}$ ). The left side of the reactor is connected to a filter assembly which prevents the metal hydride powder from being carried away by the hydrogen gas during the desorption tests. The heat generated during 
absorption is rejected to the water which circulates spirally around the reactor and hereby helps maintain almost isothermal conditions. For temperatures above $95^{\circ} \mathrm{C}$, an oven is used.

After connecting the reactor to the set-up, the volume of the tubes between V14 and V15 and the reactor volume are determined because these volumes can change after the installation of a new reactor. Before starting the absorption and desorption, an activation of the material is executed. The procedure is intended for the vaporization of liquid and gaseous substances and for the weakening of the oxide film on the surface of the metal hydride particles. The temperature, duration and the number of cycles for the activation depend on the material. Initially, the whole set-up is evacuated; all valves (except V7) are closed after evacuation. The directions of hydrogen flow during absorption and desorption are given below:

- Absorption: $\mathrm{H}_{2}$-flow from the left side to the right side via $\mathrm{V} 8$, mass flow controller and V11 (V9 and V10 are closed);

- Desorption: $\mathrm{H}_{2}$-flow from the right side to the left side via V9, mass flow controller and V10 (V8 and V11 are closed).

At the beginning of the absorption experiment, the area containing the metal hydride (area 2) is evacuated and the metal hydride is completely discharged. Area 1 is then pressurized to the desired level. Afterwards, the separating valves (V8 and V11) are opened and hydrogen is dispersed in both areas.

The mass flow controller enables a hydrogen transfer into area 2 at a constant flow rate $(5-10 \mathrm{Nml} / \mathrm{min})$. The hydrogen uptake of the sample is registered from the loss of gaseous hydrogen. During the desorption experiments, area 1 is evacuated down to $10^{-3}$ mbar and area 2 is maintained at high pressure (equilibrium with hydride pressure). By opening the pneumatic valves V9 and V10, high pressure hydrogen is dispersed to area 1 at constant flow rate through the mass flow controller. By recording the temperature and the pressure variations in both areas, and using the real gas equation, the mass of desorbed hydrogen is calculated. The step by step procedure to estimate the amount of absorbed or desorbed hydrogen is available in literature $[39,40]$. The 
uncertainty in the calculation of the metal hydride concentration depends on many variables $[39,41]$ such as the ambient temperature, operating pressures and temperatures, etc... Hence, in this $\mathrm{PhD}$ work, although the error can be smaller, a maximum error of $5 \%$ with respect to the maximum storage capacity has been assumed.

\subsubsection{Uncertainty of the measurements}

In the P-C-T tests, three variables are measured and are subject to experimental uncertainties; the pressure $(P)$, the metal hydride concentration (C) and the temperature $(\mathrm{T})$.

The pressure is measured with the pressure transducer $\mathrm{P} 3$, which has an accuracy of \pm 0.5 bar $(0.5 \%$ of full scale $=100$ bar $)$, and the temperature is measured with a $\mathrm{K}$-type thermocouple $( \pm 1.5 \mathrm{~K}$ within a temperature range from $0^{\circ} \mathrm{C}$ to $\left.130^{\circ} \mathrm{C}\right)$.

As explained previously, the metal hydride concentration is calculated by means of the volumetric method with an accuracy of a maximum error of $\pm 5 \%$ with respect to the maximum capacity. For instance, in Fig. 4, the measured absorption curves of $\mathrm{LmNi}_{4.91} \mathrm{Sn}_{0.1}$ at $60^{\circ} \mathrm{C}$ (absorption) have been represented, together with the corresponding error. 


\section{Chapter 2 - EXPERIMENTAL SET-UP}

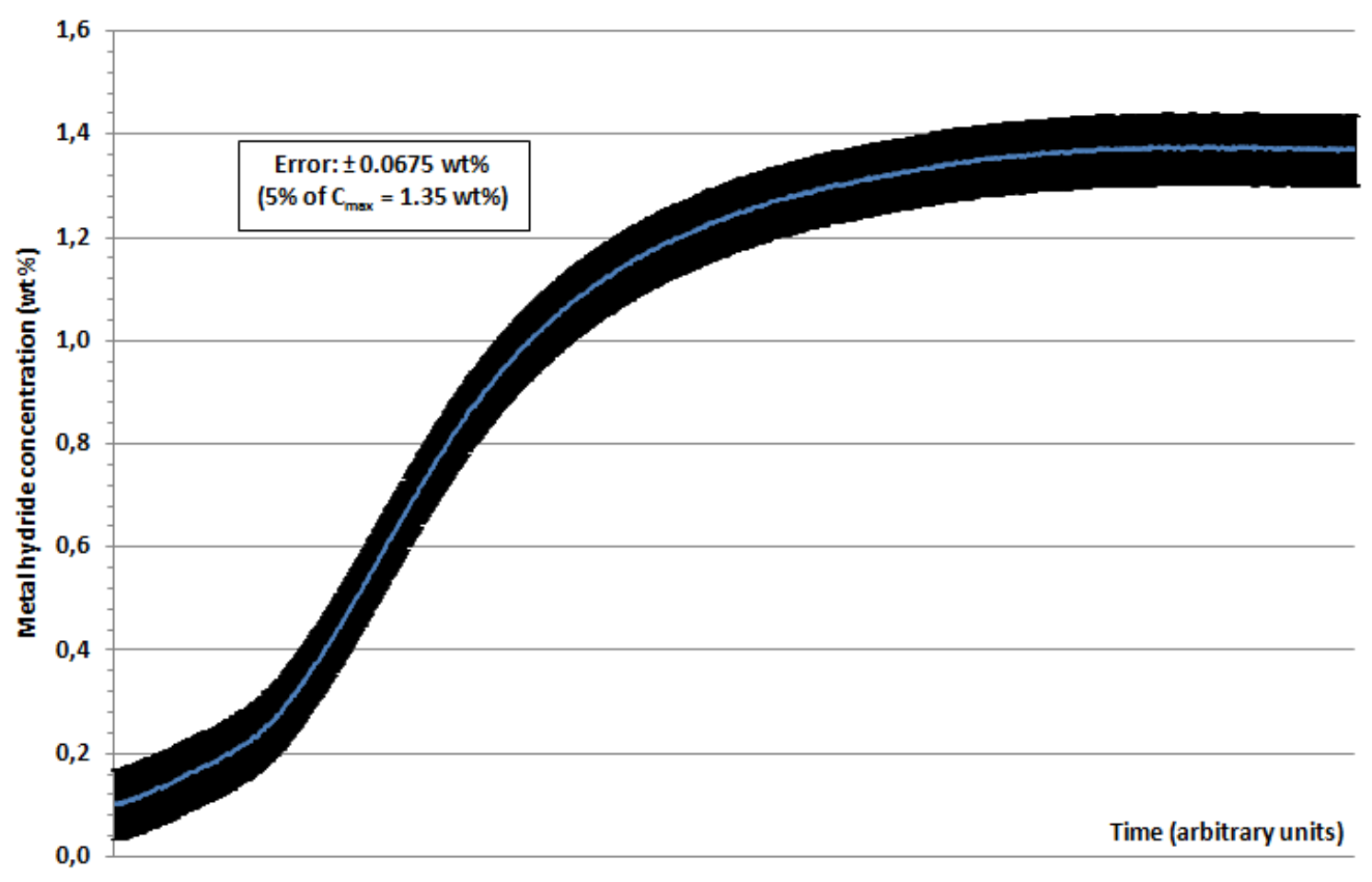

Fig. 4. Uncertainty in the calculation of the metal hydride concentration. Alloy $\mathrm{LmNi}_{4.91} \mathrm{Sn}_{0.1}$ at $60^{\circ} \mathrm{C}$ (absorption)

\subsection{Thermally driven system}

2.2.1. Description and technical specifications

Fig. 5 shows a schematic diagram of the MHCS at IKE Stuttgart. The installation consists of two coupled reaction beds, 1 pneumatic hydrogen valve and a flow meter HASTINGS HFM-201 in the hydrogen connexion line. The installation and its operation have been described recently in literature [2].

The heat transfer side consists of 2 solenoid 3-way valves, 2 pumps, 1 heatable storage tank and 3 heat exchangers. The test rig is capable of simulating different heat sources; the hot temperature heat source $\left(Q_{h}\right)$, the ambient heat sink $\left(Q_{m}\right)$ and the cold heat source $\left(Q_{c}\right)$. The flow rates of the heat transfer media are measured with 2 electromagnetic flow meters KRONE IFS 6000F. Two thermal resistances RTD Pt 100 (class A) are additionally used to measure the inlet and outlet temperature of each reaction bed. The thermal resistances 
have been calibrated in order to have an uncertainty of $\pm 0.1 \mathrm{~K}$ in the measurements.

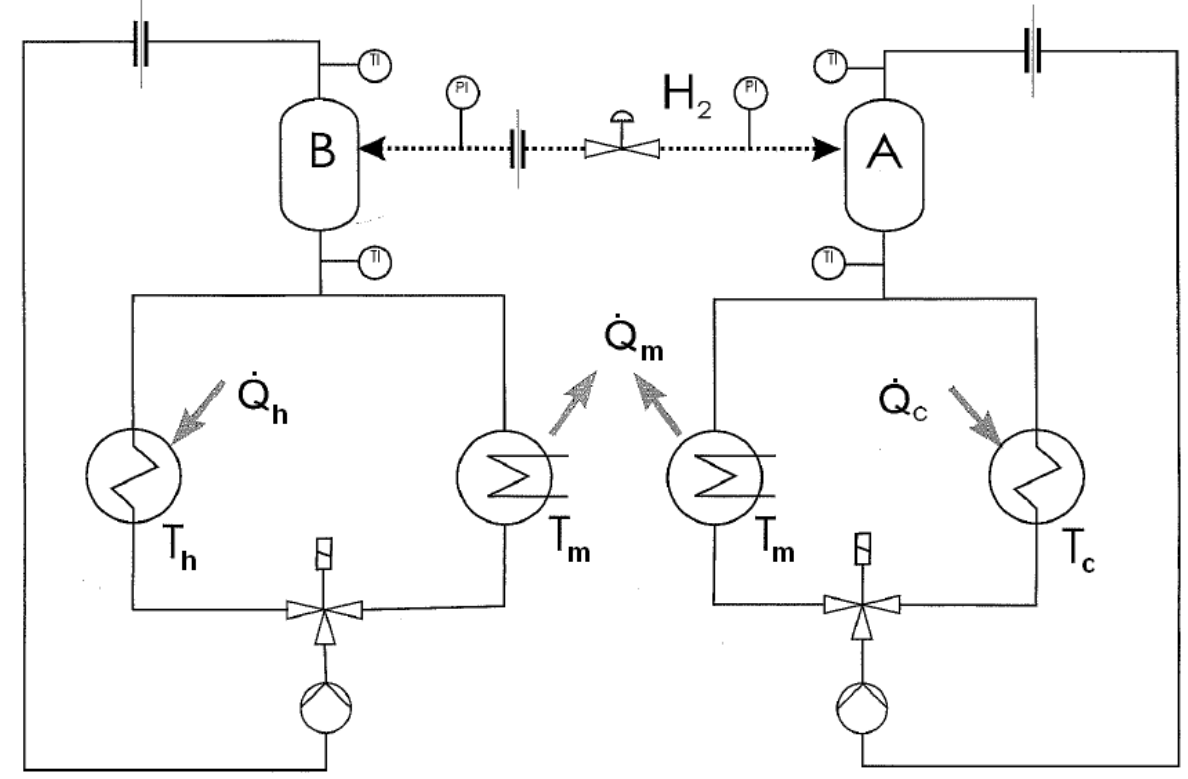

Fig. 5. Experimental set-up of the metal hydride cooling system

Fig. 6 and Fig. 7 illustrate the configuration of each reactor. Hydrogen flows through the surrounding filter tube into the powder, where the sorption reaction takes place according to the temperature and pressure conditions of the vessel. Heat transfer between the metal hydride powder and the water circuit is guaranteed by the evenly distributed mini water tubes. Both reaction beds are geometrically identical and contain around $800 \mathrm{~g}$ (bed A) and $900 \mathrm{~g}$ (bed B) of metal hydride powder.
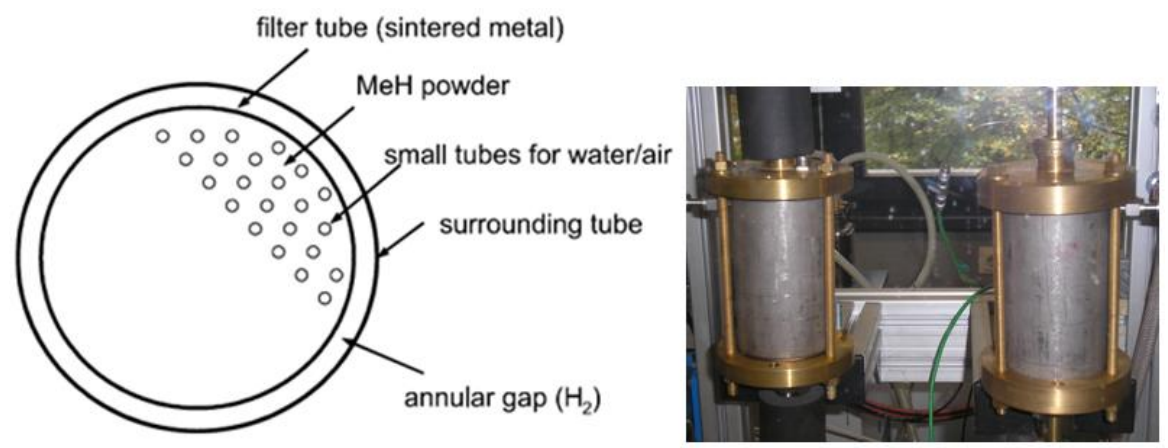

Fig. 6. Overview of the reaction beds 


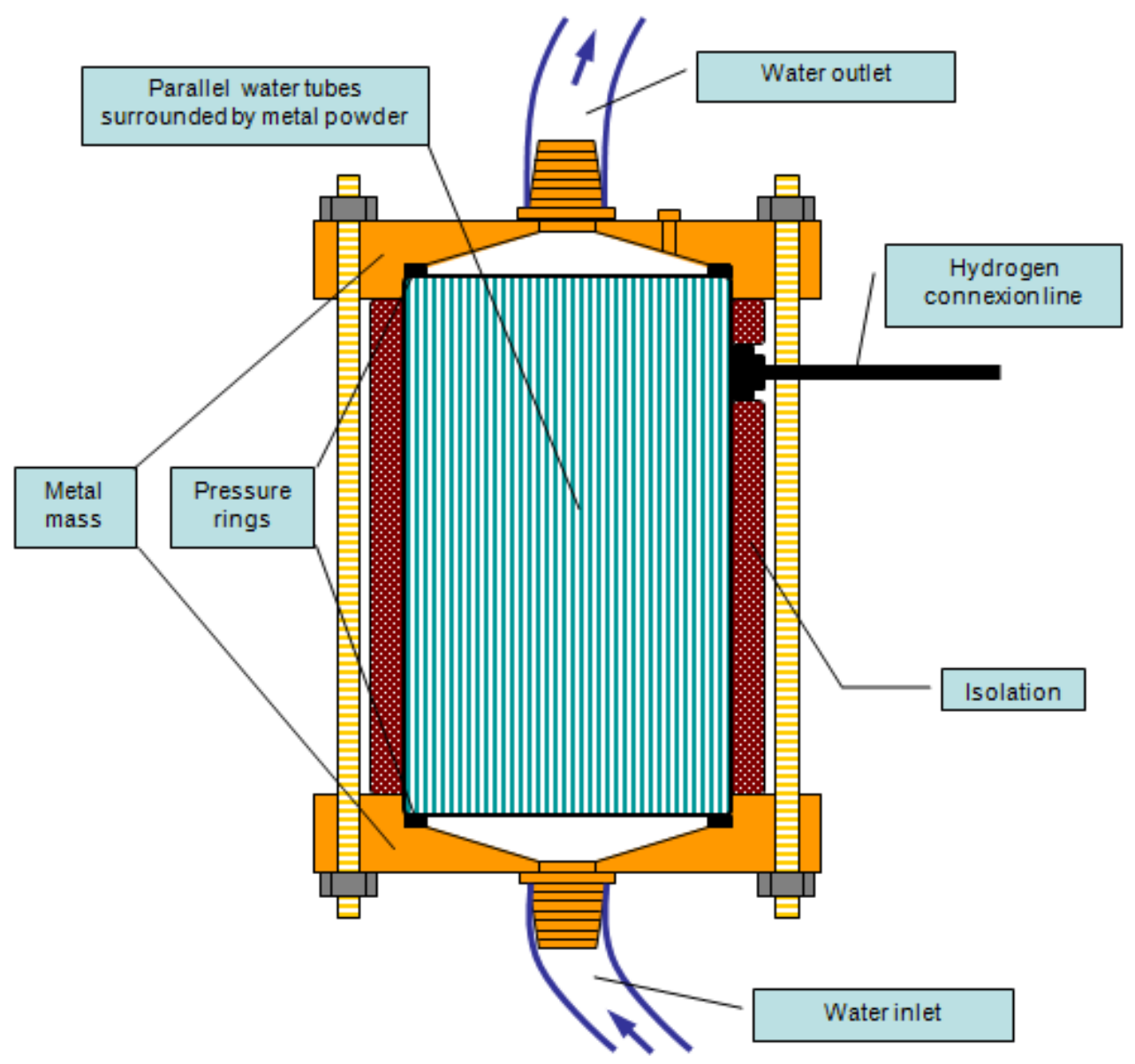

Fig. 7. Detailed configuration of the reaction beds

\begin{tabular}{ccc}
\hline & Value & Units \\
\hline Weight & 2.9 & $\mathrm{~kg}$ \\
\hline Volume & 0.7 & $\mathrm{l}$ \\
\hline Number of water tubes & 372 & - \\
\hline $\begin{array}{c}\text { Internal diameter } \\
\text { of the water tubes }\end{array}$ & 1.4 & $\mathrm{~mm}$ \\
\hline $\begin{array}{c}\text { External diameter } \\
\text { of the water tubes }\end{array}$ & 1.8 & $\mathrm{~mm}$ \\
\hline Length of the water tubes & 123 & $\mathrm{~mm}$ \\
\hline Mass of alloy in bed A & $\approx 0.8$ & $\mathrm{~kg}$ \\
\hline Mass of alloy in bed B & $\approx 0.9$ & $\mathrm{~kg}$
\end{tabular}

Table 1. Technical features of the reaction beds 
The most relevant features of the reactors are given in Table 1. Each reactor has an approximate volume of $0.7 \mathrm{I}$ and a weight of $2.9 \mathrm{~kg}$ (metal mass not included). The main contribution to this total weight is not the sorption powder $(\approx 0.9 \mathrm{~kg})$ but the thermal mass of the metallic water tubes, the filtered tube and the surrounding tube $(\approx 2 \mathrm{~kg})$.

\subsubsection{Operation of the system}

The operation of the MHCS is controlled by means of a PC which is located next to the experimental set-up. The installation is monitored using a software program based on HP VEE Pro (Agilent). This operation of the system consists in feeding the reactors with the corresponding heat sinks/sources.

The operation of the cooling system consists of two phases, and is illustrated schematically in Fig. 8. The cooling phase starts ideally when the cold temperature reactor $A$ is fully charged with metal hydride. As the pressure in this bed is higher than in bed $B$, hydrogen flows through the connection line from $A$ towards $B$. In bed $A$, the desorption enthalpy is responsible for the cooling of the cold water $T_{c}$ which circulates through the reactor.

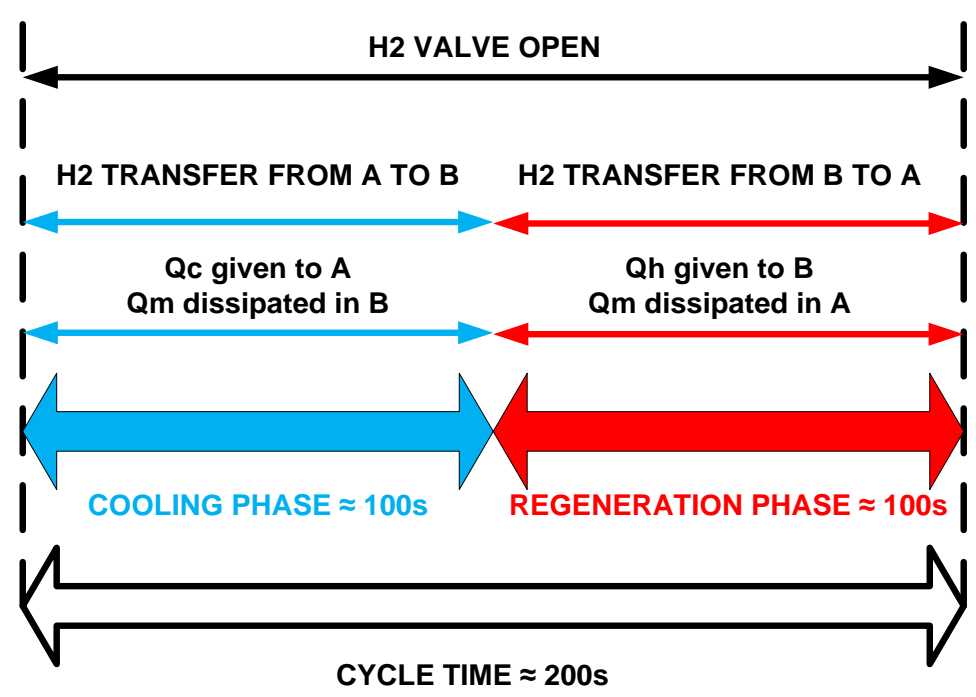

Fig. 8. Operation of the MHCS 
Fig. 9 shows an example of the driving temperatures in the dynamic cooling tests at $T_{h}=130^{\circ} \mathrm{C}, T_{m}=35^{\circ} \mathrm{C}, T_{c}=20^{\circ} \mathrm{C}$.

At the end of the cooling phase, bed A contains almost no hydrogen under metal hydride phase. For the regeneration of reactor $A$, the pressure of bed $B$ is increased by pumping hot water at $T_{h}$ through the reactor. This increases the equilibrium pressure in bed $B$, and enables hydrogen transfer from reactor $B$ towards $A$. The hot water provides the enthalpy which is required in bed $B$ for the dehydriding reaction. Hydrogen is then desorbed from bed $B$ and absorbed in bed A. The hydriding process is exothermic and the heat is rejected to the heat sink at $T_{m}$.

As explained above, the switching between the regeneration and cooling phase only depends on the temperature of the water circuits. The end of the regeneration phase is characterized by a low desorption rate. The half cycle time which has been chosen (100 s) facilitates an almost full regeneration of bed $A$. The regeneration phase could be extended in order to achieve a higher cooling power in bed $\mathrm{A}$, but this would imply a much longer regeneration phase and hence a significant decrease in the coefficient of performance (COP).

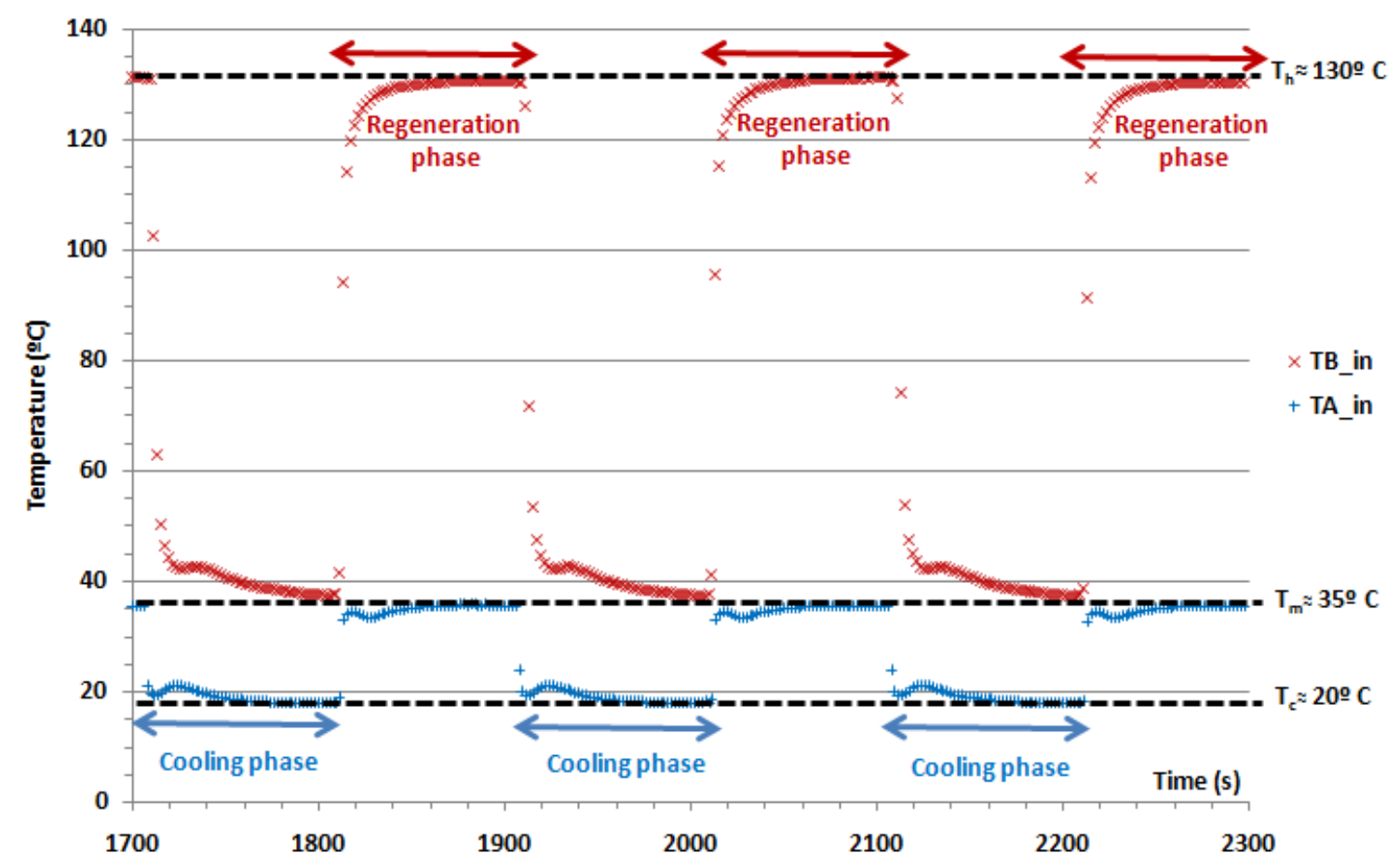

Fig. 9. Operation of the dynamic cooling tests at $\left(T_{h}, T_{m}, T_{c}\right)=(130,35,20)^{\circ} \mathrm{C}$ 
2.2.2. Uncertainty of the measurements

The following variables have been measured during the experimental campaign of the MHCS:

- Water mass flow rate through both of the reactors

- Hydrogen exchange rate between the reactors

- Pressure in each reactor

- Water temperature at the outlet of the reactors

Table 2 details the average precision of the measurement equipment.

\begin{tabular}{ccc}
\hline Equipment & Type & Average measurement precision \\
\hline Temperature sensors & Pt 100 class A & $\pm(0.3+0.005 . \mathrm{T}) \stackrel{\circ}{\circ} \mathrm{C}$ \\
\hline Water flow meters & KRONE IFS 6000F & $\pm 0.3 \% \mathrm{FS}(\mathrm{FS}=15 \mathrm{l} / \mathrm{min})$ \\
\hline Hydrogen flow meter & HASTINGS HFM-201 & $\pm 1 \% \mathrm{FS}(\mathrm{FS}=100 \mathrm{~s} / \mathrm{min})$ \\
\hline Pressure sensors & KELLER PA-23 & $\pm 0.5 \% \mathrm{FS}(\mathrm{FS}=100 \mathrm{bar})$
\end{tabular}

Table 2. Average precision of the measurements

Fig. 10 to Fig. 12 show the uncertainty of the experimental data during the dynamic cycle tests at temperatures of $T_{h}=130^{\circ} \mathrm{C}, \mathrm{T}_{\mathrm{m}}=35^{\circ} \mathrm{C}, \mathrm{T}_{\mathrm{c}}=20^{\circ} \mathrm{C}$. The measured water mass flow rate (almost constant value around $4.02 \mathrm{l} / \mathrm{min}$ ) has been plotted in Fig. 10. The error $(0.3 \%$ at full scale $=15 \mathrm{l} / \mathrm{min})$ has also been represented in this figure.

In the measurement of the water temperature, the error which is obtained using Pt-100 thermal resistances (type B) is given by the expression (1):

$$
\varepsilon_{T}=0.3+0.005 \cdot T\left({ }^{\circ} \mathrm{C}\right)
$$




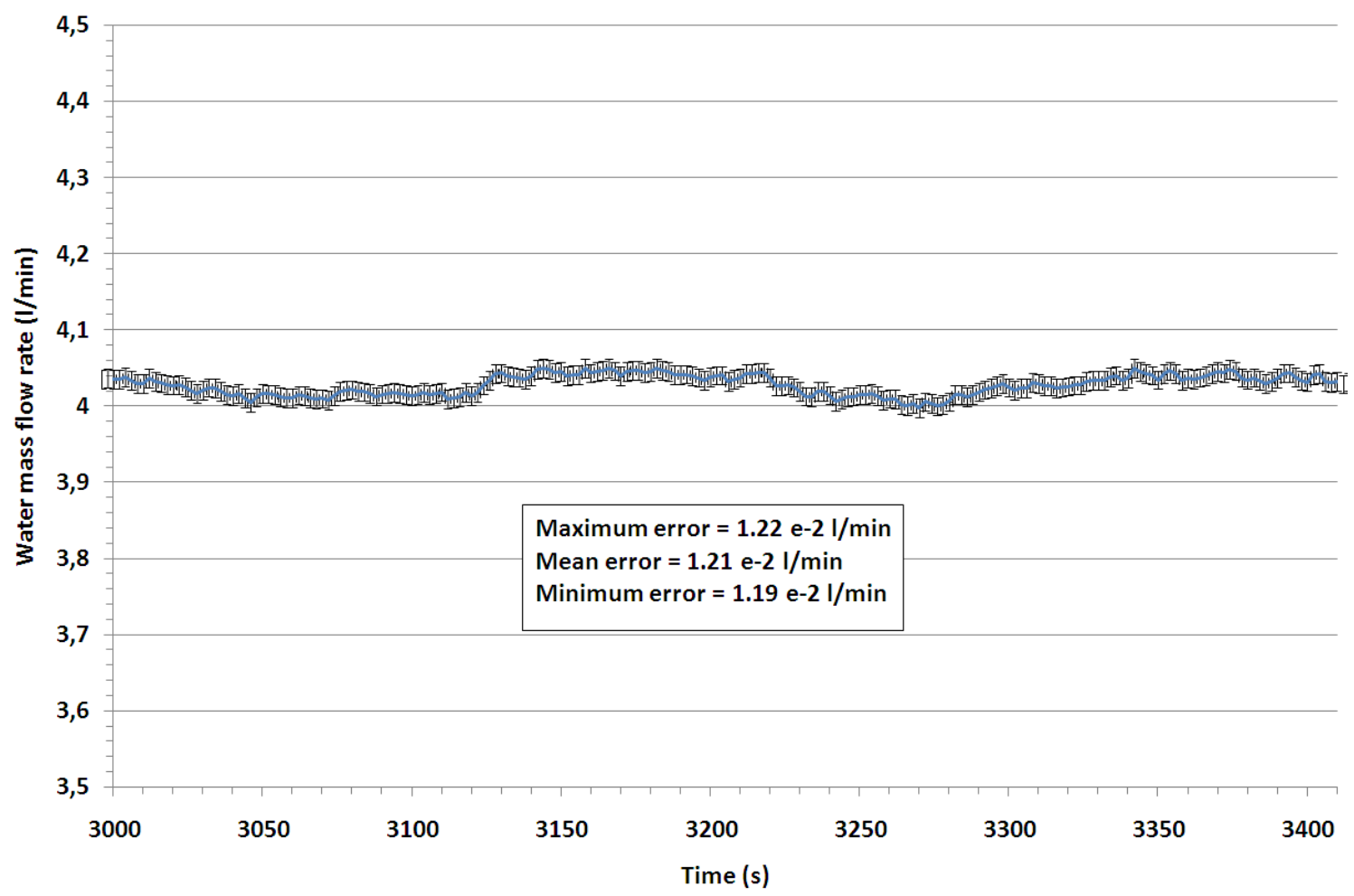

Fig. 10. Uncertainty in the measurements of the water mass flow rate. Tests: $T_{h}=130^{\circ} \mathrm{C}, \mathrm{T}_{\mathrm{m}}=35^{\circ} \mathrm{C}, \mathrm{T}_{\mathrm{c}}=20^{\circ} \mathrm{C}$

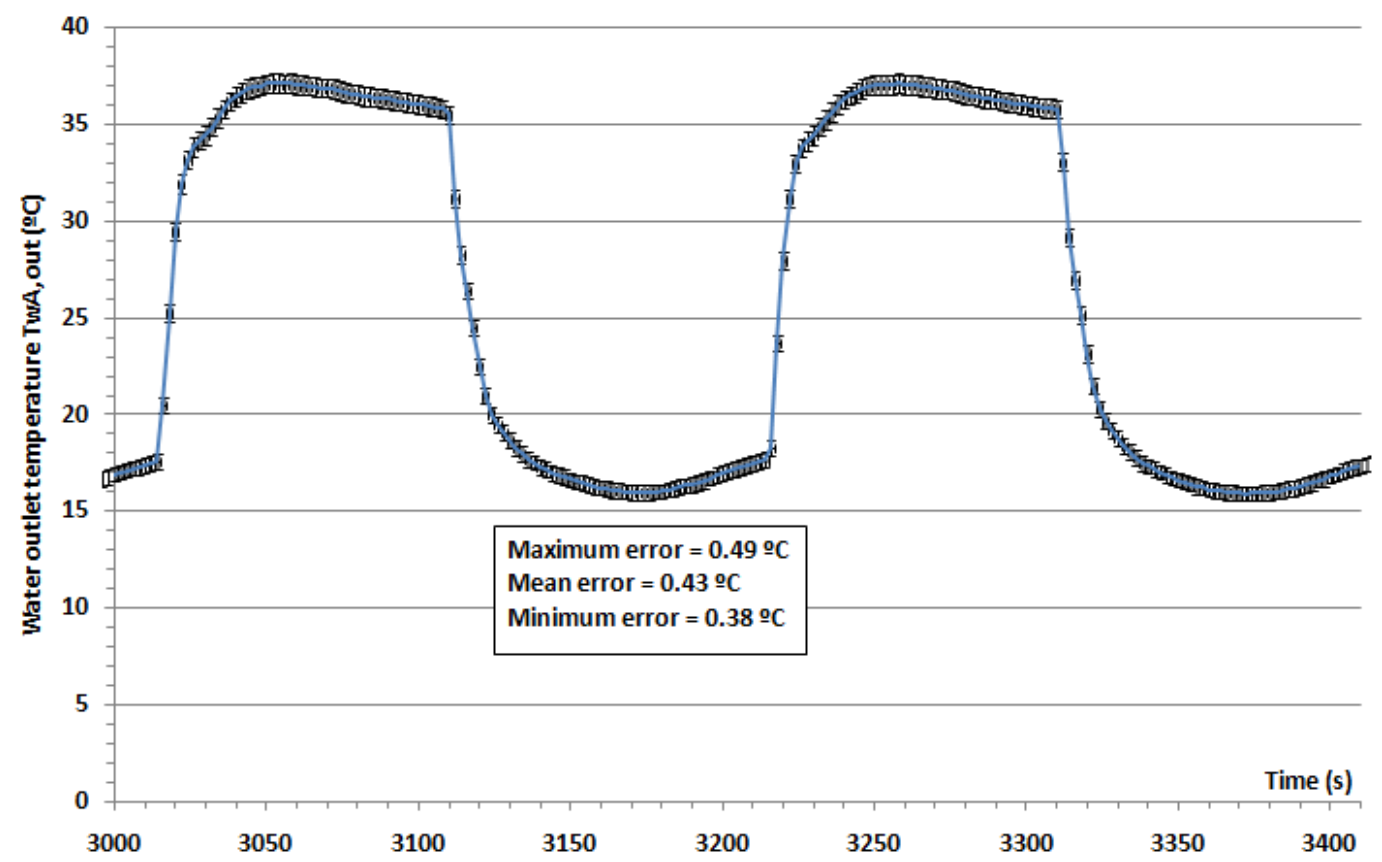

Fig. 11. Uncertainty in the measurements of the reactor outlet temperature (bed A). Tests: $\mathrm{T}_{\mathrm{h}}=130^{\circ} \mathrm{C}, \mathrm{T}_{\mathrm{m}}=35^{\circ} \mathrm{C}, \mathrm{T}_{\mathrm{c}}=20^{\circ} \mathrm{C}$ 
Fig. 11 illustrates the error in the measurements of the reactor outlet temperature in bed $\mathrm{A}$. In bed $\mathrm{B}$, the maximum error which is reached is $0.95^{\circ} \mathrm{C}$, and the mean error is $0.73^{\circ} \mathrm{C}$. Although the error is slightly higher in this bed in comparison to bed $A$ due to the higher temperatures, the error bed $B$ has not been plotted because within a temperature scale from $30^{\circ} \mathrm{C}$ to $130^{\circ} \mathrm{C}$, an error of $1^{\circ} \mathrm{C}$ is hardly visible.

Although an error of $1^{\circ} \mathrm{C}$ in the absolute temperature may seem rather high, the thermocouples which measure the inlet and outlet temperature of the reactors have been calibrated in order to guarantee that the measurements of $\left(T_{w, n^{-}}\right.$ $\left.T_{w, o u t}\right)$ have an accuracy of $\pm 0.1 \mathrm{~K}$. This temperature difference is directly related to the cooling power $\left(Q_{c}\right)$ and thus it is important to have a good accuracy in its calculation.

Fig. 12 illustrates the error in the measurements of the hydrogen exchange rate with the HASTINGS flow meter. The manufacturer specifies an uncertainty of $1 \%$ at full scale (full scale $=100 \mathrm{sl} / \mathrm{min}$ ). Thus, for flow rates ranging between 120 and $100 \mathrm{sl} / \mathrm{min}$, it is hard to notice errors of around $0.43 \mathrm{sl} / \mathrm{min}$.

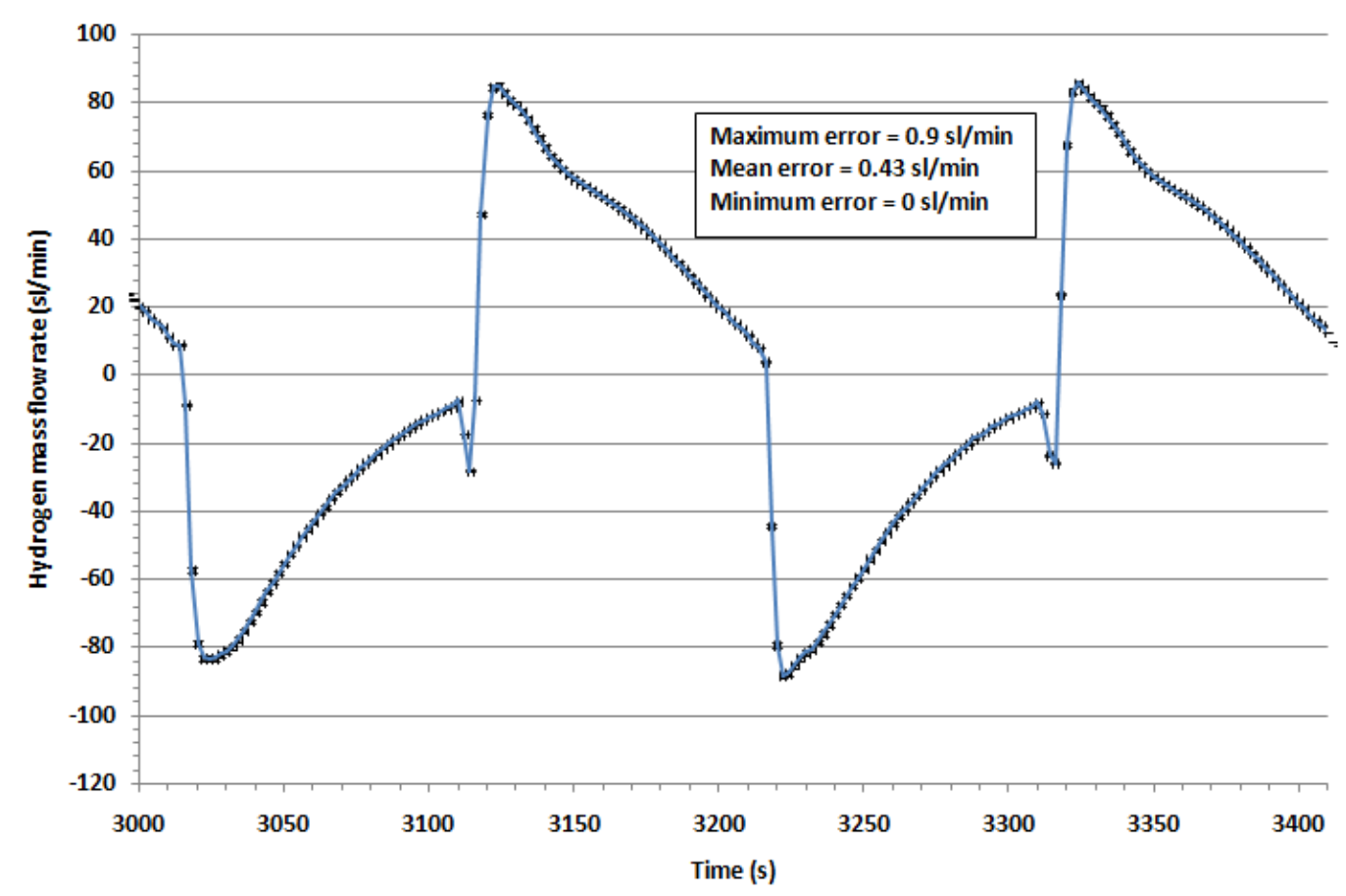

Fig. 12. Uncertainty in the measurements of the hydrogen exchange rate. Tests: $\mathrm{T}_{\mathrm{h}}=130^{\circ} \mathrm{C}, \mathrm{T}_{\mathrm{m}}=35^{\circ} \mathrm{C}, \mathrm{T}_{\mathrm{c}}=20^{\circ} \mathrm{C}$ 


\section{Chapter 3: \\ Properties of metal hydrides}




\section{Nomenclature}

\begin{tabular}{|c|c|}
\hline M & Metal \\
\hline $\mathrm{MH}$ & Metal hydride \\
\hline$\Delta \mathrm{H}$ & Enthalpy of formation, $\mathrm{J} \mathrm{mol}^{-1}$ \\
\hline $\mathrm{T}$ & Temperature, $\mathrm{K}$ \\
\hline C & Metal hydride concentration, g MH/g alloy (\%) \\
\hline $\mathrm{P}$ & Pressure, bar \\
\hline$\Phi$ & Number of phases in Gibbs' law Eq. (2) \\
\hline $\mathrm{N}_{\mathrm{c}}$ & Number of chemical components in Gibbs' law Eq. (2) \\
\hline DF & Degrees of freedom in Gibbs' law Eq. (2) \\
\hline$\Delta S$ & Entropy of formation, $\mathrm{J} \mathrm{mol}^{-1} \mathrm{~K}^{-1}$ \\
\hline$\Delta \mathrm{G}$ & Gibbs free energy of formation, $\mathrm{J} \mathrm{mol}^{-1}$ \\
\hline $\mathrm{R}$ & Universal gas constant, $\mathrm{J} \mathrm{mol}^{-1} \mathrm{~K}^{-1}$ \\
\hline$F_{\text {hys }}$ & Hysteresis factor, as expressed in Eq. (6) \\
\hline B & Deformation parameter, adim \\
\hline $\mathrm{C}_{\mathrm{p}}$ & Specific heat capacity, $\mathrm{J} \mathrm{kg}^{-1} \mathrm{~K}^{-1}$ \\
\hline $\mathrm{C}_{\mathrm{f}}$ & Form factor, adim \\
\hline d & Particle diameter, $\mathrm{m}$ \\
\hline $\mathrm{k}$ & Relative thermal conductivity, $\lambda_{\text {eff }} / \lambda_{f}$, adim \\
\hline $\bar{l}$ & Mean free path of the molecules, $m$ \\
\hline$l$ & Modified mean free path of the molecules, $\mathrm{m}$ \\
\hline$\widehat{m}$ & Molecular weight, $\mathrm{g} \mathrm{mol}^{-1}$ \\
\hline Y & Accomodation coefficient, adim \\
\hline$\epsilon$ & Emissivity \\
\hline$\lambda$ & 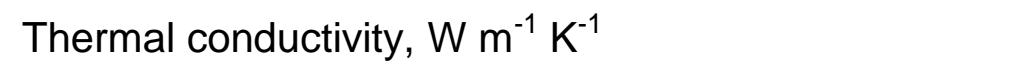 \\
\hline$\sigma$ & Stefan's constant, $\mathrm{W} \mathrm{m}^{-4} \mathrm{~K}^{-4}$ \\
\hline$\varphi$ & Flattening coefficient, adim \\
\hline$\psi$ & Porosity, adim \\
\hline $\mathrm{v}$ & Fit parameter, adim \\
\hline $\mathrm{Kn}$ & Knudsen number, adim \\
\hline$\delta$ & Pore mean diameter, m \\
\hline $\mathrm{K}, \mathrm{b}, \mathrm{C}_{\mathrm{a}}, \mathrm{C}_{\mathrm{b}}$ & Fluid specific constants \\
\hline
\end{tabular}


Chapter 3 - PROPERTIES OF METAL HYDRIDES

\begin{tabular}{|ll|}
\hline $\begin{array}{l}\text { kadiab } \\
\text { Subscripts }\end{array}$ & Adiabatic exponent \\
eq & Equilibrium in the $\alpha+\beta$ phase region of the P-C-T curves \\
0 & Reference condition $\left(P_{0}=1\right.$ bar) \\
$\alpha$ & Solid solution phase of hydrogen in the metal lattice \\
$\beta$ & Solid solution phase of hydrogen in the metal hydride lattice \\
$\alpha+\beta$ & $\alpha+\beta$ phase region in the P-C-T curves \\
mid & Middle of the $\alpha+\beta$ phase region \\
hys & Hysteresis \\
abs & Absorption (hydriding process) \\
des & Desorption (dehydriding process) \\
$f$ & Fluid \\
$G$ & Pressure dependent \\
$P$ & Particle \\
eff & Effective \\
rad & Radiation \\
\hline
\end{tabular}




\section{PROPERTIES OF METAL HYDRIDES}

\subsection{Brief description of the sorption reaction}

Before going into detail on the properties of metal hydrides, it is important to have a general overview of the sorption reaction. The hydriding and dehydriding reaction may be written as in Eq. (2):

$$
M+\frac{1}{2} x H_{2} \underset{-\Delta H}{\stackrel{+\Delta H}{\leftrightarrow}} M H_{x}
$$

Metal powders are porous materials with a diameter from $50 \mu \mathrm{m}$ to $1 \mathrm{~mm}$. These alloys have the capacity to absorb hydrogen during the so-called hydriding reaction, where the solid phase known as metal hydride $(\mathrm{MH})$ is formed. This reaction is exothermic and releases heat.

Depending on the temperature and pressure conditions, the sorption process may be reversed, and the hydrogen atoms can recombine to form gaseous hydrogen $\left(\mathrm{H}_{2}\right)$. This process is endothermic and hence metal hydride systems can also be designed for cooling purposes besides their conventional application for hydrogen storage.

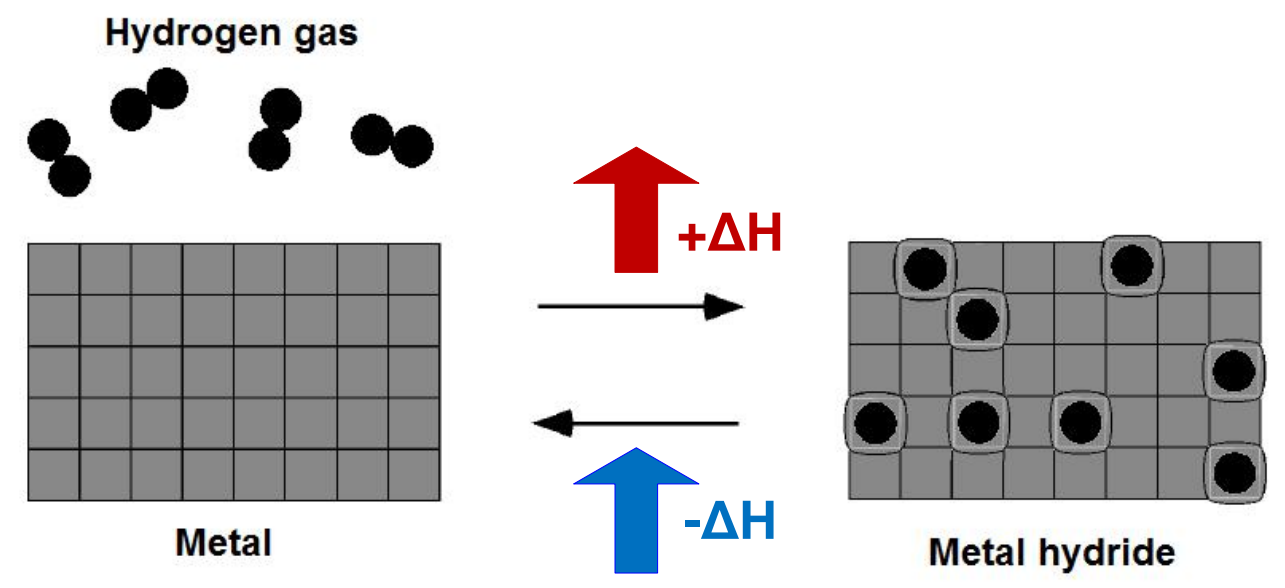

Fig. 13. Simplified sorption scheme 
Fig. 13 clearly illustrates the hydriding and dehydriding mechanisms [42]. During absorption, the hydrogen in gas state (disordered) forms a more ordered, solid metal hydride crystal where the hydrogen is in mono-atomic state. During this process the crystal expands and releases heat. On the contrary, hydrogen desorption requires heat injection, and the crystal suffers a contraction stress.

\subsection{Classification of metal hydrides and properties}

The research on metal hydrides has led to a wide range of results using many different alloys. In Table 3, the most relevant alloys are studied within a crosscutting study which compares the storage capacity, effect of impurities, preparation and kinetics of the alloys. One additional key criterion is the pressure-temperature operating range of the alloys which is given in Fig. 14 .

The criteria to select metal hydrides depend mainly on the intended application (hydrogen storage, cooling applications...). Interesting features for a metal hydride cooling system are fast intrinsic kinetics, a significant plateau capacity, and low equilibrium pressures in order to guarantee higher safety conditions. $\mathrm{LaNi}_{5}$ is for instance an alloy which is interesting for cooling systems because of its interesting temperature range, fast reaction kinetics and cyclic stability. 
Chapter 3 - PROPERTIES OF METAL HYDRIDES

\begin{tabular}{|c|c|c|c|c|c|c|}
\hline & $\begin{array}{l}\text { Lanthanum- } \\
\text { nickel } \\
\text { hydride }\end{array}$ & $\begin{array}{c}\text { Zirconium- } \\
\text { manganese } \\
\text { hydride }\end{array}$ & $\begin{array}{l}\text { Titanium- } \\
\text { iron } \\
\text { hydride }\end{array}$ & $\begin{array}{c}\text { Palladium } \\
\text { hydride }\end{array}$ & $\begin{array}{c}\text { Magnesium } \\
\text { hydride }\end{array}$ & Alanates \\
\hline $\begin{array}{c}\text { Reversible } \\
\text { capacity }\end{array}$ & $1.5 \%$ & $1.77 \%$ & $1.86 \%$ & $0.72 \%$ & $7 \%$ & $4-5 \%$ \\
\hline Activation & Easy & Moderate & Difficult & $\begin{array}{c}\text { Sensitive } \\
\text { to CO }\end{array}$ & Easy & $\begin{array}{l}\text { Hydrogenation } \\
\text { at } 150^{\circ} \mathrm{C} \\
\text { under } 170 \text { bar }\end{array}$ \\
\hline Impurities & $\begin{array}{c}\text { Sensitive to } \\
\text { oxygen, } \\
\text { water and } \\
\text { CO. Not } \\
\text { very } \\
\text { sensitive up } \\
\text { to } 500 \mathrm{ppm} \text {. }\end{array}$ & $\begin{array}{c}\text { Fairly } \\
\text { sensitive } \\
\text { (sensitive } \\
\text { to sulphur } \\
\text { dioxide) }\end{array}$ & $\begin{array}{l}\text { Highly } \\
\text { sensitive } \\
\text { to } \\
\text { oxygen, } \\
\text { water } \\
\text { and CO }\end{array}$ & - & $\begin{array}{l}\text { Relatively } \\
\text { low } \\
\text { sensitivity }\end{array}$ & Sensitive \\
\hline Preparation & Fairly easy & Difficult & Difficult & - & Difficult & Difficult \\
\hline Kinetics & Very fast & Fast & Fast & Fast & Fast & Slow \\
\hline
\end{tabular}

Table 3. Relevant characteristics of different alloys [43]

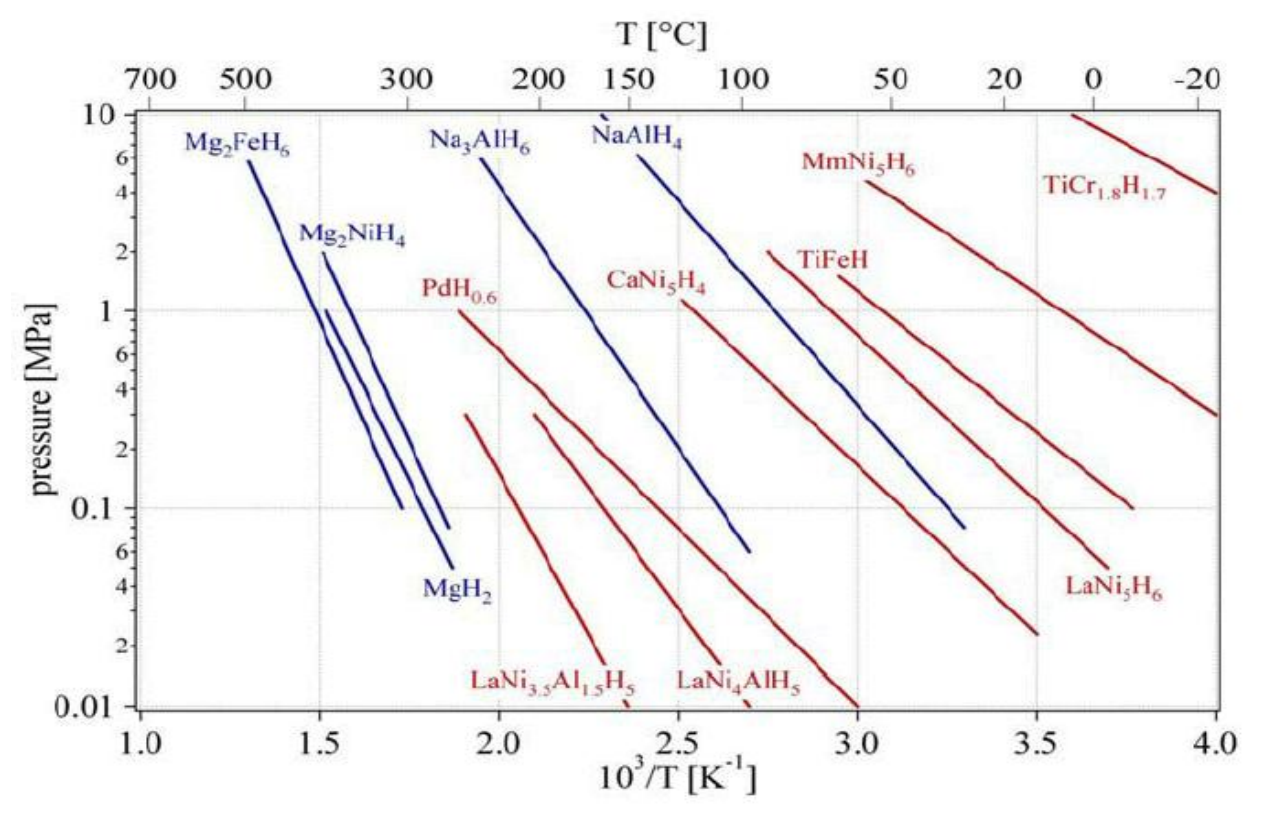

Fig. 14. Operating temperature and pressure range of different alloys 
In storage applications, the key aspect is the volumetric capacity of the alloy. For instance, it is possible to store the equivalent of a 7 -litre hydrogen tank $\left(7000 \mathrm{~cm}^{3}\right)$, filled at atmospheric pressure, in a small palladium cube of $27 \mathrm{~cm}^{3}$, under a hydrogen pressure that is ten times lower than in conventional hydrogen gas storage [43]. For mobile applications such as hydrogen storage in vehicles, there is still a major drawback on using metal hydrides, which is the low mass capacity, very often below the DOE target for vehicles (6\%). In practical terms, this means that the actual storage tanks are rather heavy, as they require a significant metal mass to store the desired amount of hydrogen for a reasonable autonomy. Only magnesium hydrides have a high mass absorption capacity (around 7\%), but their absorption/desorption kinetics are too slow and are thus incompatible with most of the targeted applications. Furthermore, magnesium alloys have the drawback to require very high desorption temperatures [43] $\left(300^{\circ} \mathrm{C}\right.$ to $\left.400^{\circ} \mathrm{C}\right)$, as also illustrated in Fig. 14 .

There are many possible classifications of metal hydrides depending on their crystalline structure, chemical composition, etc...The most extended classification relies on the chemical composition. In the conventional nomenclature of metal hydrides, the latter are divided into $A$ and $B$ elements of the periodic table.

In this nomenclature, A refers to rare earth and alkaline elements, which present a high affinity for hydrogen and tend to form stable hydrides. Element $B$ is generally a transition metal and it usually presents a poor affinity for hydrogen, hereby forming unstable hydrides. Frequently, $\mathrm{Ni}$ is used as a $\mathrm{B}$ element because it enhances the intrinsic reaction kinetics.

With this nomenclature, the different families of alloys may be divided according to their intermetallic bonds into $A B_{5}$ alloys $\left(\mathrm{LaNi}_{5}\right), \mathrm{AB}_{2}$ alloys $\left(\mathrm{ZrV}_{2}\right), A B(\mathrm{TiFe})$, $A_{2} B\left(\mathrm{Mg}_{2} \mathrm{Ni}\right), \mathrm{AB}_{3}\left(\mathrm{CeNi}_{3}\right), \mathrm{A}_{2} \mathrm{~B}_{7}\left(\mathrm{Th}_{2} \mathrm{Fe}_{7}\right)$, etc...Each alloy presents a different crystal structure, nevertheless the most common configurations are the fcc, hcp and bcc. The hydrogen atoms are usually trapped in octahedral $(\mathrm{O})$ or tetrahedral $(T)$ interstitial sites. 
$\mathrm{AB}_{5}$ alloys have been studied thoroughly in literature and they present interesting properties such as fast reaction kinetics, almost no hysteresis and a good cycling stability. These alloys present the disadvantage of having a low storage capacity, but they may be interesting for metal hydride cooling systems because of their fast intrinsic kinetics.

The $A B_{2}$ compounds are derived from the Laves phase crystal structures. The $A B_{2} s$ are usually obtained with $\mathrm{Ti}$ and $\mathrm{Zr}$ as $\mathrm{A}$ element. The $\mathrm{B}$ elements are represented mainly by combinations of $3 \mathrm{~d}$ atoms such as $\mathrm{V}, \mathrm{Cr}, \mathrm{Mn}$ and Fe. The hydrogen storage capacity can reach up to $2 w t \%$ in Laves phase $\mathrm{V}_{7.4 \%} \mathrm{Zr}_{7.4 \%} \mathrm{Ti}_{7.4 \%} \mathrm{Ni}$. The Laves phase compounds have attracted an important attention in the last decade due to their good hydrogen storage capacity. Most of the $A_{2}$ alloys show relatively high capacities, fast kinetics, long life and a relatively low cost in comparison to $\mathrm{LaNi}_{5}$ alloys. However, their hydrides are too stable at room temperature. The $A_{2}$ alloys are often more sensitive to gas impurities than $\mathrm{AB}_{5}$-type compounds. Thus, a small amount of oxygen can be a poison for the $A B_{2} s$, while for the $A B_{5} s$, it acts as a reactant, thus reducing the storage capacity. $\mathrm{CO}$ is a poison for both types of compounds, although capacity recovery is possible by recycling the impure hydrogen.

Finally, another interesting family of alloys are the complex hydrides [44][18]. In such hydrides, $\mathrm{H}_{2}$ evolves upon contact with water. Group I, II, and III elements, e.g. $\mathrm{Li}, \mathrm{Mg}, \mathrm{B}, \mathrm{Al}$, build a large variety of metal-hydrogen complexes. The interest of these alloys relies on their high volumetric density [45] $\left(150 \mathrm{~kg} / \mathrm{m}^{3}\right.$ in $\mathrm{Mg}_{2} \mathrm{FeH}_{6}$ and $\left.\mathrm{Al}\left(\mathrm{BH}_{4}\right)_{3}\right)$ and on their high gravimetric density at room temperature $\left(18 \mathrm{wt} \%\right.$ in $\left.\mathrm{LiBH}_{4}\right)$. There has been a significant research on sodium aluminum hydrides $\left(\mathrm{NaAlH}_{4}\right)$, which present a theoretically reversible hydrogen storage capacity of 5.6 wt\% and a low cost. However, they present important disadvantages due to their irreversibility (very high desorption temperatures are required) and very slow kinetics. However, by using appropriate transition or rare-earth metals as catalysts, the complex hydrides can be made reversible. 
In conclusion, the chemical nature of the alloys plays a key role on the performance of any metal hydride application as it defines the intrinsic kinetics as well as the operating temperature and pressure range. In cooling applications, fast reaction kinetics and cyclic stability are essential. This PhD work focuses on using medium temperature heat sources (between $100^{\circ} \mathrm{C}$ and $\left.150^{\circ} \mathrm{C}\right)$, and hence two of the metal hydride families which have been selected for the reactors are the $A B_{5}$ and $A B_{2}$ alloys.

\subsection{Ideal phase diagrams}

As many other phase-change materials, metal hydrides are characterized by their phase diagrams. These (Fig. 15) are obtained with equilibrium measurements of temperature $(T)$, pressure $(P)$ and metal hydride concentration $(\mathrm{C})$. The composition $(\mathrm{C})$ can be expressed as the fraction between the absorbed mass of hydrogen and the metal mass $([\mathrm{H}] /[\mathrm{M}]$ wt \%), or more classically as a ratio of the number of $\mathrm{H}$ atoms to the number of $\mathrm{M}$ atoms. The P-C isotherms (P-C-Is) are often referred to as "P-C-T" curves, but they are obtained under constant temperature. In the following chapters of this $\mathrm{PhD}$ project, the common nomenclature of "P-C-T" curves will be used.

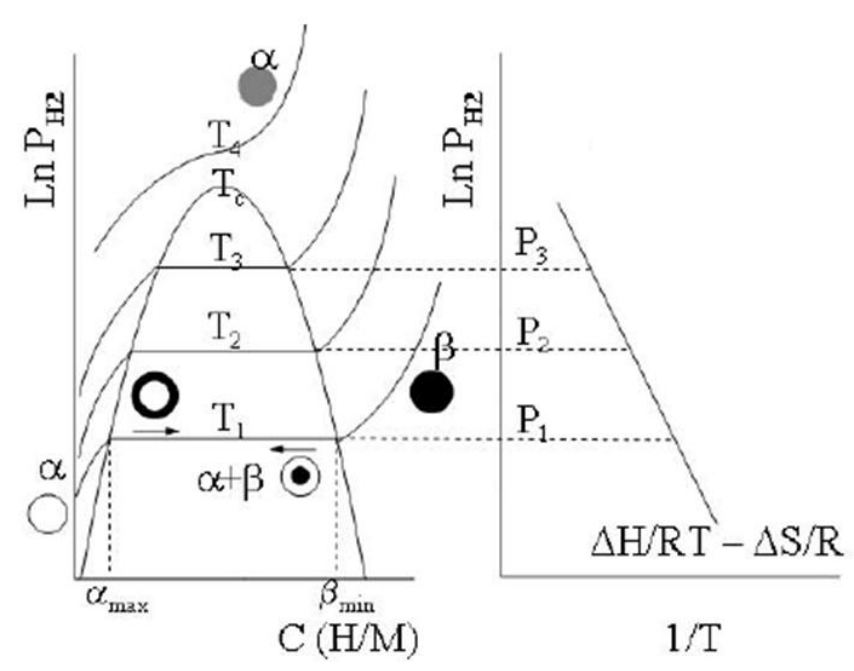

Fig. 15. Simplified static phase diagram of metal hydrides [46] 
In the phase diagrams, three different regions are usually observed; the $\alpha$ solution phase (left), the $\alpha+\beta$ or $\alpha \rightarrow \beta$ phase (middle) and the $\beta$ or hydride phase (right). In the a phase, the gas pressure has to be increased substantially for a small hydrogen absorption. However, in the plateau region, where the two phases coexist $(\alpha+\beta)$, a significant amount of hydrogen may be absorbed within small pressure variations. Once in the hydride phase, important pressure increases are required to increase the hydrogen storage. The plateau region finishes for temperatures above the critical temperature $\left(T_{c}\right)$.

From a microscopic point of view, as the pressure increases, the vibrational energy of the gas increases and hydrogen gas molecules $\left(\mathrm{H}_{2}\right)$ may break at the surface of the metal lattice. The mono-atomic hydrogen atoms can then penetrate in the interior of the crystal and, following a nucleation and growth process, the metal hydride phase is formed.

In the a phase, the gaseous hydrogen forms a solid solution in the metal crystal. In the central region $(\alpha+\beta)$, the hydrogen in gas state is dissolved in a solid crystal of both metal and metal hydride. Finally, the $\beta$ phase is a solid solution of hydrogen in the metal hydride crystal.

An important aspect which should be stressed is that the static phase diagram represented in Fig. 15 is ideal, but real metal hydrides present a different behavior:

- Metal hydrides exhibit higher pressures during absorption than during desorption. This aspect is called hysteresis and is analyzed more thoroughly in subsection 3.5 .

- The $\alpha+\beta$ phase-region is not completely flat, and depending on the alloy, the "plateau" slope may be significant.

- The dome represented by real P-C-T curves is not necessarily symmetric.

As real metal hydrides reveal a different behavior from the ideal phase diagrams (Fig. 15), the modelling of real P-C-T curves requires a specific attention and is the object of Chapter 4. Additionally, and as the sorption 
reaction is fairly complex, Chapter 5 is dedicated specifically to the modelling of the intrinsic reaction kinetics.

\subsection{Thermodynamics of sorption reactions}

This subsection focuses on the thermodynamics of the sorption reaction taking place in the two-phase region which is where the metal hydride cooling system mainly works.

In the plateau, the hydrogen gas phase coexists with two distinct solid phases (hydrogen saturated metal and metal hydride). According to the Gibbs' phase law, the following relationship must be satisfied:

$$
D F=N_{c}+2-\emptyset
$$

Where

$$
\begin{aligned}
& D F \equiv \text { degrees of freedom } \\
& N_{C} \equiv \text { number of chemical components } \\
& \Phi \equiv \text { number of phases }
\end{aligned}
$$

If the Gibbs' law is applied at any place within the plateau, 3 phases are found; saturated metal, metal hydride and gaseous hydrogen, hence $\phi=3$. There are 2 components, $H$ and $M$, so $N_{c}=2$. Therefore, in the $\alpha+\beta$ region, there is only one degree of freedom. This means that only one parameter (for instance, the temperature) is variable and all the rest, including the metal hydride concentration and the gas pressure, are determined uniquely.

In the plateau region, the solid solution phase $\alpha$, the hydride phase $\beta$ and the hydrogen gas phase are in equilibrium. Hence, each of these phases has the same chemical potential. This condition leads to the Van't Hoff Eq. (4) [42]. 


$$
\ln \left(\frac{P_{e q}}{P_{0}}\right)=\frac{\Delta H}{R \cdot T}-\frac{\Delta S}{R}
$$

In the previous equation, hydrogen is assumed to be an ideal gas in the reference state $\left(P_{0}=1\right.$ bar). This is a very good approximation at temperatures above 100K [47].

As may be inferred from Eq. (3) and from the Gibbs's rule, if the temperature is fixed, then the equilibrium pressure is fixed too. However, Eq. (3) is only valid in the middle of the $\alpha+\beta$ region. Real $P-C$ isotherms in this region usually present a non negligible slope which derives from the variations of the entropy $\Delta S$ for different metal hydride concentrations. This aspect is analyzed thoroughly in Chapter 4.

The Gibbs' free energy $\Delta G$ of the metal hydride may also be obtained as a function of the temperature [42] from the previous values of $\Delta \mathrm{H}$ and $\Delta \mathrm{S}$ :

$$
\Delta G=R T \ln \left(\frac{P}{P_{0}}\right)=\Delta H-T \cdot \Delta S
$$

The calculated entropy of formation in metal hydrides usually has a very similar value to the entropy change of the hydrogen gas $\left(\Delta \mathrm{S}_{0}\left(\mathrm{H}_{2}\right)=130.6 \mathrm{~J} \mathrm{~mol}^{-1} \mathrm{~K}^{-1}\right)$. The Gibbs' free energy is directly related to the electronegativity, atomic size, electron concentration and to the temperature [48].

From a macroscopic point of view, Fig. 16 represents the evolution of the Gibbs' free energy as a function of the temperature and of the metal hydride concentration. In the plateau region, a significant amount of hydrogen can be absorbed within a very low band of Gibbs' free energy. 


\section{Chapter 3 - PROPERTIES OF METAL HYDRIDES}

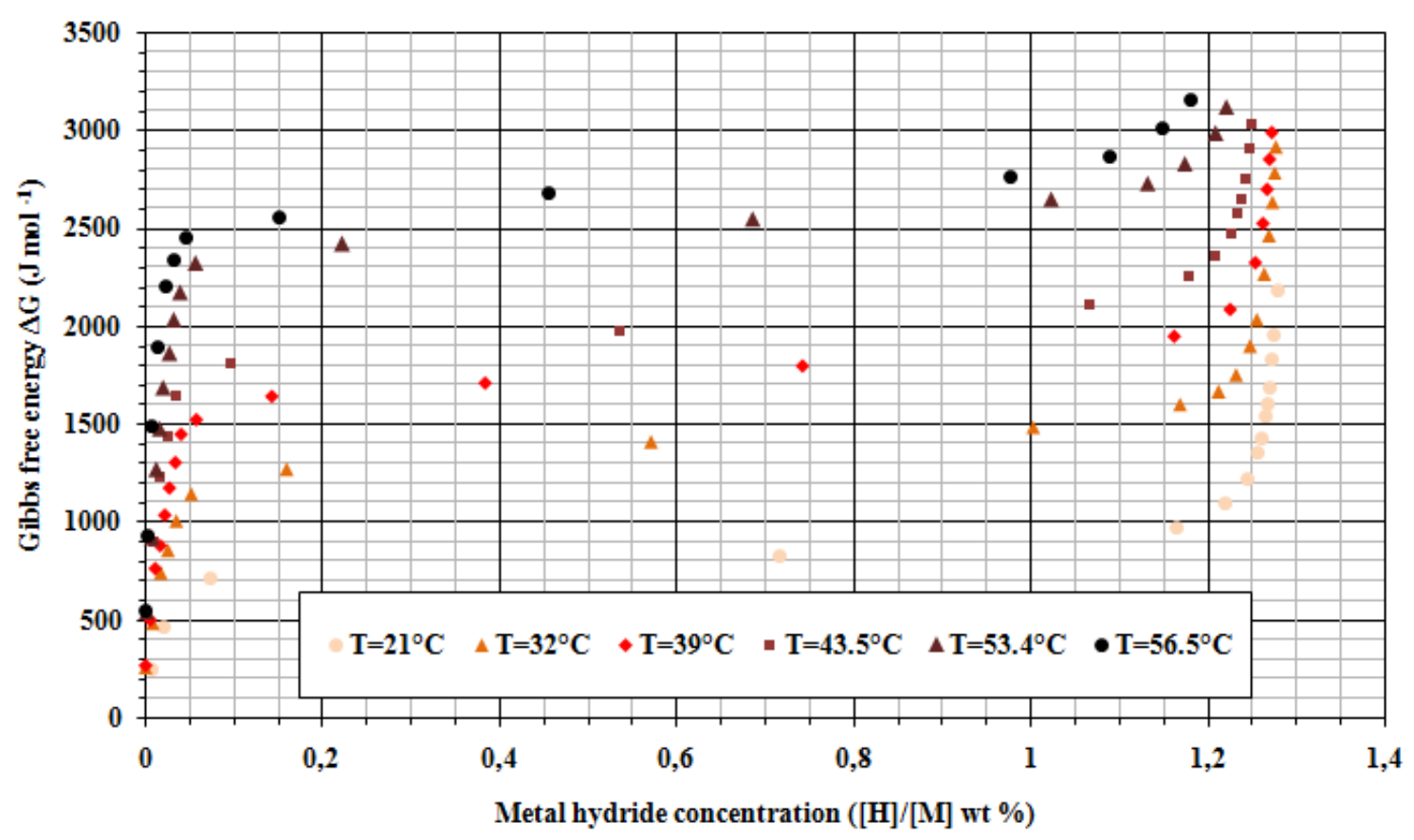

Fig. 16. Gibbs' free energy $\Delta G$ of $\mathrm{LaNi}_{5}$ tested at CNR-ITAE

\subsection{Hysteresis}

Unfortunately, the metal hydride powders which are used in MHCS often present an important difference between the absorption and desorption equilibrium pressures. Many authors have already reported the importance of hysteresis in the performance of MHCS $[13,14,21,28]$.

The effect of hysteresis can be quantified by the related loss of free enthalpy $\Delta \mathrm{G}_{\text {hys }}[47]$ :

$$
\Delta G_{h y s}=R T \ln \left(\frac{P_{a b s}}{P_{d e s}}\right)
$$

Dehouche et al. [49] have presented experimental results which show the effect of hysteresis in different $A B_{5}$ materials. In Table 4, the absorption and desorption pressures are compared, and the corresponding enthalpy loss $\Delta \mathrm{G}_{\text {hys }}$ has been calculated. 
As indicated in Table 4, in these tested $\mathrm{AB}_{5}$ alloys, the absorption pressures are always $15 \%$ to $75 \%$ higher than the desorption pressures. Hence, it cannot be assumed that the absorption and desorption pressures are equal as in the ideal P-C-T diagrams (Fig. 15).

In literature on metal hydride cooling systems, there is a general agreement that hysteresis has to be taken into account in the models. Typically, the effect of hysteresis is analyzed by adding a last term to the Van't Hoff equation $[4,13,21,28]$, as in Eq. (7).

\begin{tabular}{|c|c|c|c|c|}
\hline Alloy & Temperature $\left(^{\circ} \mathrm{C}\right)$ & $\mathrm{P}_{\text {abs }} / \mathrm{P}_{\text {des }}$ & $\ln \left[\mathrm{P}_{\text {abs }} / \mathrm{P}_{\text {des }}\right]$ & $\Delta \mathrm{G}_{\text {hys }}[\mathrm{J} / \mathrm{mol}]$ \\
\hline \multirow{4}{*}{ LaNi $_{4.8} \mathrm{Sn}_{0.2}$} & 23 & 1,33 & 0,28 & 694,9 \\
\cline { 2 - 5 } & 40 & 1,37 & 0,32 & 821,2 \\
\cline { 2 - 5 } & 60 & 1,24 & 0,22 & 604,7 \\
\cline { 2 - 5 } & 80 & 1,20 & 0,19 & 546,7 \\
\hline \multirow{4}{*}{$\mathrm{LmNi}_{4.9} \mathrm{Sn}_{0.1}$} & 80 & & & \\
& $($ after 1000 cycles $)$ & 1,16 & 0,15 & 433,1 \\
\cline { 2 - 5 } & 23 & 1,65 & 0,50 & 1230,9 \\
\cline { 2 - 5 } & 40 & 1,48 & 0,39 & 1017,5 \\
\hline \multirow{3}{*}{$\mathrm{LmNi}_{4.91} \mathrm{Sn}_{0.15}$} & 60 & 1,35 & 0,30 & 836,0 \\
\cline { 2 - 5 } & 80 & 1,30 & 0,26 & 760,2 \\
\cline { 2 - 5 } & 23 & 1,70 & 0,53 & 1312,9 \\
\cline { 2 - 5 } & 80 & 1,68 & 0,52 & 1391,2 \\
\hline
\end{tabular}

Table 4. Hysteresis in $\mathrm{AB}_{5}$-type alloys [49]

$$
\ln \frac{P_{e q}}{P_{0}}=\frac{\Delta H}{R \cdot T}-\frac{\Delta S}{R}+f s \cdot\left(C-C_{m i d}\right)+F_{h y s}
$$

During desorption, $F_{\text {hys }}=0$, and during absorption, the term $F_{\text {hys }}=\ln \left(P_{\text {abs }} / P_{\text {des }}\right)$ increases the equilibrium pressure. Hence, this approach provides a discontinuous step in the calculation of the equilibrium pressure when switching between absorption and desorption.

Eq. (7) shows the simple approach which has been used up to now for the modelling of hysteresis. In MHCSs, the reactors change dynamically from absorption to desorption and there is surely a progressive transition in the 
equilibrium pressures. In this $\mathrm{PhD}$, an original approach has been used to account for the transitions when the reactors change from absorption to desorption processes. The developed model is detailed in Chapter 6.

\subsection{Specific heat}

The specific heat is an important property of metal hydride powders as it provides information of the heat which is to be rejected or removed for a given temperature change in the alloy.

However, a theoretical evaluation of the specific heat is not simple, as the alloy is composed of a mixture of elements from the periodic table, and furthermore, many different heat transfer mechanisms are involved in such porous materials.

Dehouche et al [49] recently carried out measurements to evaluate the specific heat of $\mathrm{AB}_{5}$ alloys using a differential scanning calorimeter (DSC) apparatus. For instance, Fig. 17 illustrates the obtained specific heat for three samples of a $\mathrm{LmNi}_{4.9} \mathrm{Sn}_{0.1}$ alloy.

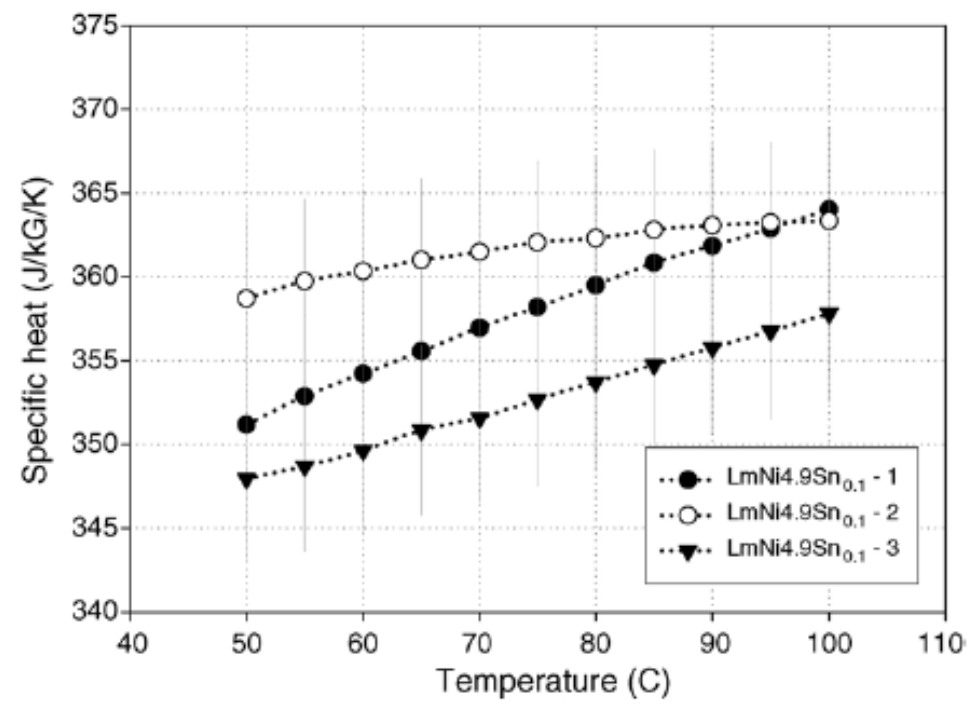

Fig. 17. Specific heat of $A B_{5}$ alloys [49] 
As may be inferred from Fig. 17, the specific heat increases with temperature, but the temperature effect is not particularly important within the operating temperatures of a MHCS. Dehouche et al. highlighted that the averaged measured specific heat does not change much in the interval of $50-100^{\circ} \mathrm{C}$. The averaged specific heat for $\mathrm{LaNi}_{4.8} \mathrm{Sn}_{0.2}$ only increases from $350.25 \mathrm{~J} / \mathrm{kg} / \mathrm{K}$ at $50^{\circ} \mathrm{C}$ up to $358.43 \mathrm{~J} / \mathrm{kg} / \mathrm{K}$ at $100^{\circ} \mathrm{C}$, which represents a variation of approximately $2.3 \%$. Similarly, the variation of the specific heat in $\mathrm{LmNi}_{4.9} \mathrm{Sn}_{0.1}$ and $\mathrm{MmNi}_{4.7} \mathrm{Al}_{0.3}$ amounts respectively to $2.6 \%$ and $1.4 \%$.

Since the specific heat increases nearly linearly and slowly for temperatures between $50^{\circ} \mathrm{C}$ and $100^{\circ} \mathrm{C}$, Dehouche et al. finally concluded that a constant specific heat value can be assumed within the operating temperatures of thermal compressors.

\subsection{Effective thermal conductivity}

As the sorption reactions are driven by heat transfer mechanisms, the effective thermal conductivity of metal hydride powders -and any other sorption materialis a very important thermo-physical property limiting reaction kinetics. In metal hydrides, aluminium foams or graphite have been used to fasten the heat transfer in reaction beds [26].

Adequate knowledge of the heat transfer in sorption beds is essential to fasten reactions and to achieve higher cooling powers with less volume. Heat transport in sorption materials is complicated since various regimes of heat transport are involved: heat conduction within the solid particles and across the contact areas of these particles, heat conduction within the filling gas, thermal radiation.

Two models have been selected from literature in order to calculate the effective thermal conductivity; the A. Griesinger model (AG) [50] and the most extended Zehner-Bauer-Schlünder model (ZBS) [51]. The ZBS model has been adopted very often in literature for metal hydrides, whereas the AG model has only been used for zeolites. In this PhD work, the AG model has also been 
tested for other sorption materials such as metal hydrides in order to check if it may have a wider applicability than only for zeolites. Thermal conductivity measurements of sorption reactors have been compiled from literature [50,5254] and they have been compared with the model results.

The effective thermal conductivity $\lambda_{\text {bed }}$ of porous beds is influenced by primary and secondary parameters. Primary parameters are the thermal conductivities of the two phases ( $\lambda_{p}$ for the particles, $\lambda_{f}$ for the filling gas) and the porosity $\psi$ of the material. Many secondary parameters are also involved to describe different mechanisms, such as heat transfer by radiation, effect of pressure on the thermal conductivity of the filling gas, etc...

Some of the primary and secondary parameters are known or can be measured directly like the thermal conductivity of the gas, the porosity, optical properties of the packed bed, the shape of the particles or the grain size distribution. Other parameters cannot be measured directly with sufficient accuracy. These parameters are the thermal conductivity of the particles $\lambda_{p}$ (in the case of small particles) and the flattening of the particles due to mechanical pressure.

The thermal conductivity is commonly determined for a unit cell that is taken as representative of the entire bed. The heat transport is subdivided in three paths with different relative areas: a pure solid path, a mixed path and a pure fluid path.

The AG model and the ZBS model calculate the effective thermal conductivity as indicated in equations (8) and (9) respectively.

$$
\begin{gathered}
\lambda_{\text {bed }}=(1-\mathrm{v})(1-\psi) \lambda_{p}+\frac{2 v}{\frac{1}{\left(\lambda_{f, e f f}+\lambda_{p}\right)}+\frac{1}{\lambda_{f, e f f}}+\frac{1}{\lambda_{p}}}+\left(1-\alpha_{p}\right) \cdot \psi \cdot \lambda_{f, \text { eff }} \\
\lambda_{b e d}=\left[(1-\sqrt{1-\psi}) \cdot \psi \cdot\left[\frac{1}{\psi-1+\frac{1}{k_{G}}+k_{r a d}}\right]+\sqrt{1-\psi} \cdot\left[\varphi \cdot k_{p}+(1-\varphi) \cdot k_{c}\right]\right] \cdot \lambda_{f}
\end{gathered}
$$

A complete description of the $A G$ model and each of the parameters is described in literature [50]. As for the AG model, the ZBS model involves 
calculating many parameters, such as the accommodation coefficient, the modified mean free path of the molecules, and the thermal conductivity of the fluid.

Additionally, the ZBS model includes parameters which refer to the geometrical characteristics of the host matrix, such as the form factor $\mathrm{C}_{\mathrm{f}}$, flattening coefficient $\varphi$, and deformation parameter B. A rigorous description of the ZBS model is indicated in the VDI-Wärmeatlas [51].

The model has been validated for different materials (Table 5.) for which the effective thermal conductivity was measured experimentally [50,52-54] by means of the transient hot-wire method. In addition to metal hydride powders, the models have also been applied for other sorption materials such as zeolites or silica-gel.

\begin{tabular}{|c|c|c|c|c|}
\hline & $\begin{array}{c}\text { Zeolite } \\
\text { NaA [50] }\end{array}$ & $\begin{array}{c}\text { Zeolite } \\
\text { NaX [52] }\end{array}$ & $\begin{array}{c}\text { Silica-gel } \\
\text { [53] }\end{array}$ & $\begin{array}{l}\mathrm{MeH} \\
{[54]}\end{array}$ \\
\hline Particle size $d p[\mu \mathrm{m}]$ & 4,31 & 4000 & 3500 & 36,1 \\
\hline Porosity $\Psi$ & 0,65 & 0,36 & 0,36 & 0,531 \\
\hline Filling gas & $\mathrm{H}_{2}$ and $\mathrm{He}$ & $\mathrm{He}$ & Air & $\mathrm{H}_{2}$ \\
\hline Temperature $\mathrm{T}\left[{ }^{\circ} \mathrm{C}\right]$ & 150 & 35 & 20 & 20 \\
\hline Pressure range [mbar] & $1-10^{4}$ & $10^{-1}-10^{3}$ & $10^{-2}-10^{3}$ & $10^{-2}-10^{4}$ \\
\hline
\end{tabular}

Table 5. Modelled porous materials

In Fig. 18, the model has been tested for a metal hydride powder type $\mathrm{LaNi}_{4,7} \mathrm{Al}_{0,3}$ with hydrogen as a filling gas at a temperature of $20^{\circ} \mathrm{C}$. Using the parameters which are given in Table 6, The ZBS model fits accurately with the experimental data [54], whereas the AG model cannot be adjusted with reasonable parameters. This might be due to the irregular distribution of the particles in a metal hydride powder. In fact, the AG model was developed specifically for zeolites which present the property of having a very regular structure with same pore and particle diameters. 


\begin{tabular}{|c|c|c|c|c|c|}
\hline \multicolumn{3}{|c|}{ Host matrix characteristics } & \multicolumn{3}{|c|}{ Filling gas characteristics } \\
\hline Particle diameter $d_{p}$ & 36.1 & $\mu \mathrm{m}$ & Fluid & Hydrogen & \\
\hline Solid conductivity $\lambda_{p}$ & 6 & $\mathrm{~W} /(\mathrm{m} . \mathrm{K})$ & Temperature & 293.15 & K \\
\hline Emissivity & 0.9 & - & b & 14.5 & - \\
\hline Form factor $\mathrm{C}_{\mathrm{f}}$ & 5 & - & $\begin{array}{l}\text { Molecular } \\
\text { mass M }\end{array}$ & 2 & $\mathrm{Kg} / \mathrm{kmol}$ \\
\hline Flattening coefficient $\varphi$ & $1 e-3$ & - & $\begin{array}{c}\text { Thermal } \\
\text { conductivity }\end{array}$ & 0.182 & $\mathrm{~W} /(\mathrm{m} \cdot \mathrm{K})$ \\
\hline Porosity $\Psi$ & 0.531 & - & $\begin{array}{l}\text { Specific } \\
\text { heat } C_{p}\end{array}$ & 14290 & $\mathrm{~J} /(\mathrm{kg} \mathrm{K})$ \\
\hline Fitting parameter $a_{p}$ & 0.999 & - & $\mathrm{C}_{\mathrm{a}}$ & 105.6 & $\mu \mathrm{m}$ \\
\hline & & & $\mathrm{C}_{\mathrm{b}}$ & 76 & $\mathrm{~K}$ \\
\hline & & & $\mathrm{k}_{\text {adiab }}$ & 1.41 & - \\
\hline & & & $\mathrm{K}$ & 2.039 & - \\
\hline
\end{tabular}

Table 6. Parameters of the ZBS model for a metal hydride powder

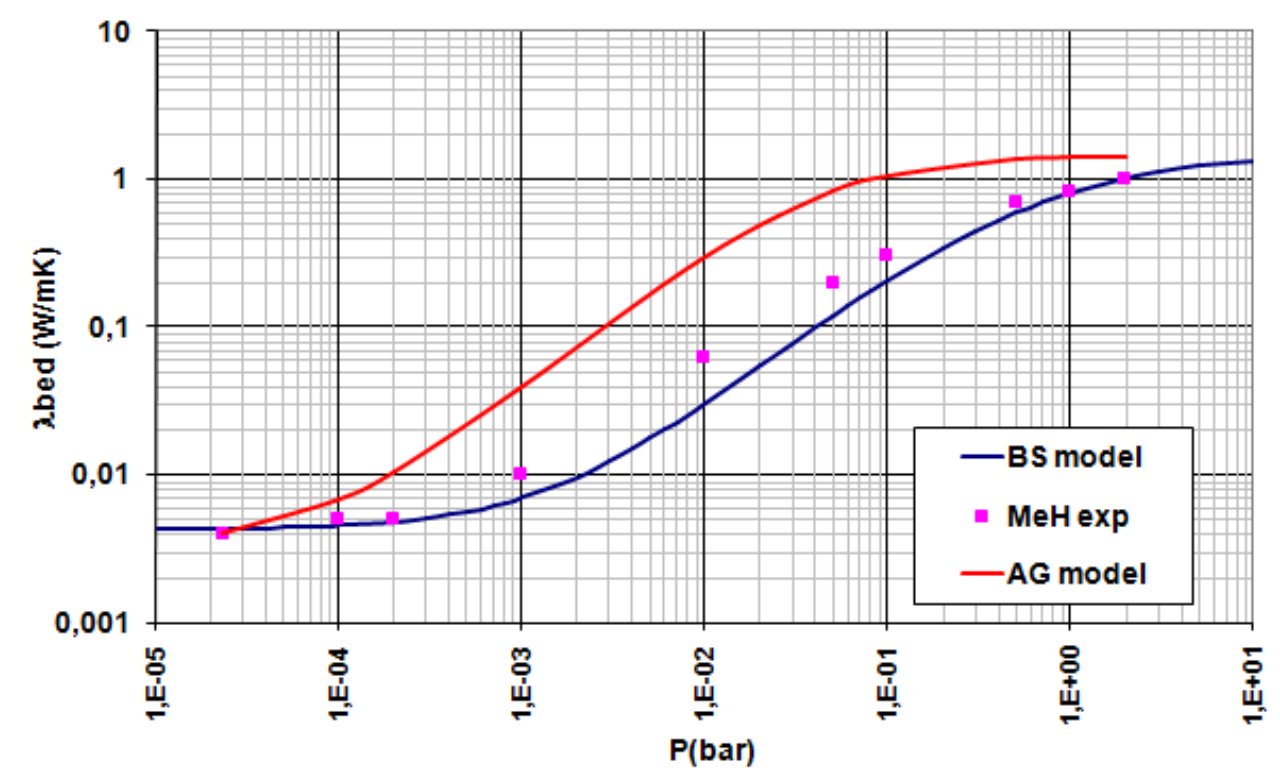

Fig. 18. Effective thermal conductivity of a metal hydride powder at $20^{\circ} \mathrm{C}$ 
It is also important that the previous study is only valid for the calculation of the effective thermal conductivity with no sorption reaction. As the metal hydride layer grows during absorption, the effective thermal conductivity changes. Thus, a detailed analysis should include a dependence of the solid conductivity on the metal hydride concentration.

The effective thermal conductivity of metal hydride powders depends on the pressure and temperature. Two models have been tested, but only the ZBS has provided a good adjustment with experimental measurements.

The results have demonstrated that the effective thermal conductivity describes an S-shape at pressures below 1 bar, and is practically constant for higher pressures.

\subsection{Mechanical and chemical treatment}

As discussed previously, each family of alloys presents specific characteristics such as the intrinsic kinetics, cyclic stability, etc...However, the alloys can also be tailored via mechanical or chemical treatment in order to achieve particular properties.

\section{Increasing the intrinsic kinetics}

In order to fasten the reaction rate, ball-milling [44] can be applied to reduce the grain size and the diffusion distance. This economic process is applied widely in order to achieve good surface properties. Ball-milling increases the surface area and creates defects on the surface and in the interior of the material. The induced lattice defects may aid the diffusion of hydrogen by providing many sites with low activation energy of diffusion. 
Another frequent approach to fasten the sorption rate is to treat the alloys with catalysts, which enable a fast and effective dissociation of hydrogen molecules [44]. Many different catalysts have been used, such as $\mathrm{TiCl}_{3}$ [55], palladium, nickel, germanium or vanadium. For instance, the poor kinetics of $\mathrm{MgH}_{2}$ have been improved by adding different oxide catalysts such as $\mathrm{V}_{2} \mathrm{O}_{5}$ and $\mathrm{Cr}_{2} \mathrm{O}_{3}$ [44].

\section{Increasing the cyclic stability}

Cyclic stability is a major criterion in metal hydride cooling systems. In order to enhance cyclic stability, it is possible to use special additives (e.g. $\mathrm{Cr}_{2} \mathrm{O}_{3}, \mathrm{Al}_{2} \mathrm{O}_{3}$, $\mathrm{CeO}_{2}$ ). Mischmetals ( $\mathrm{Mm}$ ) such as $\mathrm{Ce}, \mathrm{La}, \mathrm{Nd}$ and $\mathrm{Pr}$ are also used to increase the cyclic stability [56]. However, even if the use of mischmetals increases the stability, it also tends to exert a negative effect by making the intrinsic kinetics slower and by reducing the hydrogen storage capacity.

\section{Combining different chemical components by ball-milling}

Another approach which is actually being used is combining different compounds with complementary properties. The storage capacities and reaction kinetics present mean values of the different compounds.

For instance, magnesium has been mixed with hydrides with fast kinetics, such as $\mathrm{LaNi}_{5}$ or aluminium. Bouaricha et al. [57] prepared $\mathrm{Mg} / \mathrm{Al}$ alloys by means of high-energy ball-milling. The measured hydrogen capacity of the alloy decreased with the $\mathrm{Al}$ content, from $\mathrm{H} / \mathrm{M}=1.74$ for pure unmilled $\mathrm{Mg}$, to 1.38 for $\mathrm{Mg}: \mathrm{Al}$ (90:10), and then to 1.05 for $\mathrm{Mg}: \mathrm{Al}$ (75:25). Thus, the addition of aluminium enabled to obtain faster kinetics with lower absorption capacities. 



\section{Chapter 4: \\ Equilibrium P-C-T characterization}




\section{NOMENCLATURE}

\begin{tabular}{|c|c|}
\hline C & Metal hydride concentration, $\mathrm{kg} \mathrm{MH} / \mathrm{kg}$ alloy (\%) \\
\hline A & Fitting coefficient in Eq.(14) \\
\hline $\mathrm{P}$ & Pressure, bar \\
\hline $\mathrm{Y}$ & Hydrogen activity coefficient \\
\hline $\mathrm{V}_{\mathrm{h}}$ & Hydrogen partial molar volume, $\mathrm{I} \mathrm{mol}^{-1}$ \\
\hline $\mathrm{R}$ & Universal gas constant, atm I $\mathrm{mol}^{-1} \mathrm{~K}^{-1}\left(\mathrm{R}_{1}\right) \mathrm{J} \mathrm{mol}^{-1} \mathrm{~K}^{-1}\left(\mathrm{R}_{2}\right)$ \\
\hline $\mathrm{T}$ & Temperature, $\mathrm{K}$ \\
\hline $\mathrm{H}$ & Solution heat of hydrogen, $\mathrm{J} \mathrm{mol}^{-1}$ \\
\hline$\Delta \mathrm{H}$ & Enthalpy of metal hydride formation, $\mathrm{J} \mathrm{mol}^{-1}$ \\
\hline$\Delta S$ & Entropy of metal hydride formation, $\mathrm{J} \mathrm{mol}^{-1} \mathrm{~K}^{-1}$ \\
\hline$\Delta \mathrm{H}_{0}$ & Enthalpy contribution [62], $\mathrm{J} \mathrm{mol}^{-1}$ \\
\hline$\Delta \mathrm{S}_{0}$ & Entropy contribution [62], $\mathrm{J} \mathrm{mol}^{-1} \mathrm{~K}^{-1}$ \\
\hline fs & Slope factor in Eq. (10) \\
\hline$\theta$ & Filling fraction \\
\hline$\sigma$ & Standard deviation \\
\hline$\rho$ & Pearson's correlation coefficient \\
\hline$X$ & Composition fluctuation of the alloys \\
\hline$p_{0}$ & Reference pressure (1 bar) \\
\hline$k$ & Coefficient of the polynomial expression (23) \\
\hline$M_{M H}$ & Mass of metal hydride alloy in the reactor, $\mathrm{kg}$ \\
\hline$T^{*}$ & Measured isotherm in Eq. (24) \\
\hline \multicolumn{2}{|c|}{ Subscripts } \\
\hline$\alpha$ & $\alpha$ single phase region in the $\mathrm{P}-\mathrm{C}-\mathrm{T}$ curves \\
\hline$\beta$ & $\beta$ single phase region in the $\mathrm{P}-\mathrm{C}-\mathrm{T}$ curves \\
\hline
\end{tabular}


Chapter 4 - EQUILIBRIUM P-C-T CHARACTERIZATION

\begin{tabular}{|ll}
\hline$\alpha+\beta$ & $\alpha+\beta$ phase region in the P-C-T curves \\
mid & Middle of the $\alpha+\beta$ phase region \\
$\mathrm{s}$ & Entropy \\
$\mathrm{h}$ & Enthalpy \\
$\mathrm{c}$ & Critical \\
$\max$ & Maximum \\
ref & Reference pressure $(1$ bar $)$ \\
abs & Absorption \\
des & Desorption
\end{tabular}




\section{EQUILIBRIUM P-C-T CHARACTERIZATION}

\subsection{Theoretical background}

The relationship between the pressure $(P)$, metal hydride concentration $(C)$, and temperature $(T)$ defines the intrinsic reaction kinetics [58,59] and the performance of metal hydride cooling systems $[2,28]$. Therefore, an accurate modelling of the P-C-T correlation is a key aspect in any metal hydride system.

The first mathematical model to describe the P-C isotherms of metal hydrides was proposed by Lacher [60] in 1937 for a palladium system. The latter model was ideal and was based on the assumption of a definite number of interstitial sites in the lattice.

In order to reproduce the behaviour of real systems, the original Lacher model has been progressively extended by other authors by including a statistical thermodynamics approach. For instance, Lototsky et al. [61-65] validated the simulation results for different hydrogen storage materials $\left(\mathrm{ZrFe}_{2}, \mathrm{LaNi}_{4.8} \mathrm{Sn}_{0.2}\right)$. This model is interesting because it requires only 7 fitting parameters. Several other authors such as Beeri and Samsun $[66,67]$ have also extended the original work from Lacher.

Zhou et al. have published several articles based on a different approach for the modelling of the P-C-T curves $[68,69]$. The latter model has been successfully applied to simulate the $\mathrm{P}-\mathrm{C}$ isotherms of several storage materials such as $\mathrm{MmNi}_{3.4} \mathrm{Co}_{0.8} \mathrm{Al}_{0.3} \mathrm{Mn}_{0.5}, \mathrm{Ti}_{1.05} \mathrm{Fe}_{0.8} \mathrm{Ni}_{0.15} \mathrm{Cr}_{0.05}$, or $\mathrm{LaNi}_{2.5} \mathrm{Co}_{2.5}$.

This second model divides the behaviour of the materials in three different phase regions $(\alpha, \alpha+\beta, \beta)$, but does not take into account the transitions between each phase. In subsection 4.1.1.1, an extension of this model including a smooth transition between the different phases is described.

An empirical P-C-T equilibrium correlation is frequently found in literature $[13,16,32,70]$. This methodology consists in adjusting the P-C-T curves with 


\section{Chapter 4 - EQUILIBRIUM P-C-T CHARACTERIZATION}

polynomial expressions. The extrapolation for different temperatures derives from the reaction enthalpy, as predicted by the Van't Hoff equation.

In this same direction, several authors use the Van't Hoff equation for the twophase region and model the behaviour in the $\alpha$ and $\beta$ phase regions with polynomials [71].

More recently, Lexcellent [72] proposed a model, as an extension of the theory of Schwarz and Khachaturyan. This is a general theory for metal hydrogen systems, based on the thermodynamics of partially open two-phase systems with coherent interfaces. However, in the expressions which are obtained, the logarithm of the hydrogen pressure depends linearly on the hydrogen content, which is not in agreement with many published experimental results $[68,69,71,73]$.

Finally, an interesting model was proposed by Feng et al. [74], who used a kinetic method to obtain a relationship between pressure, temperature and metal hydride concentration under equilibrium conditions. This model requires the fitting of -among other variables- two temperature-dependent parameters such as $\mathrm{C}_{\max }$ (maximum concentration in the plateau region) and $\mathrm{x}_{0}-\mathrm{y}_{0}$ (plateau capacity). Thus, this model is only interesting within a reduced temperature range, as it cannot account for the narrowing of the plateau capacity at high temperatures.

In this chapter, a detailed background is firstly given in order to understand the governing equations of the different theoretical models. Secondly, the measurement campaign of the P-C-T curves is described and finally, the developed models are fitted to the measurement data. 


\subsubsection{Plateau region}

The plateau region (or $\alpha+\beta$ phase) is where reactors $A$ and $B$ can exchange more hydrogen, and hence, where the highest cooling powers can be achieved. It is hereby essential to develop an accurate P-C-T equilibrium correlation in this region.

In the $\alpha+\beta$ phase, the P-C-T relationship between pressure, hydrogen concentration and temperature can be modelled using the Van't Hoff Eq. (4). As in previous studies [18], [2,28], this equation has been modified in order to account for the non-negligible slope of the two-phase region in the tested materials.

$$
\ln \frac{P}{P_{r e f}}=-\frac{\Delta H}{R \cdot T}+\frac{\Delta S}{R}+f_{S} \cdot\left(C-C_{m i d}\right)
$$

As in the Clasius-Clapeyron equation for phase changes, the pressure increase with temperature is given by the enthalpy of formation $\Delta \mathrm{H}$.

In Eq. (10), the pressure and temperature are measured for each metal hydride concentration, and the reference pressure $P_{\text {ref }}$ is 1 bar. The parameter $w_{\text {mid }}$ is obtained at the middle of the two-phase region. The first term of Eq. (10) shows the effect of the temperature on the equilibrium pressure, whereas the last two terms illustrate the effect of the metal hydride concentration on the entropy. Hence, $\Delta S$ can also be understood as a mean reaction entropy in the $\alpha+\beta$ phase.

The previous Eq. (10) can be written in the form of Eq. (11), where $x_{1}$ and $x_{2}$ are measured variables, and the constants $c_{1}$ and $c_{2}$ can be obtained by means of $a$ regression analysis, using the Excel linear regression toolbox.

$$
\ln P=a+c_{1} x_{1}+c_{2} x_{2}
$$

The measured variables $x_{1}$ and $x_{2}$ are calculated with Eq.(12). 


$$
\begin{aligned}
& x_{1}=\frac{1}{T} \\
& x_{2}=C-C_{\text {mid }}
\end{aligned}
$$

Finally, the parameters of the Van't Hoff model $\left(\Delta \mathrm{H}_{\mathrm{abs}}, \Delta \mathrm{S}_{\mathrm{abs}}, \Delta \mathrm{H}_{\text {des }}, \Delta \mathrm{S}_{\text {des }}\right.$, fS $\mathrm{S}_{\mathrm{abs}}$ and $\mathrm{fs}_{\mathrm{des}}$ ) can be obtained directly from $\mathrm{c}_{1}$ and $\mathrm{c}_{2}$, using Eq. (13).

$$
\begin{aligned}
& a=\frac{\Delta S}{R} \\
& c_{1}=-\frac{\Delta H}{R} \\
& c_{2}=f_{S}
\end{aligned}
$$

Following this method, the equilibrium P-C-T correlation of the different alloys (A1-B1, A2-B2 and A3-B3) has been obtained in the plateau region.

\subsubsection{Overall P-C-T models}

\subsubsection{Smoothed Zhou model}

In the original model which was proposed by Zhou [73], it is assumed that both the first and third regions are controlled by the solubility of hydrogen atoms in the alloy ( $\alpha$ phase) and its hydride ( $\beta$ phase), and that the second region is controlled by the phase transition from the a phase into the $\beta$ phase.

For the single phase regions $\alpha$ and $\beta$, the metal hydride content $(C)$ can be calculated as a function of the hydrogen pressure $(P)$ and the absolute temperature $(\mathrm{T})$ :

$$
C=A \times P^{\frac{\gamma}{2}} \times \exp \left(-\frac{\gamma \times \overline{V_{h}} * P}{R_{1} \times T}\right) \times \exp \left(-\frac{\gamma \times H}{R_{2} \times T}\right)
$$

As described previously, the behaviour in the two-phase region may be described accurately using the modified Van't Hoff Eq. (15).

$$
\ln P_{\alpha+\beta}=-\frac{\Delta H}{R \cdot T}+\frac{\Delta S}{R}+f S \cdot\left(C_{\alpha+\beta}-C_{\text {mid }}\right)
$$

Thus, the equilibrium metal hydride concentration in the two phase region can be calculated as in Eq. (16). 


$$
C_{\alpha+\beta}=C_{m i d}+\frac{1}{f S} \cdot\left(\ln P_{\alpha+\beta}+\frac{\Delta H}{R \cdot T}-\frac{\Delta S}{R}\right)
$$

In summary, this approach is based on three different expressions, one for each phase region. Subsequently, the original model does not reproduce the smooth behaviour of the P-C-T curves in the transitions between the three phase regions. In order to do so, the following expressions may be used:

For $0.01<\mathrm{C}<\mathrm{C}_{\text {mid }}$

$$
C=\frac{1}{100} \cdot\left(\left(100 \cdot C_{\alpha}\right)^{6}+\left(100 \cdot C_{\alpha+\beta}\right)^{6}\right)^{\frac{1}{6}}
$$

For $\mathrm{C}>\mathrm{C}_{\text {mid }}$,

$$
C=\frac{1}{100} \cdot\left(\left(\frac{1}{100 \cdot C_{\alpha+\beta}}\right)^{6}+\left(\frac{1}{100 \cdot C_{\beta}}\right)^{6}\right)^{-\frac{1}{6}}
$$

Where $C_{\alpha}$ and $C_{\beta}$ are calculated with Eq. (14) and $c_{\alpha+\beta}$ with Eq. (16).

In conclusion, the model which is proposed provides a weight for each of the expressions of the metal hydride concentration according to the position in the P-C-T diagram, as illustrated in Fig. 19.

The use of Eqs. (17.1) and (17.2) enables the calculation of the metal hydride concentration as a function of the pressure and temperature. Nevertheless, this approach can also be used reversely for the calculation of the equilibrium pressure with the following expressions:

For $0.01<\mathrm{C}<\mathrm{C}_{\text {mid }}$

$$
P=\left(\left(\frac{1}{P_{\alpha}}\right)^{6}+\left(\frac{1}{P_{\alpha+\beta}}\right)^{6}\right)^{-\frac{1}{6}}
$$

For $\mathrm{C}>\mathrm{C}_{\text {mid }}$

$$
P=\left(\left(P_{\alpha+\beta}\right)^{6}+\left(P_{\beta}\right)^{6}\right)^{\frac{1}{6}}
$$


Where $P_{\alpha+\beta}$ are obtained from Eq. (15), and $P_{\alpha}, P_{\beta}$ are calculated implicitly by solving Eq. (14).

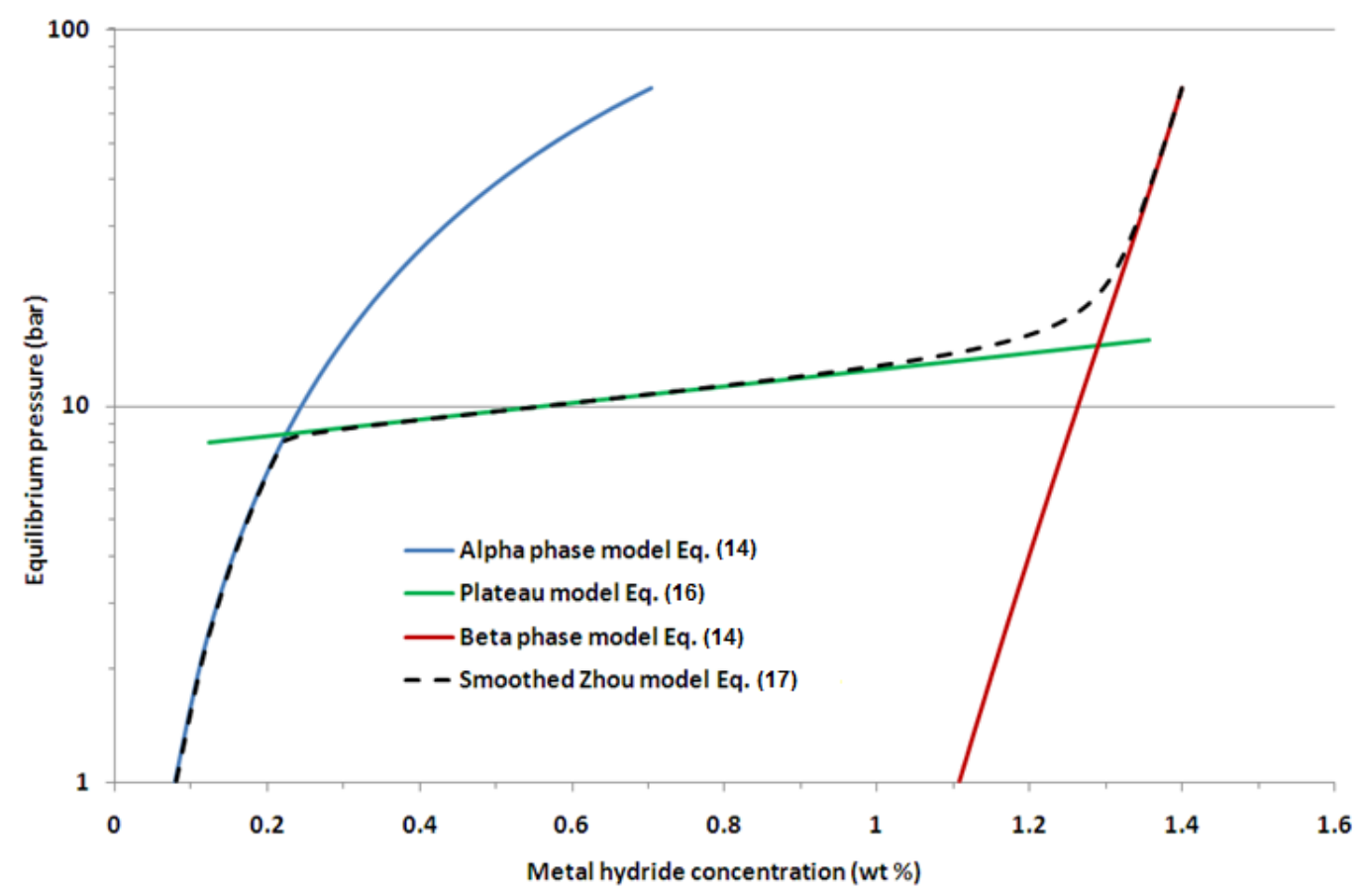

Fig. 19. Extension of the Zhou model to include smooth phase transitions

\subsubsection{Lacher-Lototsky model}

The model which was presented by Lototsky et al. [62] is an extension of the original Lacher model [60]. Lototsky et al. consider the asymmetric isotherms in total, including the three phase regions. This approach reduces substantially the number of fitting parameters.

In the original Lacher model, only attractive and indirect $\mathrm{H}-\mathrm{H}$ interactions, mediated via the metal atoms, are taken into account. As explained by Lototsky et al., $\mathrm{H}-\mathrm{H}$ repulsion can have an important effect, especially at high concentrations. Taking this aspect into account, Eq. (19) can be used. 


$$
\ln \mathrm{P}=-\frac{\Delta \mathrm{S}_{0}}{\mathrm{R}}+\frac{\Delta \mathrm{H}_{0}}{\mathrm{R} \cdot \mathrm{T}}+2 \cdot \ln \left(\frac{\theta}{1-\theta}\right)-\frac{27}{2} \cdot \frac{\mathrm{T}_{\mathrm{c}}}{\mathrm{T}} \cdot \theta+2 \cdot \frac{\theta}{1-\theta}
$$

Where $\theta$ is the filling fraction $\left(\mathrm{C} / \mathrm{C}_{\max }\right)$.

Eq. (19) is only valid for ideal metal hydrides, but cannot reproduce the behaviour of real materials. Therefore, Lototsky et al. introduced a statistical thermodynamics approach, based on the composition fluctuations of entropy $\sigma_{\mathrm{s}}$ and enthalpy $\sigma_{\mathrm{h}}$.

$$
\begin{aligned}
& \sigma=\sqrt{\frac{\sigma_{S}^{2}}{R^{2}}+\frac{\sigma_{H}^{2}}{R^{2} T^{2}}-\frac{2 \rho_{S H} \sigma_{S} \sigma_{H}}{R^{2} T}} \\
& \theta=\frac{1}{\sigma \sqrt{2 \pi}} \int_{-\infty}^{+\infty} \theta(X) \exp \left[-\frac{(X-u)^{2}}{2 \sigma^{2}}\right] d u
\end{aligned}
$$

The fluctuating parameter $\mathrm{X}$ is calculated by Eq. (22).

$$
X=\ln P-\ln P\left(\theta_{\text {mid }}\right)
$$

\subsubsection{Polynomial fitting method}

Several researchers have employed this method to characterize their experimental results $[13,17,32]$. This approach consists on adjusting the P-C-T curves with a $9^{\text {th }}$ order polynomial for a given isotherm $\mathrm{T}^{\star}$.

$$
\frac{P}{P_{\text {ref }}}=\sum_{i=0}^{i=9} k_{i} \cdot C^{i}
$$

In order to evaluate equilibrium pressures at different temperatures $T$ than the measured isotherm $T_{\text {ref, }}$ it is possible to refer to the Van't Hoff law, obtaining the following relationship:

$$
\ln \frac{P}{P_{\text {ref }}}=\frac{\Delta H}{R} \cdot\left(\frac{1}{T}-\frac{1}{T *}\right)
$$

Therefore, the equilibrium pressure at any given temperature can be directly evaluated with Eq. (25). 


$$
\frac{P}{P_{\text {ref }}}=\exp \left(\frac{\Delta H}{R} \cdot\left(\frac{1}{T}-\frac{1}{T *}\right)\right) \cdot \sum_{i=0}^{i=9} k_{i} \cdot C^{i}
$$

As this model derives from a polynomial fitting for a reference isotherm, it does not account for the narrowing of the plateau region at high temperatures. Thus, this approach is only valid within a more limited temperature range around the reference isotherm.

\subsection{Experimental results}

In the experimental laboratory from IKE which has been described in Chapter 2, the P-C-T equilibrium curves have been measured for the alloys A1-B1, A2-B2 and A3-B3, for both absorption and desorption.

Table 7 summarizes the measurement campaign which has been carried out. For each alloy, three different isotherms have been measured following the volumetric method (Chapter 2).

\begin{tabular}{|c|c|}
\hline Alloy & Tested isotherms $\left(^{\circ} \mathrm{C}\right)$ \\
\hline $\begin{array}{c}\mathrm{A} 1 \\
\mathrm{LmNi}_{4.85} \mathrm{Sn}_{0.15}\end{array}$ & $15-35-50$ \\
\hline $\begin{array}{c}\mathrm{B} 1 \\
\mathrm{LmNi}_{4.48} \mathrm{Co}_{0.1} \mathrm{Al}_{0.21} \mathrm{Mn}_{0.21}\end{array}$ & $30-41-120$ \\
\hline $\begin{array}{c}\mathrm{A} 2 \\
\mathrm{Ti}_{0.99} \mathrm{Zr}_{0.01} \mathrm{~V}_{0.43} \mathrm{Fe}_{0.09} \mathrm{Cr}_{0.05} \mathrm{Mn}_{1.5}\end{array}$ & $6-20-30$ \\
\hline $\begin{array}{c}\mathrm{B} 2\left(\mathrm{same}_{\mathrm{as}} \mathrm{A} 1\right) \\
\mathrm{LmNi}_{4.85} \mathrm{Sn}_{0.15}\end{array}$ & $15-35-50$ \\
\hline $\begin{array}{c}\mathrm{A} 3(\mathrm{same} \text { as A2) } \\
\mathrm{Ti}_{0.99} \mathrm{Zr}_{0.01} \mathrm{~V}_{0.43} \mathrm{Fe}_{0.09} \mathrm{Cr}_{0.05} \mathrm{Mn}_{1.5}\end{array}$ & $6-20-30$ \\
\hline $\begin{array}{c}\mathrm{B} 3 \\
\mathrm{LmNi}_{4.91} \mathrm{Sn}_{0.15}\end{array}$ & $27-42-60$ \\
\hline
\end{tabular}

Table 7. Measurement campaign of the equilibrium P-C-T curves 
Fig. 20 shows a sample of the measured P-C-T curves. As indicated in Table 7, the tested isotherms for this alloy are $6^{\circ} \mathrm{C}, 20^{\circ} \mathrm{C}$ and $30^{\circ} \mathrm{C}$.

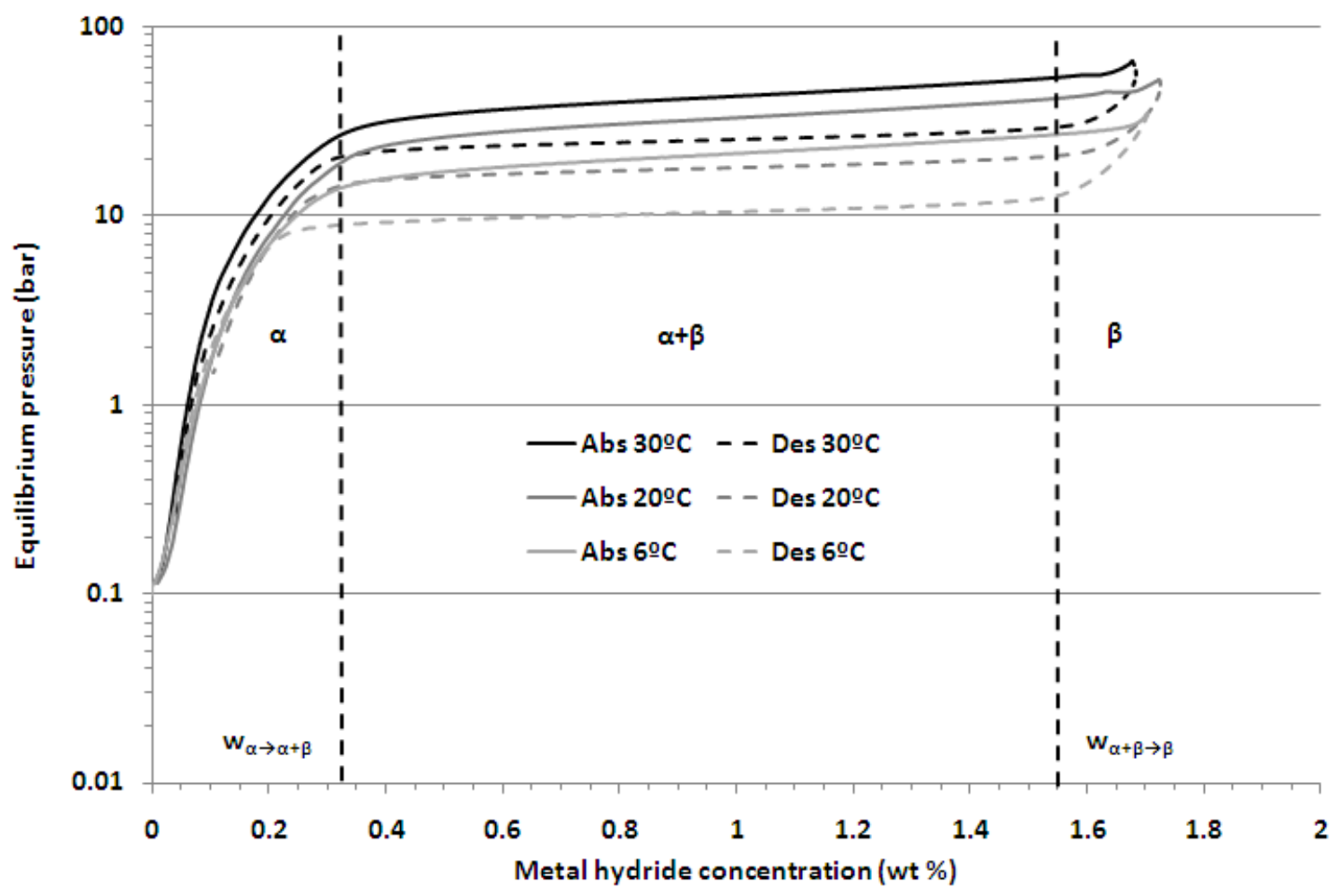

Fig. 20. Equilibrium P-C-T measurements of the cold reaction bed (A3)

The measurement campaign of the dynamic P-C-T curves is very exhaustive, as each isotherm is composed of around 1500 experimental points. Thus, in Fig. 20, continuous and dashed lines have been used to represent the experimental data points (although the experimental data is not continuous, but discrete).

As for many metal hydride powders, alloy $A 3$ and the rest of the tested alloys exhibit three different stages: two single phase regions ( $\alpha$ and $\beta$ ) and one twophase coexistence region $(\alpha+\beta)$. At low hydrogen pressures ( $\alpha$ phase), hydrogen occupies interstitial places in the metal host lattice $(\alpha)$, forming a solid solution of hydrogen in the metal. In the two phase region, the equilibrium 
pressure describes a plateau whose length determines how much hydrogen can be exchanged reversibly with small pressure variations. The end of the plateau is reached when the $\alpha$ phase has entirely been converted into the metal hydride phase $(\beta)$. In the $\beta$ phase, the pressure rises drastically for small compositional variations.

\subsection{Model adjustment}

\subsubsection{Plateau region}

In Fig. 21, the experimental measurements of alloy A3 during desorption are compared with the plateau Van't Hoff model. The proposed P-C-T correlation adjusts very clearly to the experimental measurement data, proving that the two phase region can be modelled accurately with the modified Van't Hoff Eq. (10).

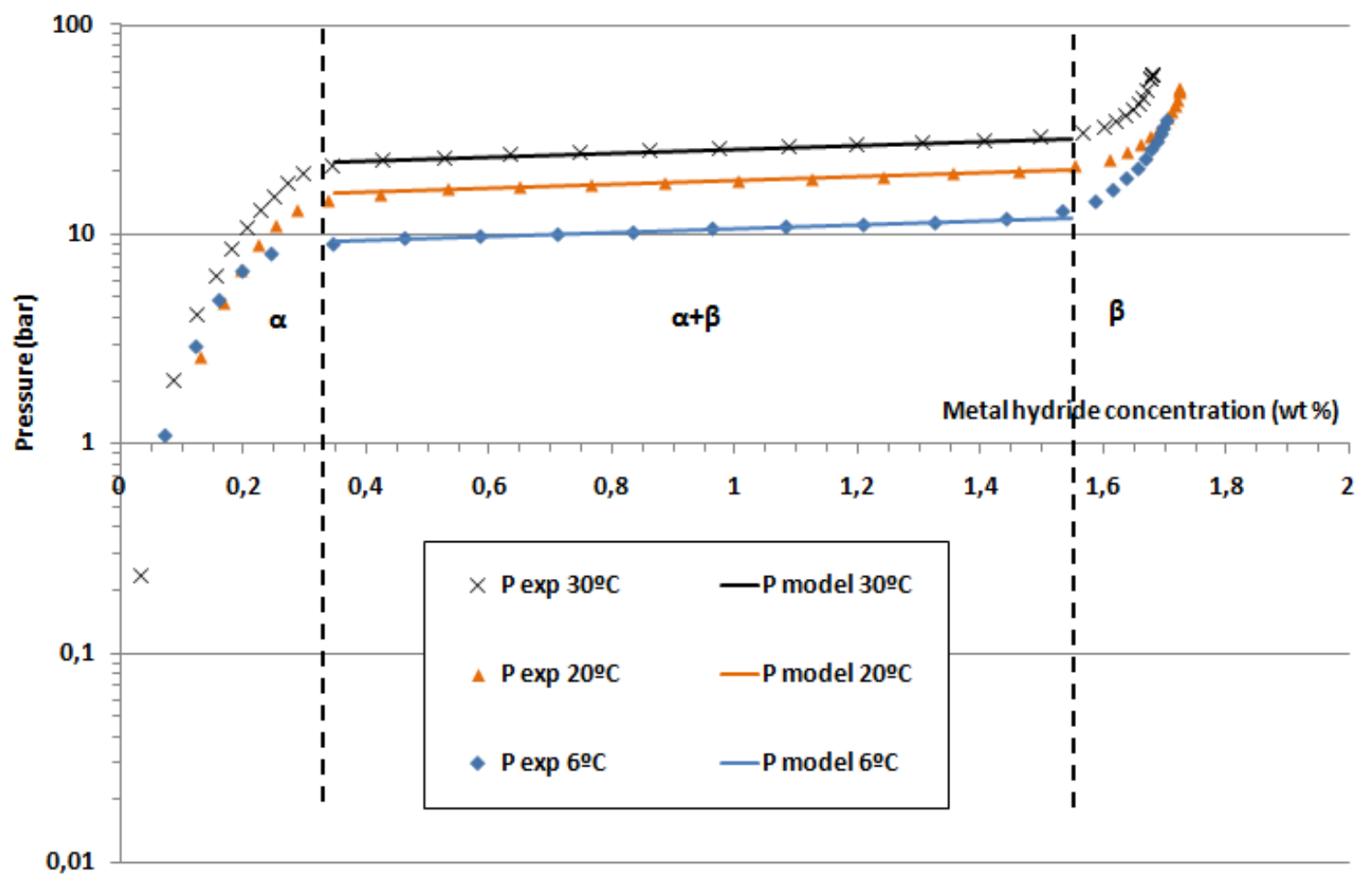

Fig. 21. P-C-T equilibrium correlation for desorption in alloy A3 
In Table 8, the fitting parameters of the Van't Hoff model are given. As may be inferred from the high determination coefficients $\left(R^{2}\right)$, the quality of the fitting is excellent for all of the tested alloys, for both absorption and desorption.

\begin{tabular}{|c|c|c|c|c|c|c|c|}
\hline Alloy & & $\underline{\underline{M}}_{\mathrm{MH}}$ & $\Delta \mathrm{H}$ & $\Delta \mathrm{S}$ & fs & $\mathrm{w}_{\text {mid }}$ & $\mathrm{R}^{2}$ \\
\hline \multirow{2}{*}{$\begin{array}{c}\mathrm{A} 1 \\
\mathrm{LmNi4} .85 \mathrm{Sn} 0.15\end{array}$} & $\begin{array}{l}A \\
b\end{array}$ & \multirow[b]{2}{*}{0.949} & 23308 & 91 & 0.290 & \multirow[b]{2}{*}{0.725} & 0.9948 \\
\hline & $\begin{array}{l}D \\
e \\
s\end{array}$ & & 31435 & 112 & 0.366 & & 0.9994 \\
\hline \multirow{2}{*}{$\begin{array}{c}\text { B1 } \\
\text { LmNi4.48Co0.1Al0.21Mn0.21 }\end{array}$} & $\begin{array}{l}A \\
b \\
s\end{array}$ & \multirow{2}{*}{0.926} & 32924 & 108 & 0.476 & \multirow{2}{*}{0.6} & 0.9999 \\
\hline & $\begin{array}{l}D \\
e \\
s\end{array}$ & & 35747 & 113 & 0.512 & & 0.9994 \\
\hline \multirow{2}{*}{$\stackrel{\mathrm{A} 2}{\mathrm{Ti}_{0.99} \mathrm{Zr}_{0.01} \mathrm{~V}_{0.43} \mathrm{Fe}_{0.09} \mathrm{Cr}_{0.05} \mathrm{Mn}_{1.5}}$} & $\begin{array}{l}A \\
b \\
s\end{array}$ & \multirow{2}{*}{0.831} & 19989 & 97 & 0.423 & \multirow{2}{*}{0.97} & 0.9984 \\
\hline & $\begin{array}{l}D \\
e \\
s\end{array}$ & & 25477 & 111 & 0.215 & & 0.9996 \\
\hline \multirow{2}{*}{$\begin{array}{l}\text { B2 (same as A1) } \\
\text { LmNi4.85Sn0.15 }\end{array}$} & $\begin{array}{l}A \\
b \\
s\end{array}$ & \multirow{2}{*}{0.949} & 23308 & 91 & 0.290 & \multirow{2}{*}{0.725} & 0.9948 \\
\hline & \begin{tabular}{|l}
$D$ \\
$e$ \\
$s$
\end{tabular} & & 31435 & 112 & 0.366 & & 0.9994 \\
\hline \multirow{2}{*}{$\begin{array}{c}\mathrm{A} 3 \text { (same as A2) } \\
\mathrm{Ti}_{0.99} \mathrm{Zr}_{0.01} \mathrm{~V}_{0.43} \mathrm{Fe}_{0.09} \mathrm{Cr}_{0.05} \mathrm{Mn}_{1.5}\end{array}$} & $\begin{array}{l}A \\
b \\
s\end{array}$ & \multirow{2}{*}{0.831} & 19989 & 97 & 0.423 & \multirow{2}{*}{0.97} & 0.9984 \\
\hline & $\begin{array}{l}D \\
e \\
s\end{array}$ & & 25477 & 111 & 0.215 & & 0.9996 \\
\hline \multirow{2}{*}{$\begin{array}{c}\mathrm{B} 3 \\
\mathrm{LmNi}_{4.91} \mathrm{Sn}_{0.15}\end{array}$} & $\begin{array}{l}A \\
b\end{array}$ & \multirow{2}{*}{0.948} & 27170 & 103 & 0.428 & \multirow{2}{*}{0.65} & 0.9997 \\
\hline & $\begin{array}{l}D \\
e \\
s\end{array}$ & & 31026 & 113 & 0.475 & & 0.9920 \\
\hline
\end{tabular}

Table 8. Fitting parameters of the modified Van't Hoff model

\subsubsection{Overall P-C-T models}

As explained in the theoretical background, the overall P-C-T models involve many more fitting parameters than the modified Van't Hoff Eq.(10), and the 


\section{Chapter 4 - EQUILIBRIUM P-C-T CHARACTERIZATION}

models are more complex. Thus, in the following section, the overall P-C-T models have only been adjusted to the experimental P-C-T measurements for the alloys A3-B3 which are those for which the experimental campaign of the metal hydride cooling system is more exhaustive (see Chapter 7). Thus, the following P-C-T results refer to an $\mathrm{AB}_{5}$-type alloy (alloy $\mathrm{LmNi}_{4.91} \mathrm{Sn}_{0.15}$ ) and an $A B_{2}$-type alloy $\left(\mathrm{Ti}_{0.99} \mathrm{Zr}_{0.01} \mathrm{~V}_{0.43} \mathrm{Fe}_{0.09} \mathrm{Cr}_{0.05} \mathrm{Mn}_{1.5}\right)$.

As explained previously, each measured isotherm consists of around 1500 points and hence, in order to visualize the adjustment of the experimental points (crosses) to the models (continuous lines), the number of experimental data points has been reduced in Fig. 22 to Fig. 27.

In the following paragraphs, a discussion is held on the most relevant points concerning the adjustment of the models and the quality of the fitting. The parameters of the different models have been obtained by means of the MATLAB non linear fitting tool, and of the Excel solver.

\subsubsection{Smoothed Zhou model}

As described previously, the Zhou model requires the fitting of the 12 parameters which are given in Table 9.

The quality of the fitting is good for both alloys and is similar to the results presented by Zhou et al. [69,73]. Fig. 22 illustrates the measured and predicted P-C-T curves for alloy $\mathrm{Ti}_{0.99} \mathrm{Zr}_{0.01} \mathrm{~V}_{0.43} \mathrm{Fe}_{0.09} \mathrm{Cr}_{0.05} \mathrm{Mn}_{1.5}$. A very good agreement between the experimental and model results, (within all the measured isotherms at $6^{\circ} \mathrm{C}, 20^{\circ} \mathrm{C}$ and $30^{\circ} \mathrm{C}$ ) is achieved. As in previous studies [2], the behaviour in the plateau region has been particularly well reproduced with the modified Van't Hoff equation. For this $A B_{2}$-type alloy, the transitions between the a phase and the plateau region is very smooth.

The results of the Zhou model for the $A_{5}$ alloy are rather good, as illustrated in Fig. 23, particularly in the plateau region and in the single phase regions at $42^{\circ} \mathrm{C}$ and $60^{\circ} \mathrm{C}$. The use of a P-C-T model is interesting because it filters 
experimental singularities, such as the difference in the maximum storage capacity at $27-42-60^{\circ} \mathrm{C}$.

\begin{tabular}{ccccc}
\hline & $\mathrm{Ti}_{0.99} \mathrm{Zr}_{0.01} \mathrm{~V}_{0.43} \mathrm{Fe}_{0.09} \mathrm{Cr}_{0.05} \mathrm{Mn}_{1.5}$ & \multicolumn{2}{c}{$\mathrm{LmNi}_{4.91} \mathrm{Sn}_{0.15}$} \\
\hline Parameters & Absorption & Desorption & Absorption & Desorption \\
\hline $\mathrm{A}_{\alpha}$ & $1.5 \mathrm{E}-03$ & $6.2 \mathrm{E}-03$ & $2.1 \mathrm{E}-02$ & $2.5 \mathrm{E}-02$ \\
$\mathrm{~V}_{\alpha}$ & 0.96 & 1.69 & 1.06 & 0.96 \\
$\mathrm{~V}_{\alpha}$ & -0.31 & 0.28 & -0.01 & -0.06 \\
$\mathrm{H}_{\alpha}$ & -9490 & -2907 & -2907 & -3300 \\
$\Delta \mathrm{H}$ & 19989 & 24600 & 27169 & 31026 \\
$\Delta \mathrm{S}$ & 97 & 108 & 103 & 113 \\
$\mathrm{~W}_{\text {mid }}$ & 0.97 & 0.97 & 0.69 & 0.69 \\
$\mathrm{fS}$ & 0.36 & 0.17 & 0.47 & 0.51 \\
$\mathrm{~A}_{\beta}$ & 0.07 & 0.78 & 0.80 & 0.95 \\
$\mathrm{Y}_{\beta}$ & $9.66 \mathrm{E}-01$ & $2.13 \mathrm{E}-01$ & $1.63 \mathrm{E}-01$ & $1.16 \mathrm{E}-01$ \\
$\mathrm{~V}_{\beta}$ & $2.00 \mathrm{E}-01$ & $1.87 \mathrm{E}-01$ & $-1.22 \mathrm{E}-05$ & $3.95 \mathrm{E}-02$ \\
$\mathrm{H}_{\beta}$ & -4537 & -5042 & -4100 & -3700 \\
\hline
\end{tabular}

Table 9. Fitting parameters of the smoothed Zhou model

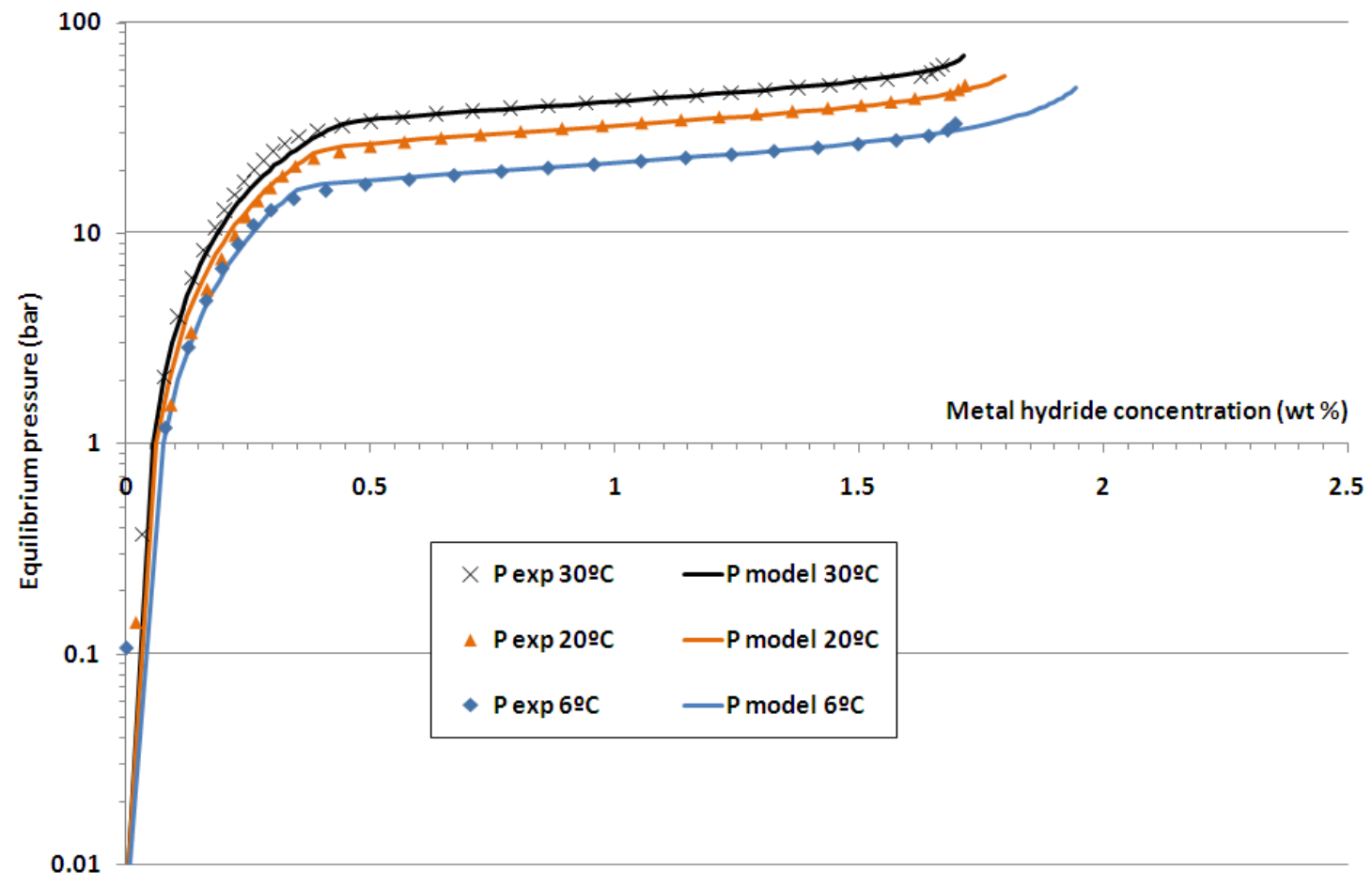

Fig. 22. $\mathrm{P}-\mathrm{C}$ isotherms for $\mathrm{Ti}_{0.99} \mathrm{Zr}_{0.01} \mathrm{~V}_{0.43} \mathrm{Fe}_{0.09} \mathrm{Cr}_{0.05} \mathrm{Mn}_{1.5}$ (abs). Smoothed Zhou model 


\section{Chapter 4 - EQUILIBRIUM P-C-T CHARACTERIZATION}

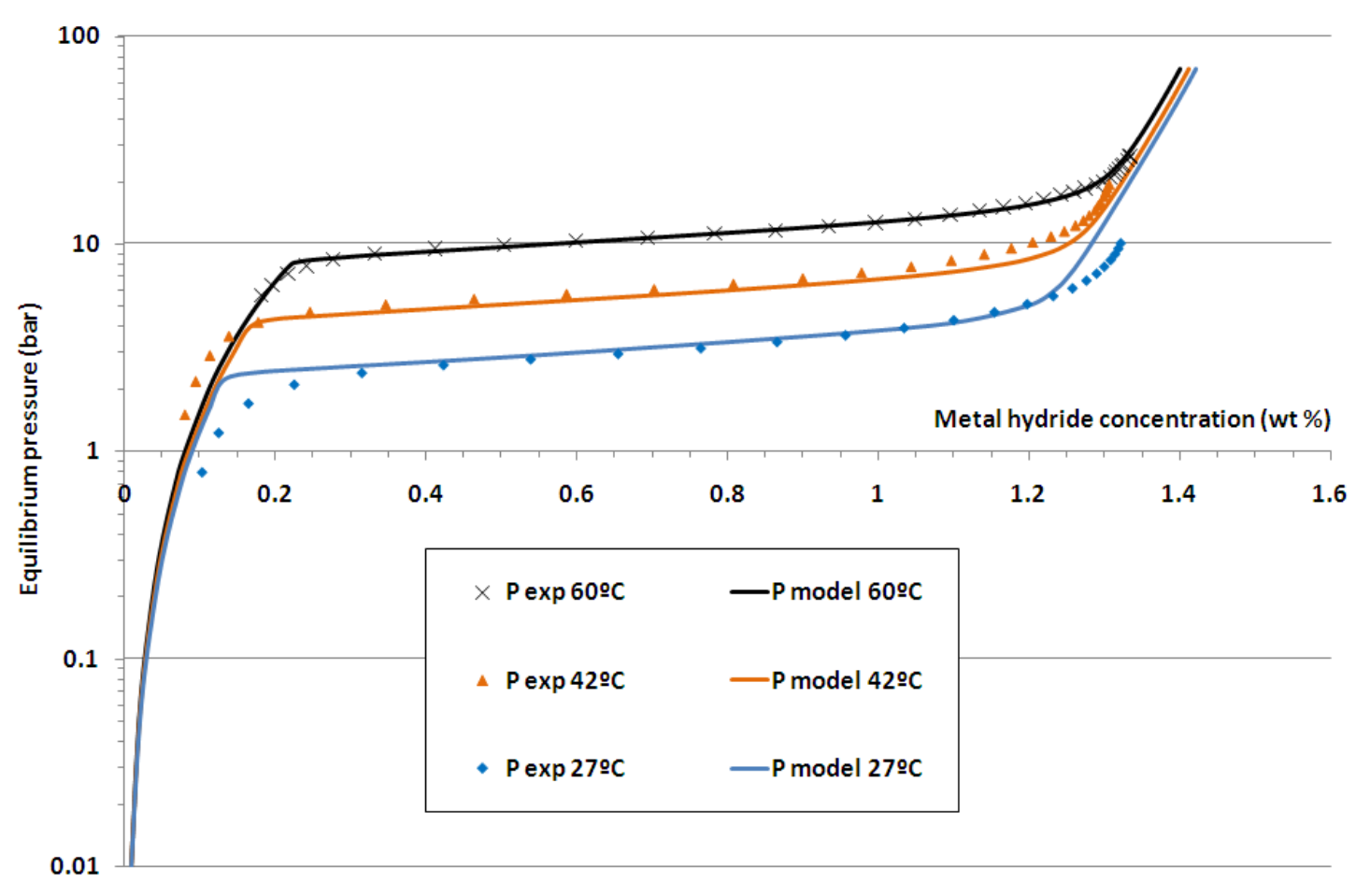

Fig. 23. P-C isotherms for $\mathrm{LmNi}_{4.91} \mathrm{Sn}_{0.15}$ (des). Smoothed Zhou model

\subsubsection{Lacher-Lototsky model}

As described in paragraph 1.2.2, the Lacher - Lototsky model involves the fitting of 7 parameters which are given in Table 10. A comparison with the measurements is illustrated in Fig. 24 and Fig. 25.

The agreement between the predicted P-C isotherms and the measurements is similar in quality to former results from Lototsky et al. $[61,62]$. In general terms, the Lacher-Lototsky model has provided a similar tendency in comparison with the experimental P-C-T curves. However, some discrepancies are observed, particularly in the $\beta$ phase region of the $A B_{2}$ alloy, and in the $\alpha$ phase of the $A B_{5}$ alloy. Hence, this model has not allowed for a good agreement in both the single and two-phase regions. 
Chapter 4 - EQUILIBRIUM P-C-T CHARACTERIZATION

\begin{tabular}{ccccc}
\hline & $\mathrm{Ti}_{0.99} \mathrm{Zr}_{0.01} \mathrm{~V}_{0.43} \mathrm{Fe}_{0.09} \mathrm{Cr}_{0.05} \mathrm{Mn}_{1.5}$ & \multicolumn{2}{c}{$\mathrm{LmNi}_{4.91} \mathrm{Sn}_{0.15}$} \\
\hline Parameter & Absorption & Desorption & Absorption & Desorption \\
\hline $\mathrm{C}_{\max }$ & 1.99 & 1.94 & 1.61 & 1.50 \\
$\mathrm{~T}_{\mathrm{c}}$ & 307.7 & 306.6 & 353.2 & 330.3 \\
$\Delta \mathrm{H}_{0}$ & $-1.65 \mathrm{e}+004$ & $-2.15 \mathrm{e}+004$ & $-3.10 \mathrm{e}+004$ & $-3.21 \mathrm{e}+004$ \\
$\Delta \mathrm{S}_{0}$ & -85 & -97 & -115 & -117 \\
$\sigma_{\mathrm{h}}$ & $4.74 \mathrm{e}+003$ & $1.05 \mathrm{e}+003$ & 489 & 570 \\
$\sigma_{\mathrm{s}}$ & 0.08 & 1.50 & 2.14 & 1.78 \\
$\rho_{\text {sh }}$ & 0.30 & 0.81 & 0.64 & 0.80 \\
\hline
\end{tabular}

Table 10. Fitting parameters of the Lacher-Lototsky model

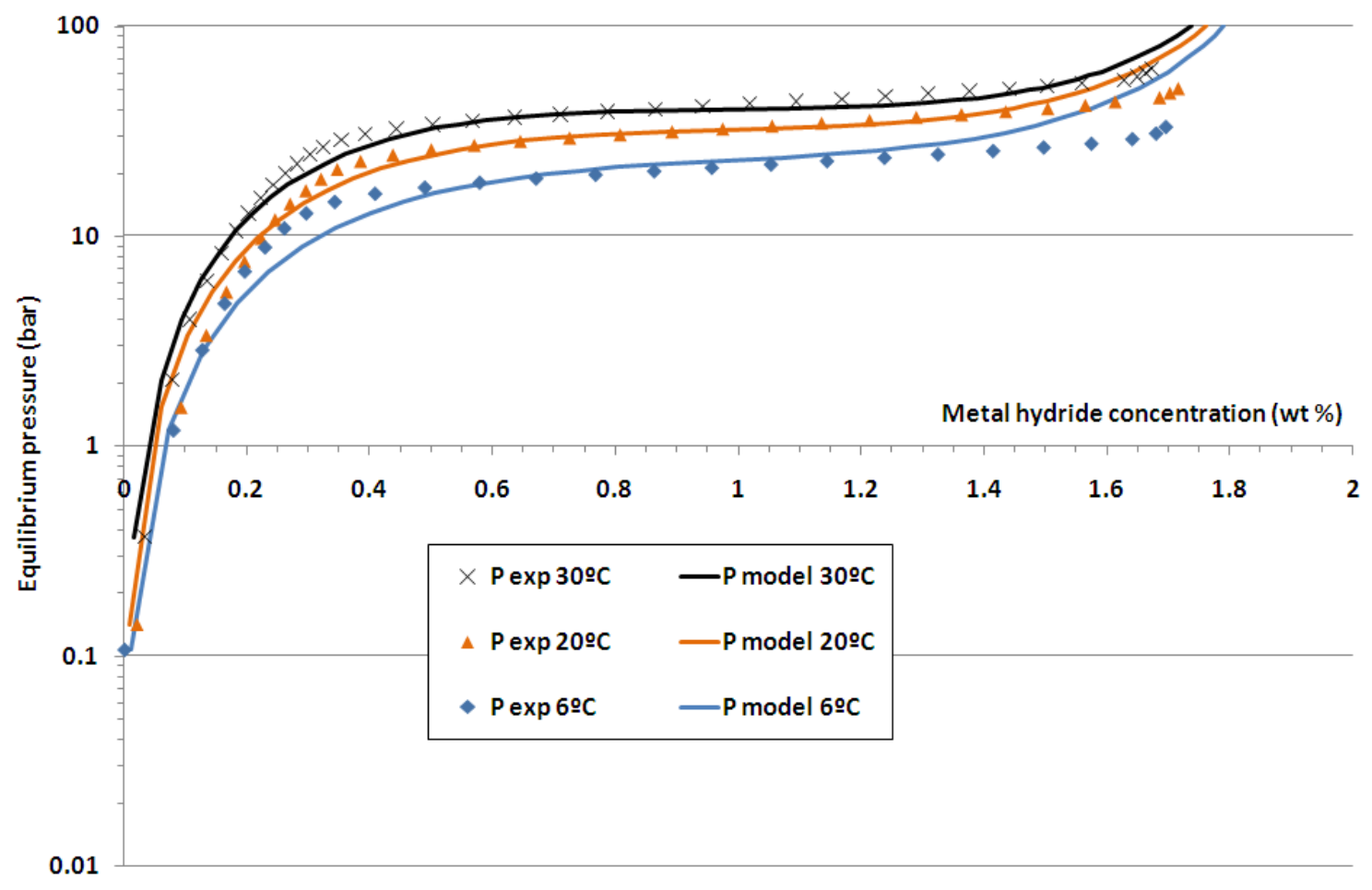

Fig. 24. $\mathrm{P}-\mathrm{C}$ isotherms for $\mathrm{Ti}_{0.99} \mathrm{Zr}_{0.01} \mathrm{~V}_{0.43} \mathrm{Fe}_{0.09} \mathrm{Cr}_{0.05} \mathrm{Mn}_{1.5}$ (abs). Lacher-Lototsky model 


\section{Chapter 4 - EQUILIBRIUM P-C-T CHARACTERIZATION}

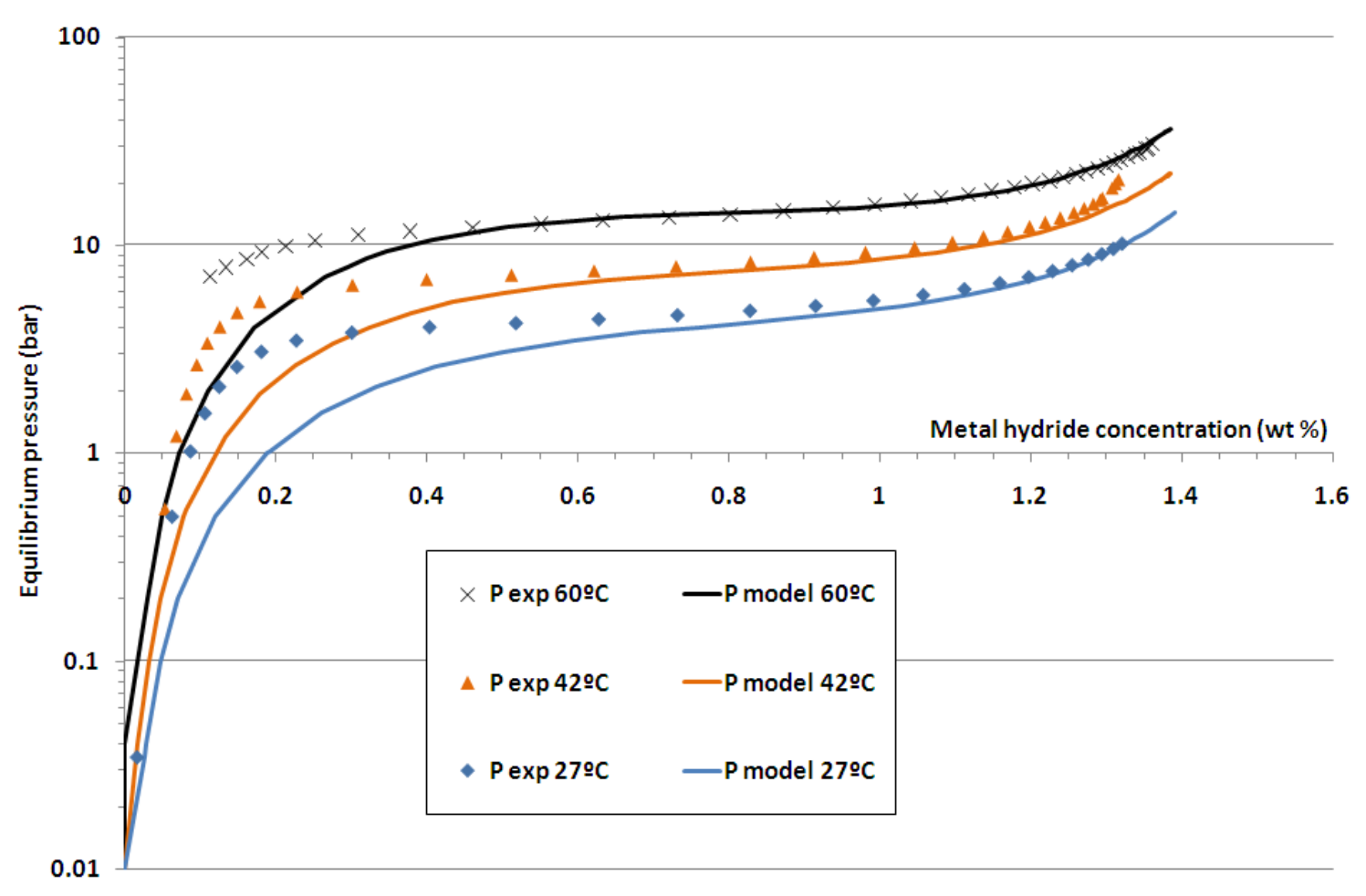

Fig. 25. P-C isotherms for $\mathrm{LmNi}_{4.91} \mathrm{Sn}_{0.15}$ (abs). Lacher-Lototsky model

\subsubsection{Polynomial fitting method}

The polynomial fitting of the measured P-C-T curves has provided the coefficients which are given in Table 11. The corresponding P-C isotherms are given in Fig. 26 and Fig. 27.

Both Fig. 26 and Fig. 27 show a very good agreement between the measurements and the model results within the whole range of isotherms. For each metal hydride concentration, this approach is very useful to obtain an accurate value of the equilibrium pressure. However, it should be highlighted that the predicted pressure curves present a wave-like behaviour in the plateau region, which is not realistic in comparison with the measured P-C isotherms. Thus, this approach should be used with caution. This model is only valid for the calculation of the equilibrium pressure, and it cannot be used inversely for the calculation of the metal hydride concentration. 


\begin{tabular}{|c|c|c|c|c|}
\hline & \multicolumn{2}{|c|}{$\begin{array}{c}\mathrm{Ti}_{0.99} \mathrm{Zr}_{0.01} \mathrm{~V}_{0.43} \mathrm{Fe}_{0.09} \\
\mathrm{Cr}_{0.05} \mathrm{Mn}_{1.5}\end{array}$} & \multicolumn{2}{|c|}{$\mathrm{LmNi}_{4.91} \mathrm{Sn}_{0.15}$} \\
\hline arameters & Absorption & Desorption & Absorption & Desorption \\
\hline$\Delta \mathrm{H}$ & 19984 & 25477 & 27169 & 31026 \\
\hline Tref & 279.15 & 279.15 & 333.15 & 333.15 \\
\hline k0 & 2.03E-01 & $-2.30 \mathrm{E}-01$ & $-2.91 E+01$ & $-1.24 \mathrm{E}+02$ \\
\hline $\mathrm{k} 1$ & $-3.00 \mathrm{E}+01$ & $-1.20 \mathrm{E}+01$ & $8.05 \mathrm{E}+02$ & $2.25 \mathrm{E}+03$ \\
\hline k2 & $5.76 \mathrm{E}+02$ & $5.50 \mathrm{E}+02$ & $-7.24 \mathrm{E}+03$ & $-1.66 \mathrm{E}+04$ \\
\hline k3 & $-1.42 E+03$ & $-2.26 \mathrm{E}+03$ & $3.58 \mathrm{E}+04$ & $6.90 \mathrm{E}+04$ \\
\hline k4 & $3.57 \mathrm{E}+02$ & $3.66 \mathrm{E}+03$ & $-1.05 E+05$ & $-1.76 \mathrm{E}+05$ \\
\hline k5 & $3.46 \mathrm{E}+03$ & $-1.88 \mathrm{E}+03$ & $1.89 \mathrm{E}+05$ & $2.85 \mathrm{E}+05$ \\
\hline k6 & $-6.10 \mathrm{E}+03$ & $-1.67 \mathrm{E}+03$ & $-2.11 E+05$ & $-2.94 \mathrm{E}+05$ \\
\hline k7 & $4.63 \mathrm{E}+03$ & $2.75 E+03$ & $1.42 \mathrm{E}+05$ & $1.87 \mathrm{E}+05$ \\
\hline k8 & $-1.71 E+03$ & $-1.36 \mathrm{E}+03$ & $-5.28 E+04$ & $-6.66 \mathrm{E}+04$ \\
\hline k9 & $2.50 \mathrm{E}+02$ & $2.39 E+02$ & $8.31 E+03$ & $1.02 \mathrm{E}+04$ \\
\hline
\end{tabular}

Table 11. Fitting parameters of the polynomial fitting method

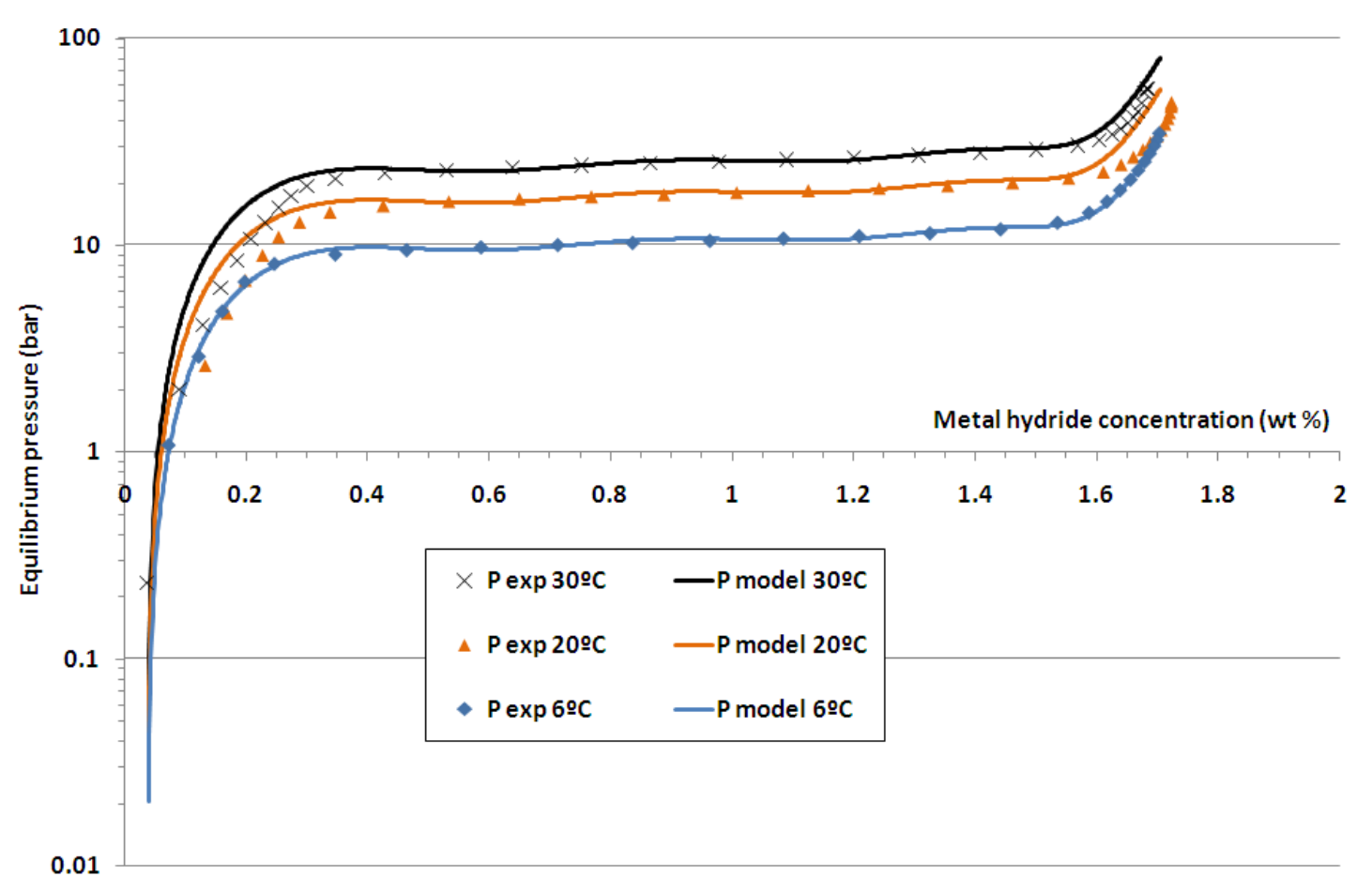

Fig. 26. $\mathrm{P}-\mathrm{C}$ isotherms for $\mathrm{Ti}_{0.99} \mathrm{Zr}_{0.01} \mathrm{~V}_{0.43} \mathrm{Fe}_{0.09} \mathrm{Cr}_{0.05} \mathrm{Mn}_{1.5}$ (des). Polynomial fitting method 


\section{Chapter 4 - EQUILIBRIUM P-C-T CHARACTERIZATION}

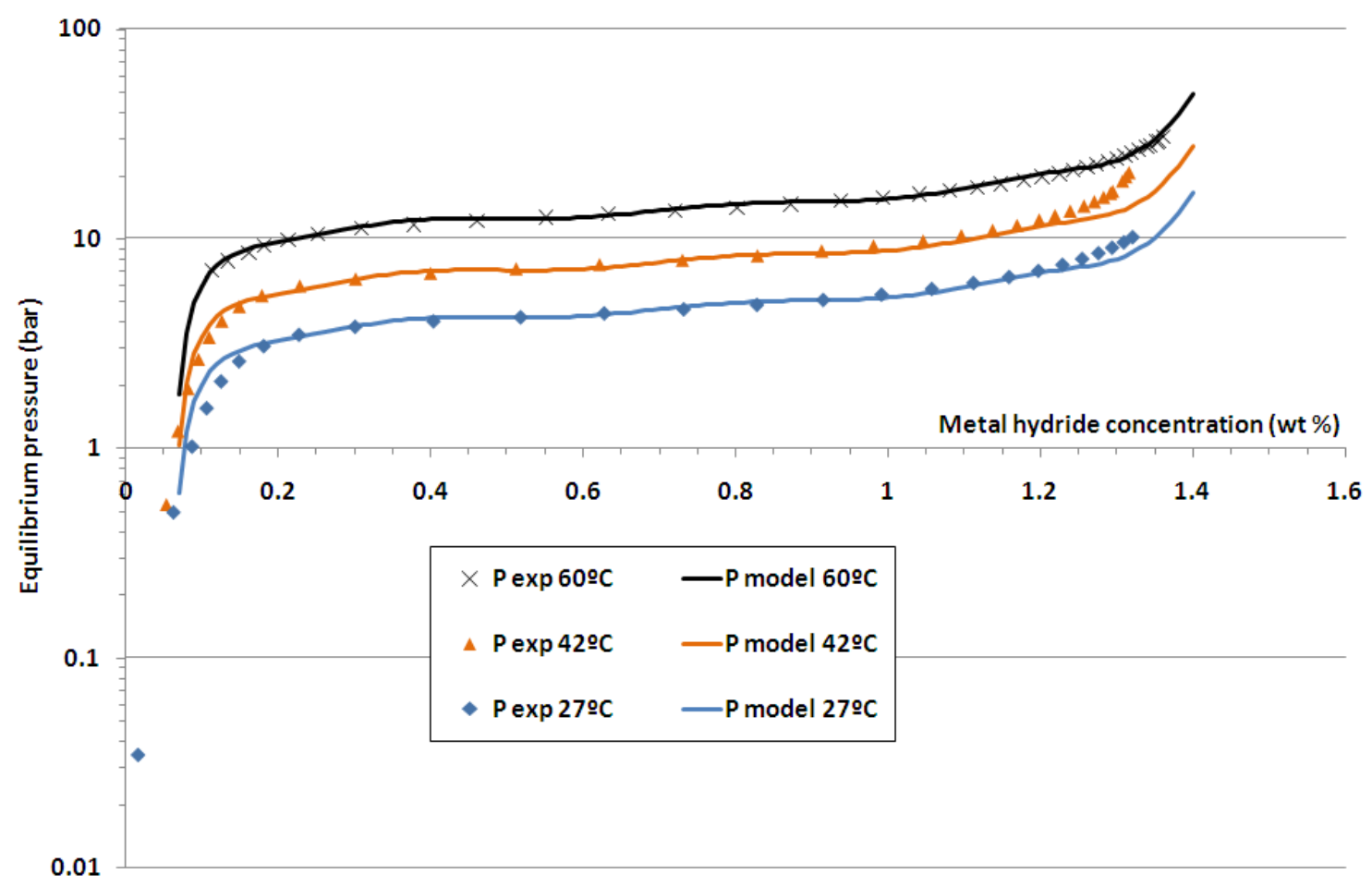

Fig. 27. P-C isotherms for $\mathrm{LmNi}_{4.91} \mathrm{Sn}_{0.15}$ (abs). Polynomial fitting method

\subsection{Conclusions on the P-C-T models}

(i) The equilibrium $\mathrm{P}-\mathrm{C}$ isotherms of the three coupled pairs of alloys (A1$\mathrm{B} 1, \mathrm{~A} 2-\mathrm{B} 2$ and $\mathrm{A3}-\mathrm{B} 3)$ have been measured.

(ii) Four different mathematical models have been used to reproduce the PC-T curves of the tested alloys. The fitting parameters of each model have been obtained. At any given temperature, the P-C isotherm can be calculated with the models.

(iii) The modified Van't Hoff equation provides an excellent fitting with the experimental results in the $\alpha+\beta$ phase region. Including a slope for this region is essential because the tested alloys reveal a non negligible pressure increase in the "plateau" region. 
(iv) The smoothed Zhou model is able to predict the behaviour of metal hydrides in any point of the P-C-T diagrams, including the smooth transition between different phase regions. This model contains the calculation of 12 physical parameters such as $\mathrm{V}_{\mathrm{H}}, \mathrm{Y}, \Delta \mathrm{H}$ or $\Delta \mathrm{S}$. A good agreement between the calculated and measured P-C-T curves has been achieved. Moreover, this model presents the advantage that it can be used for the calculation of the equilibrium pressure, or similarly, for the calculation of the metal hydride concentration.

(v) The Lacher-Lototsky model has been studied for the tested alloys. The calculation of the fitting parameters is fairly simple in this case, as it involves the determination of only 7 parameters. With this model, interesting thermodynamic parameters can be obtained. The calculated P-C-T curves have a similar tendency to the measurement data, but an accurate fitting in the whole P-C-T operation range has not been possible. Some discrepancies have also been observed in the calculation of the reaction enthalpy, in comparison with the other two models.

(vi) The use of a polynomial fitting for the P-C-T curves is a fairly simple approach which can be interesting to calculate the reaction enthalpy $\Delta \mathrm{H}$, and to predict the equilibrium pressures as a function of the metal hydride concentration and temperature. This approach should be used nevertheless with precaution as a wave-like behaviour is observed in the plateau region. The polynomial fitting approach cannot be used in reverse mode for the calculation of the metal hydride concentration as a function of the temperature and pressure. 


\section{Chapter 5:}

\section{Intrinsic reaction \\ kinetics}




\section{NOMENCLATURE}

\begin{tabular}{|c|c|}
\hline w & Metal hydride concentration, $\mathrm{g} \mathrm{MH/g}$ alloy (\%) \\
\hline $\mathrm{T}$ & Time, s \\
\hline $\mathrm{C}$ & Reaction rate constant in Eq. (26) \\
\hline$E_{a}$ & Activation energy, $\mathrm{J} \mathrm{mol}^{-1}$ \\
\hline $\mathrm{R}$ & Universal gas constant, $\mathrm{J} \mathrm{mol}^{-1} \mathrm{~K}^{-1}$ \\
\hline $\mathrm{T}$ & Temperature, $\mathrm{K}$ \\
\hline $\mathrm{P}$ & Pressure, $\mathrm{Pa}$ \\
\hline $\mathrm{K}$ & Overall reaction rate in Eq. (27) \\
\hline$f$ & Reacted fraction, $\mathrm{f}=\mathrm{w} / \mathrm{w}_{\infty}$ \\
\hline \multicolumn{2}{|c|}{ Subscripts } \\
\hline $\mathrm{MH}$ & Metal hydride \\
\hline A & $\alpha$ single phase region in the P-C-T curves \\
\hline B & $\beta$ single phase region in the $\mathrm{P}-\mathrm{C}-\mathrm{T}$ curves \\
\hline$\alpha+\beta$ & $\alpha+\beta$ phase region in the $P-C-T$ curves \\
\hline A & Cold reaction bed \\
\hline $\mathrm{B}$ & Hot reaction bed \\
\hline $\mathrm{Eq}$ & Equilibrium or static conditions \\
\hline ، & Dynamic conditions \\
\hline Gas & Hydrogen in gas phase \\
\hline$\infty$ & Final conditions (equilibrium) \\
\hline
\end{tabular}




\section{INTRINSIC REACTION KINETICS}

\subsection{Introduction}

The intrinsic reaction kinetics are a key aspect in metal hydride systems, as they characterize the charging speed in storage applications and limit the maximum desorption power in cooling applications. Hence, the modelling of the sorption kinetics is essential for the evaluation of the performance of metal hydride storage tanks $[34,75,76]$ and metal hydride cooling systems $[2,3,28]$.

The hydriding reaction takes place in 5 sequential steps [77]:

(i) Physisorption (or physical adsorption) of hydrogen molecules

(ii) Chemisorption (or chemical adsorption); dissociation of hydrogen molecules into atoms in the surface of the hydride

(iii) Penetration of the hydrogen atoms through the surface layer into the bulk

(iv) Diffusion of the hydrogen atoms through the hydride

(v) Hydride formation (nucleation and growth)

Although a detailed model of the complete hydriding reaction would require the modelling of each intermediate process [78], in practice there is often a limiting step which controls the reaction, while the other steps are in equilibrium. Hence, the modelling of the rate controlling reaction may be sufficient to predict the overall reaction rate of a metal hydride system.

It has been demonstrated that different preparation techniques of the metal hydride powders lead to different rate-controlling steps during the absorption process [79]. For instance, mechanical milling can change the rate-limiting steps of the hydriding reaction in the $\mathrm{La}_{2} \mathrm{Mg}_{17}-\mathrm{LaNi}_{5}$ composite from surface penetration to hydrogen diffusion through the hydride layer. Hence, many different kinetic models can be found in literature, even for the same alloys. 
The sorption reaction rate depends on the temperature and pressure conditions. Regarding the temperature dependence, many authors have indicated an Arrhenius dependence of the reaction rate [70,80,81]. Other authors have shown an implicit temperature dependence by correlating the reaction rate with the equilibrium pressure $[2,82]$.

Regarding the pressure influence in the reaction rate, many different models have been proposed. On the one hand, semi-empirical methods have been applied. Mayer et al. [5] originally proposed a reaction rate where the pressure weight derives from a logarithmic expression, and many authors since then have used this approach in their simulations of metal hydride reaction beds $[70,83,84]$.

On the other hand, theoretical models based on the rate controlling mechanisms have also been proposed. The most extended theoretical model is the Johnson-Mehl-Avrami model (JMA), which has been validated in literature with experimental data of different alloys, for instance of $\mathrm{ZrMn}_{0.85} \mathrm{Cr}_{0.1} \mathrm{~V}_{0.05} \mathrm{Fe}_{0.5} \mathrm{Ni}_{0.5}$ [76], $\mathrm{Ho}_{1-\mathrm{x}} \mathrm{Mm}_{\mathrm{x}} \mathrm{Co}_{2}$ [58,80], $\mathrm{Mg}_{3} \mathrm{La}$ and $\mathrm{Mg}_{3} \mathrm{LaNi}_{0.1}$ [85], $\mathrm{MgH}_{2}$ [86], $\mathrm{ZrMnFe}_{0.5} \mathrm{Ni}_{0.5}$ and $\mathrm{ZrMnFe}_{0.5} \mathrm{Co}_{0.5}$ [87]. This nucleation and growth model provides generally good results in the plateau region.

In the $\beta$ phase, where the alloys often present a diffusion controlled reaction [79,87], a few diffusion models have also been applied [77,88,89].

The objective of this study is to obtain an accurate kinetic equation to characterize the hydriding/dehydriding behaviour of alloys A3 and B3. The JMA model is interesting if the temperatures are constant, and if the final metal hydride concentration is known because it involves the calculation of the reacted fraction $\left(f=w / w_{\infty}\right)$. However, in a MHCS, the temperatures are completely dynamic and thus there is no such "reacted fraction".

A priori, it is very hard to predict the reaction kinetics of the alloys using kinetic equations from literature, because they depend not only on the operating position in the P-C-T diagrams $[79,89]$, but also on the alloy preparation, which may lead to different rate controlling steps even for same powders [79]. Thus, 
the choice has been made to test the kinetics in-situ and to develop a semiempirical equation.

\subsection{Experimental campaign}

In order to develop an accurate kinetic model, a specific experimental campaign has been realised at IKE using the same set-up as for the measurement of the P-C-T curves. Many authors agree that the intrinsic reaction kinetics depend on the operating position with respect to the static P-C-T diagrams $[79,89]$. It has been proved that the following relationship is verified: $\left.\frac{\mathrm{dw}}{\mathrm{dt}}\right|_{\alpha^{\prime}}>\left.\frac{\mathrm{dw}}{\mathrm{dt}}\right|_{\alpha^{\prime}+\beta^{\prime}}>\left.\frac{\mathrm{dw}}{\mathrm{dt}}\right|_{\beta^{\prime}}$.

Hence, the slower kinetics are achieved in the $\beta$ phase of the alloys. Conventional tests of the intrinsic kinetics involve a full absorption or desorption. In the latter tests, the experimental data has to be treated to separate the different dynamic regions $\left(\alpha^{\prime}, \alpha^{\prime}+\beta^{\prime}, \beta^{\prime}\right)$ and to find the kinetic equation for the corresponding limiting step. These dynamic regions are often dependent on the mass flow rate [22] and thus they may differ from the static P-C-T regions ( $\alpha$, $\alpha+\beta, \beta)$.

A MHCS should be designed to work mainly in the $\alpha+\beta$ phase, so in this application it is not particularly interesting to characterize the sorption dynamics in the whole P-C-T regions. As the hydrogen connexion valve between the two reactors is always open, the pressure difference is much lower than in the full absorption and desorption tests. Hence, in order to characterize the kinetics for a MHCS application, it is more convenient to realise an experimental campaign only in the plateau region, with low pressure differences.

Fig. 28 and Fig. 29 illustrate the experimental procedure which has been followed to analyze the intrinsic kinetics in the plateau region. During the absorption tests (Fig. 28), the sample is first evacuated until vacuum. Afterwards, the pressure is increased by sequential steps until the pressure $P_{\alpha \rightarrow \alpha+\beta}$ is achieved with no temperature increase. The sample is then 
maintained at this pressure, while the rest of the system is charged until the pressure $P_{\alpha+\beta \rightarrow \beta}$. The measurements start when the valve which separates the reactor is opened, and hydrogen flows towards the sample until the equilibrium pressure in the right of the plateau is reached.

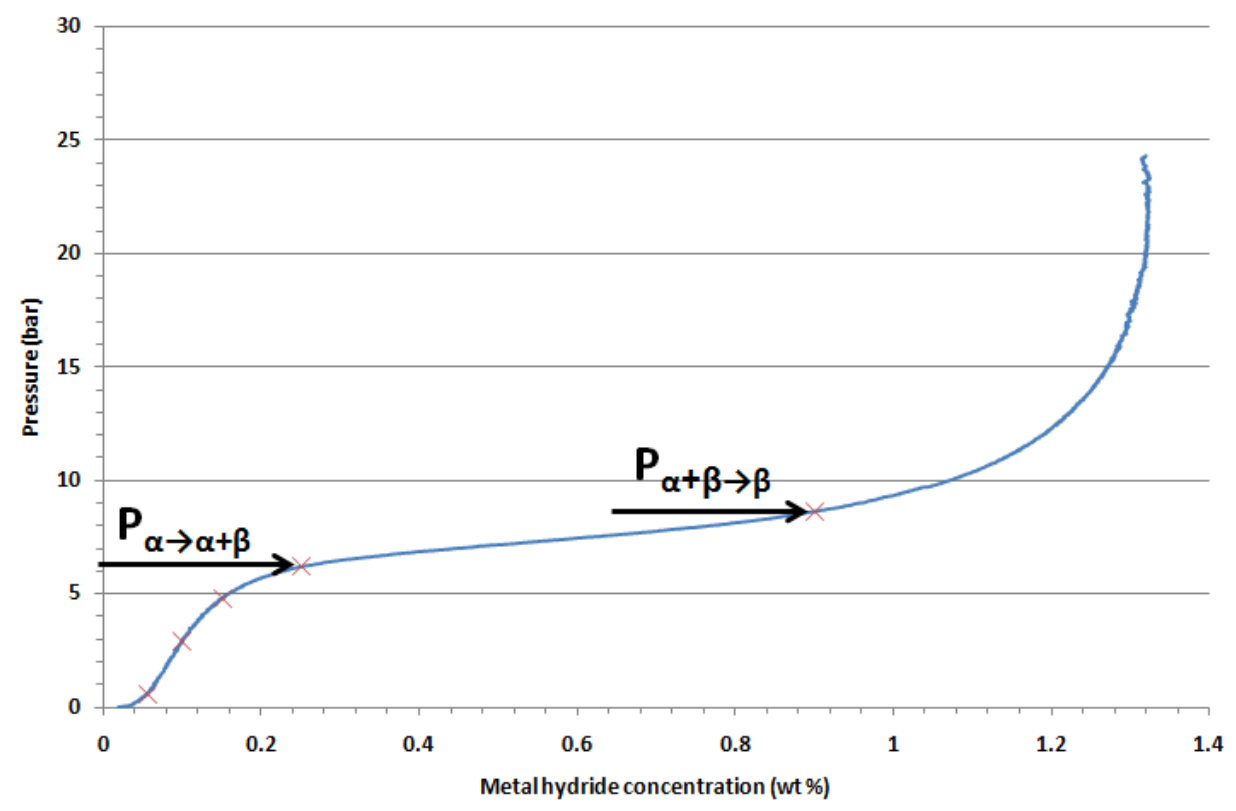

Fig. 28. Experimental procedure during the absorption tests

Similarly, during the desorption tests (Fig. 29) the sample is initially fully charged in order to guarantee that it is operating in its $\beta$ phase. Afterwards, consecutive desorption steps are followed until the pressure $P_{\beta \rightarrow \alpha+\beta}$ corresponding to the right of the plateau is reached. The sample is then maintained at this pressure while the rest of the system is evacuated until the pressure $P_{\alpha+\beta \rightarrow \beta}$. The desorption measurements begin when the valve is opened. 


\section{Chapter 5 - INTRINSIC REACTION KINETICS}

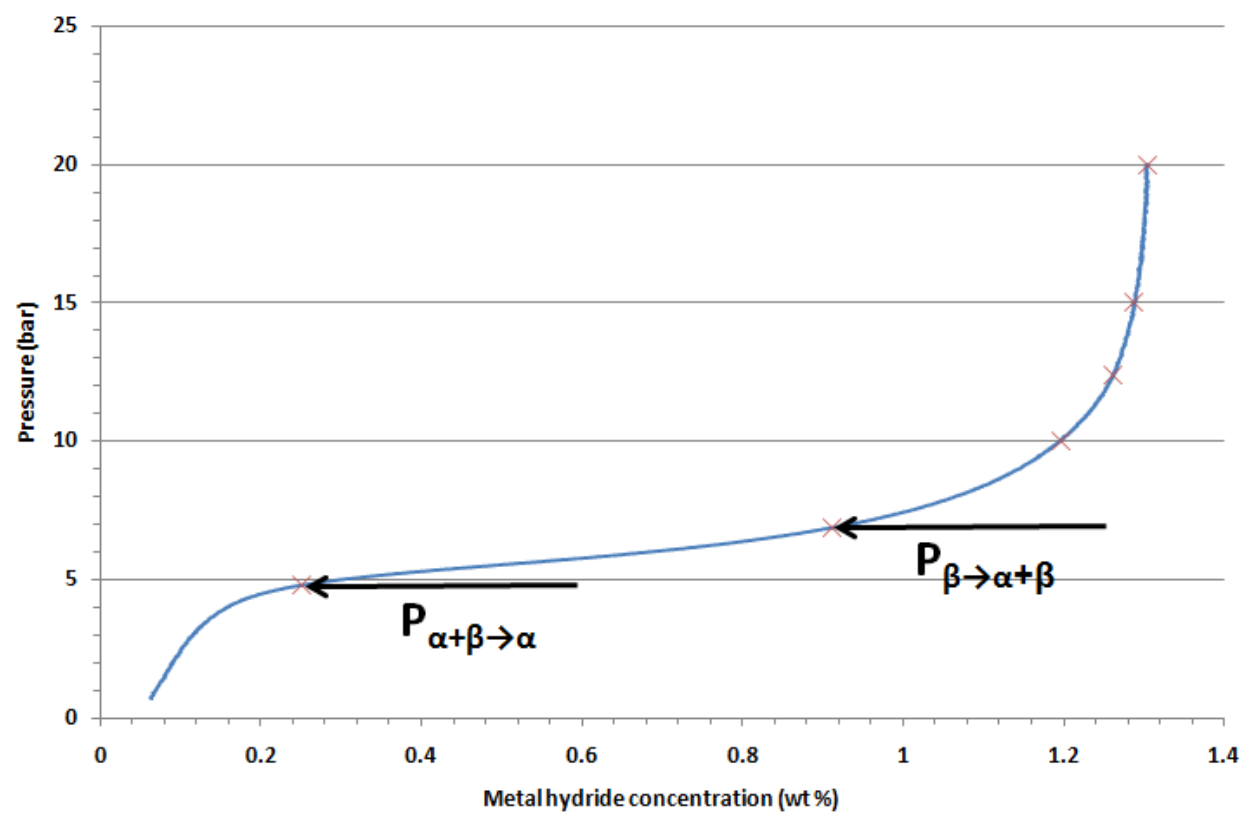

Fig. 29. Experimental procedure during the desorption tests

\subsection{Intrinsic kinetic model}

Among published literature, very few dynamic equations have been applied for the modeling of the intrinsic kinetics [2,84]. Different expressions have been compared with the experimental results of A3-B3, and the best agreement has been reached by applying the semi-empirical Eq. (26) which assumes that the difference between the static and actual pressure is the driving force of the sorption process [90].

$$
\frac{d w}{d t}=K \cdot e^{-\frac{E_{a}}{R \cdot T}} \cdot \frac{P_{g a s}-P_{e q}(T, w)}{P_{e q}\left(T, w_{\alpha+\beta \rightarrow \beta}\right)-P_{e q}\left(T, w_{\alpha \rightarrow \alpha+\beta}\right)}=k_{T} \cdot k_{P}
$$

In Eq. (26), the two terms $\mathrm{k}_{\mathrm{T}}$ and $\mathrm{k}_{\mathrm{P}}$ show the temperature and pressure dependence of the reaction rate. The equilibrium pressure is calculated for each time step depending on the instantaneous temperature and metal hydride 
concentration. The terms $w_{\alpha+\beta \rightarrow \beta}$ and $w_{\alpha \rightarrow \alpha+\beta}$ refer to the right and left limit of the plateau region.

The beginning of the sorption process presents the higher reaction rate because of the pressure difference between the hydrogen gas and the initial pressure of the sample. The temperature term $\mathrm{k}_{\mathrm{T}}$ follows an Arrhenius dependence as in many kinetic models from literature $[18,32,56,70,86]$.

\subsection{Results}

For each isotherm, a model has been developed in MATLAB to reproduce the following Eq. (27).

$$
\frac{\mathrm{dw}}{\mathrm{dt}}=\mathrm{k} \cdot\left(\mathrm{P}_{\mathrm{gas}}-\mathrm{P}_{\mathrm{eq}}(\mathrm{T}, \mathrm{w})\right)
$$

The only unknown parameter in Eq. (27) is the value of the overall reaction rate $k$. For each isotherm, the value of $k$ has been found by minimizing the mean square error between the predicted and measured sorption curves.

Once the values of $k$ have been obtained, the Arrhenius term $\mathrm{k}_{T}$ may be calculated by means of the expression (28), which may be deduced from Eqs. (26) and (27):

$$
\mathrm{k}_{\mathrm{T}}=\mathrm{k} \cdot\left(\mathrm{P}_{\mathrm{eq}}\left(\mathrm{T}, \mathrm{w}_{\alpha+\beta \rightarrow \beta}\right)-\mathrm{P}_{\mathrm{eq}}\left(\mathrm{T}, \mathrm{w}_{\alpha \rightarrow \alpha+\beta}\right)\right)
$$

As the term $\mathrm{k}_{\mathrm{T}}$ follows an Arrhenius dependency (Eq. (26)), the plot of In $\mathrm{k}_{\mathrm{T}}$ should reveal a linear behavior. This is the method which has been followed to obtain the parameters required for the kinetic Eq. (26). As indicated in Eq. (29), the Arrhenius plot provides the value of $C$ (intercept value) and the activation energy $E_{a}$ (slope). 


$$
\ln \left(\mathrm{k}_{\mathrm{T}}\right)=\ln (K)-\frac{E_{a}}{R \cdot T}
$$

\subsubsection{Alloy B3}

Fig. 30 shows the theoretical and experimental hydriding curves of alloy B3. As explained in Chapter 2, the volumetric method is used to calculate the metal hydride concentration. At the beginning of the absorption reaction, the sample of B3 is abruptly filled with pressurized hydrogen. The initial peak which is observed in all of the hydriding or dehydriding curves is due to the initial pressure wave, as well as to the temperature stabilisation. After this initial stage, the volumetric method helps measure the real metal hydride concentration, and it is in this region where the kinetic model has been applied.

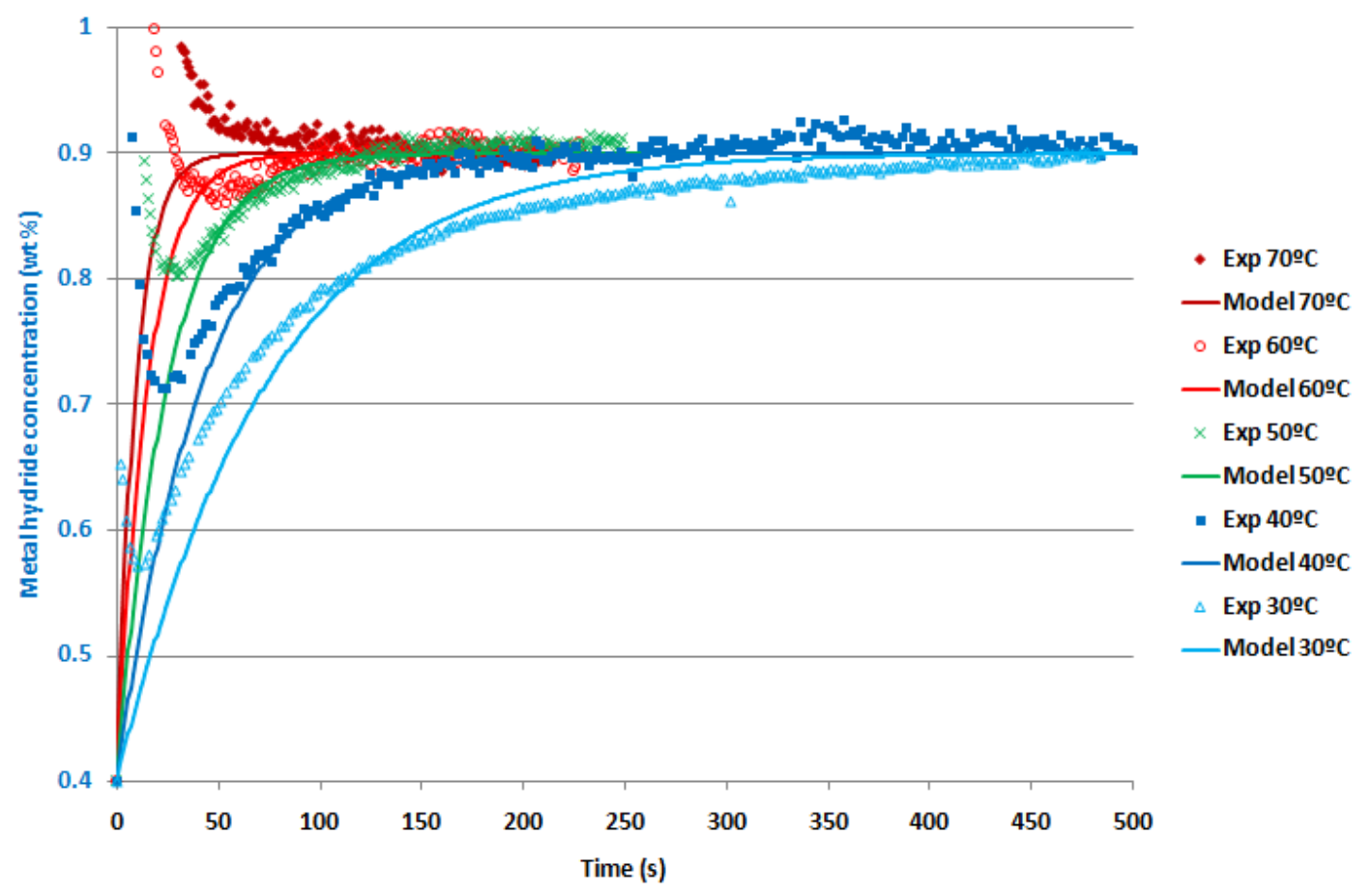

Fig. 30. Fitting of the kinetics model for B3 during absorption 
Fig. 30 shows a good agreement between the simulations and the experimental curves, particularly for the isotherms at $40^{\circ} \mathrm{C}, 50^{\circ} \mathrm{C}$ and $60^{\circ} \mathrm{C}$. At $70^{\circ} \mathrm{C}$, the reaction becomes too fast and once the pressure and temperature stabilizes, the reaction is almost finished.

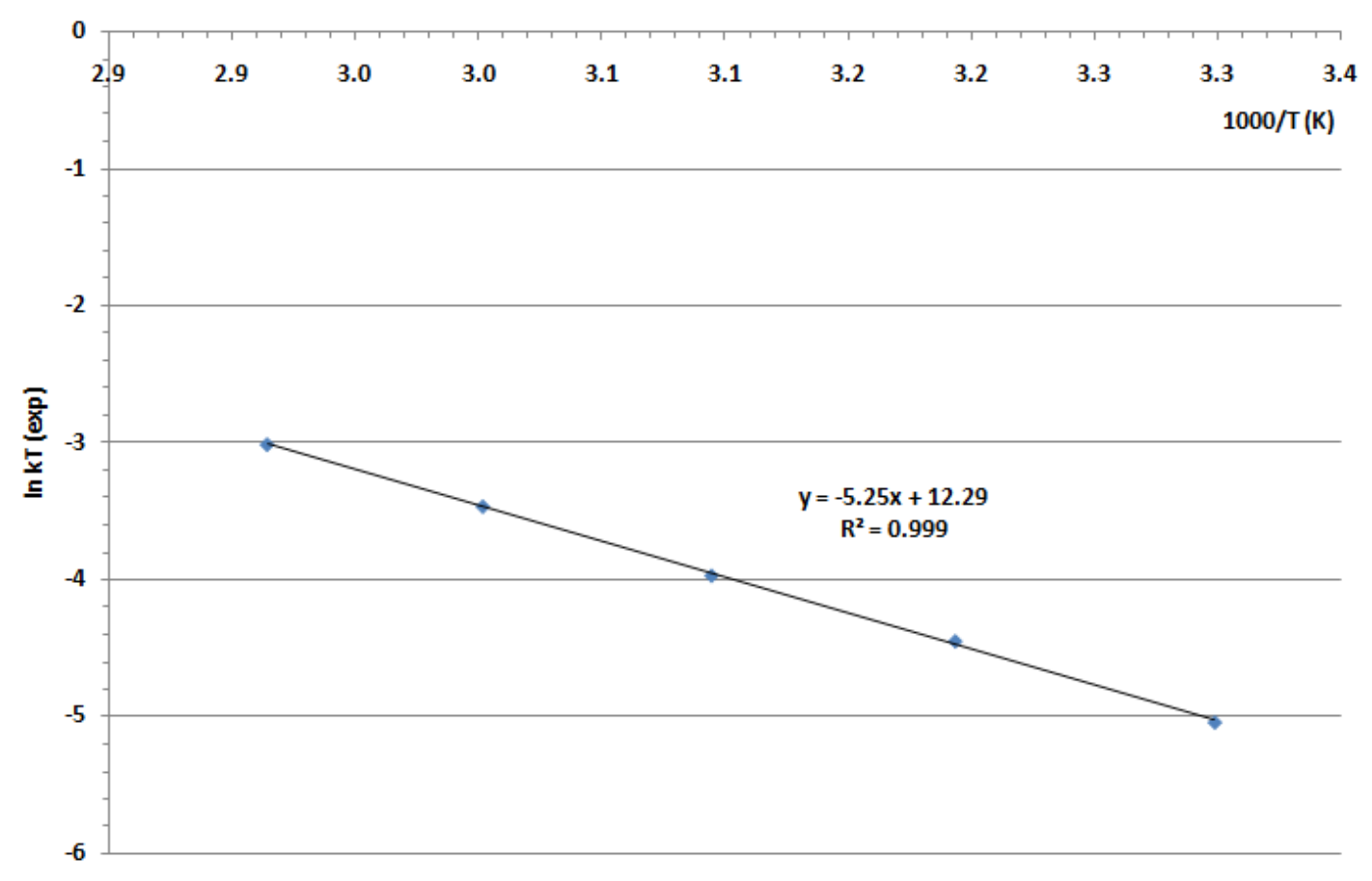

Fig. 31. Arrhenius plot of the reaction rate of B3 during absorption

Once the values of the overall reaction rate $k$ are found (Fig. 30, Eq. (27)), the Arrhenius plot of the term $\mathrm{k}_{T}$ can be obtained (Fig. 31, Eq. (28)). The agreement is very good and it clearly shows the temperature dependency of the term $\mathrm{k}_{\mathrm{T}}$, which can be described accurately by means of Eq. (29).

During desorption, very similar results have been achieved. In Fig. 32, the fitting of the kinetic Eq. (27) may be observed, and the Arrhenius plot is given in Fig. 33. As for the absorption process, the Arrhenius plot for the desorption reaction provides a very high $R^{2}$ coefficient, hereby supporting the quality of the fitting. 
Chapter 5 - INTRINSIC REACTION KINETICS

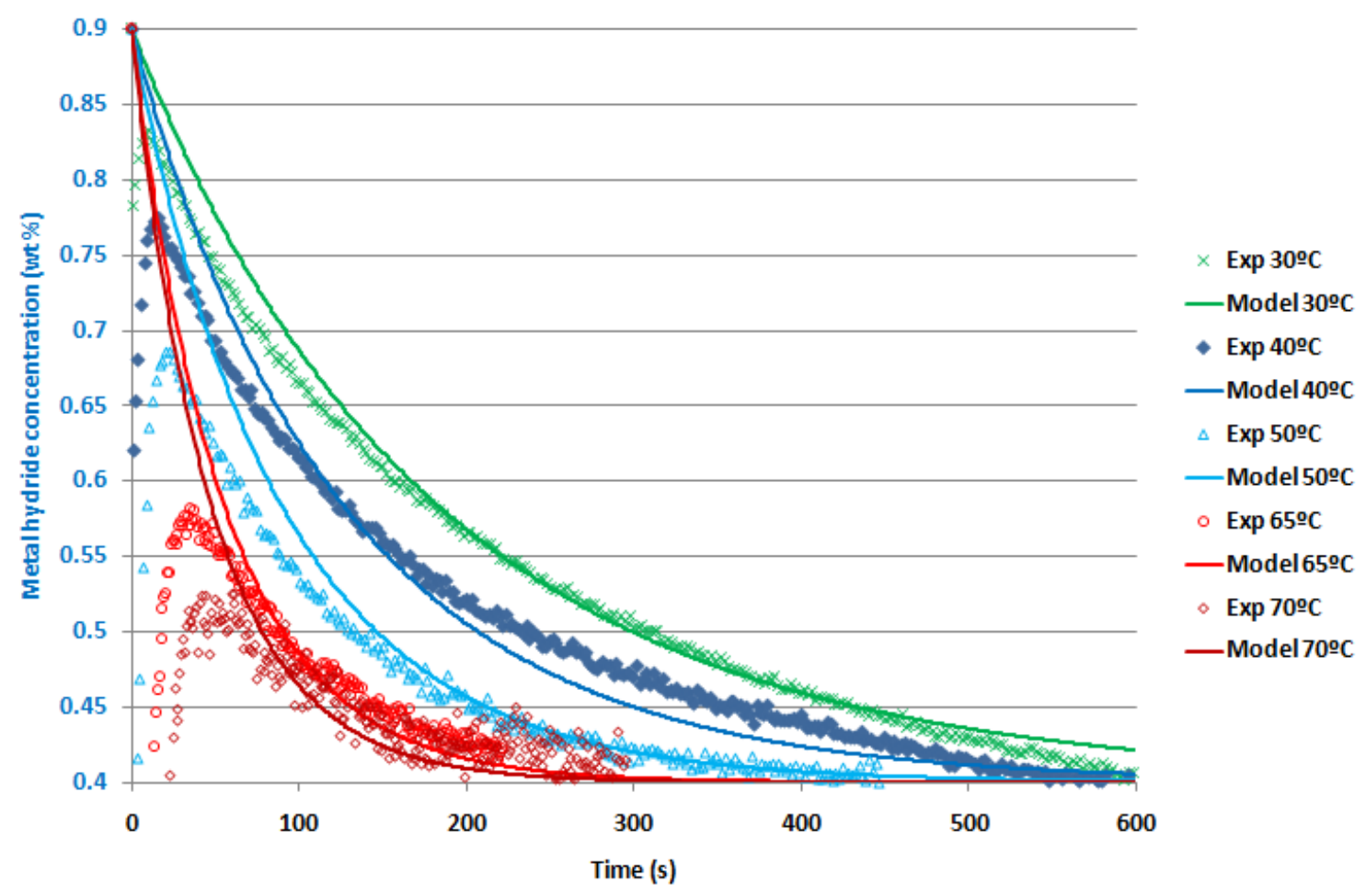

Fig. 32. Fitting of the kinetics model for B3 during desorption

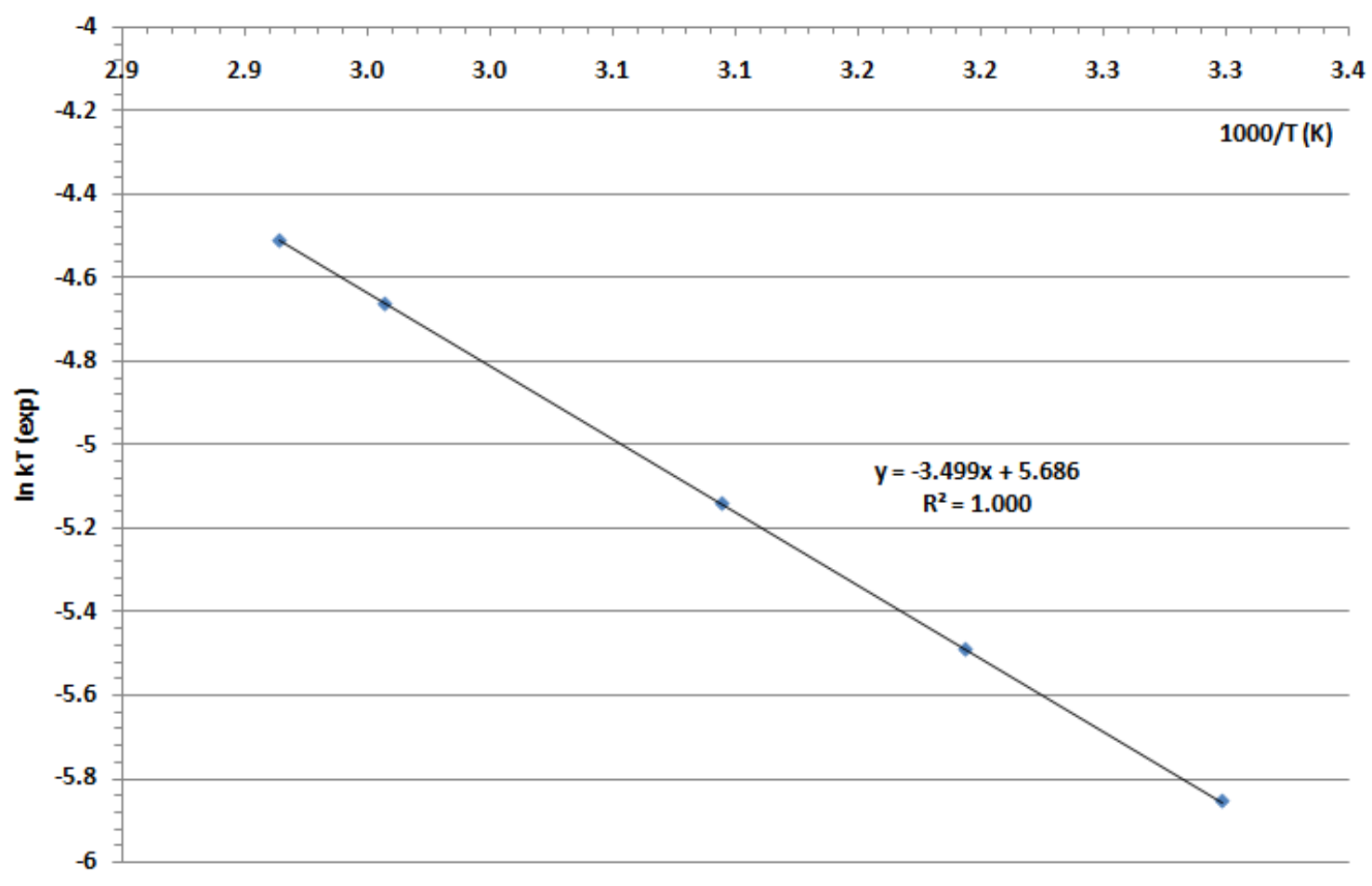

Fig. 33. Arrhenius plot of the reaction rate of B3 during desorption 
5.4.2. Alloy A3

In the case of alloy A3, the intrinsic kinetics are too fast to be measured with the actual test bench. For instance, Fig. 34 shows the hydriding curves of $A 3$ in the plateau region at $20^{\circ} \mathrm{C}$. The measured metal hydride reaction rate presents an initial peak and then stabilizes after around 170s. This initial peak was also observed for B3 (Fig. 30), but in the case of A3, once the pressures and the temperatures stabilize (after 170s), the chemical reaction is already over.

The only information which can be obtained from these tests is that the chemical reaction takes place within the first 170s, but there are different reaction rates which can lead to the same measurements, from fast intrinsic kinetics (blue dashed lines in Fig. 34) finishing after 50s to slow reaction kinetics (red dashed lines).

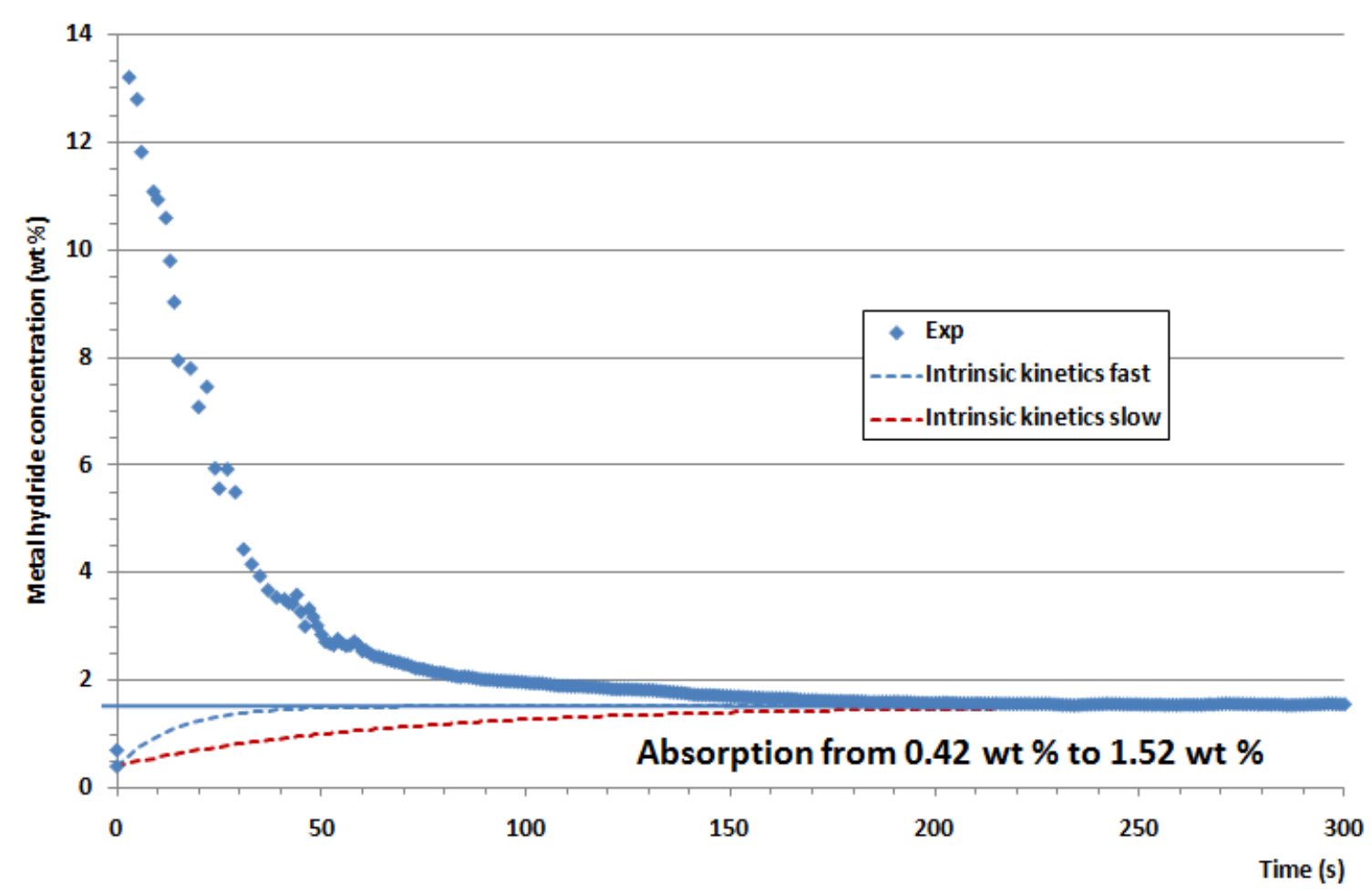

Fig. 34. Kinetics of $\mathrm{A} 3$ during absorption at $20^{\circ} \mathrm{C}$ 
Although it has not been possible to measure specifically the intrinsic kinetics of the fast alloy $A 3$, as done for alloy B3, in the overall model of the MHCS (Chapter 6), the kinetic Eq. (26) has also been used for A3. This kinetic equation requires 2 parameters which are the activation energy $E_{a}$ and the reaction rate constant $\mathrm{C}$. The activation energy has been obtained from literature [77] [56]. The parameter $A$ has been obtained indirectly by fitting the model results to experimental measurements involving the whole reaction bed $A$ such as the maximum cooling power tests and the cycle tests which are analyzed in Chapter 7.

Even if it has not been possible to analyze the intrinsic kinetics of A3 directly, it should be highlighted that the intrinsic kinetics of A3 are very fast and do not have a significant influence on the results of the coupled reactors A3-B3. The values of $A$ and $E_{a}$ for alloy $A 3$ are not particularly relevant because the reaction rate is sensibly faster than for alloy B3.

In Fig. 35 and Fig. 36, the simulated hydriding kinetics of alloy A3 have been plotted.

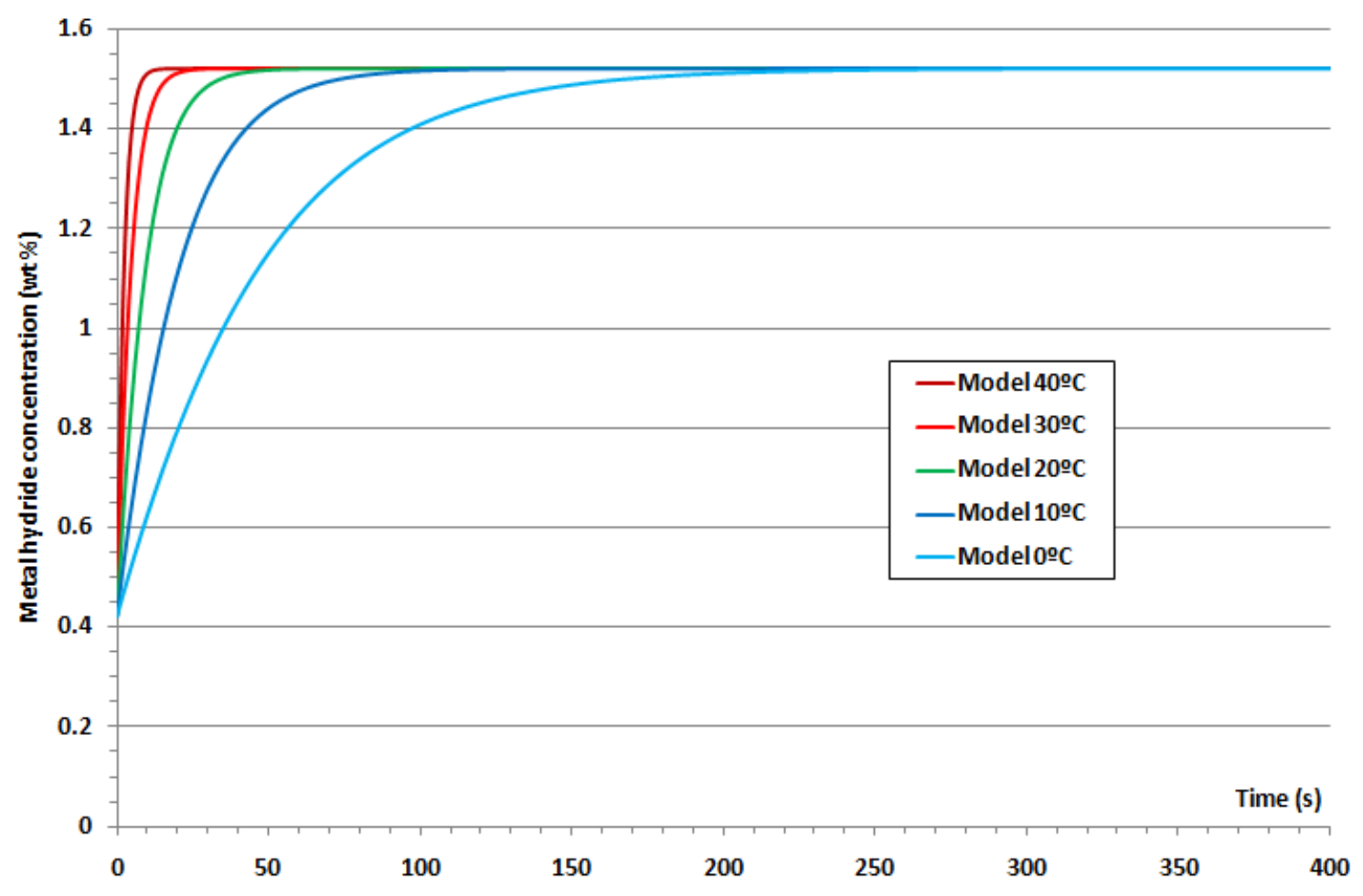

Fig. 35. Intrinsic absorption kinetics of $\mathbf{A} 3$ in the plateau region (model) 


\section{Chapter 5 - INTRINSIC REACTION KINETICS}

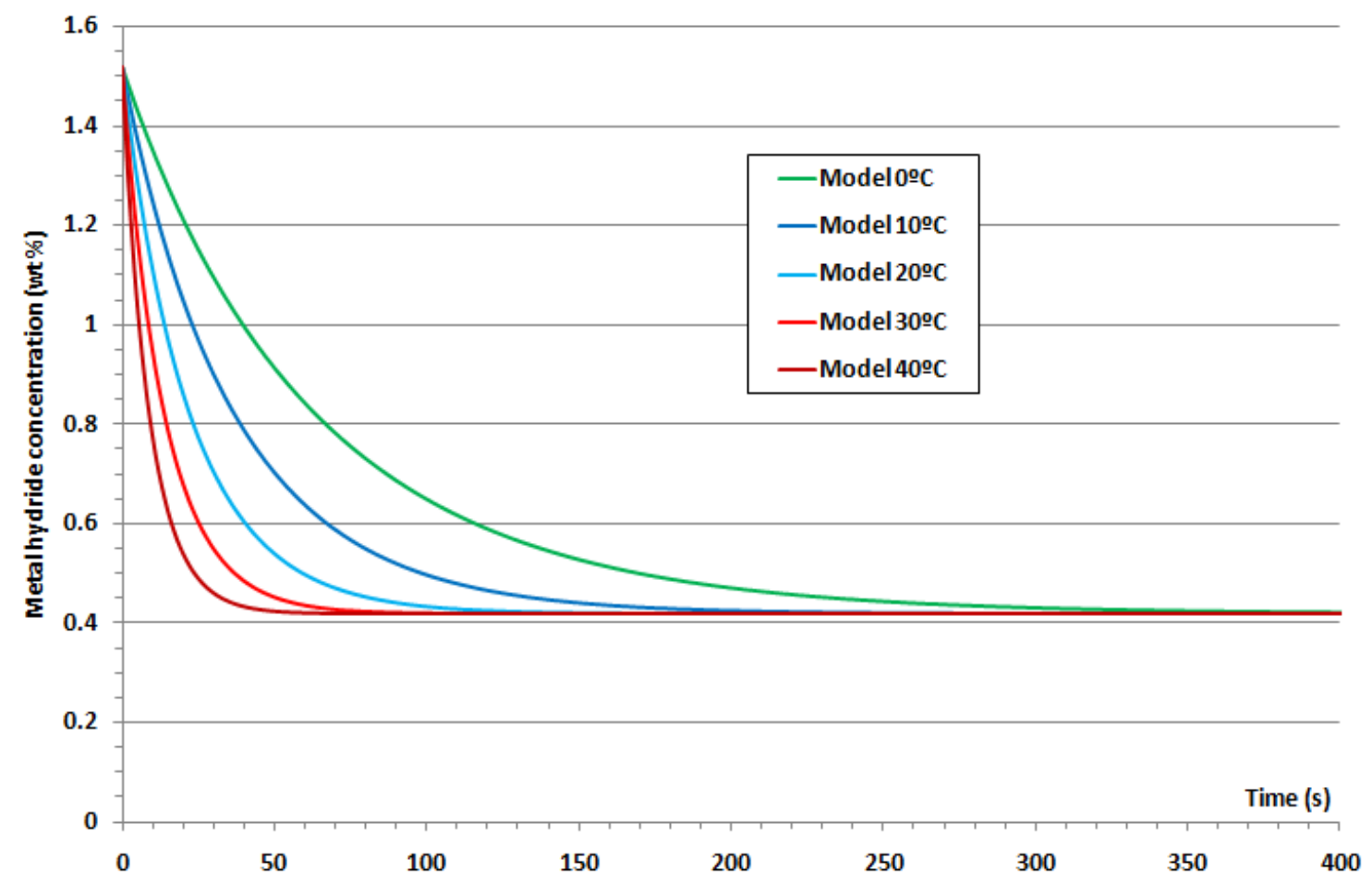

Fig. 36. Intrinsic desorption kinetics of $\mathbf{A} 3$ in the plateau region (model)

The same materials A3 and B3 have also been recently tested at IKE for full absorptions/desorptions, and similar conclusions were reached for the fast alloy A3. In order to measure the intrinsic kinetics of this alloy, a special test bench should be designed. The following remarks should be considered:

- By changing the water/glycol mixture of the thermostat, the reaction kinetics could be tested at lower temperatures where the kinetics are slower and are thus easier to be observed.

- Ideally, all of the pipes and the hydrogen they contain should have the same temperature (desired isotherm). This can only be achieved by designing a small, compact system with a same water thermostat which regulates the temperature of the reference volumes, the piping and the reactor. If not, the calculations should take into account the temperature gradient from the reference volume to the thermostated reactor.

- The pipes should be as short as possible and the valves and elbows should be chosen carefully so as to minimize the friction and hence reduce the initial temperature increase and pressure losses. 


\subsection{Conclusions on the intrinsic reaction kinetics}

The experimental tests have helped develop a semi-empirical kinetic equation for alloy B3. The cold reactor A3 presents much faster reaction kinetics and these cannot be measured with the current set-up. However, for the MHCS the reaction kinetics of $\mathrm{A} 3$ are not relevant because they do not limit the performance once the reactors are coupled.

Table 12 provides the kinetic parameters for each alloy. These values have been used in the model of the MHCS which is described in Chapter 6. As may be inferred from Table 12, the desorption rates are slower than the absorption rates. This aspect is in coherence with published literature $[56,83]$.

\begin{tabular}{|c|c|c|c|c|}
\hline & \multicolumn{2}{|c|}{ Alloy A3 } & \multicolumn{2}{c|}{ Alloy B3 } \\
\hline & Absorption & Desorption & Absorption & Desorption \\
\hline $\mathrm{K}$ & $3.10^{8}$ & $9.10^{4}$ & $1,52.10^{5}$ & $2,94.10^{2}$ \\
\hline $\mathrm{E}_{\mathrm{a}}[\mathrm{J} /(\mathrm{K} \mathrm{mol})]$ & 53000 & 35000 & 43651 & 28976 \\
\hline
\end{tabular}

Table 12. Parameters of the kinetic Eq. (26) 



\section{Chapter 6:}

\section{Description of the dynamic model}




\section{Nomenclature}

\begin{tabular}{|c|c|}
\hline $\mathrm{C}_{\mathrm{p}}$ & Specific heat capacity, $\mathrm{J} \mathrm{kg}^{-1} \mathrm{~K}^{-1}$ \\
\hline M & Alloy mass in the reactors, $\mathrm{kg}$ \\
\hline $\mathrm{T}$ & Temperature, $\mathrm{K}$ \\
\hline$\Delta \mathrm{H}$ & Enthalpy of formation, $\mathrm{J} \mathrm{mol}^{-1}$ \\
\hline$\Delta S$ & Entropy of formation, $\mathrm{J} \mathrm{mol}^{-1} \mathrm{~K}^{-1}$ \\
\hline MW & Molecular weight, $\mathrm{kg} \mathrm{mol}^{-1}$ \\
\hline w & Metal hydride concentration, g MH/g alloy (\%) \\
\hline$\dot{m}$ & Mass flow rate, $\mathrm{kg} \mathrm{s}^{-1}$ \\
\hline UA & Overall heat transfer coefficient, $\mathrm{W} \mathrm{K}^{-1}$ \\
\hline$\dot{Q}$ & Heat transfer rate, $\mathrm{W}$ \\
\hline$\varepsilon$ & Heat exchanger effectiveness, adim \\
\hline NTU & Number of heat transfer units \\
\hline$\Phi$ & Weight factor in the heat transfer Eq. (33) \\
\hline $\mathrm{K}$ & Adjustment parameter in the kinetic Eq. (38) \\
\hline $\mathrm{P}$ & Hydrogen gas pressure, bar \\
\hline $\mathrm{m}_{\text {gas }}$ & Mass of gaseous hydrogen inside each reactor, $\mathrm{kg}$ \\
\hline $\mathrm{P}$ & Density, $\mathrm{kg} \mathrm{m}^{-3}$ \\
\hline $\mathrm{R}$ & Universal gas constant, $\mathrm{J} \mathrm{mol}^{-1} \mathrm{~K}^{-1}$ \\
\hline fs & Slope factor in Eq. (44) \\
\hline$\Omega$ & Area of the hydrogen connexion line, $\mathrm{m}^{2}$ \\
\hline$\Theta$ & Angle defining the slope of the P-C-T curves in the $\beta$ phase \\
\hline$\Gamma$ & Angle defining the slope of the P-C-T curves in the $\alpha+\beta$ phase \\
\hline$\lambda_{\text {eff }}$ & Effective thermal conductivity of the alloy, $\mathrm{W} \mathrm{m} \mathrm{m}^{-1} \mathrm{~K}^{-1}$ \\
\hline $\mathrm{D}$ & Diameter of the water tubes, $\mathrm{m}$ \\
\hline $\mathrm{H}$ & Convection coefficient from the water current, $\mathrm{W} \mathrm{m} \mathrm{m}^{-2} \mathrm{~K}^{-1}$ \\
\hline S & Average distance between the water tubes, $m$ \\
\hline $\mathrm{L}$ & Length of the water tubes, $m$ \\
\hline $\mathrm{n}_{\text {tubes }}$ & Number of water tubes (372) \\
\hline$\varphi$ & $\begin{array}{l}\text { Inclination of the P-C-T curves in the boundaries of the plateau } \\
\text { region, Eqs. }(45-46)\end{array}$ \\
\hline
\end{tabular}




\section{Subscripts}

A

$B$

Cold reaction bed

Hot reaction bed

$\mathrm{H}_{2}$

Hydrogen

$\mathrm{M}_{\mathrm{m}}$

Metallic mass of the water tubes

W

Water

Inlet to the reaction bed

Outlet to the reaction bed

$\mathrm{H}$

$\mathrm{M}$

C

$\mathrm{MH}$

eq

init

0

A

B

$\alpha+\beta$

mid

abs

des

int

ext

Hot temperature level

Medium temperature level

Cold temperature level

Metal hydride alloy

Equilibrium in the $\alpha+\beta$ phase region of the P-C-T curves

Initial conditions

Reference condition ( $\mathrm{P}_{0}=1$ bar $)$

Solid solution phase of hydrogen in the metal lattice

Solid solution phase of hydrogen in the metal hydride lattice $\alpha+\beta$ phase region in the $\mathrm{P}-\mathrm{C}-\mathrm{T}$ curves

Middle of the $\alpha+\beta$ phase region

Absorption (hydriding process)

Desorption (dehydriding process)

Internal

External 


\section{DESCRIPTION OF THE DYNAMIC MODEL}

\subsection{Introduction}

The behaviour of a coupled metal hydride system derives from the mutual influence of heat and mass transfer characteristics of each reactor and from the intrinsic thermo-physical properties of each metal alloy (kinetics, equilibrium pressures, hysteresis...). Each individual process can be considered to be ruled by proper differential equations and therefore a completely dynamic model is required to calculate the time evolution of variables such as the bed pressure, temperature, hydrogen concentration and hydrogen mass flow between the reactors.

The modelling of the static and dynamic sorption curves has been analysed thoroughly in Chapters 4 and 5. Thus, in the present chapter a particular attention will be paid on the heat transfer modelling, as well as on the modelling of hysteresis.

One important choice in the simulations is to define if a spatial model is required. As explained in Chapter 1, many different spatial models can be found in literature using $3 D, 2 D$ or $1 D$ models of metal hydride reactors $[11,12,15$ $17,19]$.

However, in this PhD work, the main objective of the model is to understand the overall reaction and to predict accurately the global performance of the MHCS under different operating conditions. Hence, it may not be necessary to develop a detailed model to account for the radial and axial temperature distribution inside the reactors.

Fig. 37 illustrates the axial temperature distribution during an absorption test in reactor $\mathrm{B} 3$ at 11.75 bar, with an inlet water temperature of $25^{\circ} \mathrm{C}$ and a water flow rate of $5 \mathrm{l} / \mathrm{min}$. The simulations were done in former work at IKE with the CFX software, and they provide interesting information on the temperature distribution inside the reactors. Nevertheless, the CFX results should be 
analyzed with caution because they were not validated experimentally. Fig. 37 shows that the radial temperature distribution is practically uniform (temperatures between 320 and $323 \mathrm{~K}$ ). In the coupled system, the hydrogen connexion valve is always open and hence the pressure gradient is not so high, this is to say that the hydrogen transfer is even smaller than in Fig. 37. Thus, in this particular MHCS, it can be assumed that on any horizontal cut, the radial temperature distribution is practically uniform, and that a radial temperature model is not required. In other MHCSs from literature with less water tubes per $\mathrm{g}$ of metal hydride, this hypothesis would not be reasonable $[11,16,17,91]$ as the performance of the latter systems are often limited by the heat transfer.

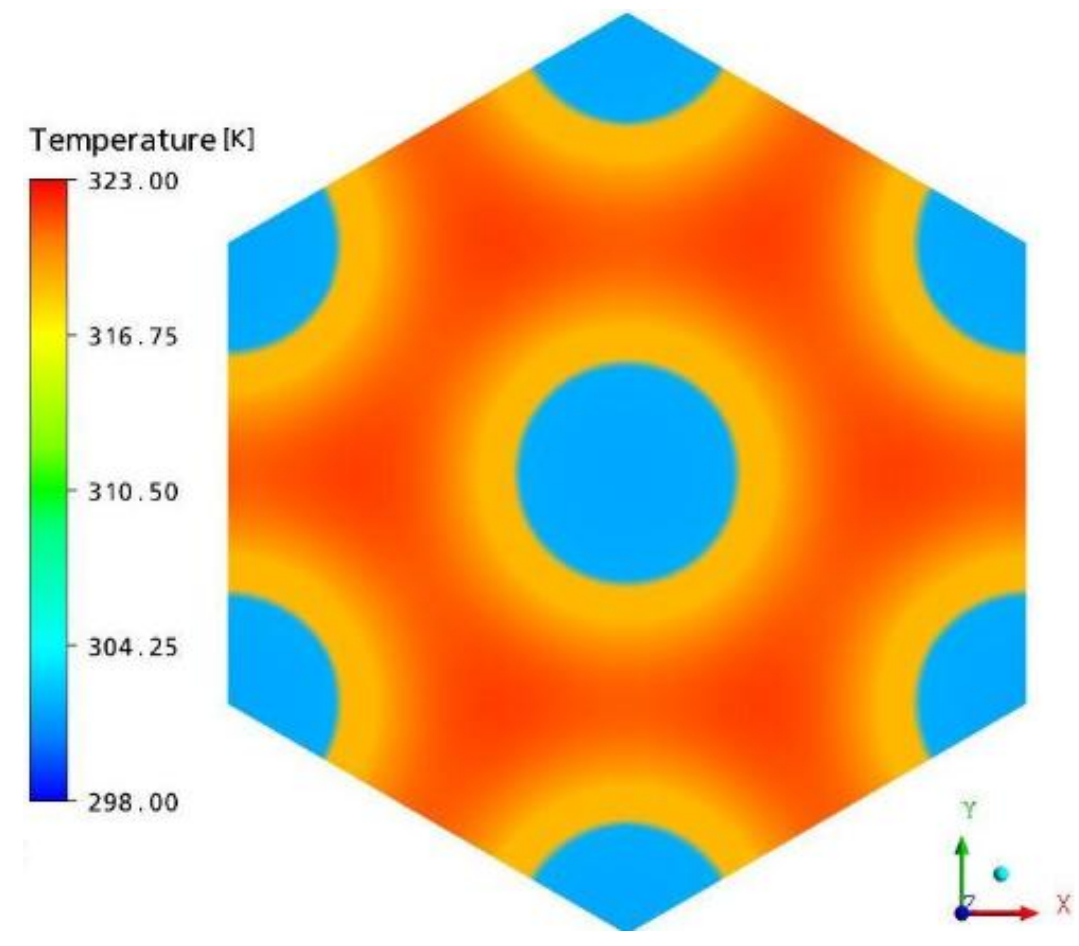

Fig. 37. CFD Radial temperature distribution of one reactor during absorption $(z=64 \mathrm{~mm})$

Although the temperatures are rather uniform on a radial cut, an axial cut would reveal a higher temperature gradient. This can be inferred from the experimental measurements, which show that there is a temperature difference between the inlet and outlet water temperature of $\pm 4^{\circ} \mathrm{C}$. Hence, an innovative approach has been applied for the modelling of the heat transfer in order to account for the temperature variations of the water flowing along the reactor. 
The mean temperature of the metal hydride is nevertheless supposed to be uniform.

\subsection{Governing equations}

Fig. 38 shows a simplified scheme of the reactor layout. The water mass flow rate and the inlet temperatures are inputs for the model, which simulates the behaviour of the system and predicts the resulting water outlet temperatures.

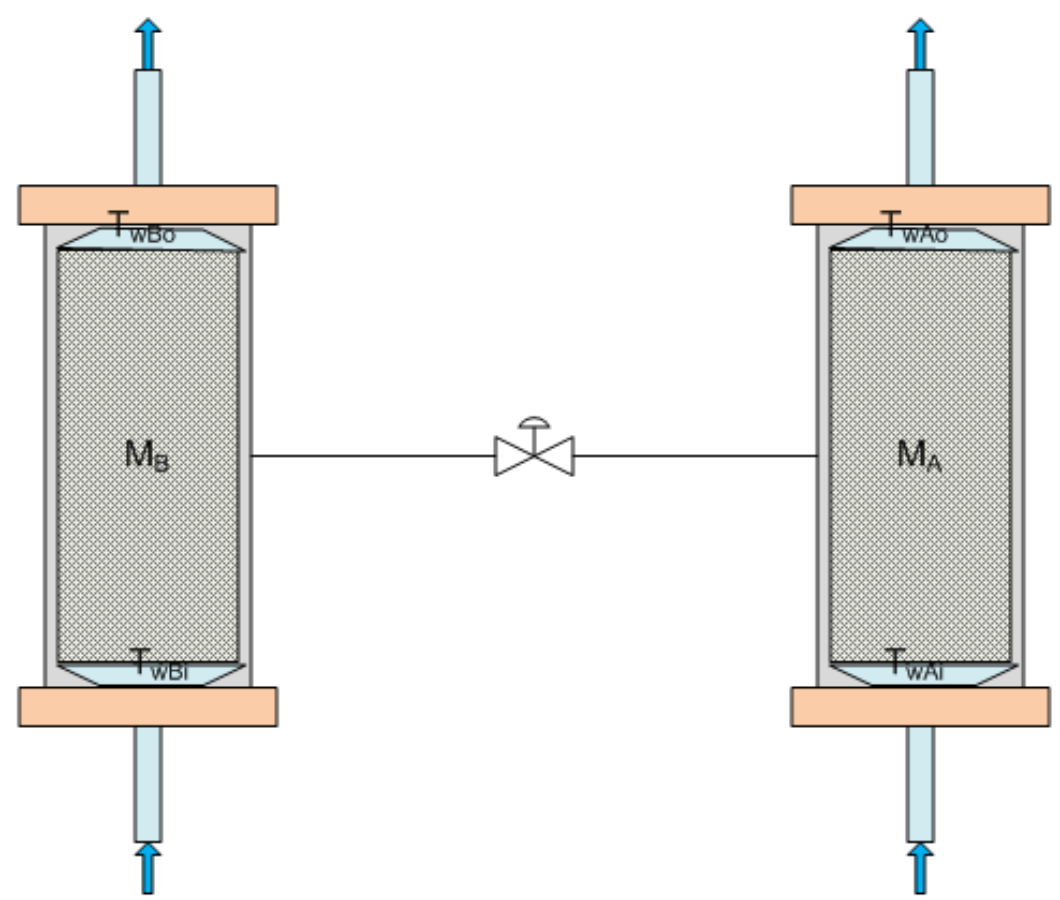

Fig. 38. Simplified scheme of the reactors

The model which has been developed is based on a set of differential equations which describe the coupled heat and mass transfer reactions which take place in the MHCS. The state equations are based on the following hypotheses:

- The tube bundle configuration (372 tubes) enables a good internal heat transfer and thus it has been assumed that the metal hydride lattice can be modelled with a quasi-uniform temperature model. 


\section{Chapter 6 - DESCRIPTION OF THE DYNAMIC MODEL}

- Hydrogen enters the reaction bed through the outer filtered tube. It has been considered that the diffusivity of hydrogen through the filter and the powder does not limit the reaction.

- Due to the low gas velocity and moderate temperature, the heat transfer by convection and radiation within the powder bulk can be neglected $[2,18,24]$.

- Hydrogen behaves as an ideal gas.

- The intrinsic reaction kinetics can be modelled with a non-equilibrium model assuming the difference between the static and actual pressure as the driving force of the sorption process [90].

In order to calculate the hydrogen sorption rates, it is necessary to evaluate the equilibrium pressures. This aspect requires a specific attention (subsection 6.2.2), as the experimental system reaches the boundaries of the plateau region. Additionally, a model has been developed in subsection 6.2 .3 to account for the transitions between absorption and desorption [2].

6.2.1. Heat and mass transfer equations

\section{Heat transfer through the metal hydride powder}

Eq. (30) evaluates the variation of internal energy in the metal hydride powder, and can be understood with the help of Fig. 39.

$$
C p_{A} \cdot M_{A} \cdot \frac{d T_{A}}{d t}=\frac{\Delta H_{A}}{M W_{H_{2}}} \cdot \frac{M_{A}}{100} \cdot \frac{d w_{A}}{d t}+U A_{M H} \cdot\left(T_{m m A}-T_{A}\right)
$$

The first term on the right of Eq. (30) takes into account the enthalpy of the sorption reaction. The second term is the heat which is exchanged between the metal hydride and the metallic wall of the water tubes. This term involves the calculation of the overall heat transfer coefficient $U A_{M H}$ within the metal hydride powder. 


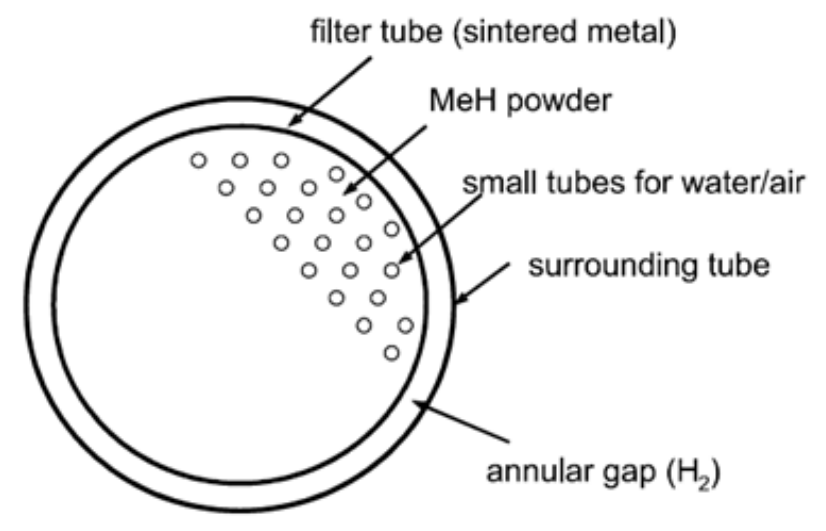

Fig. 39. Schematic design of the reaction beds

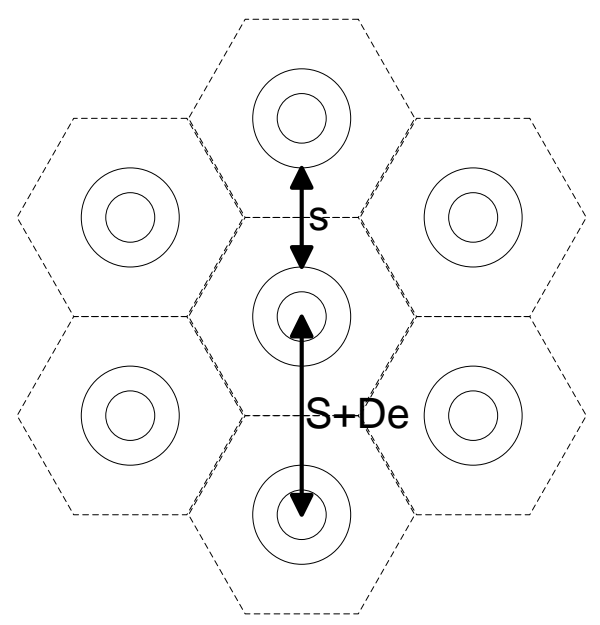

Fig. 40. Heat transfer within the metal hydride powder

As has been explained in Chapter 3, the heat transfer within the metal hydride powder derives from the effective thermal conductivity. Given the tube distribution which is represented in Fig. 40, the overall heat transfer coefficient $\cup A_{h}$ may be calculated with Eq. (31):

$$
U A_{M H}=\frac{2 \cdot \pi \cdot \lambda_{M H} \cdot L \cdot n_{\text {tubes }}}{\ln \left(\frac{D_{e}+S}{D_{e}}\right)}
$$

It has been assumed that the effect of each water tube is delimited by the hexagonal dotted lines of Fig. 40. In this model, the thermal resistance within the metallic structure of the tube has been neglected due to its high thermal conductivity and low thickness. 
Fig. 41 shows the effective thermal conductivity of an $A_{5}$ alloy with a similar content to the alloy of reactor B3. For pressures beyond 10 bar, the effective thermal conductivity is practically constant.

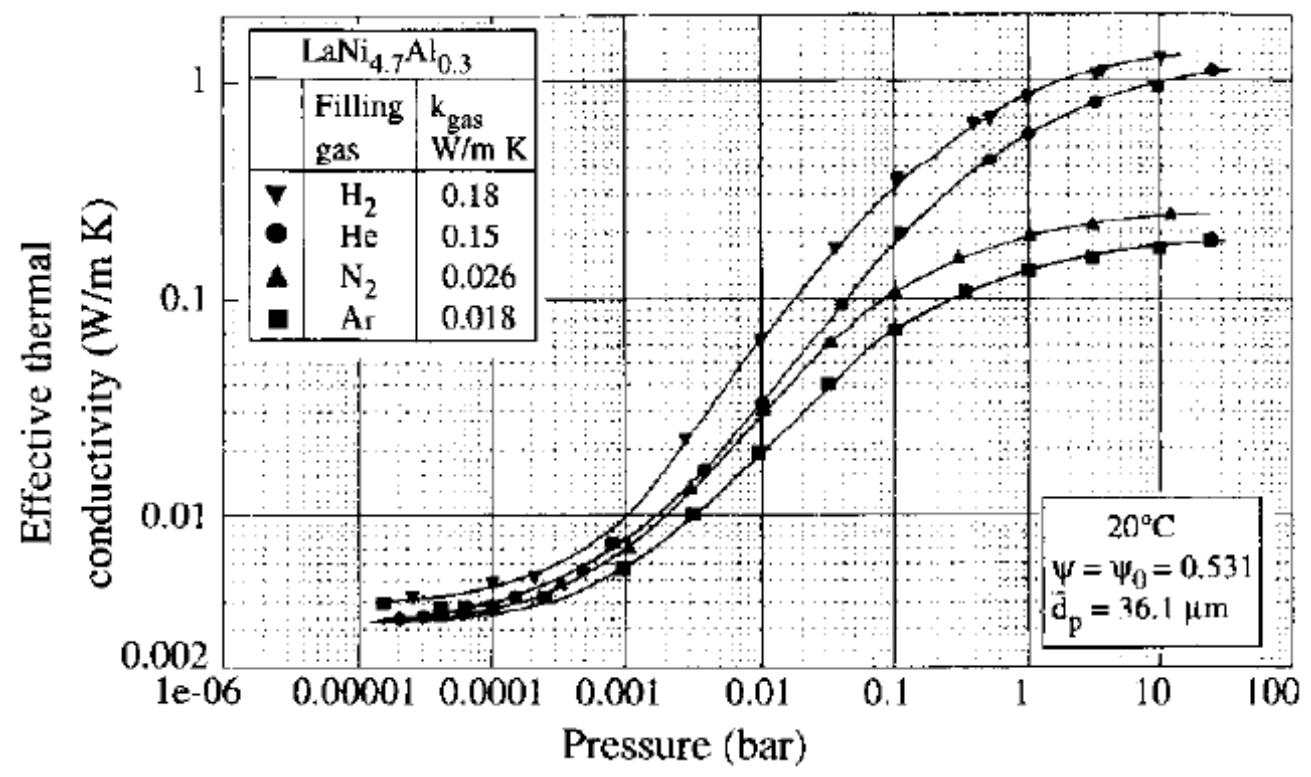

Fig. 41. Effective termal conductivity of $\mathrm{LaNi}_{4.7} \mathrm{Al}_{0.3}[54]$

The MHCS works not only under variable pressures, but also under variable temperatures. The operating conditions of reactor $\mathrm{A}\left(10^{\circ} \mathrm{C}-10\right.$ bar to $40^{\circ} \mathrm{C}-50$ bar) lead to fluctuations of $\pm 5.2 \%$ in the effective thermal conductivity, using the Bauer-Schlunder model [92] described in Chapter 3. In bed B, the operating conditions $\left(40^{\circ} \mathrm{C}-10\right.$ bar to $130^{\circ} \mathrm{C}-50$ bar) provoke oscillations in the effective thermal conductivity of $\pm 8.6 \%$. Additionally, there is an important uncertainty around the value of the conductivity of the solid metal lattice for each alloy. Thus, in the final model a constant effective thermal conductivity has been applied (1.35 W/(m K) for $\mathrm{A}, 1.46 \mathrm{~W} /(\mathrm{m} \mathrm{K})$ for $\mathrm{B})$.

\section{Heat transfer between the water circuit and the tubes}

As indicated in Fig. 39, the metallic tubes are in contact with both the metal hydride powder (external side) and the water (internal side). Eq. (32) calculates 
the variation of energy of the metallic tubes by means of an energy balance which includes the heat transfer with the metal hydride powder (first term on the right) and the water circuit (second term on the right).

$$
C p_{m m} \cdot M_{m m} \cdot \frac{d T_{m m A}}{d t}=-U A_{M H} \cdot\left(T_{m A}-T_{A}\right)+\dot{Q}_{w A}+h_{a m b} \cdot S \cdot\left(T_{a m b}-T_{m m A}\right)
$$

Where $h_{a m b}$ is the heat transfer coefficient between the metallic mass and the ambient, and includes both natural convection and radiation. $S$ is the surface of each reactor in contact with the ambient.

In the upper and lower part of the reactors, the 372 water tubes are welded together. Thus, they are all in direct contact. Additionally, they are also connected to the filtered tube and to the outer tube. In order to model the entire heat transfer mechanisms through the metal mass a far more complex model would be required. Hence, the model focuses only in the bed itself, including the metal mass of the tubes, their welding and the outer tube.

The third term in Eq. (32) does not have a significant weight, but it does account for the small heat losses towards the ambient, particularly for the hot reaction bed $B$ during the regeneration phase.

On the other side of the water tubes, the heat which is transferred to the water circuit can be estimated by the following equation.

$$
\dot{Q}_{w A}=\varepsilon_{A} \cdot \dot{m}_{w A} \cdot C_{p, w} \cdot\left((1-\phi) \cdot\left(T_{w A i}-T_{m m A}\right)+\phi \cdot\left(\frac{T_{w A d}-T_{m m A}}{1-\varepsilon_{A}}\right)\right)
$$

As the model is zero dimensional and includes no spatial variations of temperature, Eq. (33) is used to account for the variations of temperature of the water along the metal tubes [2]. These variations are represented in Eq. (33) by $T_{\text {WAi }}$ and $T_{\text {wAo. }}$. Under stationary conditions, this equation is consistent with the classic effectiveness Eq. (34).

$$
\dot{Q}_{w A}=\varepsilon_{A} \cdot \dot{m}_{w A} \cdot C_{p, w} \cdot\left(T_{w A i}-T_{m m A}\right)
$$


The parameter $\Phi$ represents the weight in the heat transfer equation of the temperature difference between the inlet and outlet water temperatures and the temperature of the metallic tubes. It has been included to adjust the heat transfer equation for unsteady processes. A value of 0.2 has provided a good agreement with the experimental data.

The effectiveness is calculated by means of Eq. (35), assuming that the water is in contact with a uniform temperature for the metallic tubes.

$$
\varepsilon=1-\exp (-N T U), \quad \quad N T U=\frac{U A_{w}}{\left(\dot{m} \cdot C_{p}\right)_{\min }}
$$

The overall heat transfer coefficient of the heat transfer between the interior wall of the tubes and the water current is calculated by means of Eq. (36):

$$
U A_{w}=\pi \cdot D_{i} \cdot L \cdot h_{\text {int }} \cdot n_{\text {tubes }}
$$

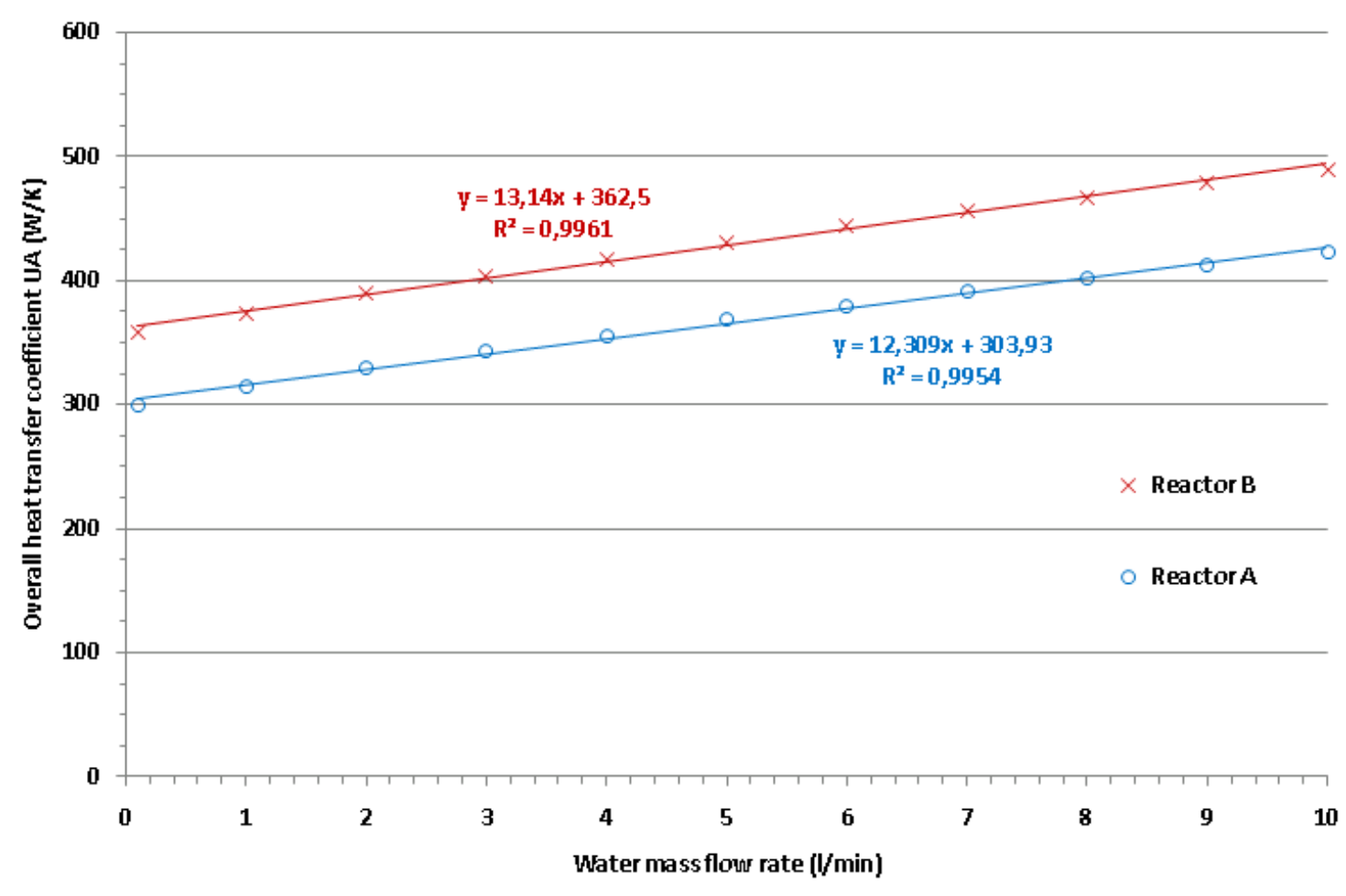

Fig. 42. Overall heat transfer coefficient UAw of each reactor 
Eq. (36) involves the calculation of the internal convection coefficient $h_{\text {int }}$, which is a function of the water mass flow rate. This coefficient has been obtained with the A.F. Mills programs for convection. Fig. 42 shows the overall heat transfer coefficients $U A_{w}$ which have been obtained for different mass flow rates. $A$ linear regression has been applied in order to obtain a simple expression of $\cup A_{w}$ to be used in the overall model.

Reactor B works at higher temperatures than bed $A$ and hence it presents a slightly higher value of the internal convection coefficient $h_{\text {int. }}$. In order to avoid an additional temperature dependence, a mean temperature of $\left(T_{h}+T_{m}\right) / 2$ and $\left(T_{h}+T_{m}\right) / 2$ has been assumed in reactors $B$ and $A$ respectively. The effect of the temperature is nevertheless negligible with respect to the overall accuracy of the dynamic model.

Finally, Eq. (37) is used to calculate the variation of temperature at the outlet collector. Under stationary conditions, the first term on the right (variation of water enthalpy) is equal to the last term (heat transferred to the metallic tubes). However, such conditions are never achieved in the MHCS, whose behaviour is completely dynamic.

$$
C_{p, w} \cdot M_{w} \cdot \frac{d T_{w A o}}{d t}=\dot{m}_{w A} \cdot C_{p, w} \cdot\left(T_{w A i}-T_{w A o}\right)-\dot{Q}_{w A}
$$

\section{Absorption/Desorption kinetics}

Initially, a model was tested assuming that the reactor pressures are equal to the equilibrium pressures. With this model it was not possible to reproduce the experimental behaviour of the system, and therefore a non equilibrium model was developed.

Eq. (38) defines the kinetic behaviour of the reaction beds, and it has been validated in Chapter 5 . The difference between the instantaneous and equilibrium pressures is the driving potential for the sorption reactions, as also indicated by Park and Lee [82]. 


$$
\frac{d w_{A}}{d t}=K_{A} \cdot e^{-\frac{E_{a, A}}{R \cdot T_{A}}} \cdot \frac{P_{A}-P_{e q, A}\left(T_{A}, w_{A}\right)}{P_{e q, A}\left(T_{A}, w_{A, \alpha+\beta \rightarrow \beta}\right)-P_{e q, A}\left(T_{A}, w_{A, \alpha \rightarrow \alpha+\beta}\right)}
$$

\section{Hydrogen mass balance}

$$
\frac{d m_{g a s, A}}{d t}=-\frac{M_{A}}{100} \cdot \frac{d w_{A}}{d t}+\dot{m}_{A i}-\dot{m}_{A o}
$$

Eq. (39) derives from a mass balance of the hydrogen gas phase in each reactor. The variation of the mass of gaseous hydrogen in the reactor is calculated by means of a mass balance which includes both the amount of hydrogen which is absorbed or desorbed from the metal powder and the hydrogen instantaneous flow between the two reactors. In Eq. (39), it has been assumed that the hydrogen diffusion through the metal and metal hydride interface is negligible in comparison to the intrinsic reaction kinetics.

\section{Ideal gas equation}

$$
\frac{d P_{A}}{d t}=P_{A} \cdot\left(\frac{d m_{g a s, A}}{d t} \cdot \frac{1}{m_{g a s, A}}+\frac{d T_{A}}{d t} \cdot \frac{1}{T_{A}}\right)
$$

The pressure of the gaseous hydrogen responds to the ideal gas equation, which has been written in Eq. (40) as a differential equation. The pressure evolution is a function of the mass and temperature variations. The temperature of the gas is assumed to be equal to the instantaneous temperature of the reactor. 


\section{Hydrogen mass flow}

The mass flow rate of gaseous hydrogen which is exchanged between the reactors is calculated by means of the set of Eqs. (41) to (43).

$$
\begin{aligned}
& \dot{m}_{A i}\left\{\begin{array}{lll}
=\Omega \cdot \sqrt{2 \cdot \rho_{H 2, A}\left(T_{A}\right) \cdot\left(P_{B}-P_{A}\right)} & \text { if } & P_{B} \geq P_{A} \\
=0 & \text { if } & P_{B}<P_{A}
\end{array}\right. \\
& \dot{m}_{B i}\left\{\begin{array}{l}
=0 \quad \text { if } \quad P_{A}<P_{B} \\
=\Omega \cdot \sqrt{2 \cdot \rho_{H 2, A}\left(T_{A}\right) \cdot\left(P_{A}-P_{B}\right)} \text { if } \quad P_{A} \geq P_{B}
\end{array}\right. \\
& \dot{m}_{B i}=\dot{m}_{A o}, \quad \dot{m}_{B o}=\dot{m}_{A i}
\end{aligned}
$$

\subsubsection{P-C-T equilibrium correlation}

Although different detailed P-C-T models have been presented in chapter 4, in the overall model of the MHCS, it is important to calculate the P-C-T equilibrium correlations using simple and robust expressions.

As discussed in Chapter 4 , in the $\alpha+\beta$ phase, the P-C-T relationship between pressure $(P)$, hydrogen concentration $(w)$ and temperature $(T)$ of alloys A3-B3 can be modelled accurately with the modified Van't Hoff Eq. (44). As in previous studies [2,93], this equation includes a last term which accounts for the nonnegligible slope of the two phase region in the tested materials.

$$
\ln P_{e q}=-\frac{\Delta H}{R \cdot T}+\frac{\Delta S}{R}+f_{S} \cdot\left(w-w_{\text {mid }}\right)
$$

For more information on the parameters of Eq. (44), the reader may refer to Chapter 4. 
Although the MHCS should ideally work in the plateau region, in practical terms this is hardly achievable. Thereby, a simple expression has been used to account for the tails of the plateau in the boundaries of the $\alpha$ and $\beta$ region.

For $w<w_{\alpha \rightarrow \alpha+\beta}$, Eq. (45) has been used to account for the pressure decrease when the desorbing reactor reaches the left limit of the plateau:

$$
P_{e q}=P_{e q}\left(T, w_{\alpha \rightarrow \alpha+\beta}\right) \cdot\left(1-\varphi_{\alpha \rightarrow \alpha+\beta} \cdot\left(w_{\alpha \rightarrow \alpha+\beta}-w\right)^{2}\right)
$$

For $w>_{\alpha+\beta \rightarrow \beta}$, the pressure increase which is observed when the hydriding reactor reaches the right of its plateau has been calculated by means of Eq. (46):

$$
P_{e q}=P_{e q}\left(T, w_{\alpha+\beta \rightarrow \beta}\right) \cdot\left(1+\varphi_{\alpha+\beta \rightarrow \beta} \cdot\left(w-w_{\alpha+\beta \rightarrow \beta}\right)^{2}\right)
$$

In the previous equations, $P_{e q}\left(T, w_{\alpha \rightarrow \alpha+\beta}\right)$ and $P_{e q}\left(T, w_{\alpha+\beta \rightarrow \beta}\right)$ are the equilibrium pressures in the boundaries of the plateau, and are calculated by means of the modified Van't Hoff Eq. (44).

Globally, the use of Eqs. $(44,45,46)$ provides the results which are shown in Fig. 43. Although these equations do not reproduce the behaviour in the whole P-C-T region, they do reproduce the smooth transitions in the boundaries of the plateau. This is very important, because in the MHCS, the alloys do not operate beyond this limit. Once one of the alloys reaches the boundaries of its plateau, there is no more pressure difference available to continue with the sorption reaction. This aspect is clearly seen in the validation of the model which is given in Chapter 7. 
Chapter 6 - DESCRIPTION OF THE DYNAMIC MODEL

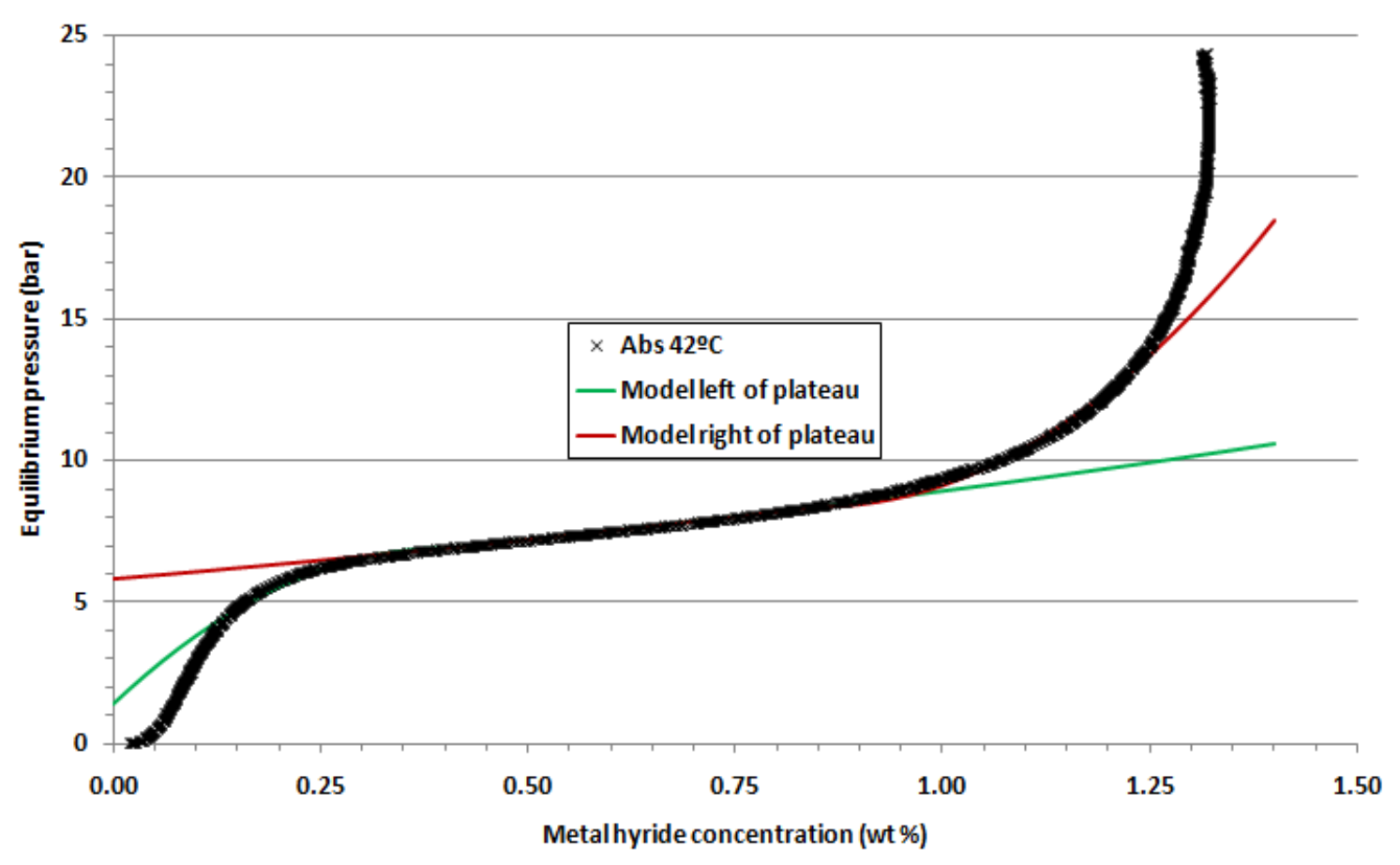

Fig. 43. Overall calculation of the equilibrium pressure.

Example: alloy B3 at $42^{\circ} \mathrm{C}$

6.2.3. Hysteresis

As can be deduced from the equilibrium P-C-T curves of Chapter 4, the absorption pressures in the tested materials differ significantly from the desorption pressures. During the cooling phase, desorption takes place in bed A, while absorption occurs during the regeneration phase. Therefore, a transition process [2] is required to model the switching between absorption and desorption.

During absorption, the gas pressure is higher than the equilibrium pressure, and during desorption, the gas pressure is lower than the equilibrium pressure. Whenever this pressure difference changes sign, the transition phase starts.

For instance, when changing from desorption to absorption, Eq. (47) is used to account for the smooth transition of the alloy properties. 


$$
P_{e q}=P_{e q, d e s}(T, w)+\left(P_{e q, a b s}(T, w)-P_{e q, d e s}(T, w)\right) \cdot x^{2}
$$

Where

$$
x=\frac{t-t_{\text {init }}}{\Delta t_{\text {transition }}}
$$

$\Delta t$ is the duration of the transition phase. The initial value of $x$ is $0\left(P_{\text {eq }}=P_{\text {eq,des }}\right)$ and its final value is $1\left(P_{\text {eq }}=P_{\text {eq, abs }}\right)$. Empirically, it has been observed that $\Delta t \approx 9$ $s$ are required for both of the reactors to switch from absorption to desorption pressures and viceversa.

Similarly, when changing from absorption to desorption, the following equation is used:

$$
P_{e q}=P_{e q, a b s}(T, w)-\left(P_{e q, a b s}(T, w)-P_{e q, d e s}(T, w)\right) \cdot x^{2}
$$

The use of Eqs. (47) and (49) only has an effect on the kinetic equation, and hence on the predicted hydrogen exchange rate between the reactors. These transitions make the model more robust since there are no abrupt changes in the equilibrium pressure, and hence on the exchange rate of hydrogen.

This approach, which accounts for the smooth changes in the properties of the alloys, has also been applied for the change of enthalpy and of the parameters of the kinetic equation (38).

Fig. 44 illustrates the results which are achieved when modelling the smooth transitions. $f A$ and $f B$ reveal the phase which is being followed in each alloy; 0 for the cooling phase, 1 for the transition towards the regeneration phase, 2 for the regeneration phase, and 3 for the transition towards the cooling phase.

During the cooling phase, the condition $\mathrm{P}_{\mathrm{A}, \mathrm{eq}}>\mathrm{P}_{\text {gas }}>\mathrm{P}_{\mathrm{B}, \text { eq }}$ is fulfilled. However, by the end of this phase, bed $B$ is heated up to the regeneration temperature $T_{h}$. This implies a significant increase of the equilibrium pressure which helps achieve the condition $P_{B, e q}>P_{\text {gas }}$. The condition $P_{\text {gas }}>P_{A, e q}$ is fulfilled slightly later 
because this can only be achieved once the gas pressure has increased substantially due to the desorption of alloy $B$.

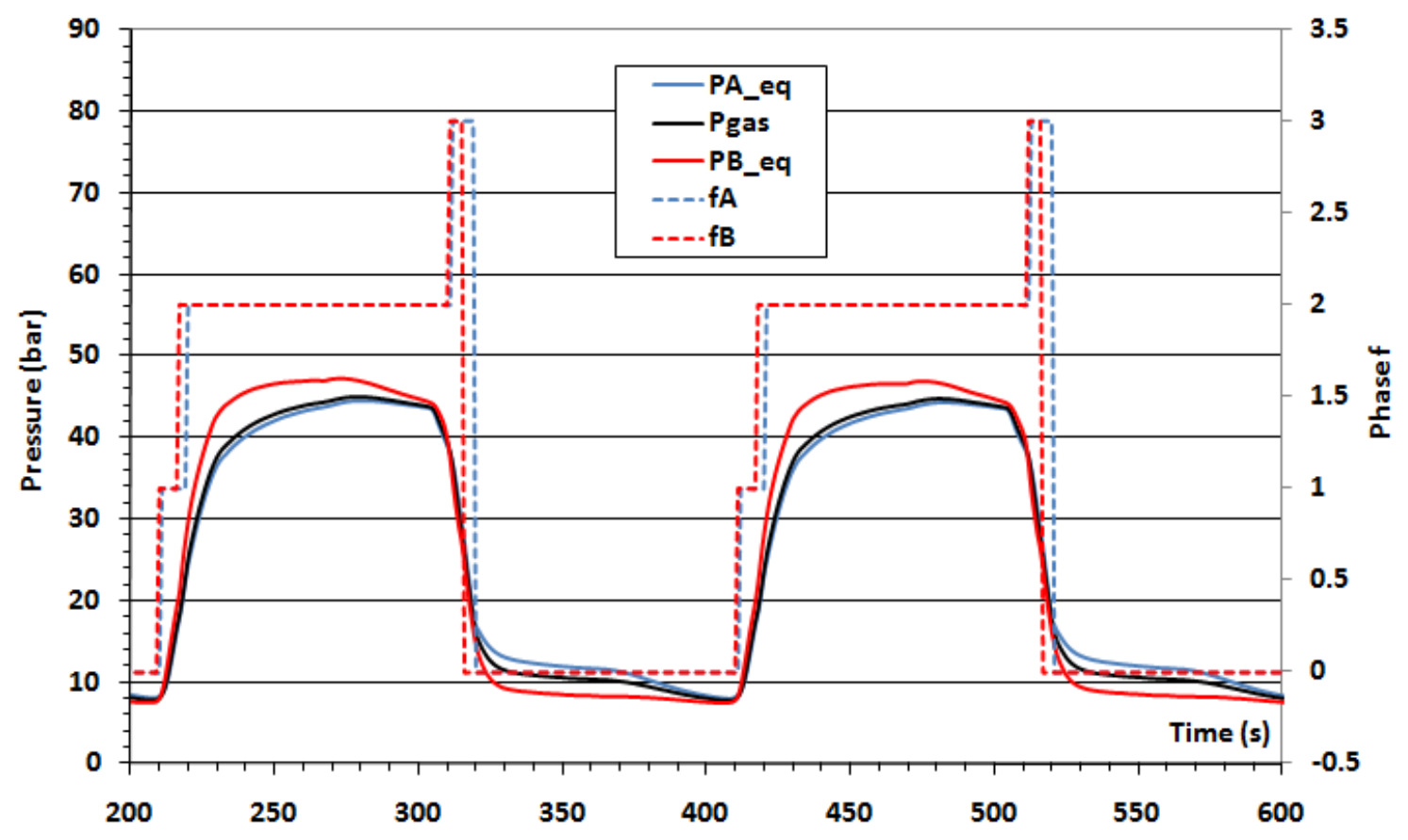

Fig. 44. Example: Modelling of the transitions between absorption and desorption

At the end of the regeneration phase, the change of temperature of bed $B$ changes the condition $\mathrm{P}_{\text {eq, } \mathrm{B}}>\mathrm{P}_{\text {gas }}$ to $\mathrm{P}_{\text {eq, } \mathrm{B}}<\mathrm{P}_{\text {gas. }}$. The transition phase starts and is faster than in bed $A$ because the temperature decrease helps achieve such pressure differences. Bed $A$ finishes the transition slightly later, once the condition $P_{\text {eq, } A}>P_{\text {gas }}>P_{\text {eq, } B}$ is fulfilled.

\subsection{Solver}

The set of Eqs. (30) to (49) forms a system of DAEs (differential and algebraic equations). The system is stiff due to the employment of the dynamic gas equation, which produces changes of sign according to the hydrogen flow direction. The differential equations have been implemented in MATLAB as an S-Function and solved dynamically in SIMULINK with the solver ode23tb (stiff/TR-BDF2). 
Table 13 summarises the input data which are required by the model. Class A inputs define the initial conditions (pressure, temperature...) of the system.

\section{CLASS A}

Initial conditions: $w_{A 0} ; w_{B 0} ; T_{A 0} ; T_{B 0} ; P_{A 0} ; P_{B 0}$

\section{CLASS B}

Time dependent inputs: $m_{w A} ; m_{w B} ; T_{w A i n} ; T_{w B i n}$

\section{CLASS C}

\section{Parameters}

C1) Metal hydride powder properties: $C_{p} ; \Delta H ; \Delta S ; w_{\text {mid }} ; f s ; M$

C2) Reactor configuration: $S ; M_{m n} ; U A_{M H} ; U A_{w} ; M_{w}$

\section{Table 13. Classification of the input data}

In order to make a direct comparison with the experimental results, the model involves the time dependent inputs which are indicated as class $B$. These inputs are coincident with the experimental data (water inlet temperature and mass flow rate feeding each reaction bed).

The parameters of the model are indicated in class C. Two groups of parameters may be distinguished: firstly, intrinsic thermo-physical properties of the metal hydride powders (class $\mathrm{C} 1$ ), such as the specific heat, enthalpy of reaction, P-C-T equilibrium correlation, effective thermal conductivity and the mass of powder in each reactor; secondly, the model requires values for class C2 parameters, which are in direct relation with the reactor physical design (area of the hydrogen connexion line, free volume of gas inside each reactor, metallic mass, etc...). 



\section{Chapter 7:}

\section{Validation of the dynamic model}




\section{Nomenclature}

\begin{tabular}{|c|c|}
\hline $\mathrm{T}$ & Temperature, ${ }^{\circ} \mathrm{C}$ \\
\hline $\mathrm{P}$ & Pressure, bar \\
\hline$\Delta \mathrm{t}$ & Cycle duration (s) \\
\hline COP & Coefficient of performance, $C O P=\overline{\dot{Q}_{c}} / \overline{Q_{h}}$ \\
\hline W & Metal hydride concentration, g MH/g alloy (\%) \\
\hline$\dot{Q}$ & Heat transfer rate, $\mathrm{W}$ \\
\hline \multicolumn{2}{|c|}{ Subscripts } \\
\hline$A$ & Cold reaction bed \\
\hline $\mathrm{B}$ & Hot reaction bed \\
\hline $\mathrm{H}$ & Hot temperature level \\
\hline M & Medium temperature level \\
\hline C & Cold temperature level \\
\hline Reg & Regeneration phase \\
\hline Cool & Cooling phase \\
\hline Cycle & Full cycle (complete cooling and regeneration phase) \\
\hline W & Water \\
\hline $\mathrm{i}$ & Inlet to the reaction bed \\
\hline 0 & Outlet to the reaction bed \\
\hline$\alpha$ & Solid solution phase of hydrogen in the metal lattice \\
\hline$\beta$ & Solid solution phase of hydrogen in the metal hydride lattice \\
\hline$\alpha+\beta$ & $\alpha+\beta$ phase region in the $P-C-T$ curves \\
\hline mid & Middle of the $\alpha+\beta$ phase region \\
\hline abs & Absorption (hydriding process) \\
\hline des & Desorption (dehydriding process) \\
\hline eq & Equilibrium in the $\alpha+\beta$ phase region of the P-C-T curves \\
\hline $\mathrm{MH}$ & Metal hydride alloy \\
\hline
\end{tabular}




\section{VALIDATION OF THE DYNAMIC MODEL}

\subsection{Introduction}

The dynamic model which has been presented in Chapter 6 has been validated with many different experimental tests done at IKE. Chapter 7 shows the adjustment of the dynamic model with different tests where both reactors $A$ and $B$ are coupled.

Table 14. summarises the experimental tests which have been compared with the dynamic model.

\begin{tabular}{|c|c|c|c|c|c|c|c|c|c|c|}
\hline Test & Type & Alloys & $\begin{array}{c}\text { Fluid } \\
\text { in A }\end{array}$ & $\begin{array}{c}\text { Fluid } \\
\text { in B }\end{array}$ & $\begin{array}{c}\mathrm{T}_{\mathrm{m}} \\
\left({ }^{\circ} \mathrm{C}\right)\end{array}$ & $\begin{array}{c}\mathrm{T}_{\mathrm{h}} \\
\left({ }^{\circ} \mathrm{C}\right)\end{array}$ & $\begin{array}{c}\mathrm{P}_{\text {reg }} \\
(\mathrm{bar})\end{array}$ & $\begin{array}{c}\mathrm{P}_{\text {cool }} \\
(\text { bar })\end{array}$ & $\begin{array}{c}\mathrm{T}_{\mathrm{c}} \\
\left({ }^{\circ} \mathrm{C}\right)\end{array}$ & $\Delta \mathrm{t}_{\text {cycle }}(\mathrm{s})$ \\
\hline 1 & Cycles & A1-B1 & Air & Water & 32 & 90 & 6.5 & 2 & 32 & 720 \\
\hline 2 & Cycles & A2-B2 & Air & Water & 36 & 130 & 50 & 10 & 30 & 612 \\
\hline 3 & Cycles & A2-B2 & Water & Water & 36 & 130 & 47 & 10 & 16 & 240 \\
\hline 4 & Cycles & A2-B2 & Water & Water & 33 & 130 & 48 & 10 & 16 & 300 \\
\hline 5 & Cycles & A3-B3 & Water & Water & 29 & 130 & 48 & 10 & 18 & 200 \\
\hline 6 & Cycles & A3-B3 & Water & Water & 28 & 100 & 33 & 8 & 15 & 140 \\
\hline 7 & Cycles & A3-B3 & Water & Water & 35 & 130 & 48 & 10 & 18 & 200 \\
\hline 8 & $\begin{array}{c}\text { Maximum } \\
\text { cooling } \\
\text { power } \\
\text { tests }\end{array}$ & A3-B3 & Water & Water & \multicolumn{1}{|c|}{$\begin{array}{c}\text { A initially full at } 26 \text { bar, } \\
\text { B initially empty at } 4 \text { bar, } \mathrm{T}_{\text {wB,in }, \text { in }} \approx 14^{\circ} \mathrm{C}\end{array}$} \\
\hline
\end{tabular}

Table 14. Experimental tests which have been validated with the model

The tests which have been analyzed more thoroughly are the cooling cycles, which involve consecutive regeneration and cooling phases. The last coupled pair of reactors A3-B3 has been studied in depth for cycle tests and maximum cooling power tests. In the latter tests ( $\mathrm{nr} 8$ ), hydrogen only flows in one direction $(A$ to $B$ ) and thus the reaction is slightly easier to analyze. Reactor $A$ is initially full at 26 bar, whereas reactor $B$ is initially empty at 4 bar. This pressure difference leads to a very high hydrogen exchange rate once the hydrogen valve opens. This pressure difference is higher than in the cycle tests where the valve is always open. Hence, these tests indicate the maximum cooling power which can be achieved using the coupled pair of alloys A3-B3. 


\section{Chapter 7 - VALIDATION OF THE DYNAMIC MODEL}

During the TOPMACS project, the cycle tests have been realised using different fluids as heat transfer. In the first coupled reactors (A1-B1), air was initially used in bed $A$ in order to have a direct cooling. Starting from the next coupled reactors (A2-B2) the air heat transfer was changed to water and hence A2-B2 and A3-B3 were tested with indirect cooling.

The model has been validated not only for different alloys, but also for different operating temperatures, such as regeneration temperatures ranging from $90^{\circ} \mathrm{C}$ to $130^{\circ} \mathrm{C}$.

The variables which have been compared with the measurements are the pressure, the outlet temperature of the water which flows through the reactors and the hydrogen exchange rate.

For more clarity, in this chapter only the most relevant results are given for the first two coupled reactors (A1-B1 and A2-B2). The A3-B3 system is nevertheless analyzed in-depth for both the maximum cooling power tests and the dynamic cooling tests. The model results agree accurately with the experimental measurements, hereby providing an accurate tool to carry out the optimization study which is detailed in Chapter 8. 


\subsection{Validation of the model with experimental tests}

\subsubsection{Reactors A1-B1}

The cycle tests of A1-B1 (test 1 in Table 14.) were carried out under temperatures of $T_{h}=90^{\circ} \mathrm{C}, T_{m}=T_{c}=32^{\circ} \mathrm{C}$. These coupled pair of reactors were used in the first set-up of the TOPMACS project. The main drawback of this first pair of reactors, besides the low cooling capacity, was that the P-C-T properties of A1-B1 could not produce cooling under low temperatures $T_{c}$.

It should be highlighted that the alloy A1 was installed in the reactor around 1985. Since then, many different tests have been carried out in the laboratory and the actual properties of the alloy can be different to the equilibrium P-C-T curves presented in Chapter 4 due to the cycling degradation of the alloy.

Hence, the results of A1-B1 should be analyzed with caution. Fig. 45 and Fig. 46 show a comparison between the simulation results and the measurement data for dynamic cooling cycles. The tests were carried out during $1 \mathrm{~h} 20 \mathrm{~min}$, but for more clarity only the last 5 cycles have been represented.

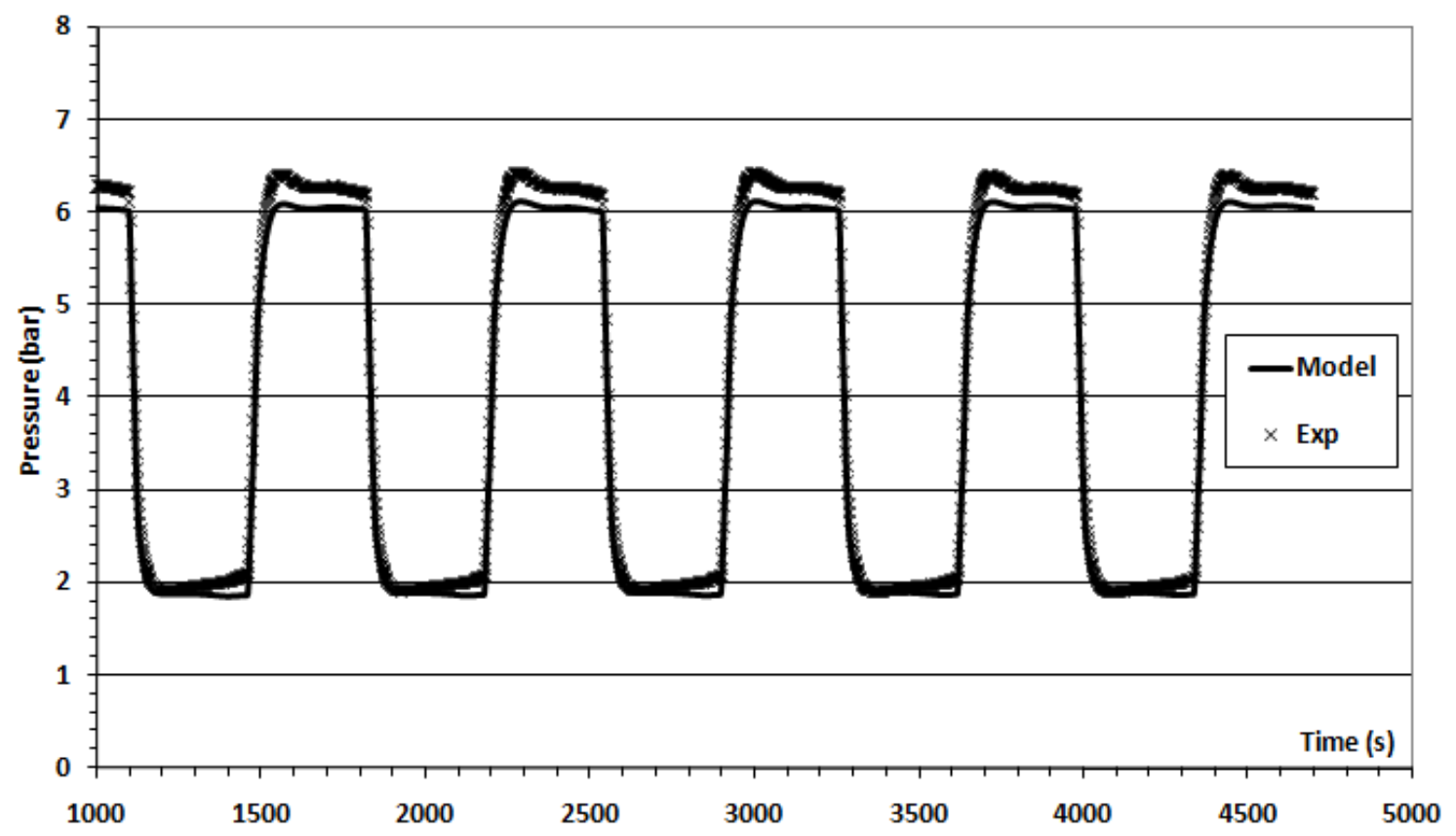

Fig. 45. Bed pressure vs time (test 1 ) 


\section{Chapter 7 - VALIDATION OF THE DYNAMIC MODEL}

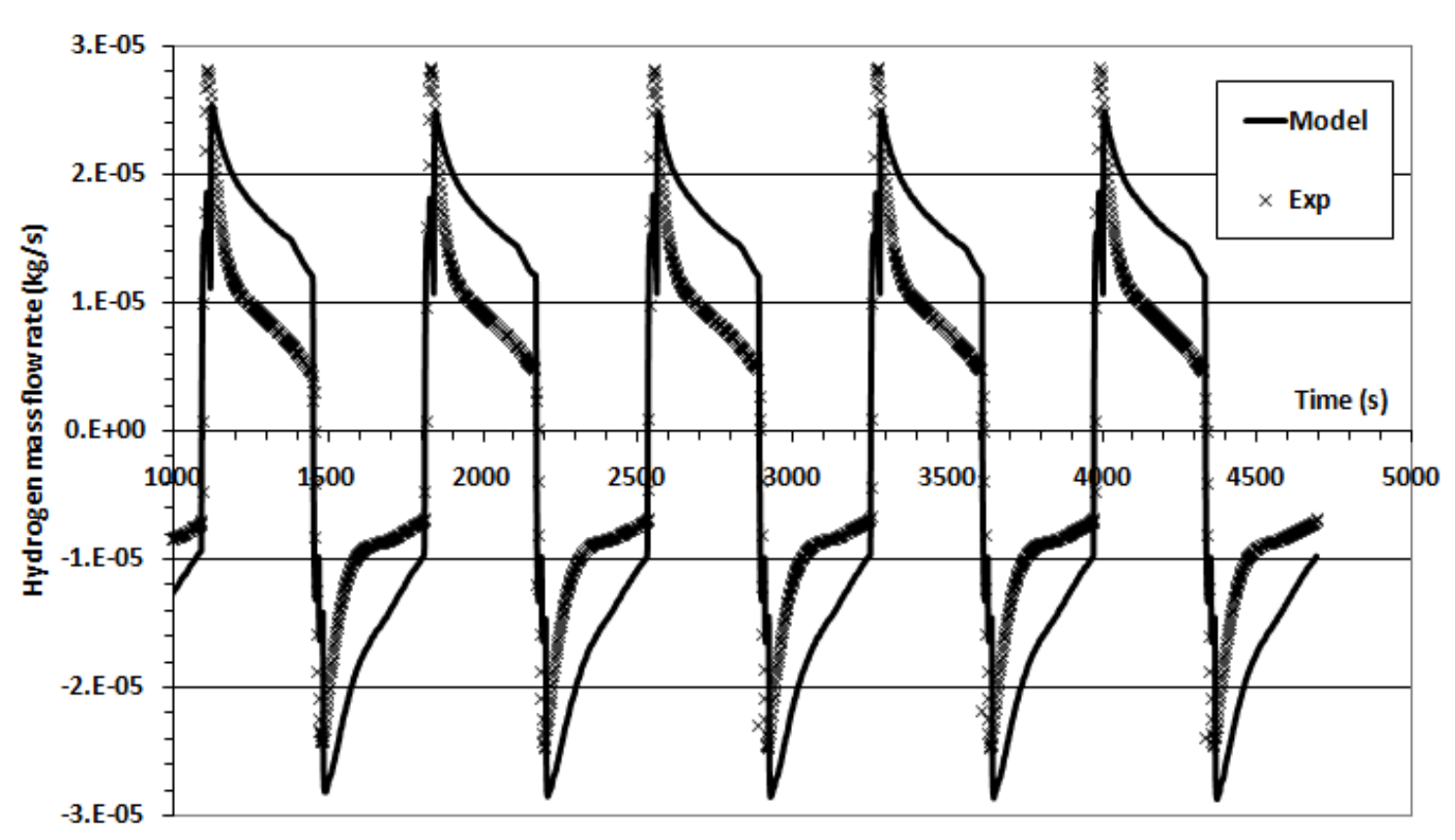

Fig. 46. Hydrogen transfer rate vs time (test 1)

Fig. 45 shows the bed pressures during four operating cycles. As the pressure difference between both reactors is very low (a few mbar), one unique bed pressure has been represented in Fig. 45.

The predicted pressures have a similar tendency than the experimental curves, but there are still small differences, particularly in the regeneration phase. As the prediction of the reactor pressure is very good for the rest of reactors (A2$B 2$ and $A 3-B 3)$, the behaviour of reactors $A 1-B 1$ seems to be very sensitive to the cyclic degradation of $A 1$. In order to reach a better agreement for the A1-B1 system, the P-C-T curves of alloy A1 should be measured after many cycles and the new correlation should be used in the dynamic model.

In Fig. 46, the exchanged rate of hydrogen between both reactors has been represented. This rate has been arbitrarily chosen as positive during the cooling phase (hydrogen exchange from bed A towards bed $B$ ) and negative during the regeneration phase.

As may be inferred from Fig. 46, the model tends to overpredict the exchange rate of hydrogen. This comparison should also be considered with caution because the exchange rate is very sensitive to the reactor pressures, which 
derive from the equilibrium P-C-T tests. Due to the cyclic degradation of alloy A1, it is hard to predict both the pressures (Fig. 45) and the hydrogen exchange rate (Fig. 46). More results on the A1-B1 system have been published recently in literature [94].

\subsubsection{Reactors $\mathrm{A} 2-\mathrm{B} 2$}

Fig. 47 and Fig. 48 show a comparison between the simulation results and the measurement data of test 3 . The three temperature levels in these cooling tests (test 3 in Table 14.) are $T_{h}=130^{\circ} \mathrm{C}, T_{m}=35^{\circ} \mathrm{C}, T_{c}=11^{\circ} \mathrm{C}$. The cycle duration which has been fixed (240s) enables an almost full hydrogen transfer in the plateau region of both alloys. The test was carried out during one hour, and for more clarity only 5 cycles have been represented.

The simulations show a very good agreement with the experimental results [95] for both the regeneration phase (pressures up to 48 bar) and the cooling phase (pressures down to 10 bar).

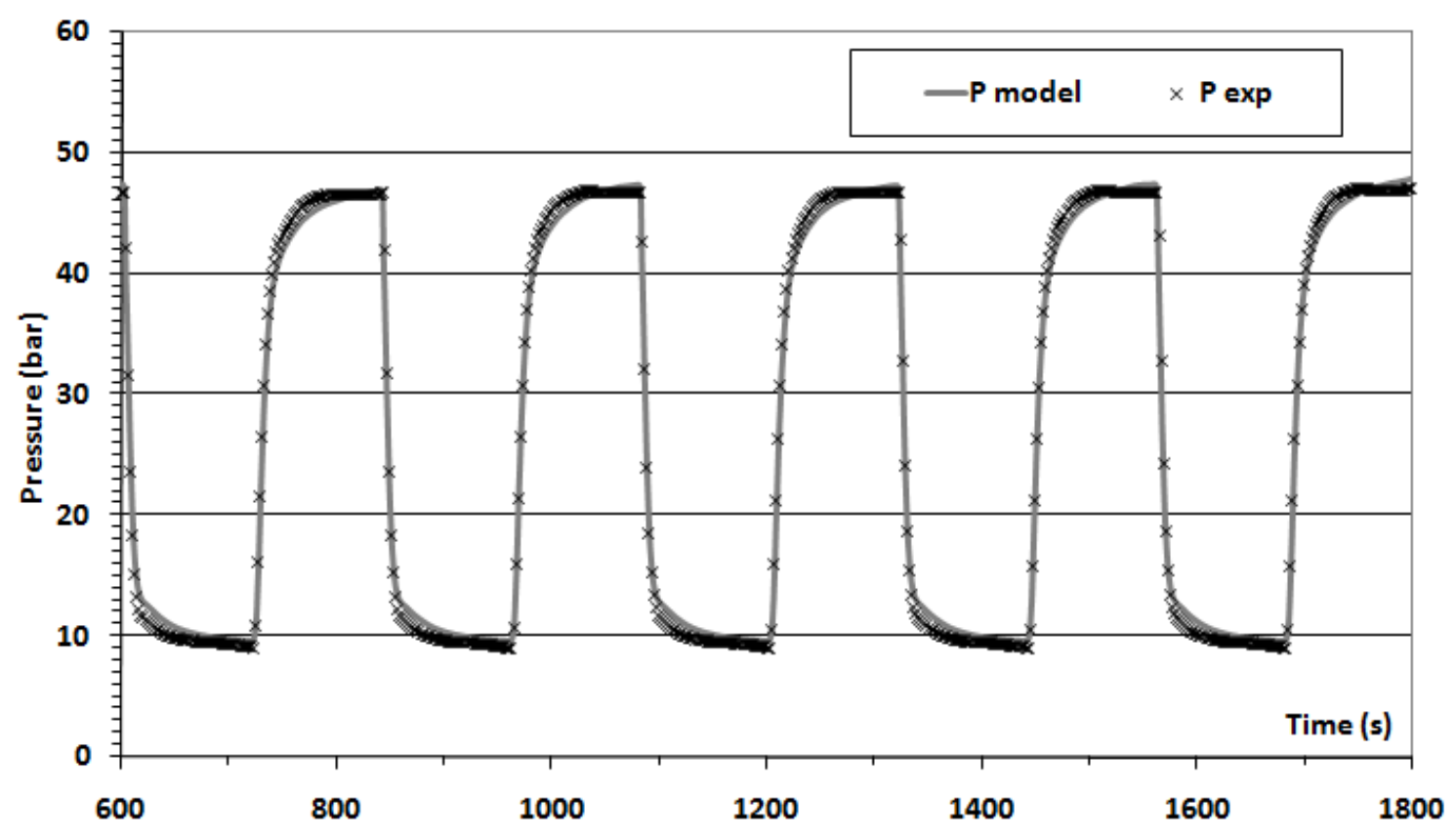

Fig. 47. Bed pressure vs time (test 3 ) 
Fig. 48 shows the hydrogen mass flow rate which is exchanged between both reactors. The model provides a similar mean exchange rate but differs slightly from the measurements, particularly at the end of both the regeneration and cooling phase.

The prediction of the hydrogen mass flow rate is improved in the final version of the model, which has only been applied for the last couple of reactors A3-B3. In fact, in order to predict the hydrogen exchange rate, it is essential to model the $\mathrm{P}-\mathrm{C}-\mathrm{T}$ curves in the boundaries of the plateau region, and in these results of A2B2, only the modified Van't Hoff Eq. (44) was implemented, without including Eqs. (45) and (46) for the left and right tails of the plateau.

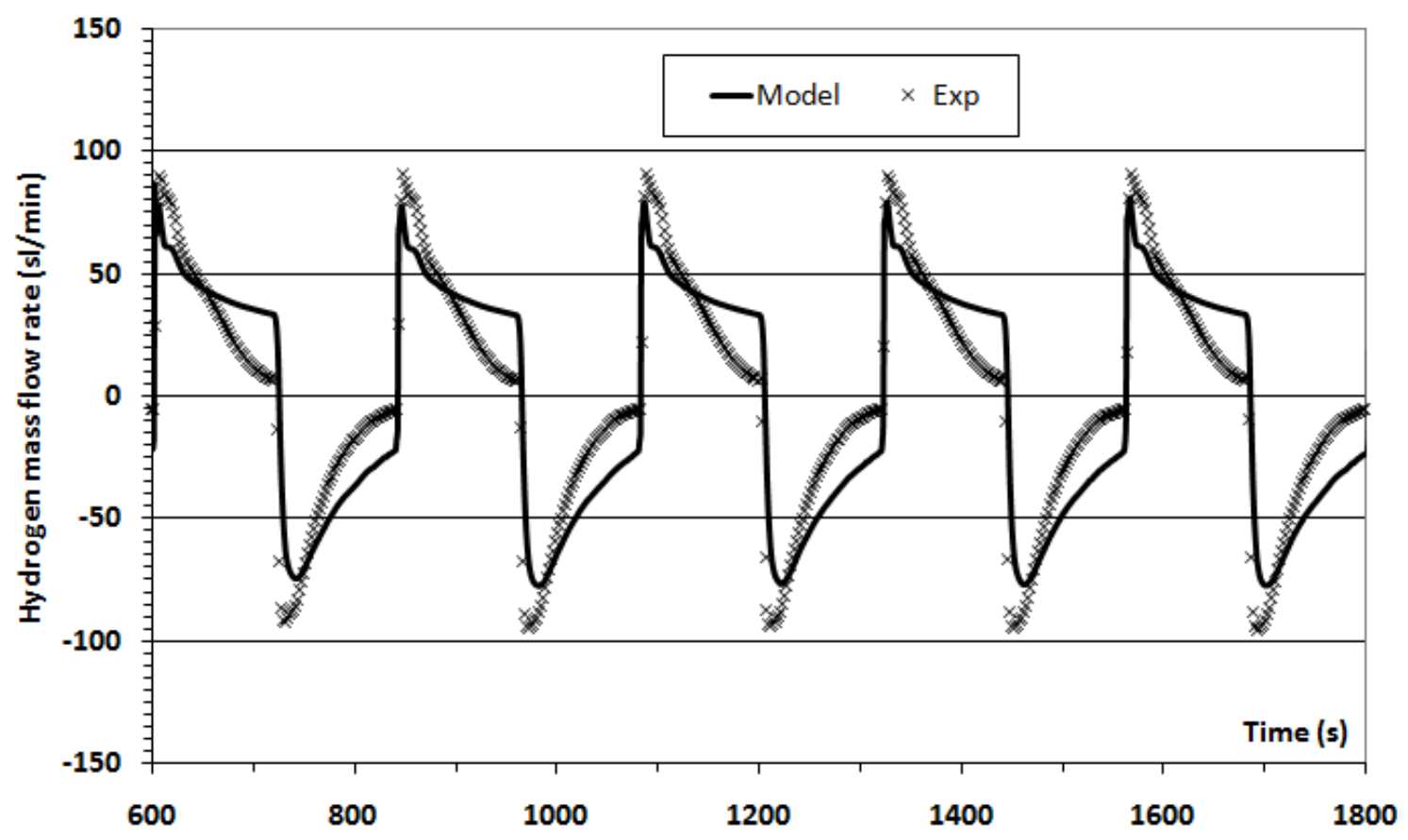

Fig. 48. Hydrogen mass flow rate vs time (test 3 )

Finally, in Fig. 49 the model reveals some interesting information on the operating conditions of the reactors. Alloy B2 is working slightly on the left-hand side of its plateau, whereas bed A works mostly on the right-hand side. Globally, both reactors are operating in almost their whole plateau region, which explains the good performance of this MHCS. 
Chapter 7 - VALIDATION OF THE DYNAMIC MODEL

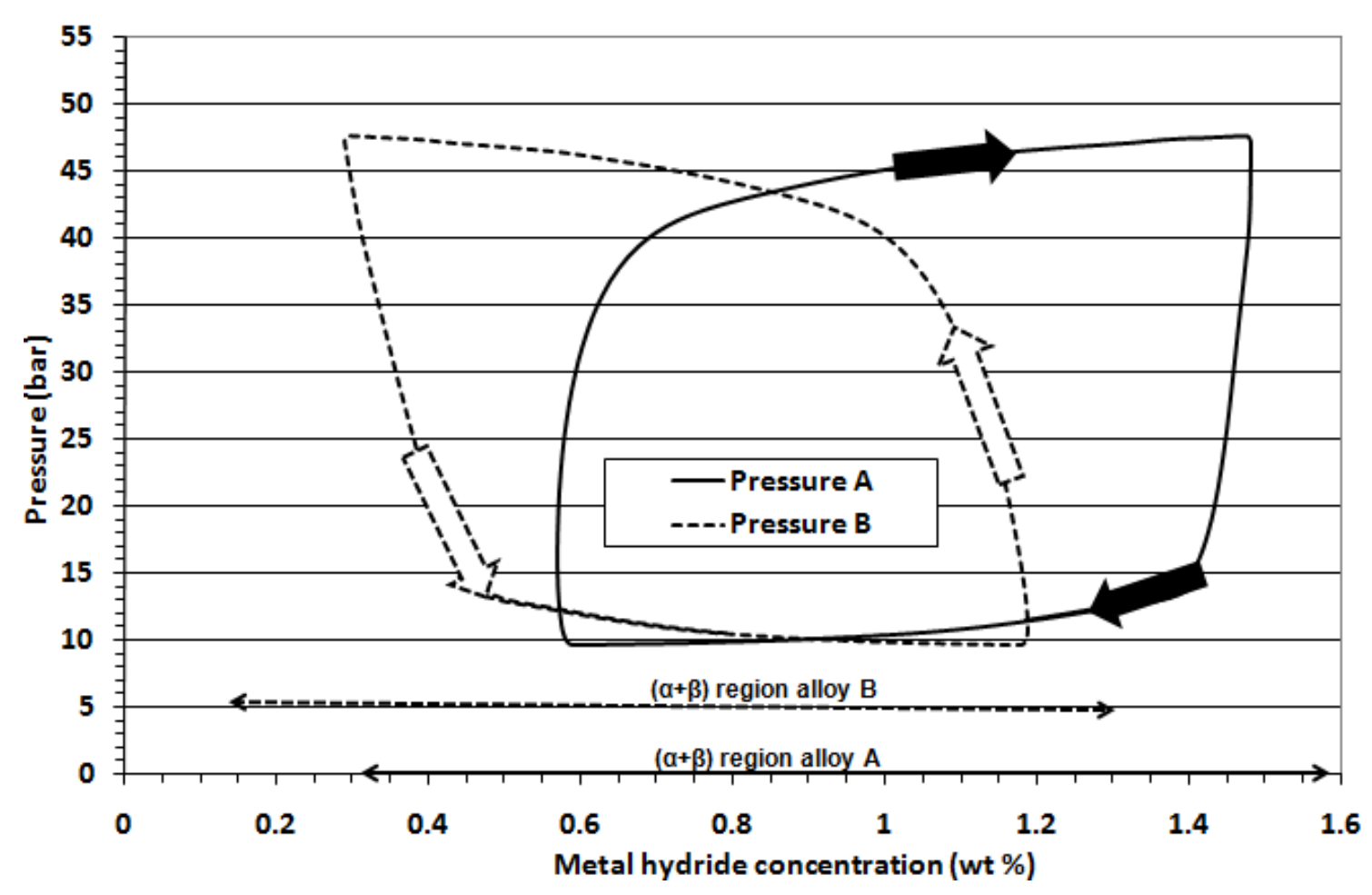

Fig. 49. Dynamic P-C cycle (test 3)

A mean cooling power of $410 \mathrm{~W}$ is achieved in these tests, with a thermal COP of around 0.19 , as calculated in Eq. (50):

$$
C O P=\frac{\bar{Q}_{c}}{\bar{Q}_{h}}
$$

The COP is low because of the consecutive cooling and heating of the mass of the reactor. The measured exchange rate of hydrogen is of $38 \pm 1 \mathrm{~s} / / \mathrm{min}$.

\subsubsection{Reactors A3-B3}

\subsubsection{Maximum cooling power tests}

The maximum cooling power tests refer to test 8 in Table 14. As mentioned previously, in these tests bed $A$ has initially a temperature of $14^{\circ} \mathrm{C}$ and a pressure of 26 bar. Bed $B$ is almost empty, with a pressure of 4 bar at $33^{\circ} \mathrm{C}$. 
According to the equilibrium P-C-T tests of A2-B2 (Chapter 4), these conditions imply an initial metal hydride concentration of $1.2 \mathrm{wt} \%$ in $A$ and of $0.4 \mathrm{wt} \%$ in B. In order to obtain these concentrations, a full regeneration has been carried out previously, under low temperatures in bed $A\left(<10^{\circ} \mathrm{C}\right)$ and high temperatures in bed $\mathrm{B}\left(>130^{\circ} \mathrm{C}\right)$.

This initial pressure difference induces a very high hydrogen transfer in comparison to the dynamic cooling tests, where the hydrogen connexion valve is always open. Fig. 50 illustrates the measured bed pressures during test 8 . The results should be analyzed parallel wise with Fig. 51, where the instantaneous metal hydride concentration has been plotted.

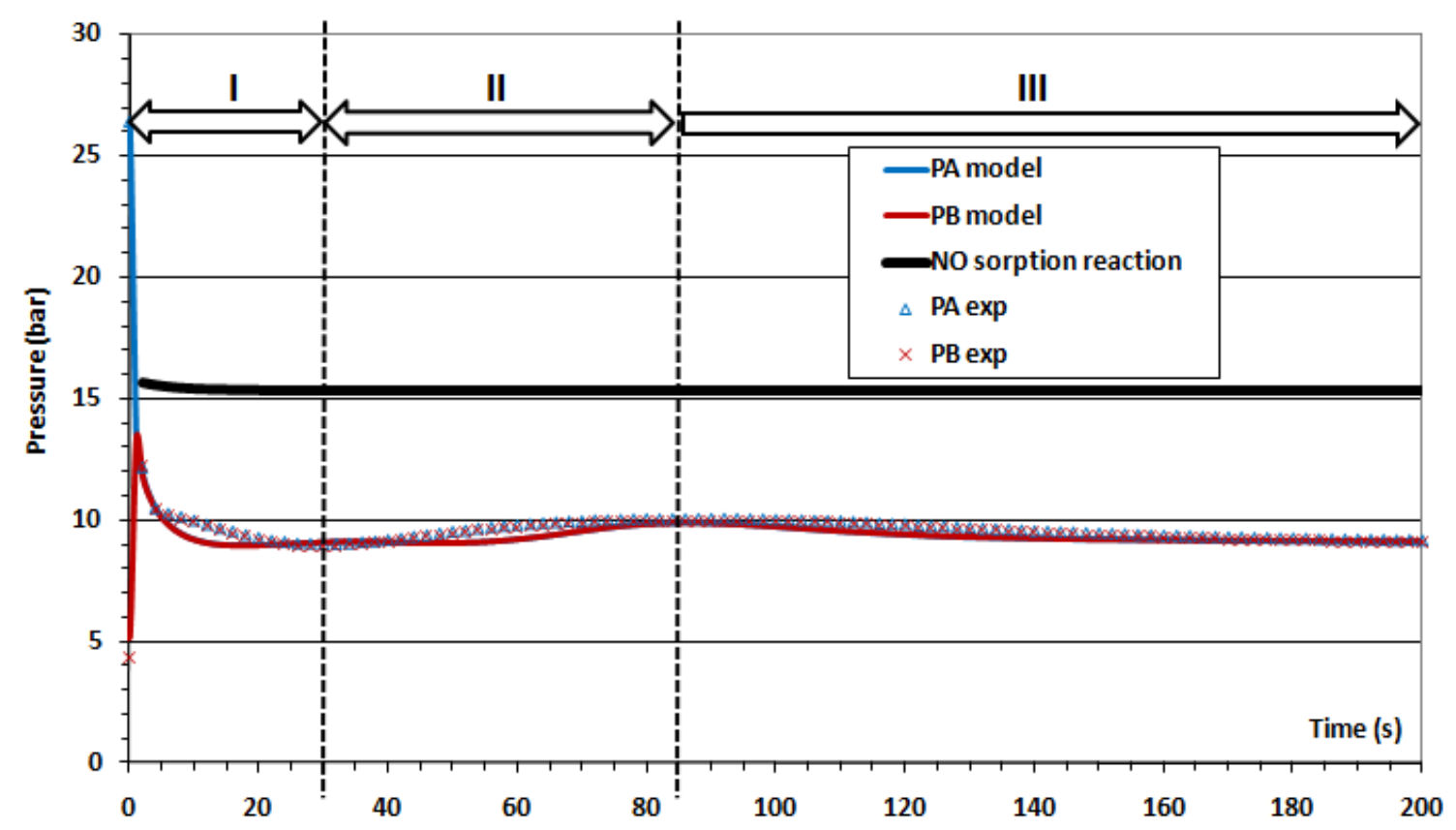

Fig. 50. Bed pressure vs time (test 8 )

As soon as both beds are connected, the mass transfer of hydrogen is very fast and thus, the bed pressures equalize almost instantaneously. However, it is interesting to highlight that if there was no sorption reaction, the pressure would be constant, with a value of around 15.3 bar. Hence, the dynamic evolution of the pressure is due to the sorption reactions which take place in both beds. 


\section{Chapter 7 - VALIDATION OF THE DYNAMIC MODEL}

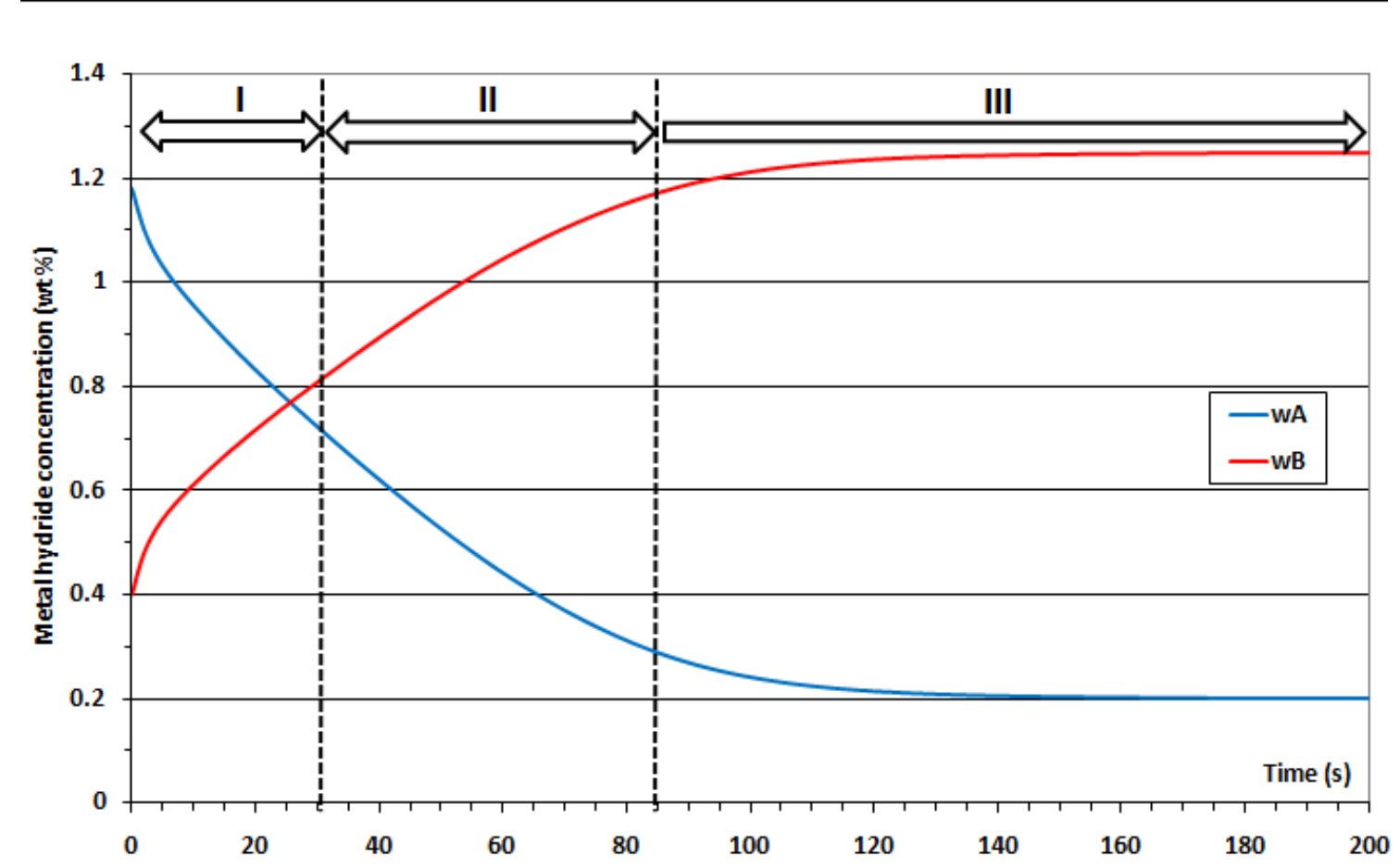

Fig. 51. Metal hydride concentration in the alloys vs time (test 8)

The reaction rate in $B$ is lower than the reaction rate in $A$ and hereby the initial part of the tests (step I) tends to follow the equilibrium pressures of bed A. In other words, bed $A$ is closer to the equilibrium pressures than bed $B$. This is the reason why the measured pressure decreases during step I, following the same tendency as the equilibrium pressure in $A$, which decreases during desorption.

In step II (between 30s to 85s), the pressure of the system increases. The reason for this can be explained by means of the equilibrium properties of A3B3. In fact, the slope in the $\alpha+\beta$ phase of B3 is double the slope of A3 (Chapter 4). As hydrogen is absorbed in B3, its equilibrium pressure increases and induces the small pressure increase which can be observed in Fig. 50.

After $85 \mathrm{~s}$, the pressure of the system decreases once again. Fig. 51 brings out interesting information on this matter. Although both alloys are mainly operating in their respective $\alpha+\beta$ phase, at the end of the reaction bed $A$ reaches the left part of its plateau region. This zone is characterized by a significant pressure decrease, hereby producing a pressure drop in the system. 


\section{Chapter 7 - VALIDATION OF THE DYNAMIC MODEL}

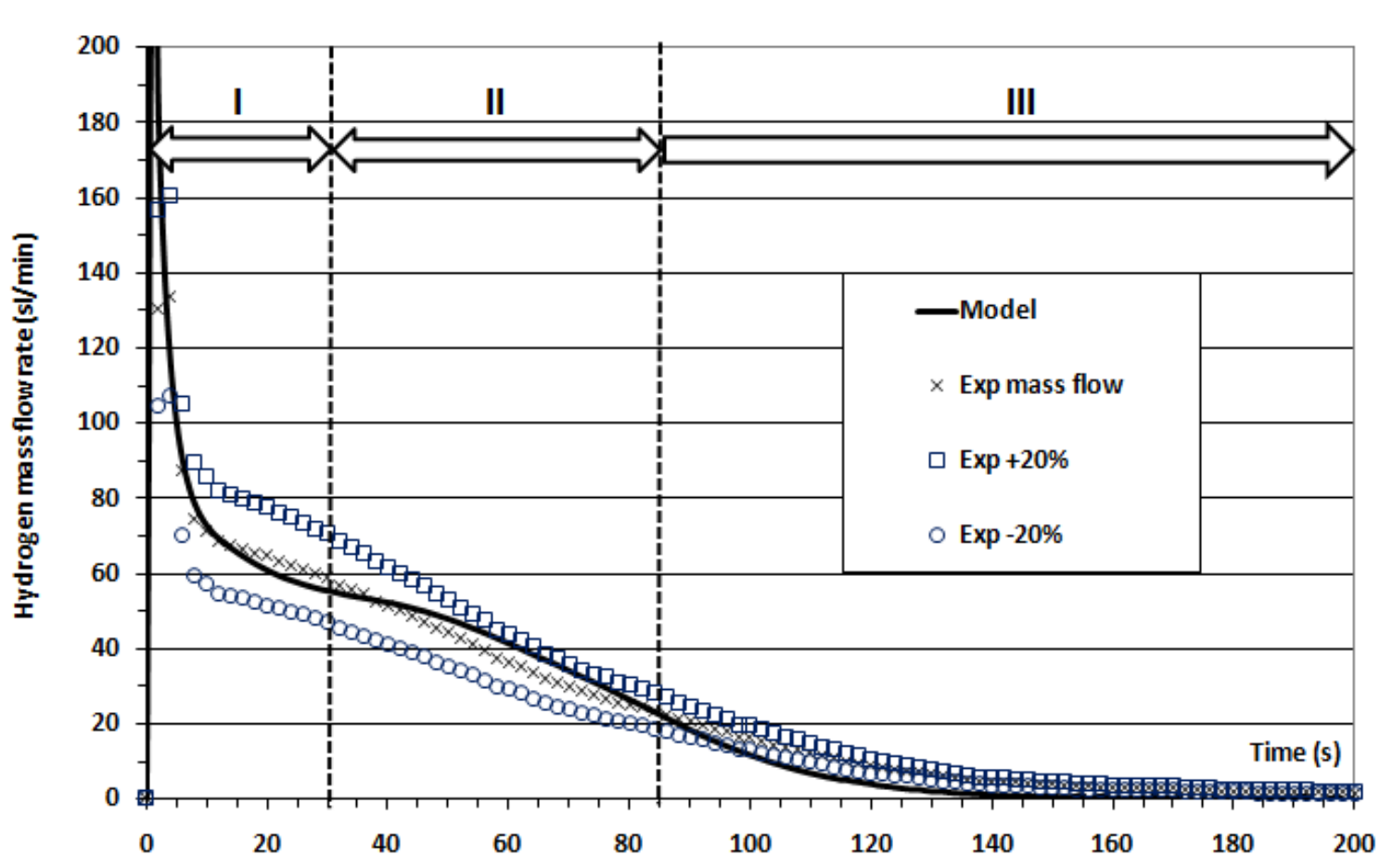

Fig. 52. Hydrogen transfer rate vs time (test 8)

Fig. 52 shows the hydrogen mass flow rate which is transferred from $A$ to $B$. The model results are rather accurate within a range of $\pm 20 \%$. In step I a first peak is observed and is purely due to the difference of pressure of the gas phases in A and B. In step II the model presents a slightly difference tendency in comparison to the measurements. In the maximum cooling power tests, the polynomial fitting method (Chapter 4 ) has been used to calculate the equilibrium pressures. In step II, bed $B$ is in the $\alpha+\beta$ phase, and the oscillations of the polynomial equilibrium pressure generate an oscillation in the hydrogen transfer rate. This is one inconvenient of using the polynomial approach to model the $\mathrm{P}$ C-T curves. However, in the maximum cooling power tests, as the reaction involves an almost full absorption/desorption in alloys B3 and A3 respectively, it is preferable to use the polynomial fitting method because it allows modelling the whole operation range of the reactors. 


\section{Chapter 7 - VALIDATION OF THE DYNAMIC MODEL}

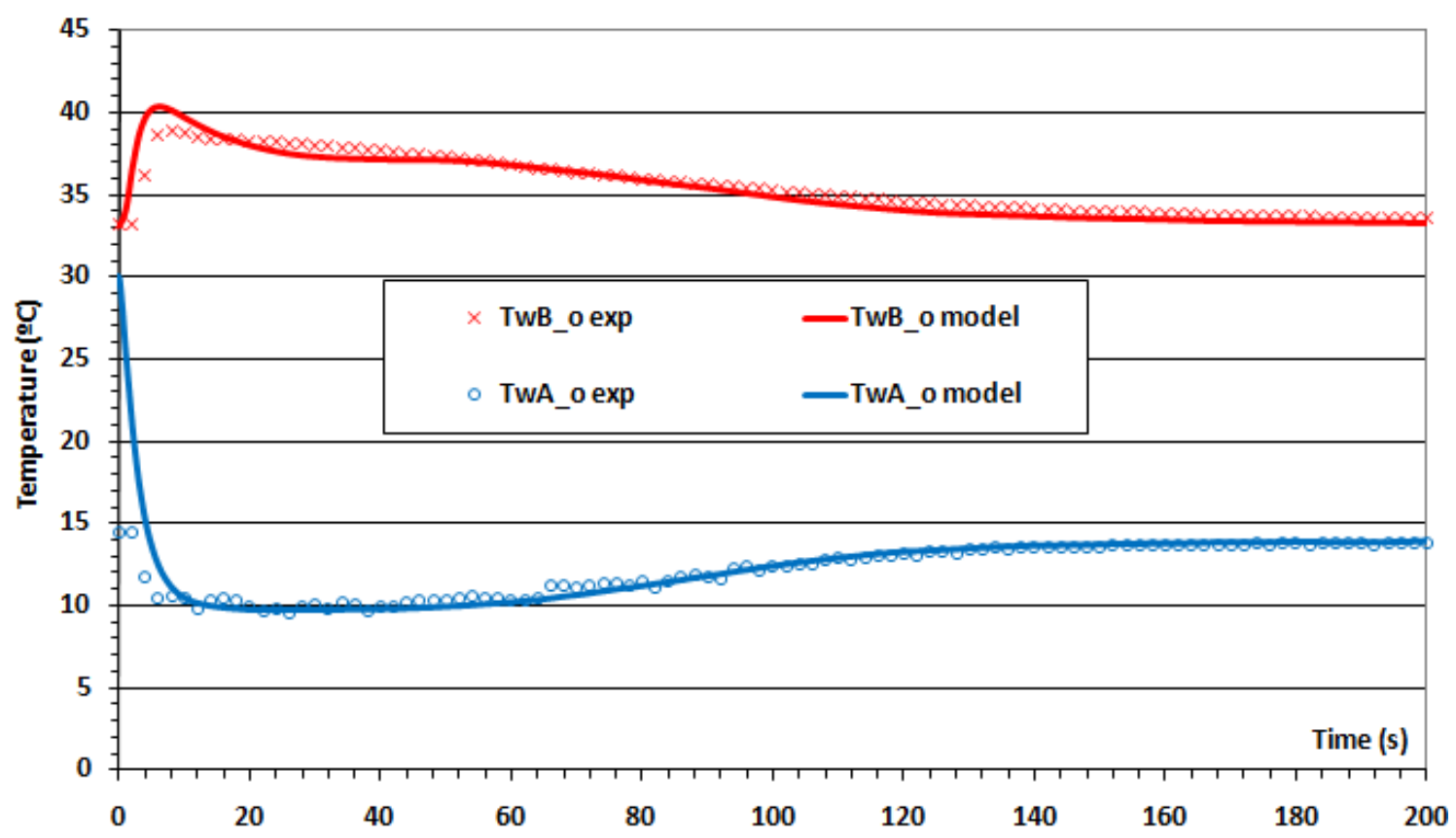

Fig. 53. Water outlet temperatures vs time (test 8)

Fig. 53 represents the water outlet temperatures of both reactors. In bed $A$ the water is cooled (desorption) whereas in bed B the water is heated up (absorption). The model results agree almost perfectly with the measurements.

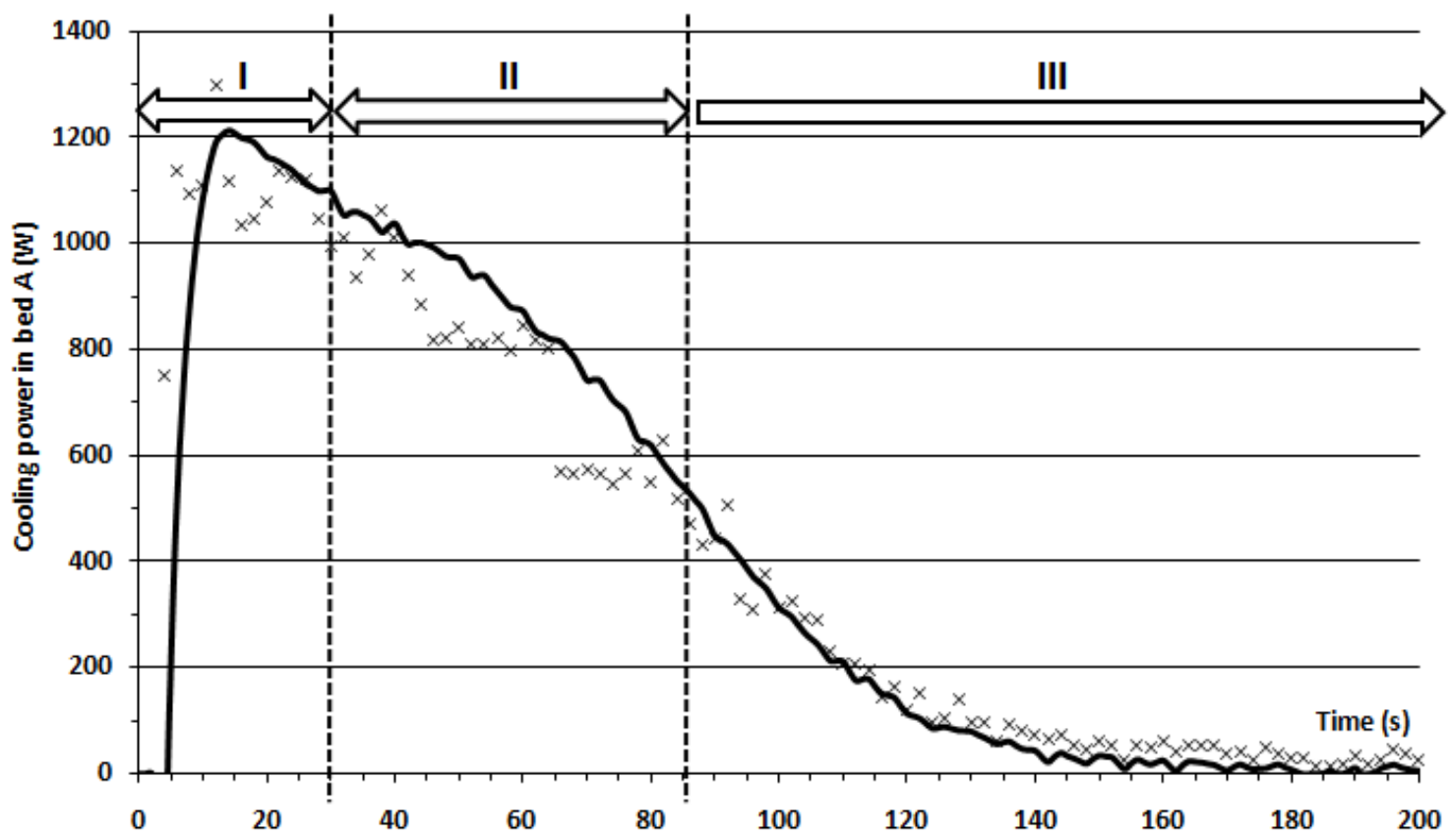

Fig. 54. Cooling power in bed A vs time (test 8 ) 


\section{Chapter 7 - VALIDATION OF THE DYNAMIC MODEL}

Fig. 54 shows the cooling power in bed A, as calculated from the mass flow rate and from the difference of temperature between the inlet and outlet of the reactor. The model predicts accurately the cooling power. In step III, as bed A reaches the left of the plateau, the cooling power decreases down to zero.

With the alloy combination A3-B3, a maximum cooling power of around $1200 \mathrm{~W}$ can be achieved. Nevertheless, in the cycle tests the cooling power is sensibly lower because a full regeneration of bed $A$ is not possible (it would require too much time) and because the hydrogen connexion valve is always open and hence the available pressure difference is not so high. Keeping the valve always open is a choice which has been done to make the operation of the system easier. In order to achieve a continuous cooling, if the connexion valve is always open, only two additional coupled reactors are required.

\subsubsection{Dynamic cooling tests}

The simulation results of A3-B3 have been compared with measurement data from IKE under different experimental conditions (see Table 14.). The simulations match well with the measurement data for regeneration temperatures of $130^{\circ} \mathrm{C}$ and $100^{\circ} \mathrm{C}$.

The following results apply to test 5 of Table 14.. Other experimental tests of A3-B3 such as test $7\left(T_{h}=130^{\circ} \mathrm{C}, \mathrm{T}_{m}=35^{\circ} \mathrm{C}, \mathrm{T}_{\mathrm{c}}=18^{\circ} \mathrm{C}\right)$ have been validated in literature by Payá [2].

Fig. 55 to Fig. 59 are a sample of the results which have been obtained for test 5. Although the test is done during around $4300 \mathrm{~s}$, for more clarity only the last 1000s have been illustrated. The three temperature levels in these cooling tests are $\mathrm{T}_{\mathrm{h}}=130^{\circ} \mathrm{C}, \mathrm{T}_{\mathrm{m}}=29^{\circ} \mathrm{C}, \mathrm{T}_{\mathrm{c}}=18^{\circ} \mathrm{C}$.

In Fig. 55, the reactor pressure has been represented. The simulations show a very good agreement with the experimental results for both the regeneration phase (pressures up to 48 bar) and the cooling phase (pressures down to 8.5 bar). 


\section{Chapter 7 - VALIDATION OF THE DYNAMIC MODEL}

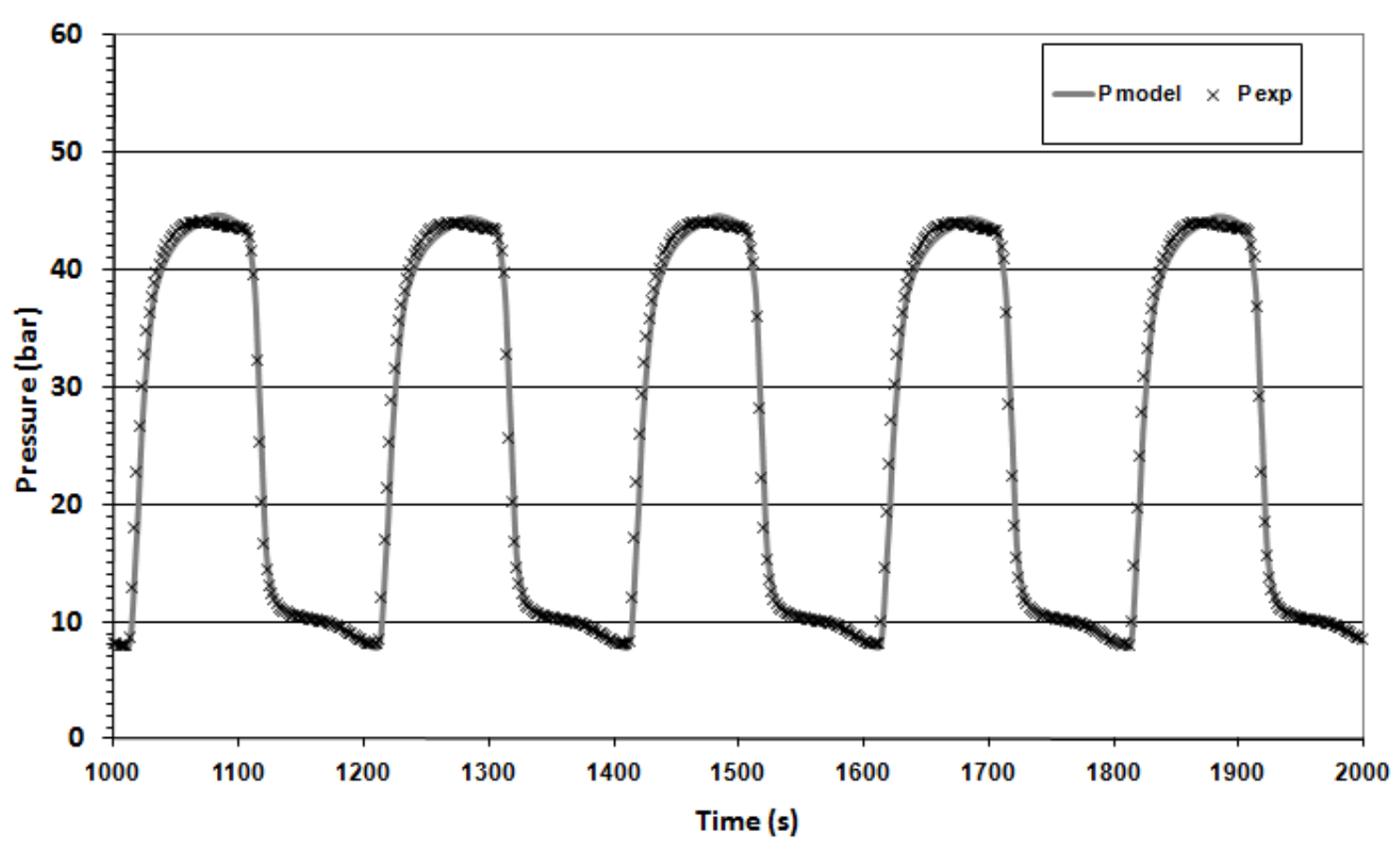

Fig. 55. Bed pressure vs time (test 5 )

The water outlet temperatures of the reaction beds have been plotted in Fig. 56. The theoretical curves fit accurately with the experimental data. During the cooling phase, the water outlet temperature in bed A decreases down to around $13.7^{\circ} \mathrm{C}$. Meanwhile, in bed $\mathrm{B}$ the ambient heat exchanger is used to decrease its temperature from the regeneration temperature down to $29^{\circ} \mathrm{C}$.

During the regeneration phase, bed $B$ is heated up to $130^{\circ} \mathrm{C}$ in order to achieve a pressure difference which allows for hydrogen transfer towards bed $A$. As bed A absorbs hydrogen, it tends to heat up and the ambient heat exchanger is used to dissipate the enthalpy of the reaction.

Fig. 57 shows the hydrogen mass flow rate which is exchanged between both reactors. In previous versions of the model [2], it was observed that the use of a $\mathrm{P}-\mathrm{C}-\mathrm{T}$ model just in the $\alpha+\beta$ phase implied an over-prediction of the hydrogen exchange rate. This final model includes a calculation of the P-C-T correlation even in the boundaries of the plateau, and this is the key to reach a good agreement with the experimental results. In fact, after half of the cooling phase, alloy $A$ reaches the left limit of its plateau region in test 5 , and once the 
equilibrium pressures decrease, the condition $P_{\text {eq,des, } A}>P_{\text {gas }}>P_{\text {eq,abs, } B}$ can hardly be reached, and hence the exchanged mass flow rate decreases down to zero.

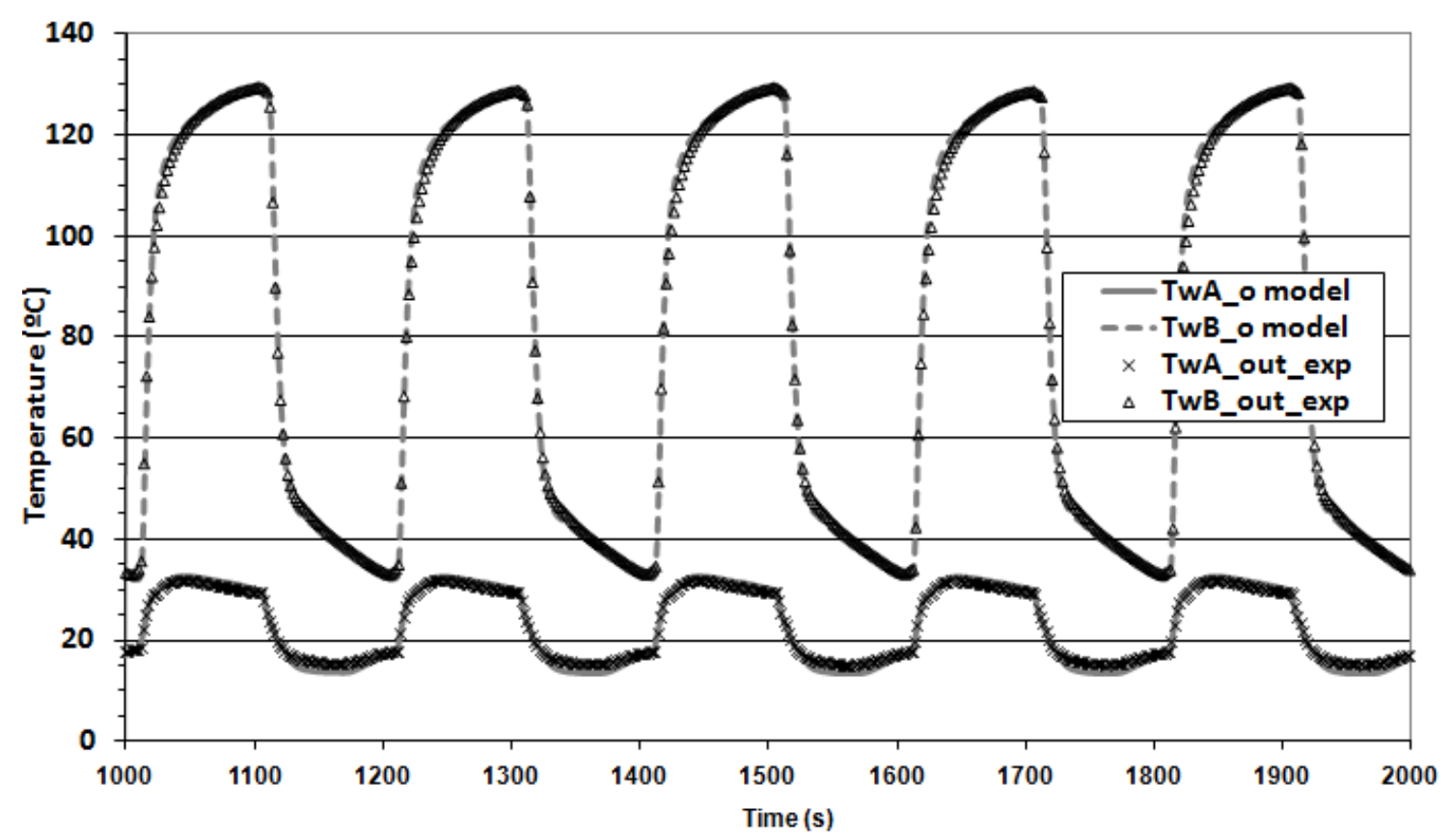

Fig. 56. Water outlet temperatures vs time (test 5)

The model reproduces rather accurately the exchanged mass flow rate of hydrogen (Fig. 57), and this is a clear improvement with respect to the state of the art of the modelling of MHCS's [2,3,95]. The peaks which are observed in Fig. 57 take place in the transitions between absorption and desorption. As mentioned in Chapter 6, a special model has been developed to account for these transitions. Although it induces peaks during the $9 \mathrm{~s}$ duration of the transition phases, this approach presents an advantage: it avoids discontinuities in the exchanged mass flow rate, hereby making the model more robust. 


\section{Chapter 7 - VALIDATION OF THE DYNAMIC MODEL}

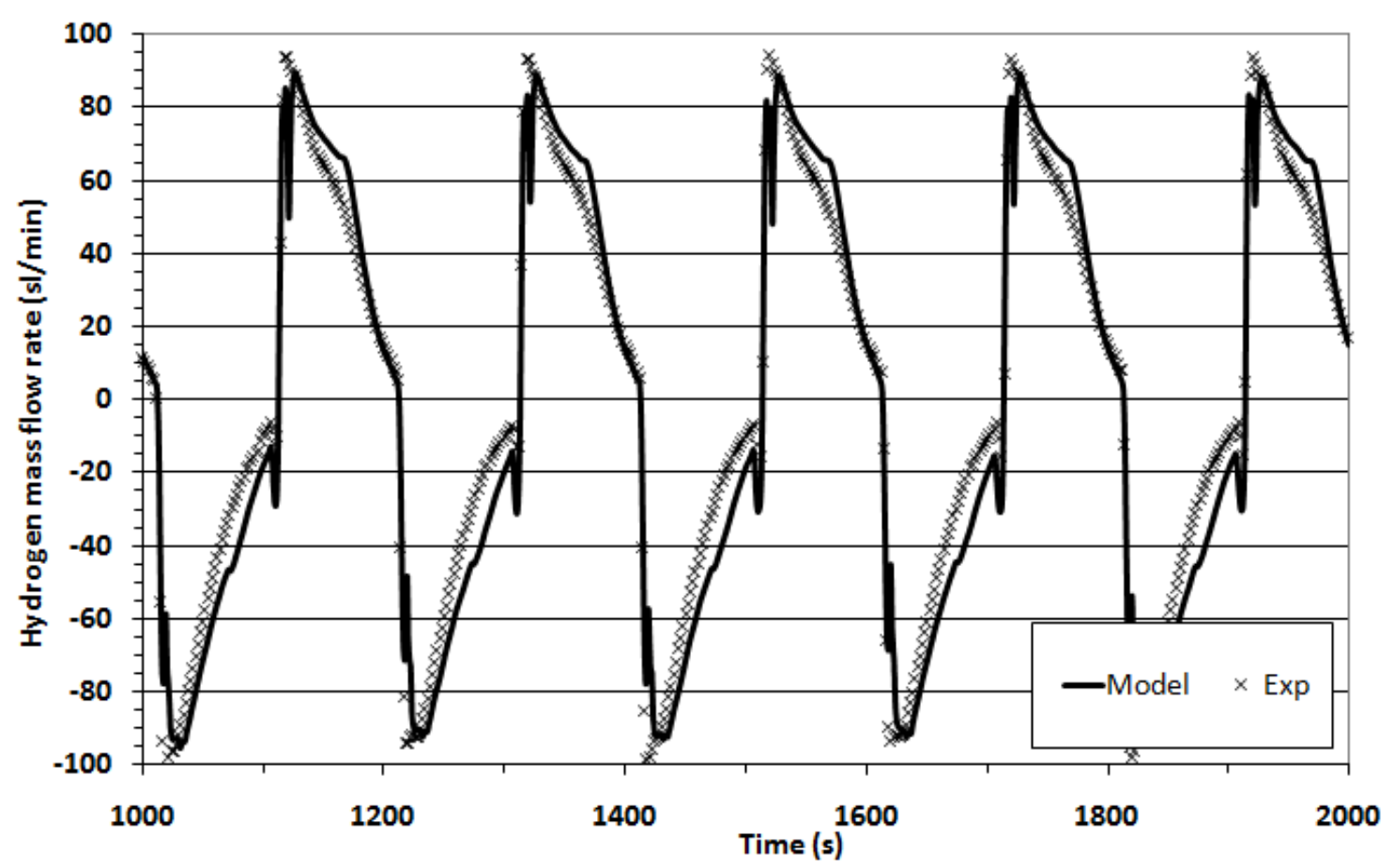

Fig. 57. Hydrogen transfer rate vs time (test 5)

Fig. 58 shows the evolution of the hydrogen concentration in the alloys. It is very difficult to measure this value during dynamic cycles and therefore the model is providing some valuable information.

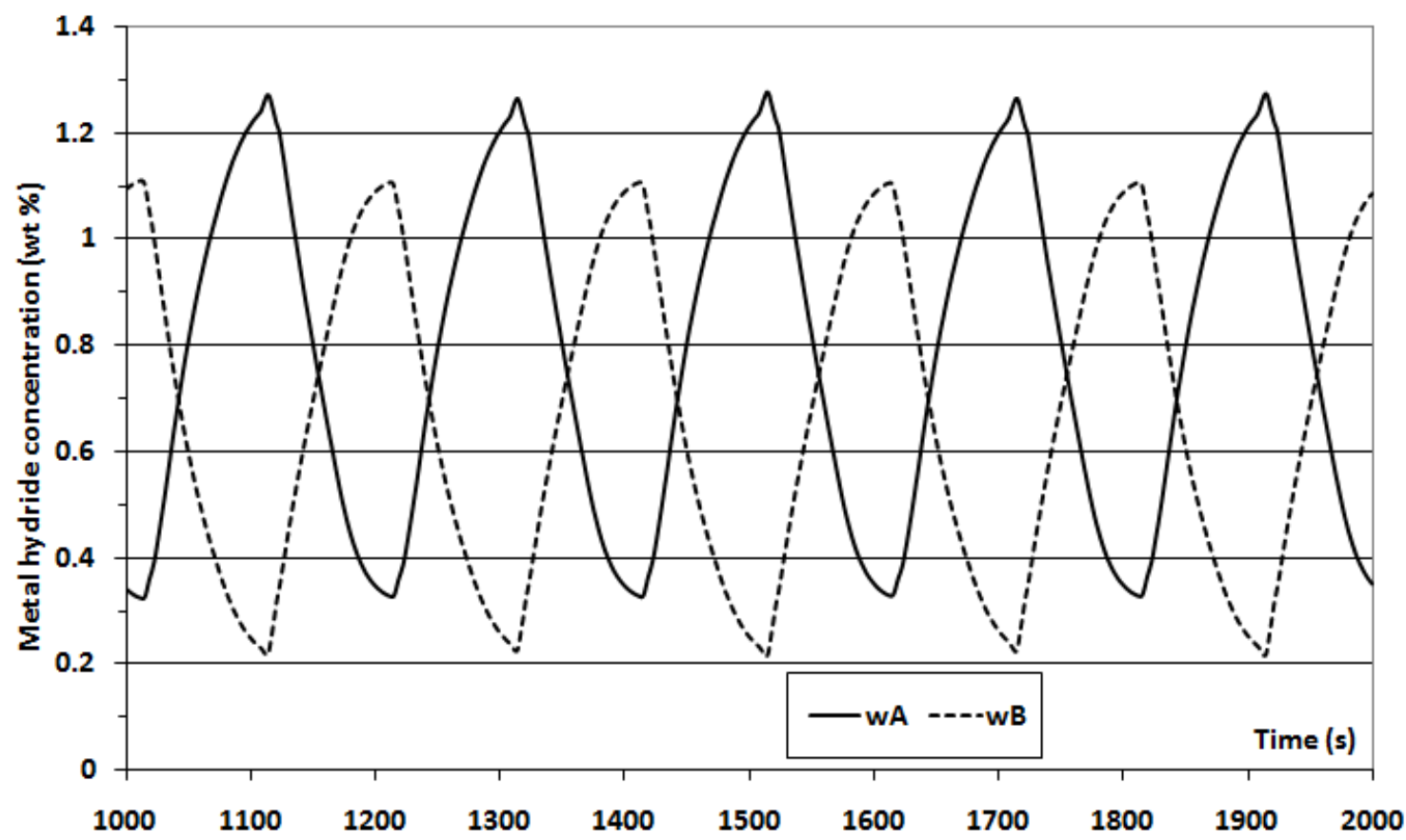

Fig. 58. Metal hydride concentration in the alloys vs time (test 5) 
Fig. 58 can be understood together with Fig. 59 where the instantaneous pressures and concentrations have been compared with the static P-C-T diagrams of the alloys.

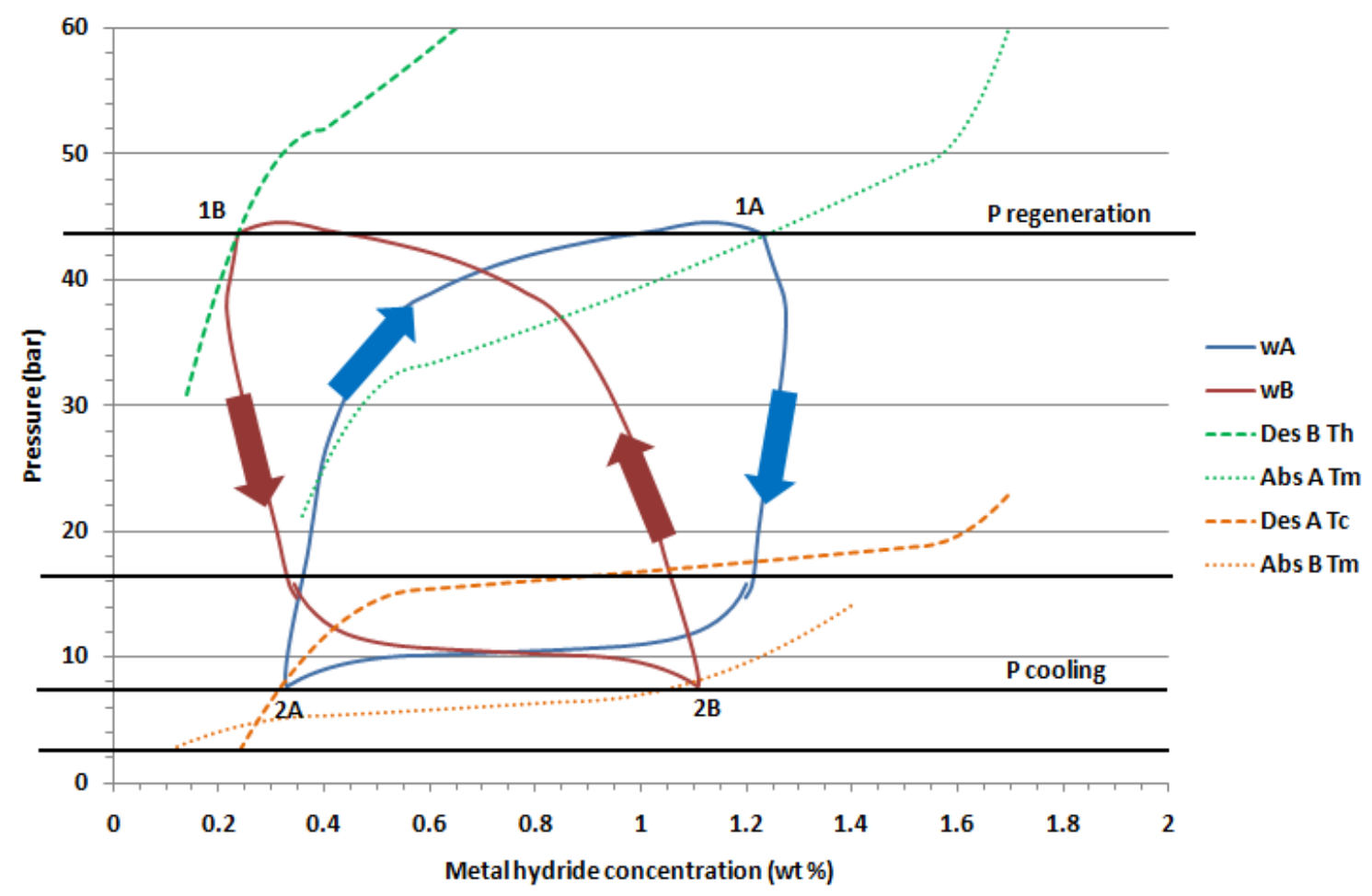

Fig. 59. Bed pressure vs metal hydride concentration (test 5)

During the regeneration, bed $B$ is heated up and as long as the pressure is higher than in bed $A$, hydrogen flows from $B$ towards $A$. However, as the concentration and the temperature increases in $A$, its equilibrium pressure increases too. The final point of the regeneration phase (1B and $1 A$ on Fig. 59) corresponds to the intersection between the desorption curves of bed $B$ at $T_{h}$ and the absorption curves of bed $A$ at $T_{m}$. At this point, bed $B$ is in the left part of its plateau region. During the cooling phase, the pressure decreases, mainly due to the temperature decrease in bed $\mathrm{B}$. This is the driving potential which allows to absorb hydrogen in this alloy and to desorb it in bed A. At the end of the cooling phase (points $2 \mathrm{~A}$ and $2 \mathrm{~B}$ ) bed $\mathrm{A}$ reaches the left boundary of its plateau region, and from this moment on, it is not necessary to extend the cooling phase. Points $2 \mathrm{~A}$ and $2 \mathrm{~B}$ correspond to the intersection between the desorption pressures of bed $A$ at $T_{c}$ and the absorption pressures of $B$ at $T_{m}$. 


\section{SYSTEM PERFORMANCE}

In test 5 , the duration of each cycle (complete cooling and regeneration phase) is 200 s, which is much shorter than in former studies $[3,9,13,21]$. The mean hydrogen exchange rate between the reactors $(54.1 \pm 1 \mathrm{sL} / \mathrm{min})$ is rather high for such a small system (only $900 \mathrm{~g}$ of metal hydride powder in each reaction bed).

In order to have a continuous cooling effect, 4 reactors would be needed. The following remarks on the system performance refer to a MHCS with two pairs of reactors A3-B3.

During test $5\left(T_{h}=130^{\circ} \mathrm{C}, T_{m}=29^{\circ} \mathrm{C}, T_{c}=18^{\circ} \mathrm{C}\right)$ a mean cooling and heating power of $887 \mathrm{~W}$ and $2487 \mathrm{~W}$ can be achieved assuming a low thermal mass of the reactors. This implies a mean COP of around 0.36. However, in the experimental set-up, the upper and lower brass heads involve an additional mass which reduces the COP down to around 0.20. These values are similar to the coupled system presented by Qin et al [6].

May the mean COP be low in comparison to other sorption cooling systems, the interest of this MHCS is that it is rather compact $(317 \mathrm{~W} / \mathrm{L})$. These values are higher than other in adsorption cooling systems [2].

\subsection{Conclusions on the model validation}

The dynamic model has provided a good agreement with the experimental tests carried out at IKE for different metal hydride alloys and different operating temperatures. For the last coupled pair of reactors A3-B3, an in-depth study has been carried out, and the simulations have reproduced accurately the results of the maximum cooling power tests and the dynamic cooling tests.

The model which has been developed for A3-B3 is used in Chapter 8 for the optimization study. 



\section{Chapter 8:}

\section{Optimization and}

design of the MHCS 


\section{Nomenclature}

\begin{tabular}{|c|c|}
\hline $\mathrm{T}$ & Temperature, ${ }^{\circ} \mathrm{C}$ \\
\hline$P$ & Pressure, bar \\
\hline$\Delta t_{\text {cycle }}$ & Cycle duration (s) \\
\hline w & Metal hydride concentration, g MH/g alloy (\%) \\
\hline$\dot{Q}$ & Heat transfer rate, $\mathrm{W}$ \\
\hline COP & Coefficient of performance, $C O P=\overline{\dot{Q}_{c}} / \overline{\dot{Q}_{h}}$ \\
\hline UA & Overall heat transfer coefficient, $\mathrm{W} \mathrm{K}^{-1}$ \\
\hline f & Enhancement factor \\
\hline MF & Hydrogen mass flow rate, sl/min \\
\hline $\mathrm{K}$ & Kinetic parameter in Eq. (53) \\
\hline$\lambda$ & Effective thermal conductivity of the alloy, $\mathrm{W} \mathrm{m} \mathrm{m}^{-1} \mathrm{~K}^{-1}$ \\
\hline $\mathrm{L}$ & Length of the water tubes, $\mathrm{m}$ \\
\hline$n_{\text {tubes }}$ & Number of water tubes (372) \\
\hline$D_{e}$ & Diameter of the water tubes, $\mathrm{m}$ \\
\hline S & Average distance between the water tubes, $\mathrm{m}$ \\
\hline \multicolumn{2}{|c|}{ Subscripts } \\
\hline A & Cold reaction bed \\
\hline B & Hot reaction bed \\
\hline $\mathrm{h}$ & Hot temperature level \\
\hline $\mathrm{m}$ & Medium temperature level \\
\hline C & Cold temperature level \\
\hline w & Water \\
\hline in & Inlet to the reaction bed \\
\hline out & Outlet to the reaction bed \\
\hline$\alpha$ & Solid solution phase of hydrogen in the metal lattice \\
\hline$\beta$ & Solid solution phase of hydrogen in the metal hydride lattice \\
\hline$\alpha+\beta$ & $\alpha+\beta$ phase region in the $P-C-T$ curves \\
\hline abs & Absorption (hydriding process) \\
\hline des & Desorption (dehydriding process) \\
\hline eq & Equilibrium in the $\alpha+\beta$ phase region of the P-C-T curves \\
\hline
\end{tabular}




\section{OPTIMIZATION AND DESIGN OF THE MHCS}

\subsection{Introduction}

Chapter 7 has shown that the developed model is an accurate tool to predict the performance of this MHCS with different alloy pairs working under dynamic operating conditions.

Chapter 8 aims to obtain the key parameters which limit the cooling performance of the system. A sensitivity analysis has been carried out to quantify the effect of the most relevant parameters.

Based on the results of the sensitivity analysis, an optimised solution is finally proposed in subsection 8.4. The sensitivity analysis focuses on the following performance indicators:

- Mean cooling power

- Mean COP

- Operating position of the alloys with respect to the static P-C-T curves

In subsection 8.3, the effect of each parameter is first studied and compared with the reference case, which is very close to test 7 of A3-B3 (see Chapter 7). The main difference with respect to test 7 is that the water mass flow rates and inlet temperatures to the reactors are constant in the sensibility analysis. Test 7 is an experimental test realised at IKE and thus, in the model validation (Chapter 7), the water mass flow rates and inlet temperatures were measured and provided to the model as dynamic inputs. In the reference test of the optimisation study, the water mass flow rates and inlet temperatures are held constant in order to better characterize the reactors.

Based on the results of the sensitivity analysis, in paragraph 8.4 an optimised metal hydride cooling system is proposed, and its performance is analyzed and compared with the reference case. 


\section{Chapter 8 - OPTIMISATION AND DESIGN OF THE MHCS}

\subsection{Reference case}

The sensibility analysis has been carried out for reactors A3-B3, for which a thorough validation has been given in Chapter 7 . The reference conditions have been chosen as $\mathrm{T}_{\mathrm{h}}=130^{\circ} \mathrm{C}, \mathrm{T}_{\mathrm{m}}=35^{\circ} \mathrm{C}, \mathrm{T}_{\mathrm{c}}=18^{\circ} \mathrm{C}$. These conditions are very similar to test 7, for which the model has provided a good agreement with the experimental data [2].

As mentioned in Chapter 7, the laboratory prototype of the MHCS has two upper and lower brass heads, each of them with a mass of around $1 \mathrm{~kg}$. These heads are not pressurized and their only purpose is to fix the reaction beds to the test bench and facilitate their connexion with the water loops. In any potential application, these heads should be substituted by plastic heads capable of working under temperatures of up to $130^{\circ} \mathrm{C}$. This is a fairly simple modification of the set-up which is essential to achieve a more practical relevance. The reference case assumes that the upper and lower heads are made out of plastic, hereby reducing the thermal mass of the system with respect to the first prototype. With this modification the thermal losses due to the periodic heating and cooling of the reaction beds are reduced.

As mentioned previously, the inlet temperatures in the reactors as well as the water mass flow rate $(4 \mathrm{l} / \mathrm{min}$ through each reactor) are constant inputs in the reference case. The input temperatures for the reference case are plotted in Fig. 60 and are compared with the inputs of test 7 . In real conditions the temperature change between the regeneration and cooling phase is more progressive because the temperature sources are not ideal and are given either by a hot water tank at $T_{h}$, or by heat exchangers for the medium and cold temperature levels $\left(T_{m}\right.$ and $\left.T_{c}\right)$. 


\section{Chapter 8 - OPTIMISATION AND DESIGN OF THE MHCS}

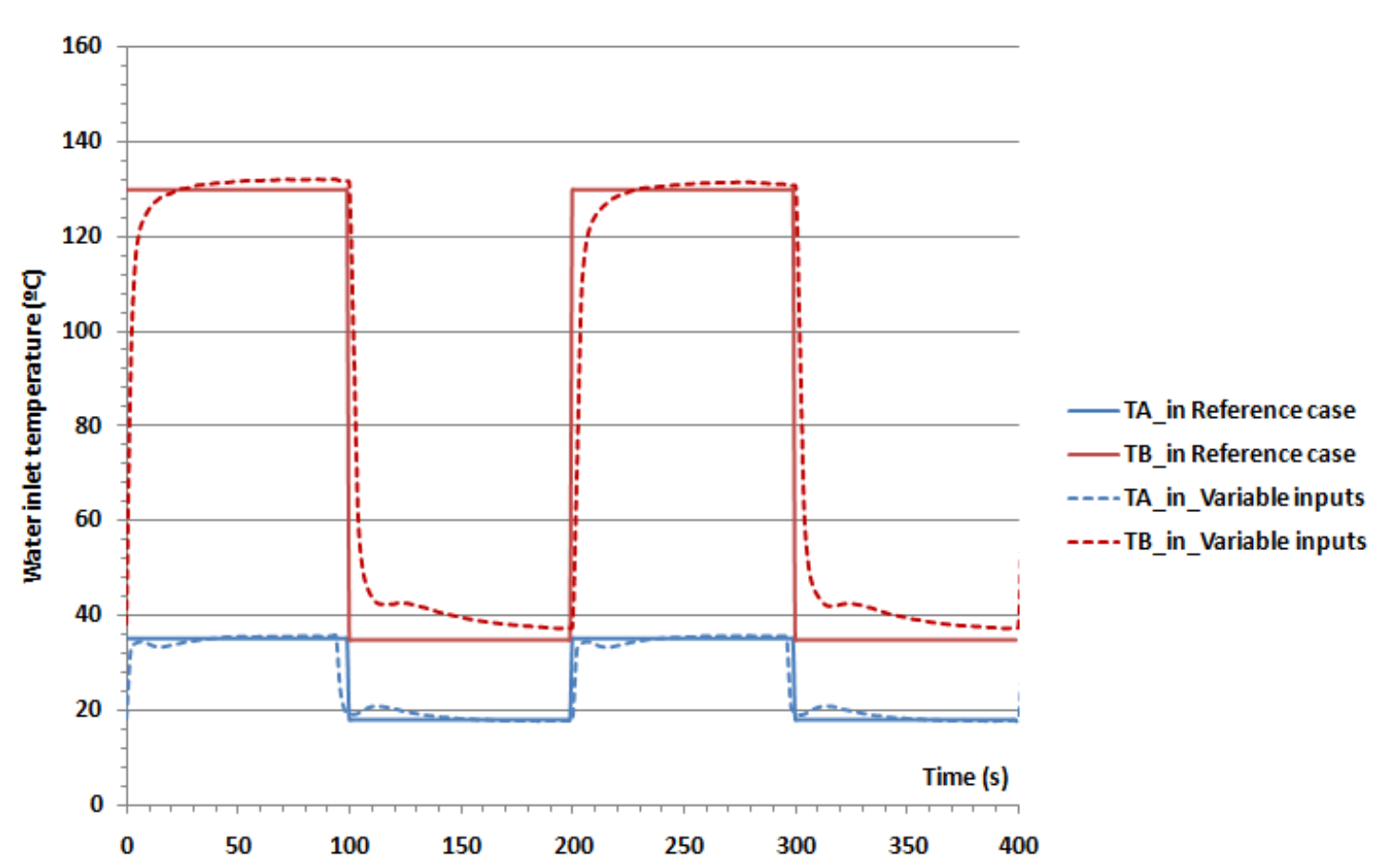

Fig. 60. Inputs of the model in the reference case

Table 15 summarises the performance which is obtained in the reference case.

\begin{tabular}{|c|c|c|c|}
\hline Mean $\mathrm{H}_{2}$ transfer $(\mathrm{s} / \mathrm{min})$ & Mean $\mathrm{Q}_{\mathrm{c}}(\mathrm{W})$ & Mean $\mathrm{Q}_{\mathrm{h}}(\mathrm{W})$ & Mean COP \\
\hline 44.8 & 693 & 2247 & 0.31 \\
\hline
\end{tabular}

Table 15. Performance of the reference case

The mean COP which is obtained is of around 0.31 , this is to say slightly lower than the value of 0.36 which was obtained during test 5 . The reason for this is that test 5 was run with a more favourable heat sink of $T_{m}=29^{\circ} \mathrm{C}$ and the reference conditions are at $\mathrm{T}_{\mathrm{m}}=35^{\circ} \mathrm{C}$. The higher the heat sink temperature level, the lower the COP, as can be deduced from the ideal COP from CARNOT in Eq. (51):

$$
\operatorname{COP}_{\text {CARNOT }}=\frac{\left(1 / T_{m}\right)-\left(1 / T_{h}\right)}{\left(1 / T_{c}\right)-\left(1 / T_{m}\right)}
$$




\subsection{Sensitivity analysis}

8.3.1. Regeneration temperature

The regeneration temperature is a crucial parameter which defines the performance of the MHCS and it also defines its potential applications. For instance, for automobile cooling, the engine can provide temperatures $T_{h}$ of around $90^{\circ} \mathrm{C}$. In solar-cooling applications, a wider temperature range between $80^{\circ} \mathrm{C}$ and $180^{\circ} \mathrm{C}$ can be achieved depending on the technology of the solar panels.

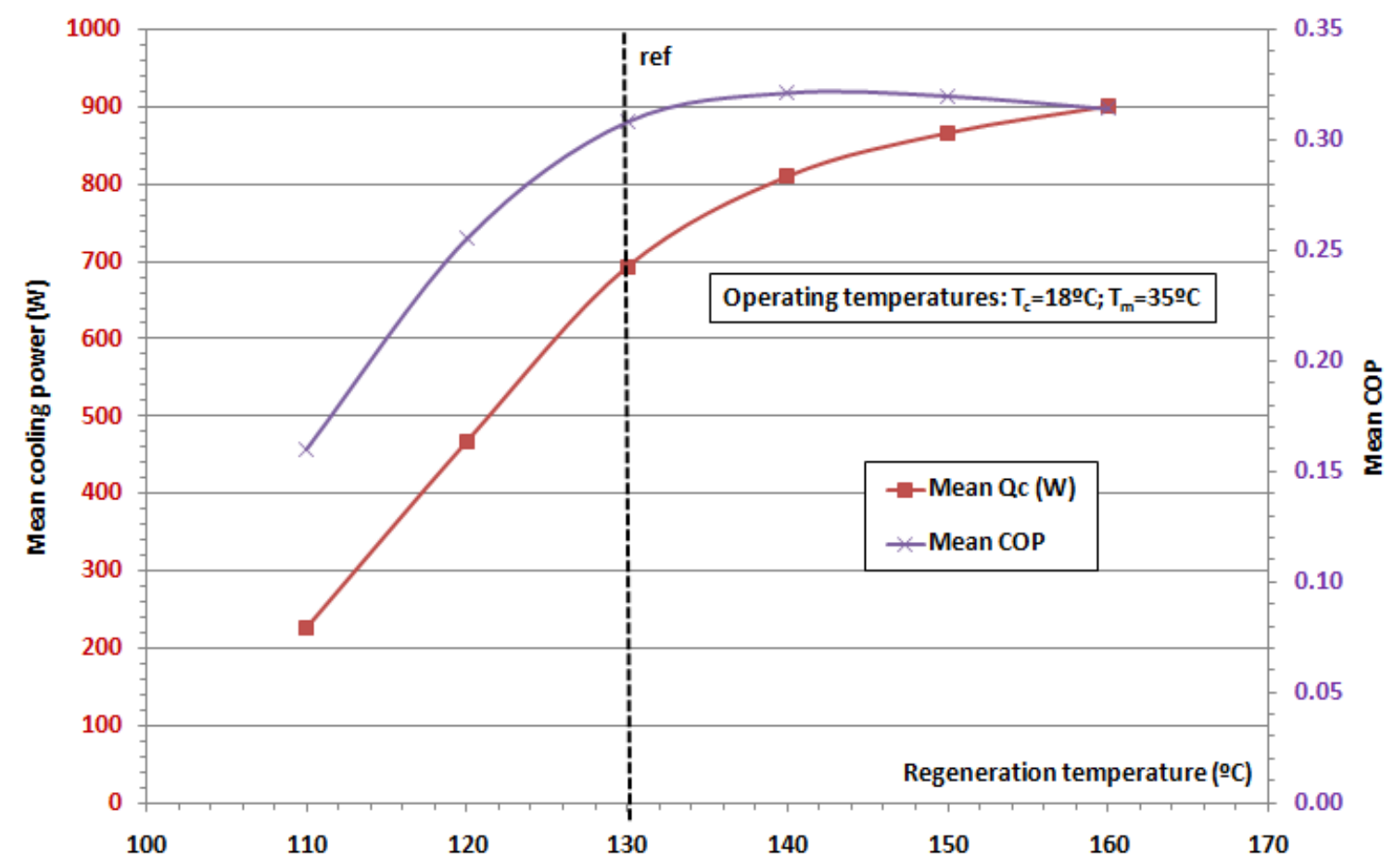

Fig. 61. Performance of the MHCS under different regeneration temperatures $T_{h}$

Fig. 61 illustrates the overall performance of the MHCS under different regeneration temperatures, and is typical for many other sorption systems. At temperatures below $110^{\circ} \mathrm{C}$, the system can hardly work because it is practically impossible to regenerate bed $A$. For more favourable ambient conditions such as for heat sinks of $T_{m}<30^{\circ} \mathrm{C}$, test 6 showed that it is possible to work with a regeneration temperature of $100^{\circ} \mathrm{C}$, although with a very low cooling power. 


\section{Chapter 8 - OPTIMISATION AND DESIGN OF THE MHCS}

In general terms, the higher the regeneration temperature, the higher the metal hydride concentration in bed $A$ by the end of the regeneration phase. $A$ maximum COP of 0.32 is achieved for a regeneration temperature of around $140^{\circ} \mathrm{C}$. Above this temperature, it is not possible to desorb more hydrogen from bed $B$ in the regeneration phase, because this reactor is reaching the left limit of its plateau region. Thus, a higher regeneration temperatures increases the mean heating power but the mean cooling power remains practically constant, hereby decreasing the overall COP. This aspect can be clearly seen in Fig. 62 and Fig. 63, where the operating conditions of each alloy have been compared with their static P-C-T's. As also studied by M. Nagel et al. [90], a comparison between the actual and static P-C curves helps analyze the results. However, instead of an analytical approach [90], the actual P-C curves have been obtained by means of the dynamic, physical model explained in Chapter 6 . In the actual P-C curves, the temperature is dynamic, whereas in the static P-C-Is the temperature is constant.

As seen in Fig. 62, the hot temperature level $T_{h}$ only has an effect on the final pressure of the regeneration phase. In order to charge reactor $A$, the pressures in bed $B$ have to be higher, and this is achieved with the increase of temperature in bed $B$. The maximum concentration in bed $A$ is defined by the intersection between the absorption curves of $\mathrm{A} 3$ at $35^{\circ} \mathrm{C}$ and the desorption curves of $\mathrm{B} 3$ at the regeneration temperature $T_{h}$. Hence, the higher the regeneration temperature, the higher the pressures in bed $\mathrm{B}$ and the higher the load of reactor $A$ by the end of the regeneration phase. 
Chapter 8 - OPTIMISATION AND DESIGN OF THE MHCS

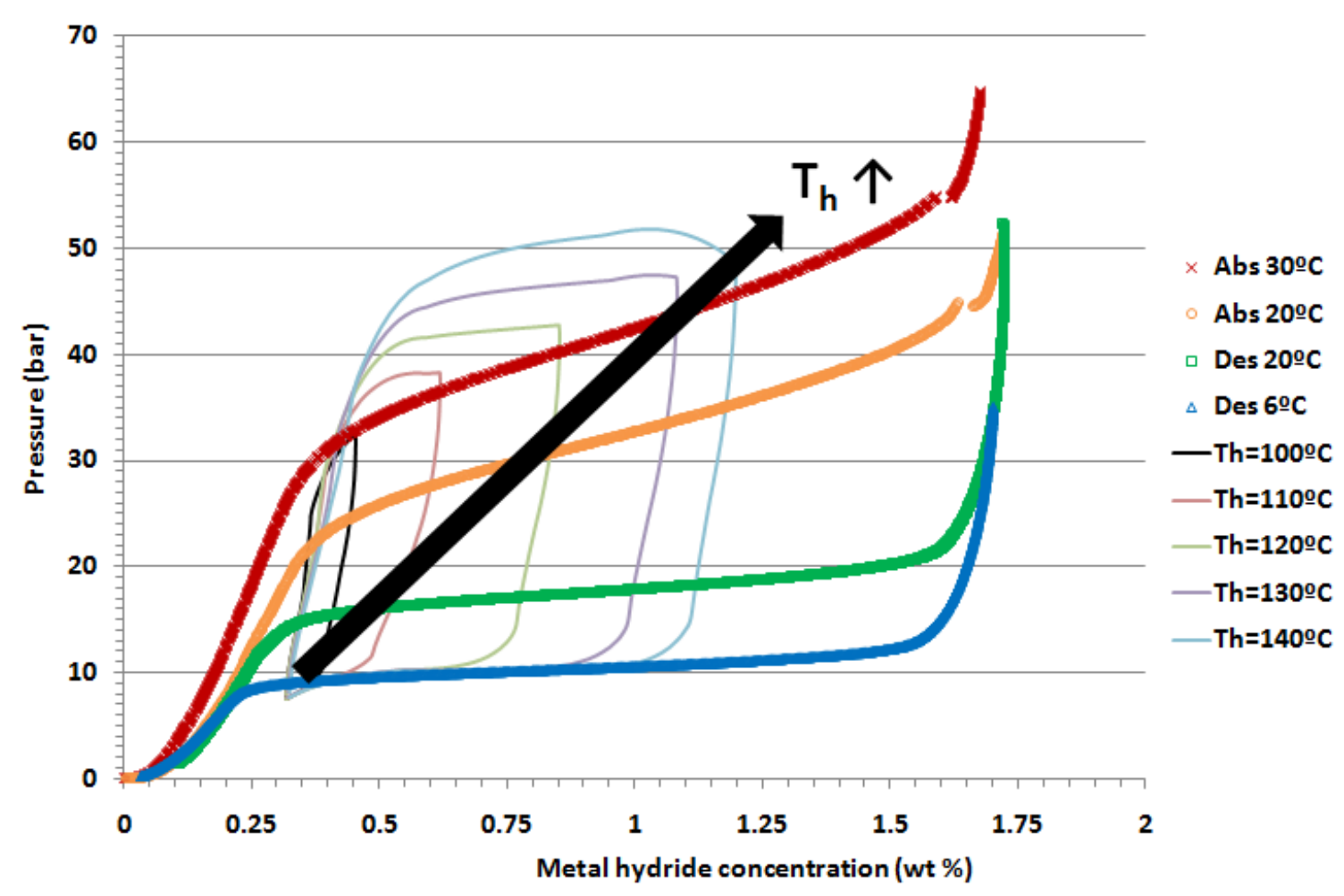

Fig. 62. Effect of the regeneration temperature on the operating conditions of A3

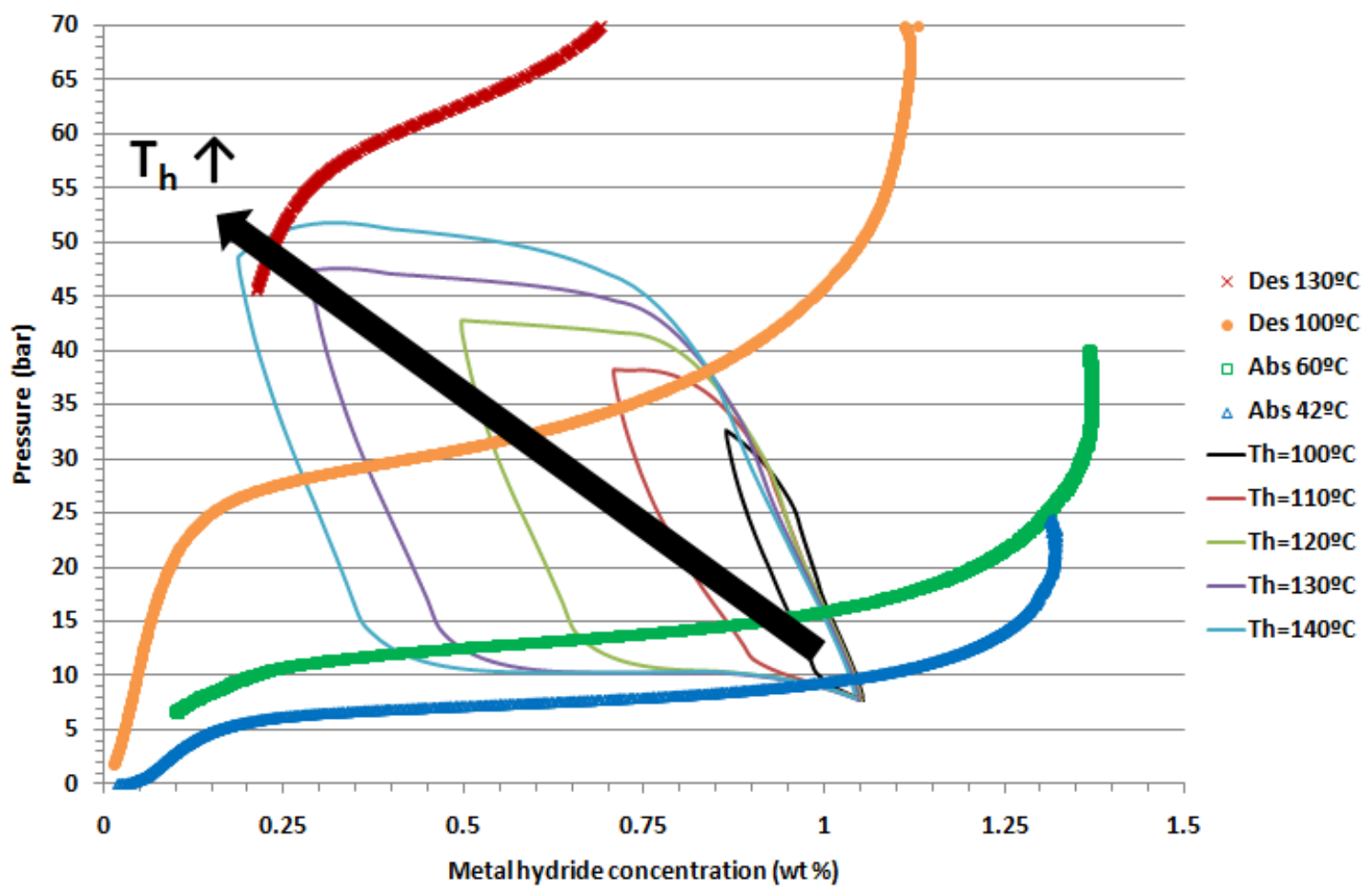

Fig. 63. Effect of the regeneration temperature on the operating conditions of B3 
8.3.2. Chilled water temperature

Although in the reference test the chilled water temperature is produced at $T_{C}=18^{\circ} \mathrm{C}$, it is interesting to analyze if it is possible to work under lower cooling temperatures. The cold temperature $T_{c}$ is generally a design condition which depends on the final application. Water at $18^{\circ} \mathrm{C}$ can be sufficient to cover the sensible cooling demand in any potential application, but the latent load can only be supplied if there is also dehumidification. In this case, temperatures below the dew point are required (conventionally below $12^{\circ} \mathrm{C}$ in fan coils).

Fig. 64 illustrates the performance of the MHCS for different chilled water temperatures $T_{c}$.

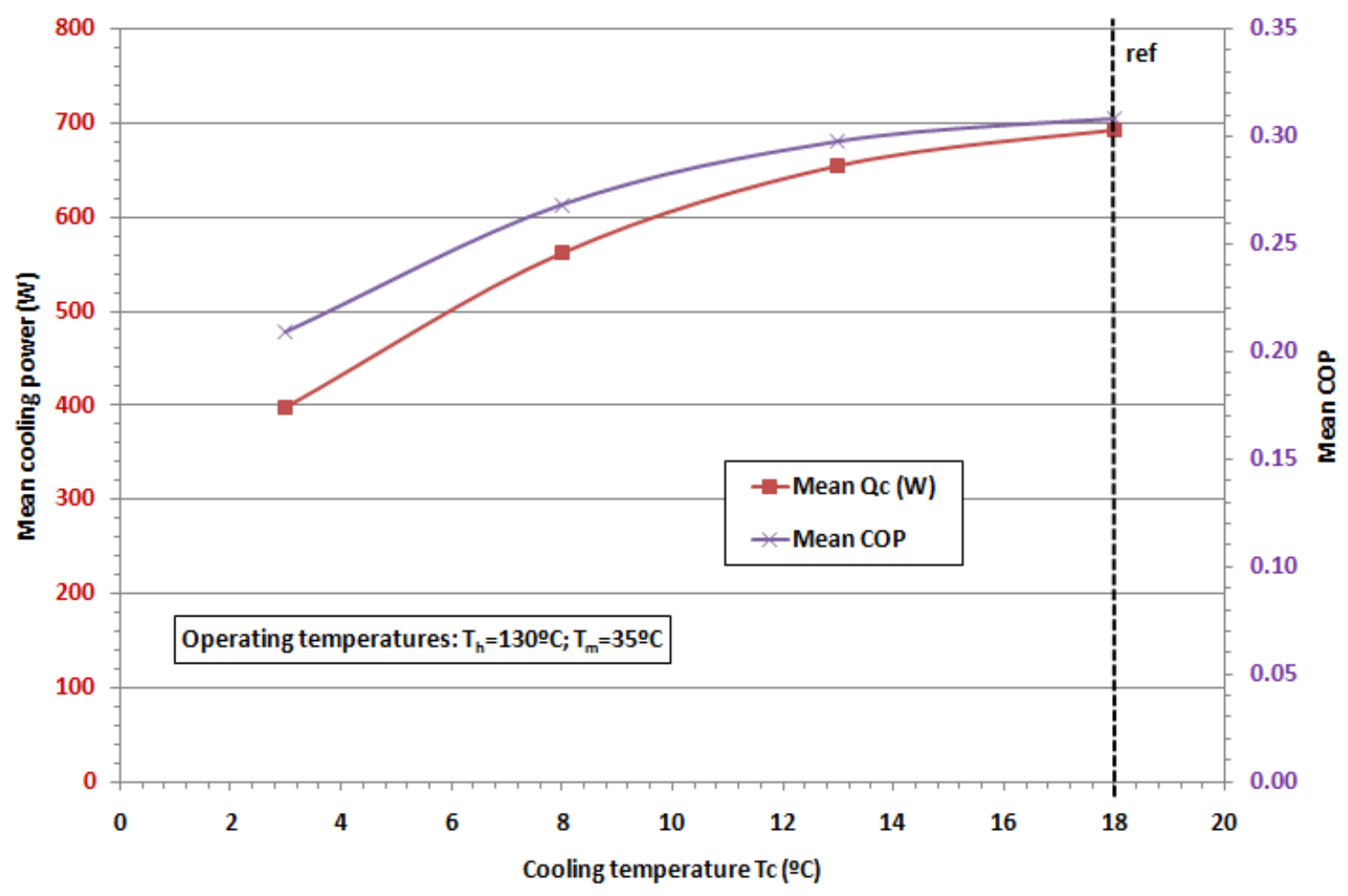

Fig. 64. Performance of the MHCS under different cooling temperatures $T_{c}$

As may be inferred from Fig. 64, it is possible to work under cooling temperatures between $0^{\circ} \mathrm{C}$ and $20^{\circ} \mathrm{C}$. Particularly in the range $12-18^{\circ} \mathrm{C}$, which 
defines the potential applications (cooled ceilings, fan coils) the system can work with a very similar performance

However, the lower the cooling temperature, the lower the mean cooling power and COP. This aspect can be easily understood with the help of Fig. 65 and Fig. 66 , where the actual P-C curves of alloy A have been compared with the static P-C-T curves.

During the cooling phase, the desorption pressure of reaction bed $A$ has to be higher than the absorption pressure of reaction bed $B$. If the cooling temperature increases, then the equilibrium pressure in $A$ increases. This means that the pressure difference with respect to the equilibrium pressures in reaction bed $B$ (which is held at $T_{m}$ ) is higher, and more hydrogen can be exchanged. In practical terms, this implies that the higher the cooling temperature, the more hydrogen can be exchanged between the reactors, as illustrated in Fig. 65 and Fig. 66.

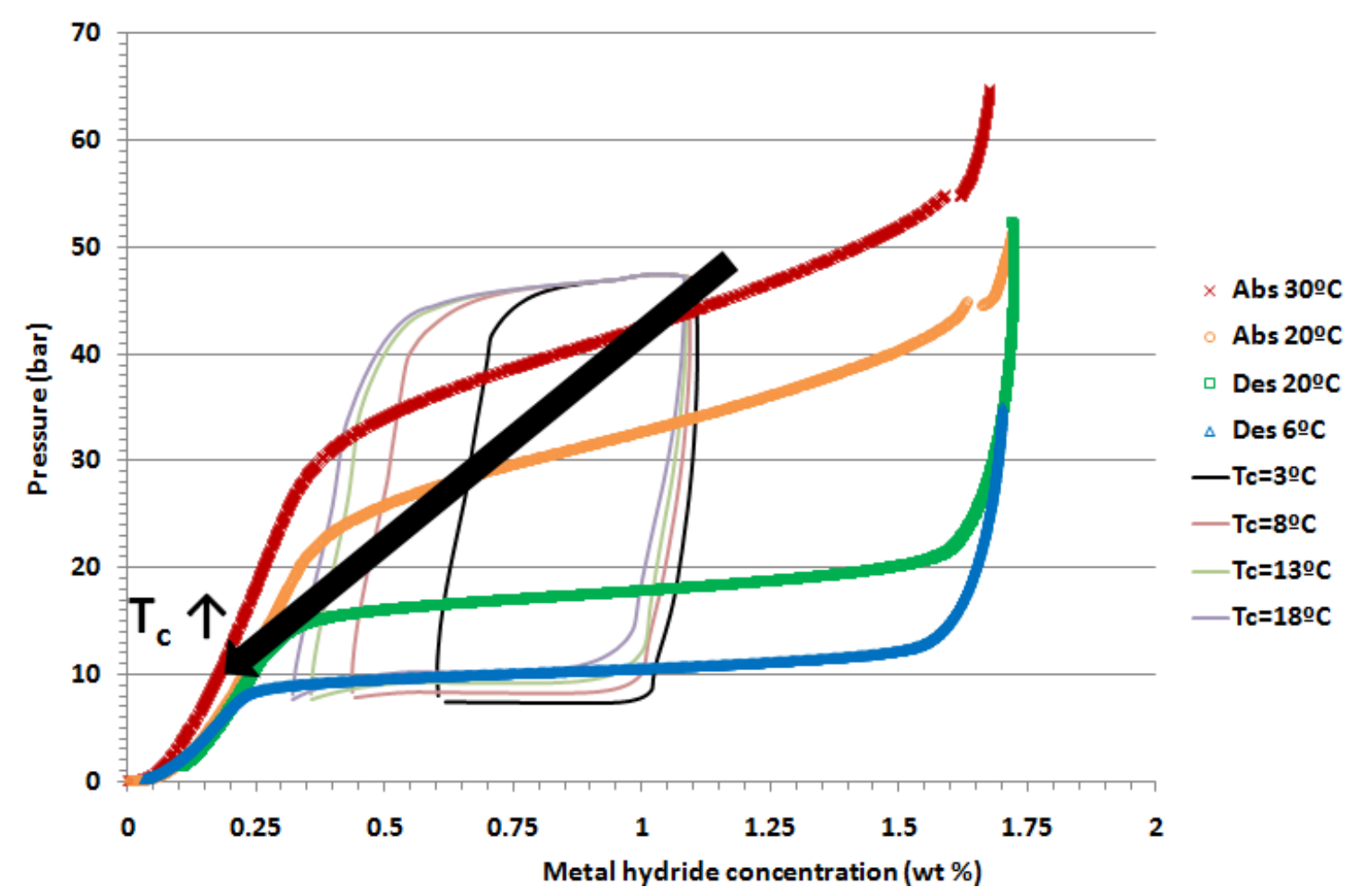

Fig. 65. Effect of the cooling temperature on the operating conditions of A3 


\section{Chapter 8 - OPTIMISATION AND DESIGN OF THE MHCS}

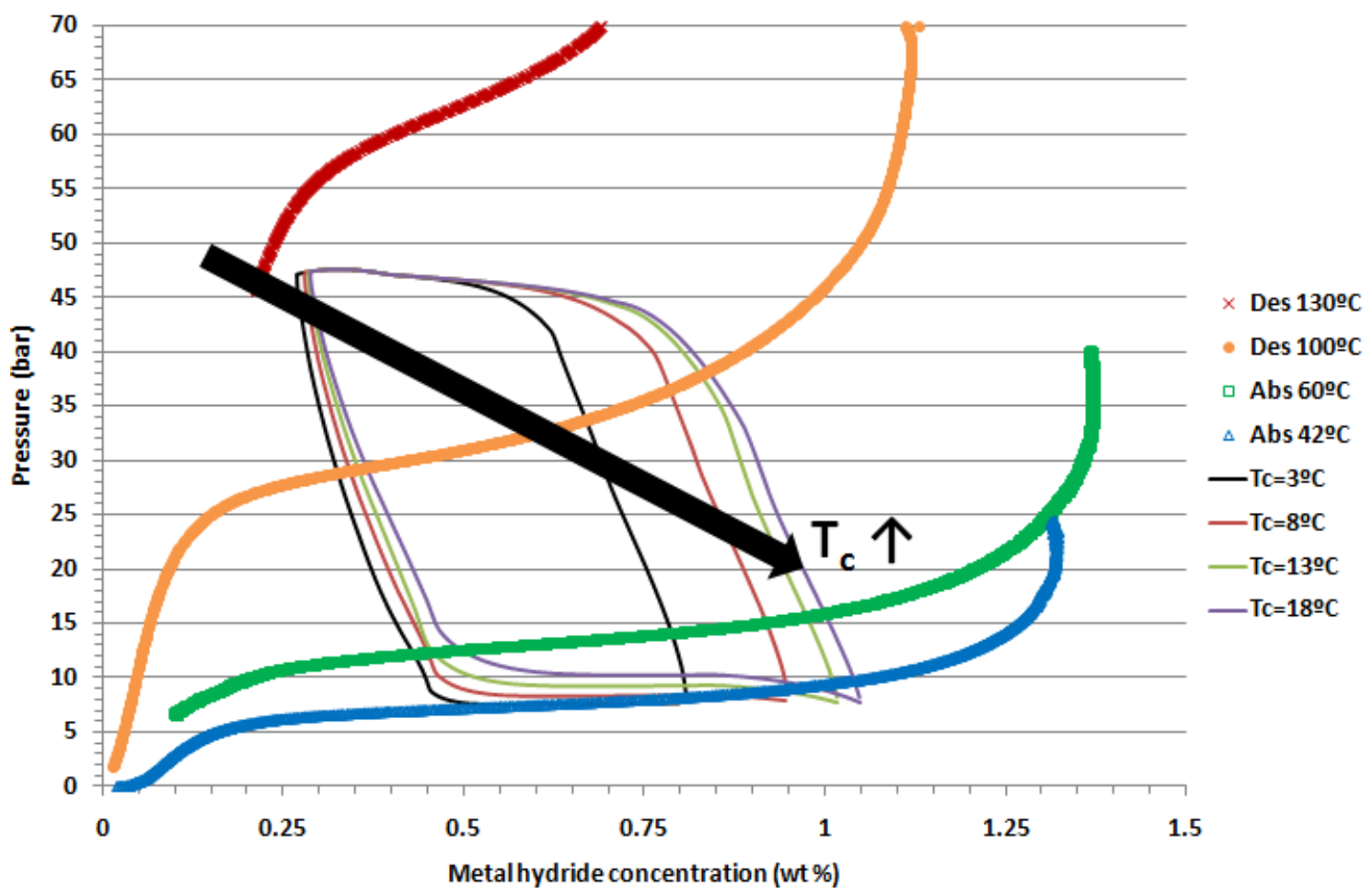

Fig. 66. Effect of the cooling temperature on the operating conditions of B3

\subsubsection{Cycle duration}

The duration of the cycles (commonly referred to as "cycle time") is one of the parameters which is fixed in the simulations and experimental tests, as it determines the duration of the regeneration and the cooling phase. The results of test 5 indicate that the cooling phase can be realized in less time than the regeneration phase. However, the aim of this study is to have a same duration for both the cooling and the regeneration phase. This simplifies the operation of the system and makes it possible to obtain a continuous cooling effect with only 4 reaction beds.

Fig. 67 shows the effect of the cycle duration on the performance of the MHCS. For low cycle durations (below 100s), bed A changes towards the cooling phase before it is regenerated to the maximum value defined by the intersection of the equilibrium pressures in both beds. Between 100s and 120s, bed A can be 
regenerated to this maximum value, and if the cycle duration is longer, there is no significant increase in the cooling power, because the cooling effect takes place mainly in the first part of the cooling phase.

If the COP is additionally taken into account, it is convenient to work with cycle times between $120 \mathrm{~s}$ and $200 \mathrm{~s}$ as then both, the cooling power and the COP, show reasonable high values.

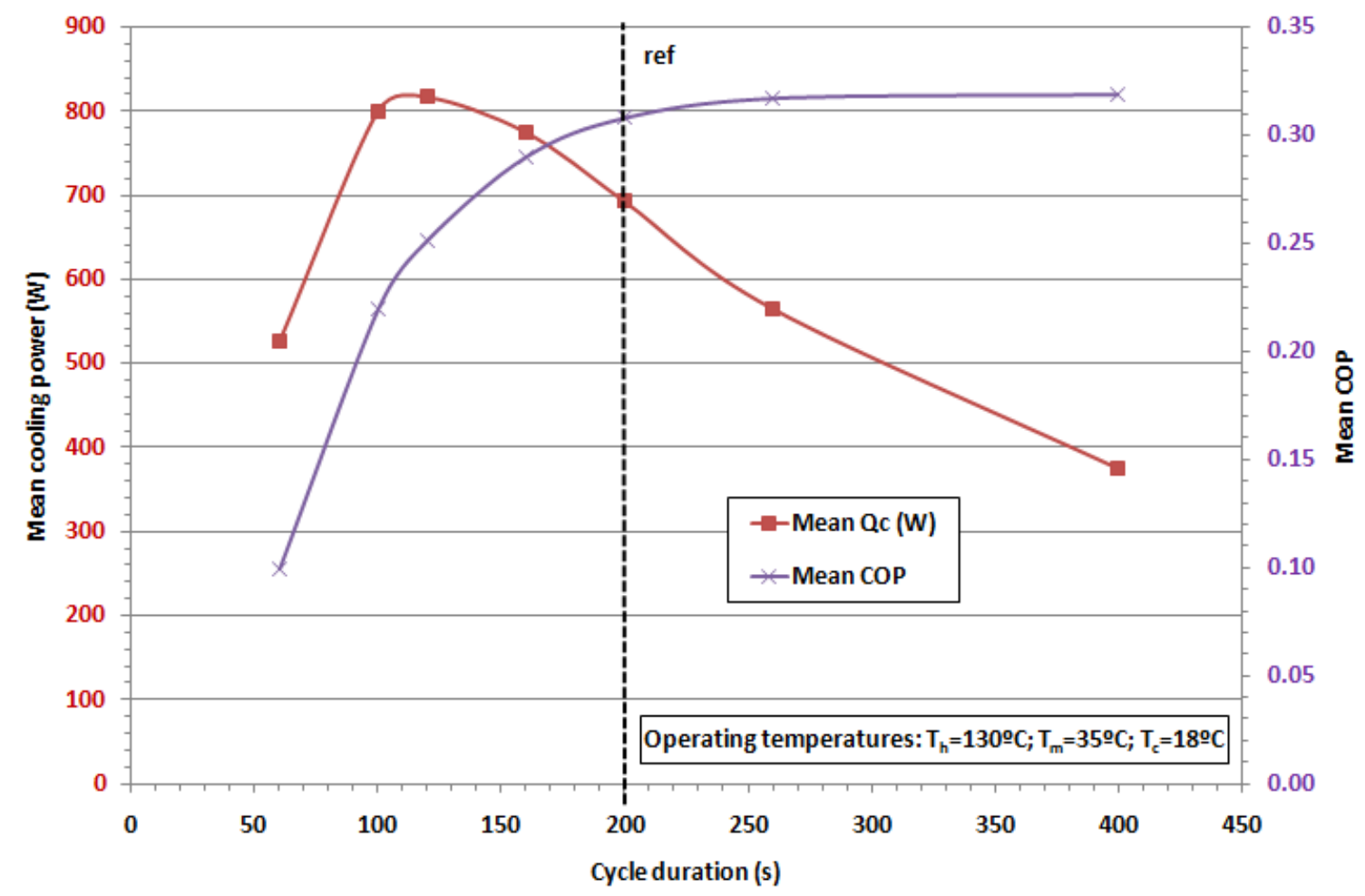

Fig. 67. Performance of the MHCS under different cycle durations $\Delta t_{\text {cycle }}$

Fig. 68 and Fig. 69 help to better understand the effect of the cycle duration. As mentioned previously, the cooling phase requires less time than the regeneration phase. Thus, for different cycle durations, the concentration of the alloys by the end of the cooling phase is practically the same. Only the final concentration by the end of the regeneration phase changes. The higher the cycle duration, the longer the regeneration phase. This allows the charging of bed A with more metal hydride. However, beyond 200s, the COP is practically constant and the cooling power reduces because it is not possible to regenerate more reactor $A$ given the temperature levels $\left(T_{h}, T_{m}, T_{c}\right)$. 
Chapter 8 - OPTIMISATION AND DESIGN OF THE MHCS

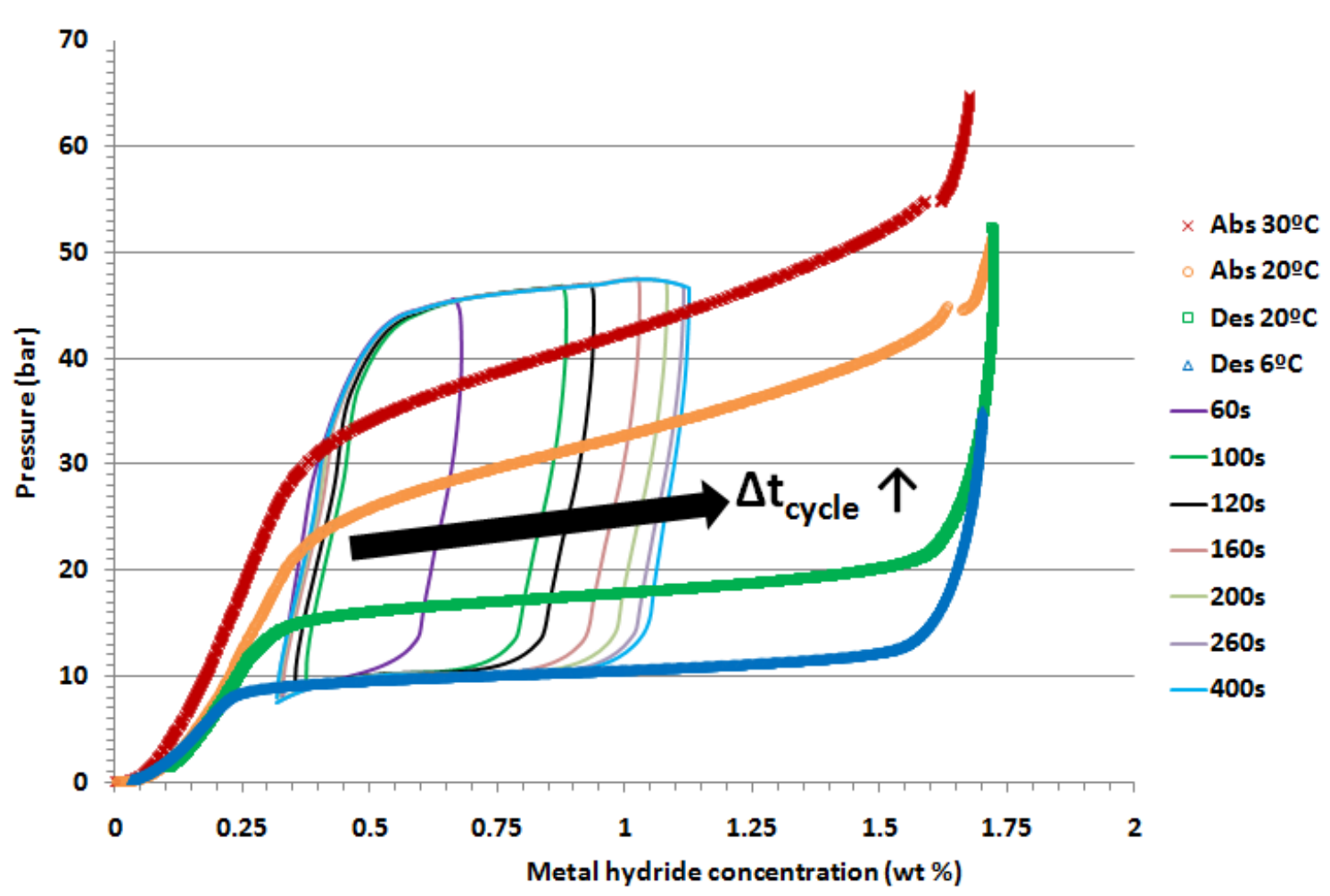

Fig. 68. Effect of the cycle duration on the operating conditions of A3

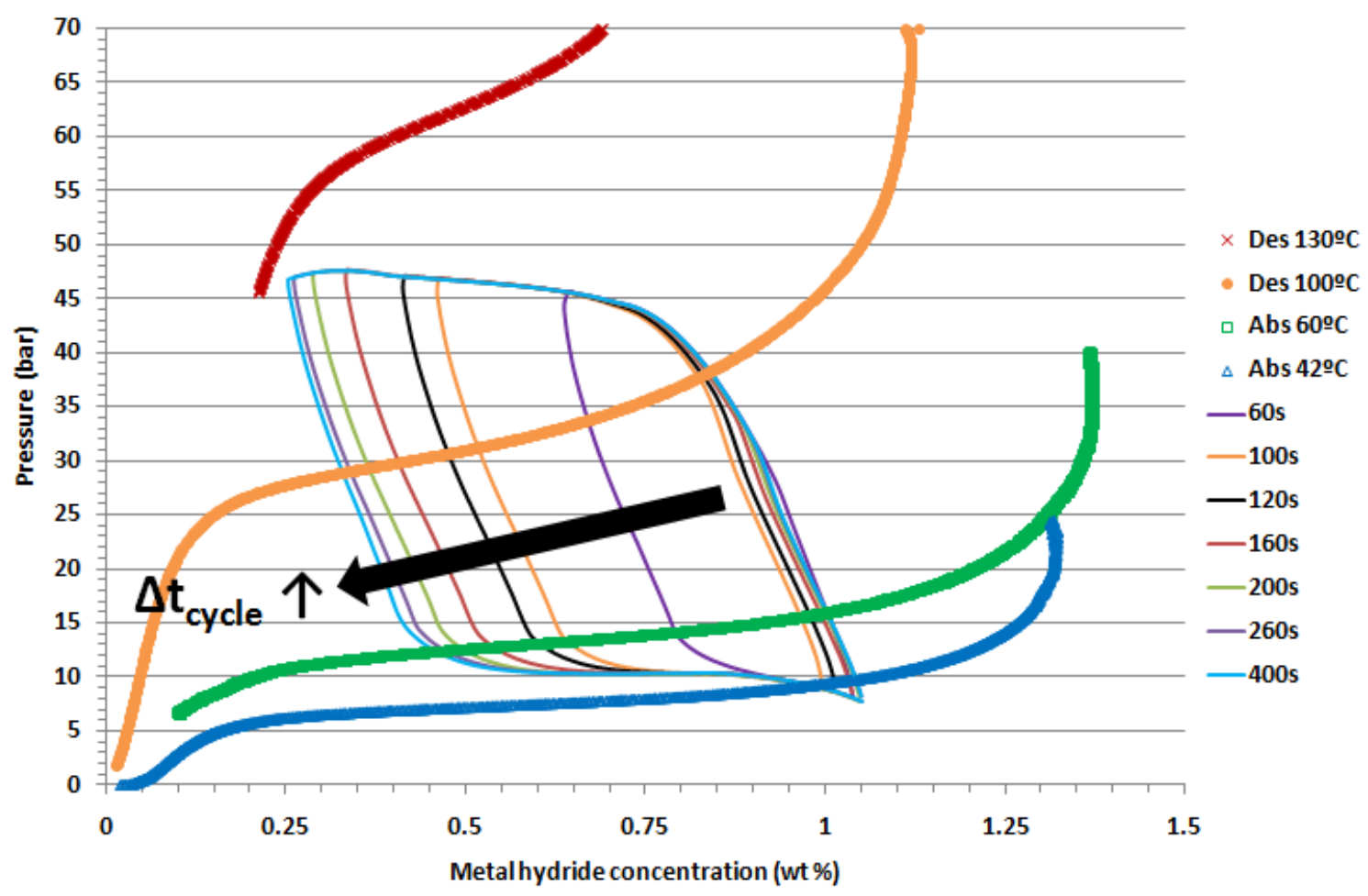

Fig. 69. Effect of the cycle duration on the operating conditions of B3 


\subsubsection{Initial hydrogen charge}

Fig. 70 to Fig. 72 illustrate the impact of the initial hydrogen charge on the performance of the MHCS. The operation of the system starts at the beginning of the regeneration phase, where reactor $B$ has its maximum metal hydride content. In the reference case, bed B has an initial concentration of 1.05 wt \%. In this study, different initial metal hydride concentrations have been analyzed from 0.68 wt \% up to $1.39 \mathrm{wt} \%$.

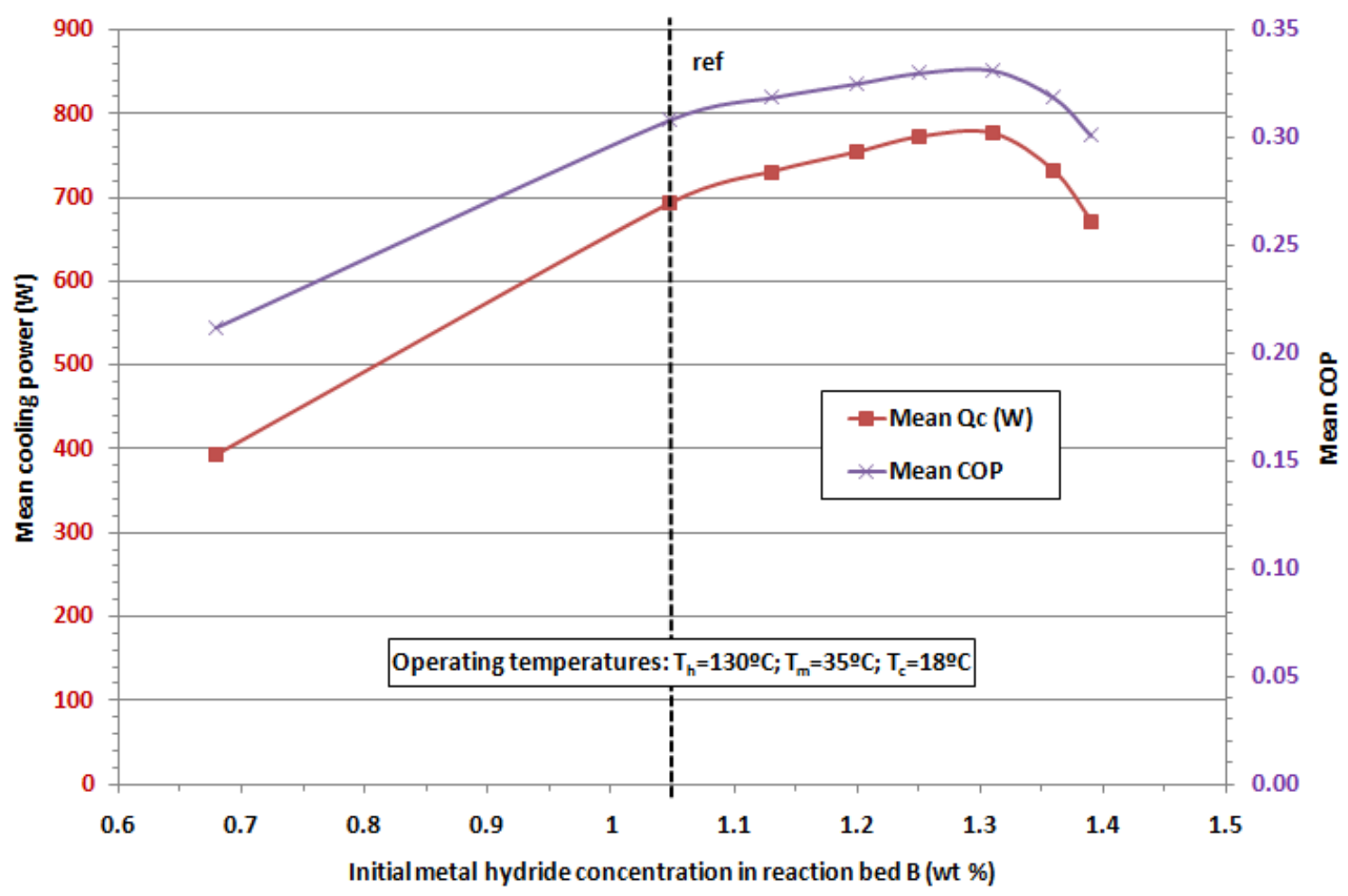

Fig. 70. Performance of the MHCS for different initial metal hydride concentrations in B3

Fig. 70 shows that the initial charge of the reactors has a sensible impact on the performance of the system. The evolution of the cooling power and COP must be analyzed in parallel to Fig. 71 and Fig. 72 where the operating conditions of the reactors have been plotted. If the hydrogen charge is increased, the region where alloy $B$ works is shifted towards the right of its plateau. This pressure increase in the regeneration phase helps to charge bed $A$ with more metal hydride. However, there is an optimum charge value because if alloy $B$ operates 
mostly in the right of its plateau, then the absorption pressures become too high and alloy $A$ cannot fully desorb (the relationship $P_{\text {des, } A}>P_{a b s, B}$ must be fulfilled during the cooling phase). For the optimum value of $1.31 \mathrm{wt} \%$, an additional cooling power of $83 \mathrm{~W}$ is achieved with respect to the reference case.

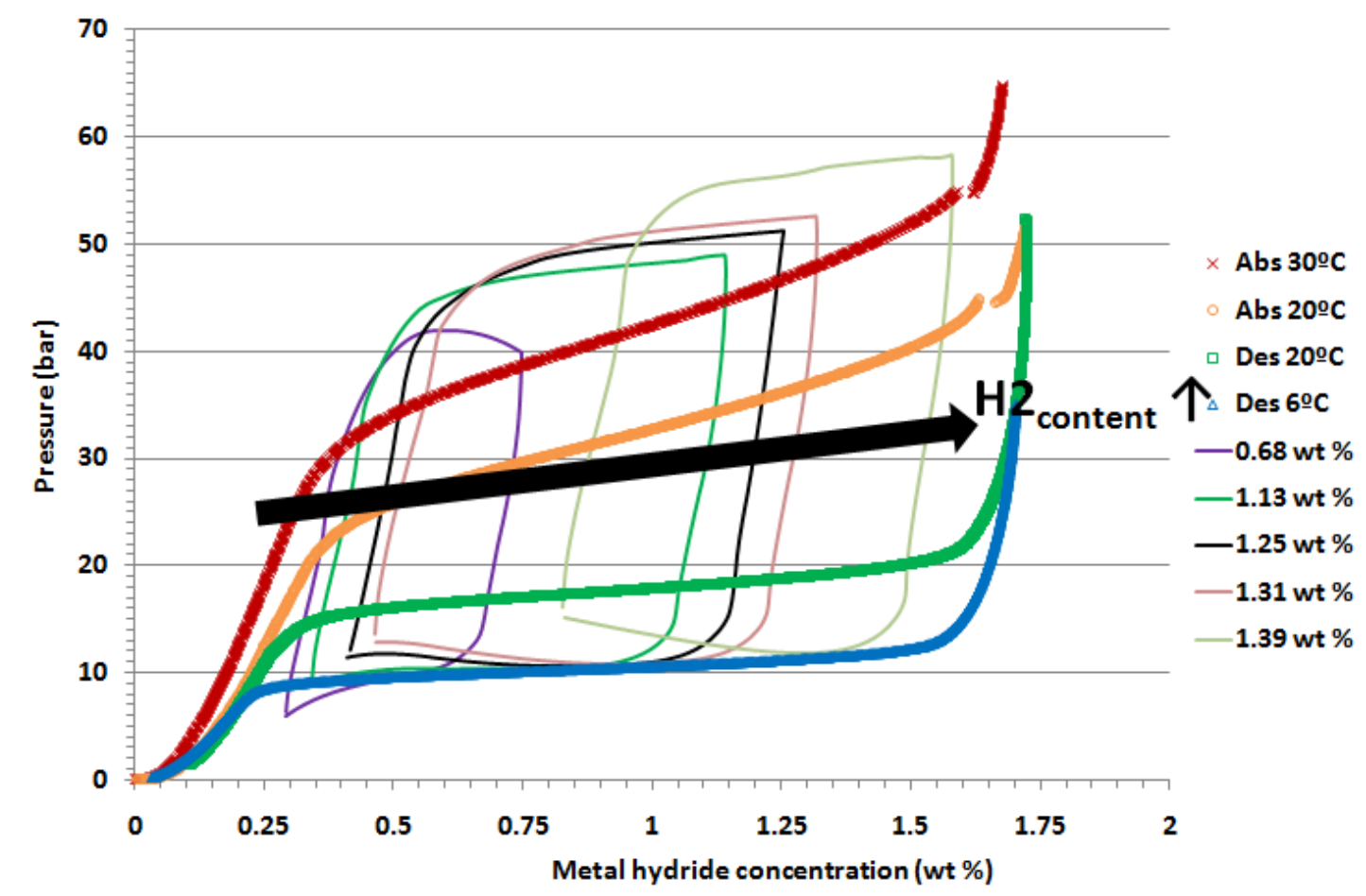

Fig. 71. Effect of the hydrogen charge on the operating conditions of A3

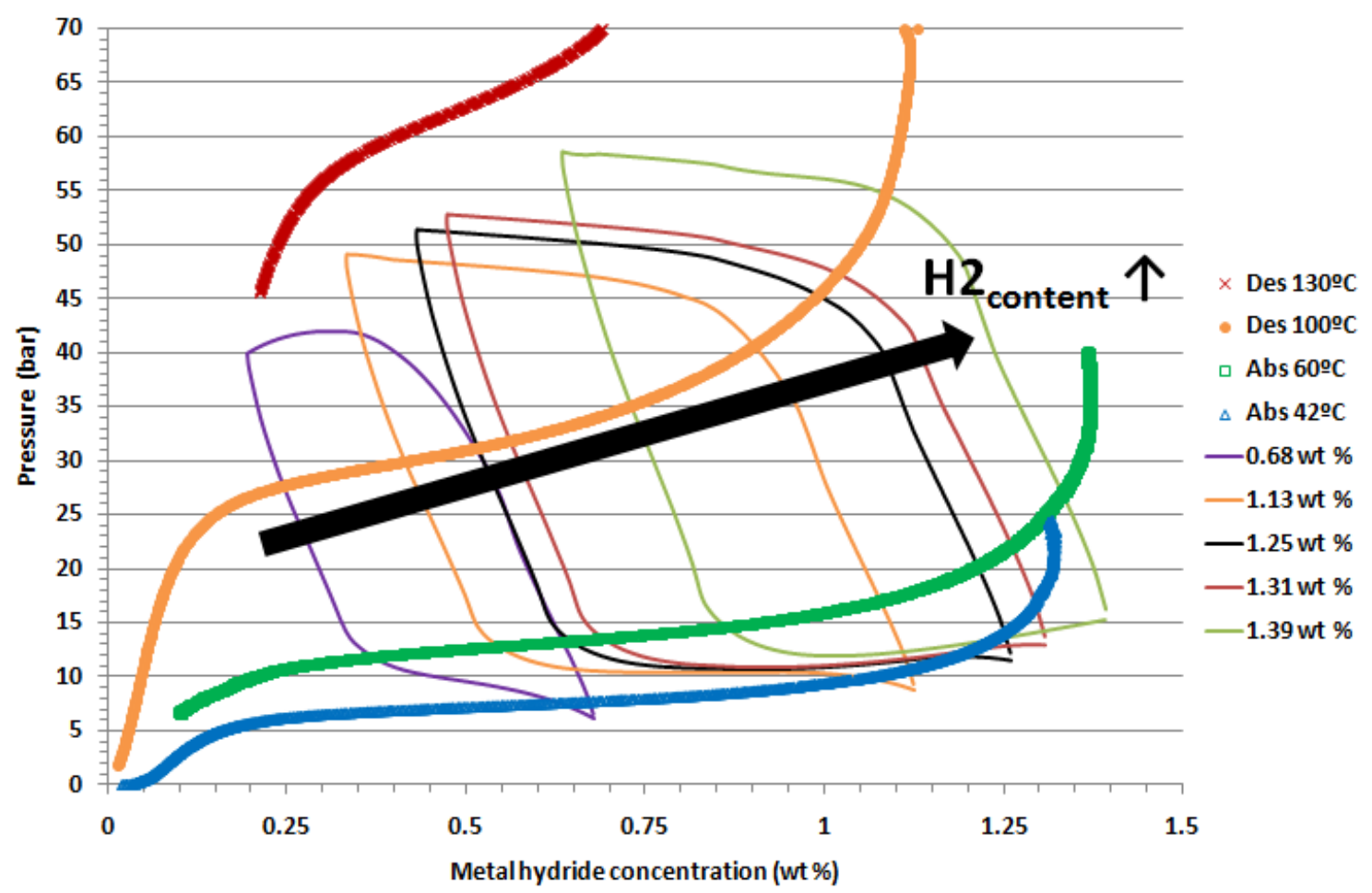

Fig. 72. Effect of the hydrogen charge on the operating conditions of B3 


\subsubsection{Water heat transfer}

In this section, the influence of the overall heat transfer coefficient has been analyzed by means of an enhancement factor $\mathrm{f}$ :

$$
\mathrm{UA}_{\mathrm{w}}=\mathrm{UA}_{\mathrm{w}, \mathrm{ref}} \cdot \mathrm{f}
$$

Different values of $f$ have been tested from 0.5 up to 3 . In the latter case, the overall heat transfer coefficient is 3 times higher than in the reference test. In order to achieve this value, increasing the water mass flow rate would not be sufficient and the water tubes should have fins to improve the heat transfer.

\begin{tabular}{|c|c|c|c|c|}
\hline $\mathrm{f}$ factor & Mean MF $(\mathrm{s} / / \mathrm{min})$ & Mean $\mathrm{Q}_{\mathrm{c}}(\mathrm{W})$ & Mean $\mathrm{Q}_{\mathrm{h}}(\mathrm{W})$ & Mean COP \\
\hline 0.5 & 40.4 & 583 & 2122 & 0.275 \\
\hline 1 & 44.8 & 693 & 2247 & 0.308 \\
\hline 1.5 & 45.7 & 708 & 2274 & 0.312 \\
\hline 3 & 46.2 & 713 & 2287 & 0.312 \\
\hline
\end{tabular}

Table 16. Effect of the overall heat transfer coefficient on the performance of the MHCS

Table 16 summarizes the influence of the overall heat transfer coefficient on the performance of the MHCS. The better the heat transfer, the higher the cooling power and the COP. Nevertheless, the differences are not as significant as for other parameters because the heat transfer in the reference case is already very good. Hence the operating conditions are practically the same for the 4 cases. Basically the heat transfer makes the cooling and regeneration phase faster but the differences can only be seen if the cycle durations are shortened. 


\subsubsection{Intrinsic reaction kinetics}

As discussed in Chapter 5, the reaction kinetics of alloy B3 are sensibly lower than the reaction kinetics of alloy A3. Hence, in this subsection the impact of the intrinsic kinetics of alloy B3 have been analyzed. As indicated in Chapter 3, the reaction kinetics may be improved, for instance, by using catalysts [55].

The effect of the intrinsic kinetics has been studied by modifying the reaction rate constant of the kinetic equation with the introduction of the following enhancement factor:

$$
\mathrm{K}_{\mathrm{B}}=\mathrm{K}_{\mathrm{B}, \mathrm{ref}} \cdot \mathrm{f}
$$

Again, $f$ values of $0.5,1,1.5$ and 3 have been tested. Table 17 summarizes the effect of the intrinsic reaction kinetics of $B 3$.

\begin{tabular}{|c|c|c|c|c|}
\hline$f$ factor & Mean $\mathrm{H}_{2}$ transfer (sl/min) & Mean $\mathrm{Q}_{\mathrm{c}}(\mathrm{W})$ & Mean $\mathrm{Q}_{\mathrm{h}}(\mathrm{W})$ & Mean COP \\
\hline 0.5 & 42.9 & 661 & 2191 & 0.302 \\
\hline 1 & 44.8 & 693 & 2247 & 0.308 \\
\hline 1.5 & 45.4 & 700 & 2261 & 0.310 \\
\hline 3 & 45.8 & 706 & 2273 & 0.311 \\
\hline
\end{tabular}

\section{Table 17. Effect of the intrinsic kinetics of B3} on the performance of the MHCS

The intrinsic kinetics exerts a similar impact on the performance as the heat transfer. The higher the reaction rate, the faster the reaction and the higher the mean hydrogen transfer. However, an increase of the reaction rate of 3 times with respect to the current value yields no significant differences (only $13 \mathrm{~W}$ additional cooling power) because the reaction is already very fast. As for the heat transfer in the previous subsection, the impact of this higher reaction rate can only be seen if the cycle duration is shortened. 
8.3.7. Effective thermal conductivity

As mentioned in Chapter 3, the effective thermal conductivity of the metal powers is sensibly lower than the thermal conductivity of a metal. The powder acts as a porous material and the effective thermal conductivity depends on different heat transfer mechanisms relative to the fluid, to the gas and to the mixed path.

The impact of the effective thermal conductivity has been analyzed by means of Eq. (54), where the f factor has values of $0.5,1,3$ and 6 . This increase in the effective conductivity can be achieved for instance with aluminium foams, but a careful attention has to be paid to guarantee the same diffusion conditions through the power.

$$
U A_{M H}=\frac{2 \cdot \pi \cdot \lambda_{M H} \cdot L \cdot n_{\text {tubes }}}{\ln \left(\frac{D_{e}+S}{D_{e}}\right)} \cdot f
$$

Table 18 shows the influence of the effective thermal conductivity on the cooling performance. The higher the conductivity, the higher the performance in terms of cooling power, but the differences are hardly noticeable because of the short heat conduction distance in the metal hydride layer. The COP is practically constant for all values (COP $\approx 0.308$ ).

\begin{tabular}{|c|c|c|c|c|}
\hline f factor & $\begin{array}{c}\text { Mean H2 transfer } \\
(\mathrm{sl} / \mathrm{min})\end{array}$ & $\begin{array}{c}\text { Mean Qc } \\
(\mathrm{W})\end{array}$ & $\begin{array}{c}\text { Mean Qh } \\
(\mathrm{W})\end{array}$ & Mean COP \\
\hline 0.5 & 42.8 & 666 & 2192 & 0.304 \\
\hline 1 & 44.8 & 693 & 2247 & 0.308 \\
\hline 3 & 45.8 & 702 & 2275 & 0.309 \\
\hline 6 & 46.1 & 703 & 2280 & 0.308 \\
\hline
\end{tabular}

Table 18. Effect of the effective thermal conductivity on the performance of the MHCS 


\section{Chapter 8 - OPTIMISATION AND DESIGN OF THE MHCS}

\subsubsection{Reaction enthalpy}

As mentioned previously, high temperatures are required in order to guarantee the relationship $P_{\text {eq,des, } B}>P_{\text {eq,abs, } A}$ during the regeneration phase. Below $110^{\circ} \mathrm{C}$, it is hardly possible to regenerate reactor $\mathrm{A}$ given the current alloys $\mathrm{A} 3$ and $\mathrm{B} 3$.

However, it is possible to treat the alloys in order to taylor them towards a specific application. In solar cooling applications for instance, a lower regeneration temperature is interesting in order to avoid using expensive solar technologies such as compound parabolic collectors. This can be achieved if alloy B3 has a higher plateau pressure, in other words, if the reaction enthalpy is lower.

As highlighted by $\mathrm{A}$. Züttel [42], the partial replacement of $\mathrm{Ni}$ atoms with other elements such as $\mathrm{Cu}, \mathrm{Fe}$ or $\mathrm{Al}$ can change the plateau pressures. The mentioned atoms are then bounded in the interstitial sites of the crystal, and thus the size of the interstitial sites is changed. This can improve the hydrogen diffusion through the metal lattice, lower the reaction enthalpy and hence increase the equilibrium pressure.

Fig. 73 to Fig. 75 show the effect of the reaction enthalpy on the performance of the system. If the regeneration temperature is fixed at $130^{\circ} \mathrm{C}$, the lower the reaction enthalpy, the higher the regeneration pressures and the higher the cooling power. For instance, with respect to the reference case, $725 \mathrm{~W}$ cooling power may be achieved with a decrease of the enthalpy of $200 \mathrm{~J} / \mathrm{mol}$. Despite the small increase in the performance, this reduction of enthalpy does not allow to reduce the regeneration temperature sensibly, because it also increases the equilibrium pressures in $B$ during the cooling phase, hereby making the condition $P_{\text {eq,des, } A}>P_{\text {gas }}>P_{\text {eq,abs,B }}$ more difficult. 


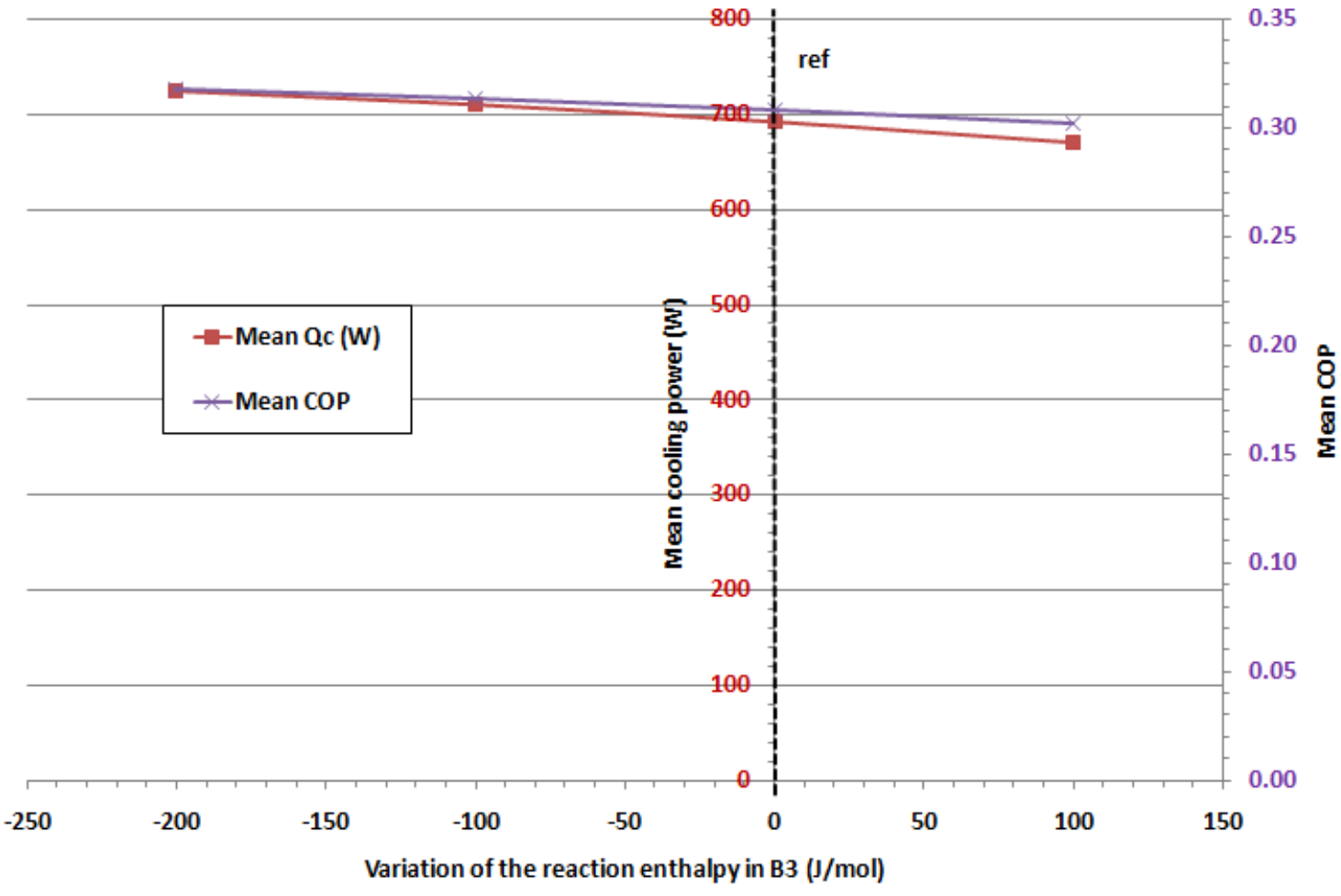

Fig. 73. Effect of the reaction enthalpy in B3 on the performance of the MHCS

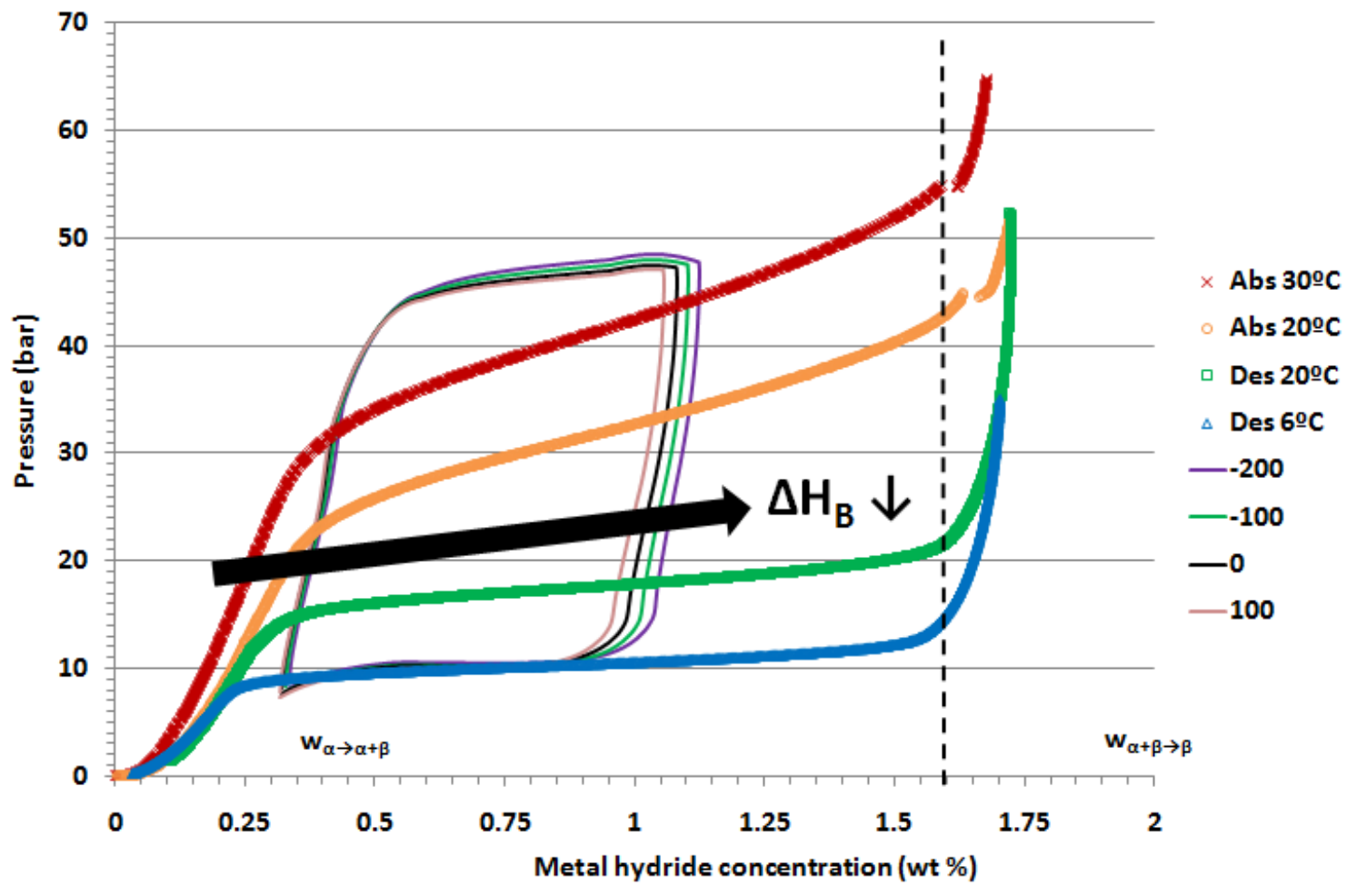

Fig. 74. Effect of the reaction enthalpy in B3 on the operating conditions of $\mathrm{A} 3$ 


\section{Chapter 8 - OPTIMISATION AND DESIGN OF THE MHCS}

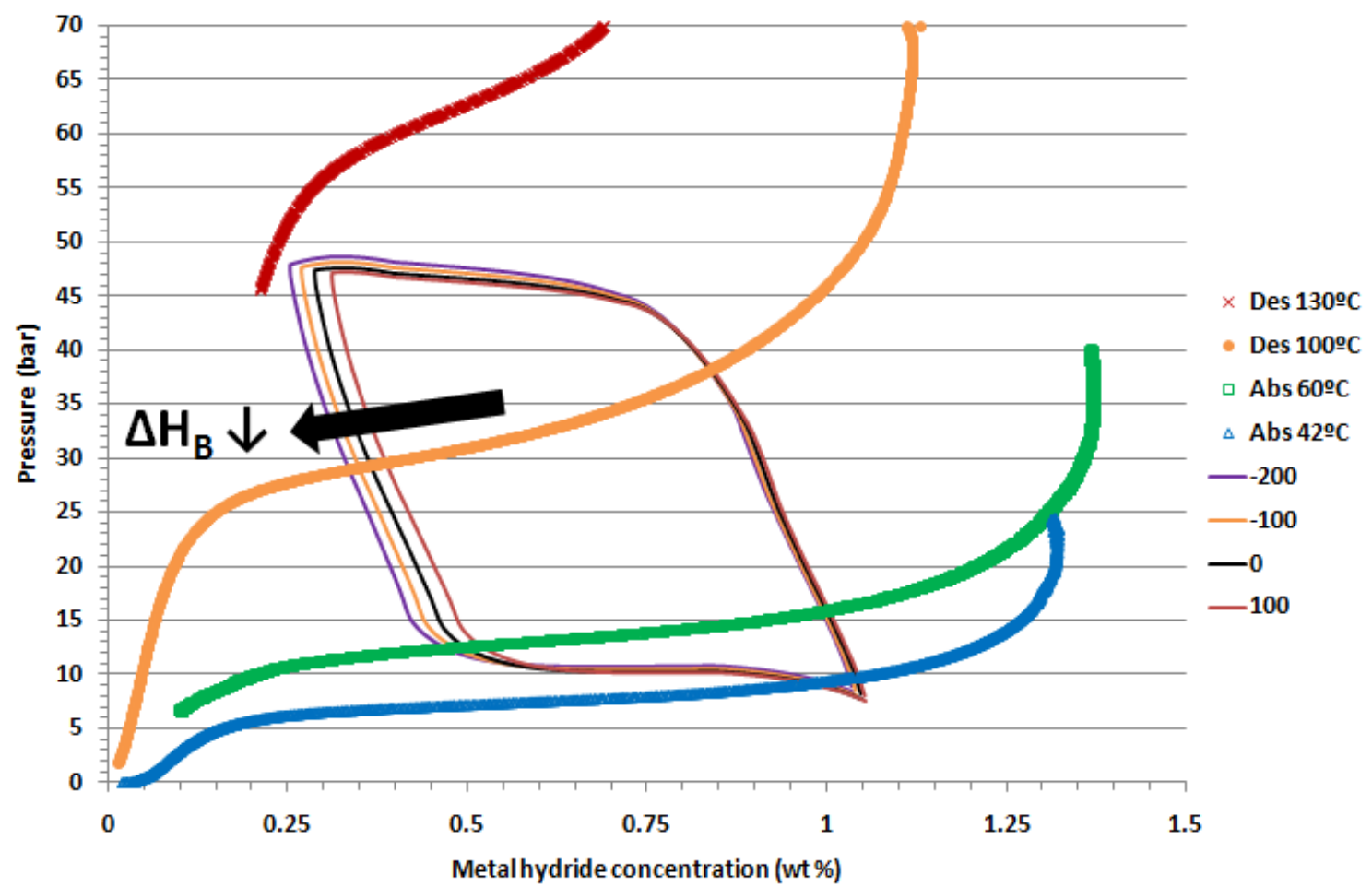

Fig. 75. Effect of the reaction enthalpy in B3 on the operating conditions of B3

\subsection{Optimised metal hydride cooling system}

The results of the sensitivity analysis have shown that the cooling performance of the MHCS can be improved by optimizing the operation of the reactors. The parameters which have a bigger impact on the performance are the cycle duration, the initial metal hydride concentration and the characteristics of the alloys. Given the kinetics of alloys A3-B3 and the good heat transfer in the current prototype, it is not necessary to improve the heat transfer with the water circuit, nor the effective thermal conductivity of the alloys.

As shown in literature [1], the use of metal hydrides in cooling applications presents a drawback in the low COPs. In the current MHCS, even if plastic heads are used, it is inevitable to have a passive metal mass of around $1.5 \mathrm{~kg}$ which decreases the COP substantially, generally around 0.3. Nevertheless, the same MHCS is interesting in terms of its high volumetric cooling power. 


\section{Chapter 8 - OPTIMISATION AND DESIGN OF THE MHCS}

The optimization has been divided into two subsections. In the first one (8.4.1), only the operating conditions have been optimized. Basically, the initial hydrogen charge and the cycle duration have been modified. These modifications can be easily done in the laboratory because they do not involve removing the powders from the current reactors.

The second optimization (subsection 8.4.2) involves treating the alloys so that they work under lower regeneration temperatures. This implies removing the current powders, preparing the new ones, inserting them in the reactors and activating them. Thus, these modifications are more cost and time expensive.

\subsubsection{Optimal operating conditions}

Given the temperature levels of the reference test $\left(T_{h}=130^{\circ} \mathrm{C}, T_{m}=35^{\circ} \mathrm{C}\right.$, $\mathrm{T}_{\mathrm{c}}=18^{\circ} \mathrm{C}$ ), the optimal operating conditions are achieved for a cycle duration of 120 s with an initial metal hydride concentration in B of $1.14 \mathrm{wt} \%$ and of $0.43 \mathrm{wt}$ $\%$ in bed $A$ at the beginning of the regeneration phase. Table 19 summarizes the optimal operation parameters for reactor A3-B3 so as to achieve the highest mean cooling power.

\begin{tabular}{|c|c|c|}
\hline$\Delta \mathrm{t}_{\text {cycle }}$ & 120 & $\mathrm{~s}$ \\
\hline $\mathrm{wB}_{\text {init_reg }}$ & 1.15 & wt $\%$ \\
\hline $\mathrm{wA}_{\text {init_reg }}$ & 0.43 & wt $\%$ \\
\hline
\end{tabular}

Table 19. Optimal operation parameters with reactors A3-B3

With these operating conditions, a mean cooling power of $853 \mathrm{~W}$ is achieved. In comparison to the reference test, this implies an increase in the mean cooling power of $23 \%$.

The key to make the hydrogen transfer faster and to obtain a larger operation in the plateau is to increase the initial metal hydride concentration in bed $\mathrm{B}$. This aspect can be clearly seen in Fig. 76 and Fig. 77, where the operating conditions of each alloy have been plotted. 
Chapter 8 - OPTIMISATION AND DESIGN OF THE MHCS

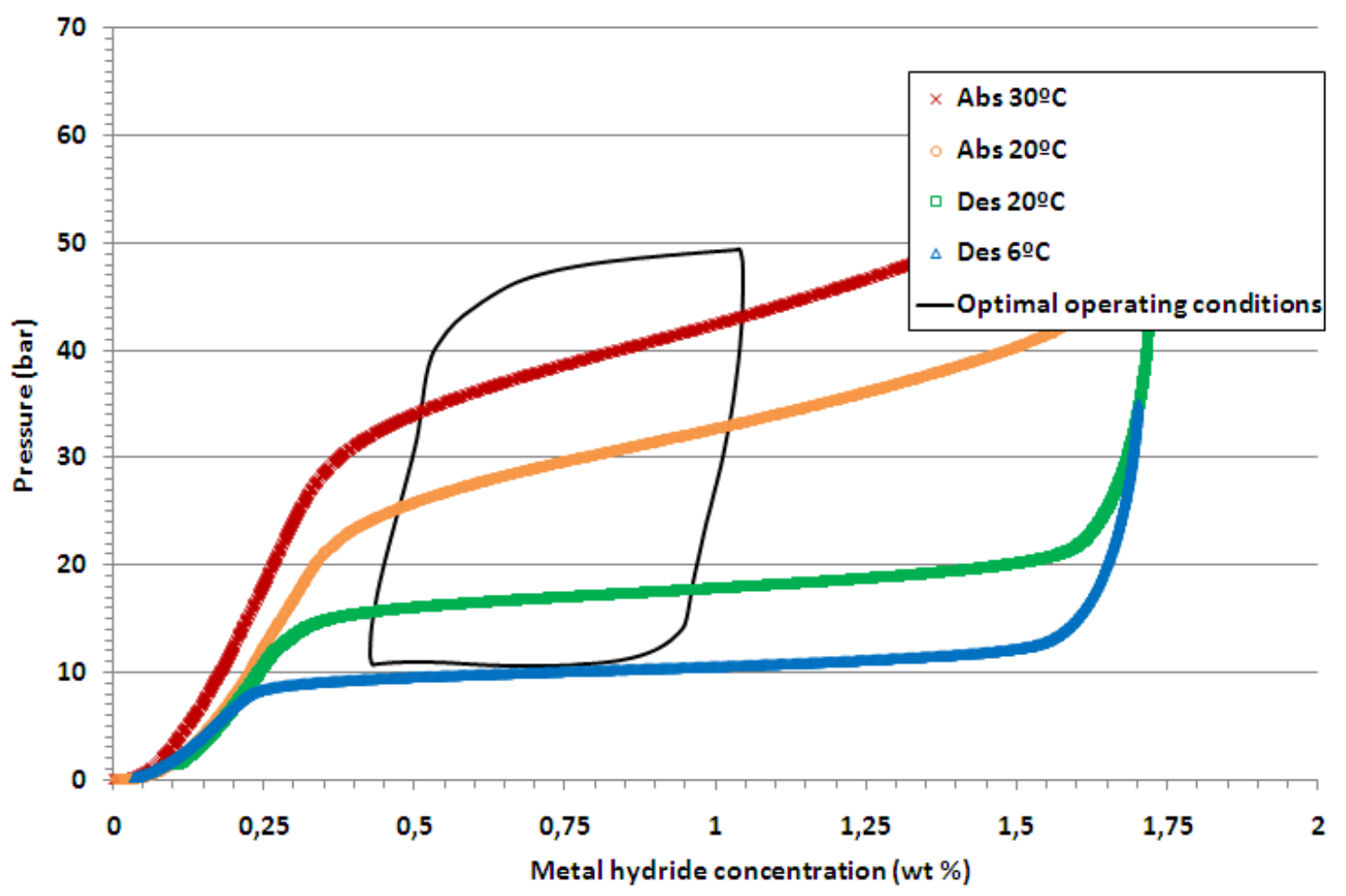

Fig. 76. Operating conditions in A3 with an optimised operation

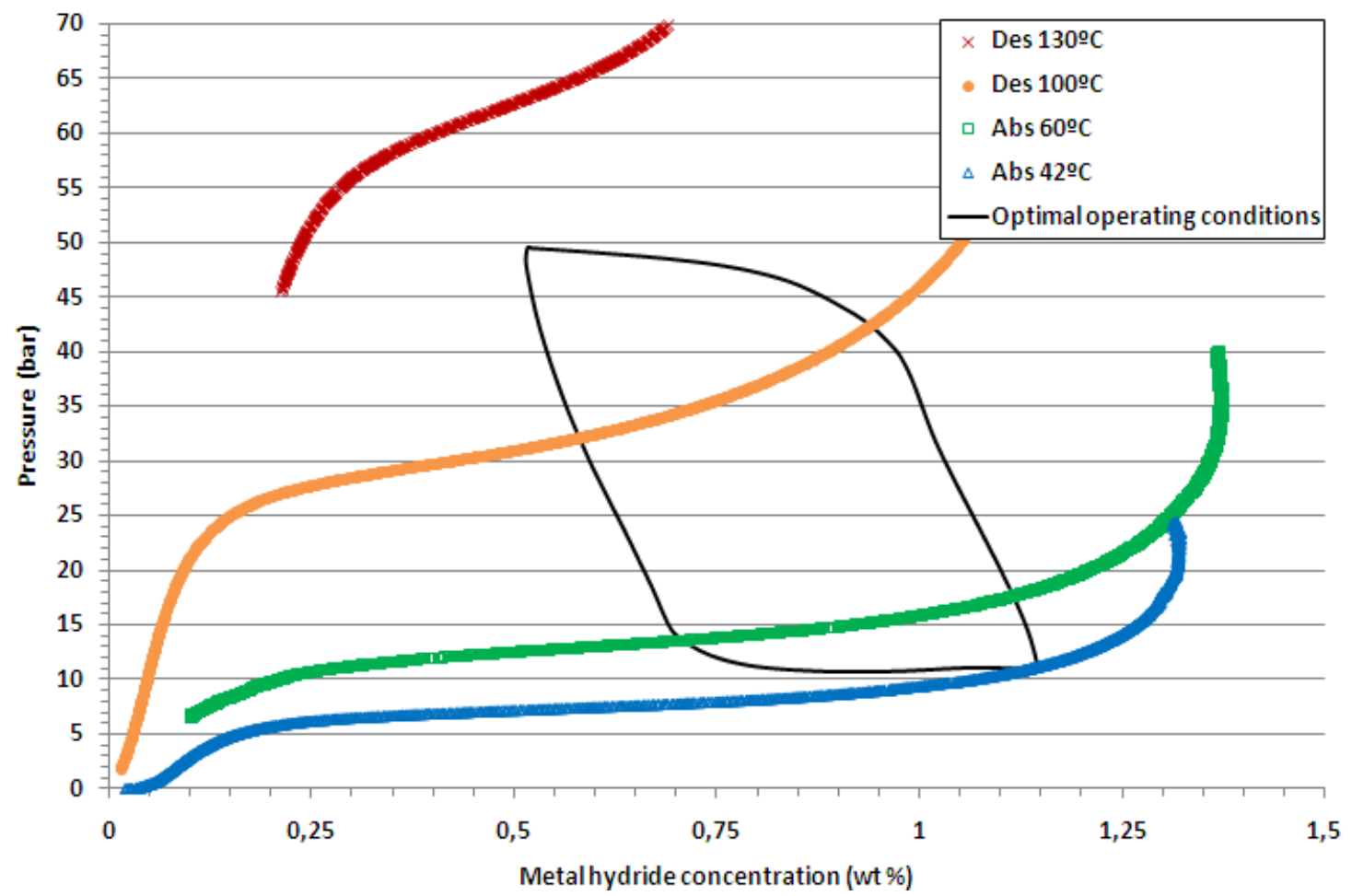

Fig. 77. Operating conditions in B3 with an optimised operation 


\section{Chapter 8 - OPTIMISATION AND DESIGN OF THE MHCS}

As shown in Fig. 77, if alloy B3 operates mainly in the right region of its plateau, then the pressures are higher in the regeneration and hence more hydrogen can be exchanged in this phase.

If required, this optimized solution would also allow to work under lower regeneration temperatures $T_{h}$ than for the reference conditions because the pressures in B are slightly higher due to the metal hydride content. For instance, under the reference temperature levels $\left(T_{m}=35^{\circ} \mathrm{C}, T_{c}=18^{\circ} \mathrm{C}\right)$, the simulations show that the regeneration temperature can be reduced down to $T_{h}=102^{\circ} \mathrm{C}$, though in this case the mean cooling power is only of around $147 \mathrm{~W}$.

\subsubsection{Modification of the alloy properties}

The kinetics and the P-C-T equilibrium properties of the alloys depend on their composition and on their preparation. Hence, each selected pair of alloys in $A$ and $B$ defines the performance of the metal hydride cooling system.

In this paragraph, the properties of the alloys (A3-B3) have been changed in order to search for a pair of alloys (A4-B4) capable of cooling with lower regeneration temperatures. The enthalpies of the alloys have been modified, but the hysteresis effect has been kept constant, in other words, that the related loss of free enthalpy $\Delta G_{\text {hys }}=R \cdot T \cdot \ln \left(P_{\text {abs }} / P_{\text {des }}\right)$ [47] is the same than for the reference alloys (A3-B3). The proposed (A4-B4) alloys are very similar to (A3B3) and could be reached by means of alloy treatment techniques.

By modifying the P-C-T properties of alloys A and B as well as the operation of the system, a new material combination A4-B4 is proposed where the system is more robust and capable of working under even lower regeneration temperatures than A3-B3.

Table 20 illustrates the operating conditions and the enthalpy characteristics which should be aimed with alloy treatment. With the suggested properties of alloys A4-B4, and under the reference temperatures levels $\left(T_{h}=130^{\circ} \mathrm{C}\right.$, $\mathrm{T}_{\mathrm{m}}=35^{\circ} \mathrm{C}, \mathrm{T}_{\mathrm{c}}=18^{\circ} \mathrm{C}$ ), a mean cooling power of around $852 \mathrm{~W}$ would be achieved. 
This value is practically the same as the performance of the optimised operation with A3-B3, but with the main difference that the A4-B4 system presents a better performance for regeneration temperatures below $130^{\circ} \mathrm{C}$. Even at $T_{h}=100^{\circ} \mathrm{C}$, as seen in Fig. 78 , the A4-B4 system is able to produce $293 \mathrm{~W}$ cooling power.

\begin{tabular}{|c|c|c|}
\hline$\Delta \mathrm{t}_{\text {cycle }}$ & 130 & $\mathrm{~S}$ \\
\hline$\Delta \mathrm{H}_{\text {abs, } A 4}$ & 20989 & $\mathrm{~J} \mathrm{~mol}^{-1}$ \\
\hline$\Delta \mathrm{H}_{\text {des, } A 4}$ & 26477 & $\mathrm{~J} \mathrm{~mol}^{-1}$ \\
\hline$\Delta \mathrm{H}_{\text {abs, } \mathrm{B} 4}$ & 27570 & $\mathrm{~J} \mathrm{~mol}^{-1}$ \\
\hline$\Delta \mathrm{H}_{\text {des, } \mathrm{B} 4}$ & 31426 & $\mathrm{~J} \mathrm{~mol}^{-1}$ \\
\hline $\mathrm{W}_{\text {A4,init reg }}$ & 0.72 & $\mathrm{wt} \%$ \\
\hline $\mathrm{W}_{\mathrm{B} 4 \text {, init reg }}$ & 0.91 & $\mathrm{wt} \%$ \\
\hline
\end{tabular}

Table 20. Characteristics of the A4-B4 system

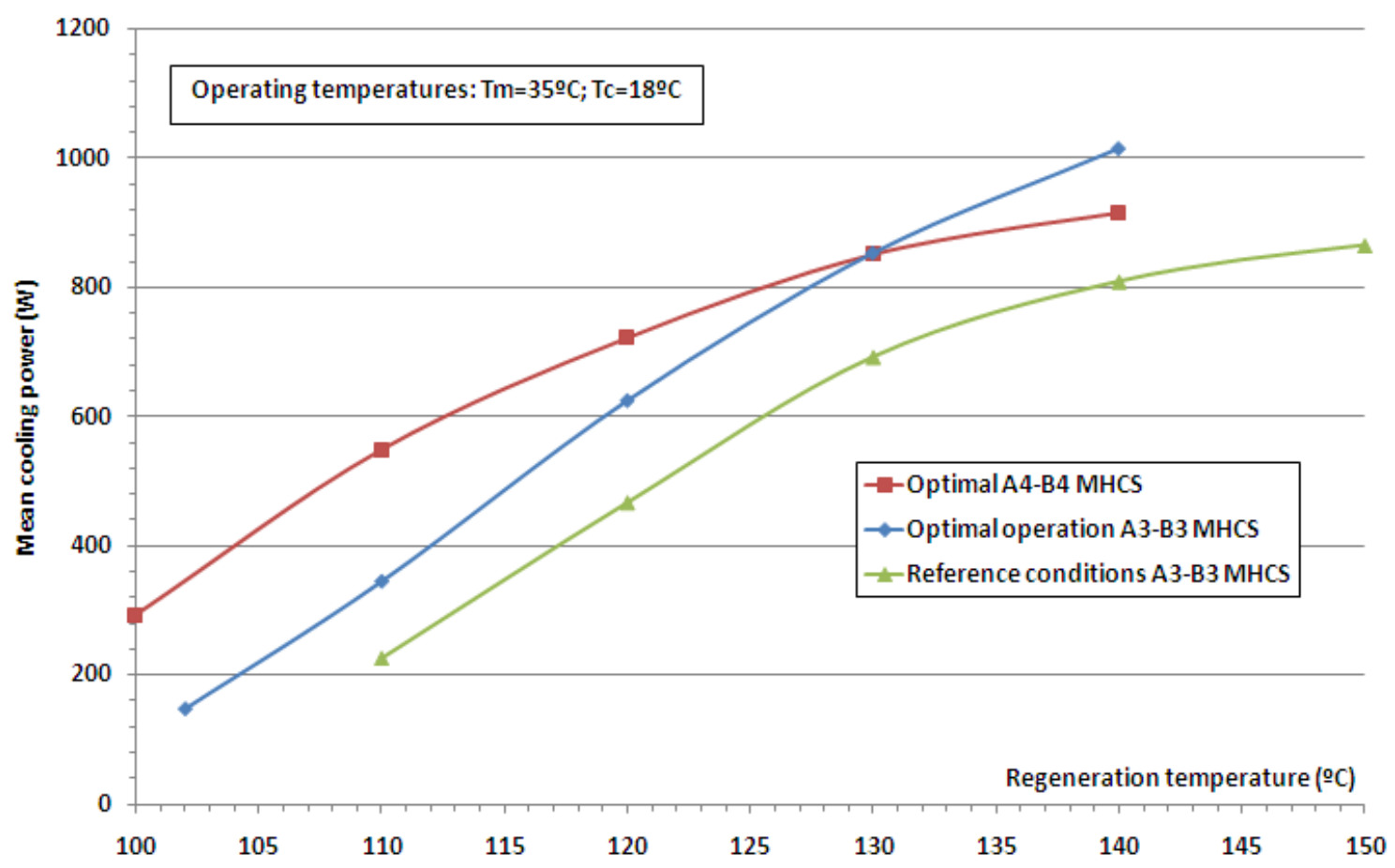

Fig. 78. Mean cooling power for the optimal A4-B4 MHCS

Fig. 79 shows the COP which is obtained with the optimal A3-B3 and A4-B4 systems. The aim of this study is to achieve the highest cooling powers and not the highest COP values. Hence, the highest COPs are obtained for the reference conditions, which have a cycle duration of $200 \mathrm{~s}$. In order to obtain higher cooling powers, the cycle duration has to be shortened, with the 
secondary effect of a lower COP. At regeneration temperatures below $123^{\circ} \mathrm{C}$., Fig. 79 shows that the most interesting system, also in terms of COP, is the optimal A4-B4 MHCS.

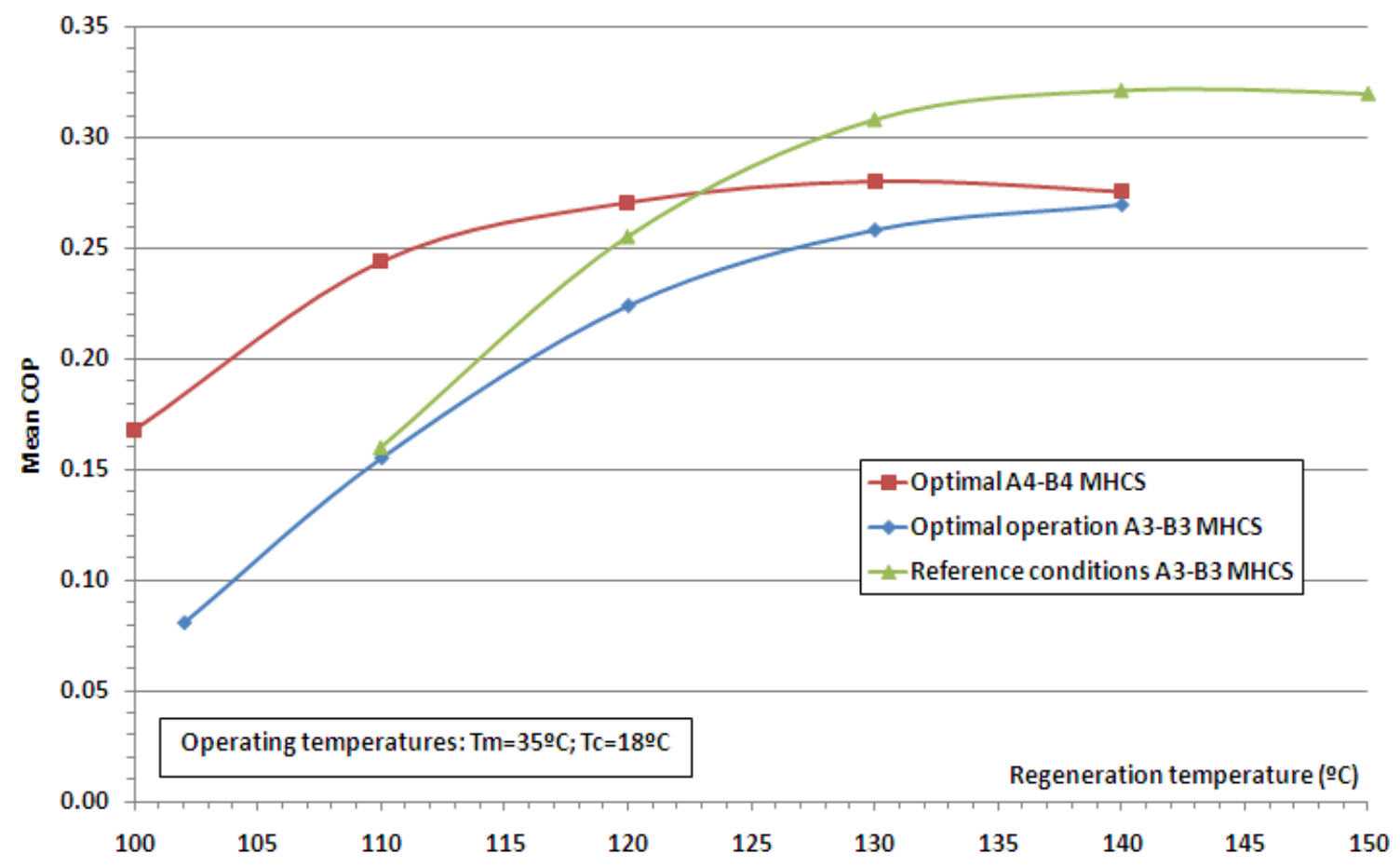

Fig. 79. Mean COP for the optimal A4-B4 MHCS

\subsection{Conclusions on the optimization results}

Fig. 80 summarises the cooling power which may be achieved with this same MHCS for different operation strategies given the temperature levels of $\left(\mathrm{T}_{\mathrm{h}}=130^{\circ} \mathrm{C}, \mathrm{T}_{\mathrm{m}}=35^{\circ} \mathrm{C}, \mathrm{T}_{\mathrm{c}}=18^{\circ} \mathrm{C}\right)$.

Before any optimization it is essential to first reduce the parasitic thermal inertia of the reaction beds. Only the substitution of the 2 brass heads for plastic heads may increase the cooling performance by $25 \%$, as seen in case (1).

Cases (1) to (5) also include the reduction of the metal mass, which is essential to achieve high cooling powers. If the cycle duration is shortened, the mean cooling power may increase up to $48 \%$. An increase in the hydrogen charge of the system helps to achieve an additional $41 \%$ cooling power with respect to case (0). 


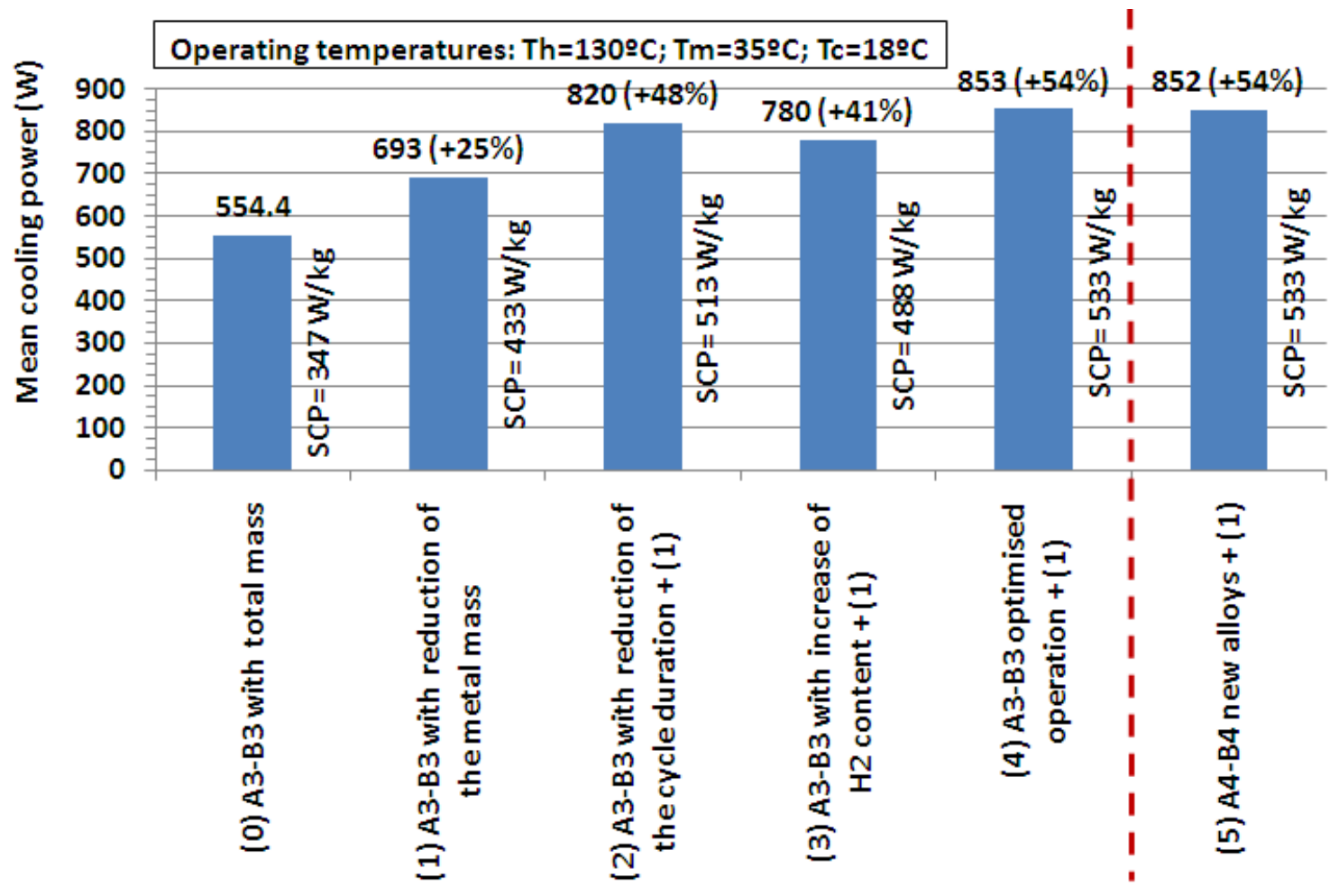

Fig. 80. Overall performance of the MHCS with different operation strategies

By optimising the whole operation of the reaction beds (less thermal mass, shorter cycle duration and increase of the hydrogen charge) the cooling performance can be increased in around $54 \%$, hereby achieving $853 \mathrm{~W}$ instead of the current $554 \mathrm{~W}$. With a proper optimization of the operating conditions (case (4)) a mean specific cooling power (SCP) of $533 \mathrm{~W} / \mathrm{kg}$ of desorbing metal powder ( $1.6 \mathrm{~kg}$ distributed in two cold reaction beds A) can be achieved. This value is sensibly higher than in former experimental systems from literature [1]. It is important to highlight that there is also a potential improvement to be made by means of a specific design of the alloy pairs which are inserted in the reaction beds. If the aim is to reduce the required regeneration temperature, the model shows in which direction the alloys should be tailored. With the suggested properties of A4-B4, the MHCS would have a better performance below $T_{h}=123^{\circ} \mathrm{C}$ than the current $A-B$ system.

Hence, the alloy selection is essential in any MHCS and the alloys may be chosen so as to achieve a target performance for any desired temperature levels $T_{h}-T_{m}-T_{c}$. 

Conclusions 


\section{Chapter 9. CONCLUSIONS}

\section{CONCLUSIONS}

In this $\mathrm{PhD}$, a dynamic model of a metal hydride cooling system has been developed. A priori, the modelling of such as system is not simple, as it involves coupled reactions of heat and mass transfer based on many unknown parameters. Hence, an important effort has been done to first characterize the alloys which are used in each reactor.

In the first place, it is essential to model the equilibrium P-C-T properties of the alloys which are used in the reactors, as these define the operating pressures of the system. The results have shown that in real conditions, it is hardly avoidable to work partially in the boundaries of the plateau region. Thus, it is important to include the modelling of the plateau boundaries. This aspect has been addressed in the overall model of the MHCS.

In the second place, the intrinsic kinetics of the alloys plays an important role on the performance of the system. Some innovative kinetic tests in the plateau region have been realized at IKE, particularly for alloy B3 which has the slower kinetics. A3 has very fast kinetics and hence, it works under quasi-equilibrium conditions. By means of the measured sorption curves, the intrinsic reaction kinetics of alloys A3 and B3 have been characterized.

In a coupled metal hydride cooling system, the exchange rate of hydrogen derives from the intrinsic kinetics of each reactor. Thus, it is complicated to predict this exchange rate unless the dynamics of each reactor is properly 


\section{Chapter 9. CONCLUSIONS}

modelled. This PhD work has provided a very good prediction of the exchanged mass flow rate with respect to the current state of the art in the modelling of such coupled systems.

The property variations of metallic alloys, when switching between absorption and desorption, have hardly been considered in literature. These are not relevant in storage applications, but in metal hydride cooling systems it is essential to take them into account. This $\mathrm{PhD}$ work presents an interesting approach to account for hysteresis. Although the experimental evolution has not been reproduced perfectly, a semi-empirical treatment of hysteresis has provided a robust simulation tool.

The dynamic model of the metal hydride cooling system has been validated with many different alloy combinations and operating conditions. Although the performance of this cooling system may seem low in comparison to other sorption technologies such as lithium bromide machines, the performance which has been achieved is very interesting with respect to the actual state of the art on metal hydride cooling systems. The cycle duration and the hydrogen exchange rate in the reactors are very fast, particularly due to the fast intrinsic kinetics of the alloys, and to the chosen regeneration temperatures. The specific cooling power of this system is interesting, although this technology cannot compete in terms of COP. The heating and cooling of pressurized reactors implies that a significant part of the energy is inevitably lost due to the parasitic thermal inertia of these systems.

From the point of view of the modelling, the results have shown that, even if the temperature of each particle in the reactor may be different, a zero dimensional 


\section{Chapter 9. CONCLUSIONS}

model based on a mean particle temperature may be sufficient to understand the behaviour of the whole system. This zero dimensional model is interesting for MHCS's which are not heat transfer limited. Furthermore, the results have shown the importance of the instantaneous metal hydride concentration on the performance of the coupled reactors. For the first time, the actual P-C curves have been calculated and compared with the static P-C-T curves. In the boundaries of the plateau region, the reactors are no longer performing because the hydrogen exchange rate is reduced substantially.

The optimization study has provided very interesting results proving that the operating conditions have a sensible impact on the performance of the system. Short cycle durations are essential to reach high cooling powers. Additionally, the hydrogen charge of the system plays a relevant role, as it determines the working position of the alloys with respect to their static P-C-T curves. Nevertheless, in parallel to the optimization of the operation, the thermal inertia of the reactors should be reduced. Particularly, a fairly simple modification which should be considered is to substitute the external brass heads with plastic heads.

Finally, the optimization study has shown that there is a potential improvement which can be made with different material combinations in the reactors. The performance of the MHCS depends strongly on the properties of the selected alloys. For instance, it has been shown that a new A4-B4 alloy combination, rather similar to the A3-B3 materials, can lower the required regeneration temperatures and achieve the same cooling power as the A3-B3 system, but with $118^{\circ} \mathrm{C}$ regeneration temperature instead of $130^{\circ} \mathrm{C}$. 
In conclusion, both the experimental installation and the modelling of the reactors have provided very interesting results with respect to the current state of the art on metal hydride cooling systems. As future work, some nice piece of work would be to build a new prototype with less thermal inertia in the heads, and with a careful selection of the alloys, trying to reach similar properties to the suggested A4-B4 alloys. 



\section{REFERENCES}

[1]. Muthukumar, P. and Groll, M., Metal hydride based heating and cooling systems: A review, International Journal of Hydrogen Energy 35 (8) (2010), pp. 3817-3831

[2]. Paya, J., Linder, M., Laurien, E., and Corberan, J. M., Dynamic model and experimental results of a thermally driven metal hydride cooling system, International Journal of Hydrogen Energy 34 (7) (2009), pp. 3173-3184

[3]. Gopal, M. Ram and Murthy, S. Srinivasa, Experiments on a metal hydride cooling system working with ZrMnFe/MmNi4.5Al0.5 pair, International Journal of Refrigeration 22 (2) (1999), pp. 137-149

[4]. Izhvanov, L. A., Solovey, A. I., Frolov, V. P., and Shanin, Y., Metal hydride heat pump-New type of heat converter, International Journal of Hydrogen Energy 21 (11-12) (1996), pp. 1033-1038

[5]. Mayer, U., Groll, M., and Supper, W., Heat and mass transfer in metal hydride reaction beds: Experimental and theoretical results, Journal of the Less Common Metals 131 (1-2) (1987), pp. 235-244

[6]. Qin, F., Chen, J., Lu, M., Chen, Z., Zhou, Y., and Yang, K., Development of a metal hydride refrigeration system as an exhaust gas-driven automobile air conditioner, Renewable Energy 32 (12) (2007), pp. 20342052

[7]. Kang, B. H., Park, C. W., and Lee, C. S., Dynamic behavior of heat and hydrogen transfer in a metal hydride cooling system, International Journal of Hydrogen Energy 21 (9) (1996), pp. 769-774

[8]. Bjurstrom, H., Komazaki, Y., and Suda, S., The dynamics of hydrogen transfer in a metal hydride heat pump, Journal of the Less Common Metals 131 (1-2) (1987), pp. 225-234

[9]. Lee, S.-G., Kim, Y.-K., and Lee, J.-Y., Operating characteristics of metal hydride heat pump using Zr-based laves phases, International Journal of Hydrogen Energy 20 (1) (1995), pp. 77-85

[10]. Gopal, M. Ram and Murthy, S. Srinivasa, Prediction of metal-hydride refrigerator performance based on reactor heat and mass transfer, International Journal of Hydrogen Energy 20 (7) (1995), pp. 607-614

[11]. Aldas, K., Mat, M. D., and Kaplan, Y., A three-dimensional mathematical model for absorption in a metal hydride bed, International Journal of Hydrogen Energy 27 (10) (2002), pp. 1049-1056

[12]. Demircan, A., Demiralp, M., Kaplan, Y., Mat, M. D., and Veziroglu, T. N., Experimental and theoretical analysis of hydrogen absorption in LaNi5- $\mathrm{H} 2$ reactors, International Journal of Hydrogen Energy 30 (13-14) (2005), pp. 1437-1446 
[13]. Gambini, M., Manno, M., and Vellini, M., Numerical analysis and performance assessment of metal hydride-based hydrogen storage systems, International Journal of Hydrogen Energy 33 (21) (2008), pp. 6178-6187

[14]. Gopal, M. Ram and Murthy, S. Srinivasa, Studies on heat and mass transfer in metal hydride beds, International Journal of Hydrogen Energy 20 (11) (1995), pp. 911-917

[15]. Mat, M. D. and Kaplan, Y., Numerical study of hydrogen absorption in an Lm-Ni5 hydride reactor, International Journal of Hydrogen Energy 26 (9) (2001), pp. 957-963

[16]. Jemni, A. and Nasrallah, S. B., Study of two-dimensional heat and mass transfer during absorption in a metal-hydrogen reactor, International Journal of Hydrogen Energy 20 (1) (1995), pp. 43-52

[17]. Jemni, A. and Nasrallah, S. B., Study of two-dimensional heat and mass transfer during desorption in a metal-hydrogen reactor, International Journal of Hydrogen Energy 20 (11) (1995), pp. 881-891

[18]. Jemni, A., Nasrallah, S. B., and Lamloumi, J., Experimental and theoretical study of a metal-hydrogen reactor, International Journal of Hydrogen Energy 24 (7) (1999), pp. 631-644

[19]. Askri, F., Jemni, A., and Nasrallah, S. B., Prediction of transient heat and mass transfer in a closed metal-hydrogen reactor, International Journal of Hydrogen Energy 29 (2) (2004), pp. 195-208

[20]. Askri, F., Jemni, A., and Nasrallah, S. B., Dynamic behavior of metalhydrogen reactor during hydriding process, International Journal of Hydrogen Energy 29 (6) (2004), pp. 635-647

[21]. Gambini, M., Metal hydride energy systems performance evaluation. Part B: Performance analysis model of dual metal hydride energy systems, International Journal of Hydrogen Energy 19 (1) (1994), pp. 81-97

[22]. Anil Kumar, E., Prakash Maiya, M., and Murthy, S. Srinivasa, Influence of transient operating conditions on pressure-concentration isotherms and storage characteristics of hydriding alloys, International Journal of Hydrogen Energy 32 (13) (2007), pp. 2382-2389

[23]. Ni, J. and Liu, H., Experimental research on refrigeration characteristics of a metal hydride heat pump in auto air-conditioning, International Journal of Hydrogen Energy 32 (13) (2007), pp. 2567-2572

[24]. Yang, F. S., Wang, G. X., Zhang, Z. X., Meng, X. Y., and Rudolph, V., Design of the metal hydride reactors - A review on the key technical issues, International Journal of Hydrogen Energy 35 (8) (2010), pp. 38323840 
[25]. Pons, M., Meunier, F., Cacciola, G., Critoph, R. E., Groll, M., Puigjaner, L., Spinner, B., and Ziegler, F., Thermodynamic based comparison of sorption systems for cooling and heat pumping, International Journal of Refrigeration 22 (1) (1999), pp. 5-17

[26]. Rodriguez, A., Klein, H. P., and Groll, M., Expanded graphite as heat transfer matrix in metal hydride beds, International Journal of Hydrogen Energy 28 (5) (2003), pp. 515-527

[27]. Groll, M., Reaction beds for dry sorption machines, Heat Recovery Systems and CHP 13 (4) (1993), pp. 341-346

[28]. Gambini, M., Metal hydride energy systems performance evaluation. Part A: Dynamic analysis model of heat and mass transfer, International Journal of Hydrogen Energy 19 (1) (1994), pp. 67-80

[29]. Satheesh, A., Muthukumar, P., and Dewan, Anupam, Computational study of metal hydride cooling system, International Journal of Hydrogen Energy 34 (7) (2009), pp. 3164-3172

[30]. Satheesh, A. and Muthukumar, P., Simulation of double-stage doubleeffect metal hydride heat pump, International Journal of Hydrogen Energy 35 (3) (2010), pp. 1474-1484

[31]. Nasrallah, S. B. and Jemni, A., Heat and mass transfer models in metalhydrogen reactor, International Journal of Hydrogen Energy 22 (1) (1997), pp. 67-76

[32]. Askri, F., Jemni, A., and Nasrallah, S. B., Study of two-dimensional and dynamic heat and mass transfer in a metal-hydrogen reactor, International Journal of Hydrogen Energy 28 (5) (2003), pp. 537-557

[33]. Sun, D. and Deng, S., Study of the heat and mass transfer characteristics of metal hydride beds: A two-dimensional model, Journal of the Less Common Metals 155 (2) (1989), pp. 271-279

[34]. Dogan, A., Kaplan, Y., and Veziroglu, T. N., Numerical investigation of heat and mass transfer in a metal hydride bed, Applied Mathematics and Computation 150 (1) (2004), pp. 169-180

[35]. Isselhorst, A., Heat and mass transfer in coupled hydride reaction beds, Journal of Alloys and Compounds 231 (1-2) (1995), pp. 871-879

[36]. Ram Gopal, M. and Srinivasa Murthy, S., Performance of a metal hydride cooling system, International Journal of Refrigeration 18 (6) (1995), pp. 413-420

[37]. Gopal, M. Ram and Murthy, S. Srinivasa, Performance of a metal hydride cooling system, International Journal of Refrigeration 18 (6) (1995), pp. 413-420 
[38]. Muthukumar, P., Linder, M., Mertz, R., and Laurien, E., Measurement of thermodynamic properties of some hydrogen absorbing alloys, International Journal of Hydrogen Energy 34 (4) (2009), pp. 1873-1879

[39]. Friedlmeier, G., Schaaf, M., and Groll, M., How to Measure PressureConcentration-Isotherms Representative for Technical Applications, Zeitschrift fur Physikalische Chemie-International Journal of Research in Physical Chemistry \& Chemical Physics 183) (1994), pp. 185-195

[40]. Ying, F., PhD thesis: Investigation on hydrogen storage properties of Mgbased nanostructured composites (2007)

[41]. Friedlmeier, G., PhD thesis: Characterization of magnesium based high temperature metal hydrides (1997)

[42]. Züttel, A., Metall-hydride. Vorlesungsskript (Lecture note) (1988)

[43]. Storage Technology Report. ST5: Electrolyser, hydrogen storage and Fuel Cell. European Project FP5 Contract n ENK5-CT-2000-20336 (2003)

[44]. Sakintuna, B., Lamari-Darkrim, F., and Hirscher, M., Metal hydride materials for solid hydrogen storage: A review, International Journal of Hydrogen Energy 32 (9) (2007), pp. 1121-1140

[45]. Zhou, L., Progress and problems in hydrogen storage methods, Renewable and Sustainable Energy Reviews 9 (4) (2005), pp. 395-408

[46]. Fabre, E. and Spinner, B., Une politique de recherche et développement pour des énergies durables. CNRS \& Ministère de la Recherche et des Nouvelles Technologies (2003)

[47]. Fukai, Y., The Metal-Hydrogen System (1992), pp. 88-95

[48]. Kandavel, M. and Ramaprabhu, S., Semi-empirical model for enthalpy of formation and hydrogen content in Zr-based AB2 alloys, International Journal of Hydrogen Energy 32 (5) (2007), pp. 620-625

[49]. Dehouche, Z., Grimard, N., Laurencelle, F., Goyette, J., and Bose, T. K., Hydride alloys properties investigations for hydrogen sorption compressor, Journal of Alloys and Compounds 399 (1-2) (2005), pp. 224-236

[50]. Griesinger, A., Spindler, K., and Hahne, E., Measurements and theoretical modelling of the effective thermal conductivity of zeolites, International Journal of Heat and Mass Transfer 42 (23) (1999), pp. 4363-4374

[51]. VDI Heat Atlas. VDI-Verlag, Düsseldorf (1993)

[52]. Sahnoune, H. and Grenier, P. H., Mesure de la conductivité thermique d'une zeolithe, The Chemical Engineering Journal 40 (1) (1989), pp. 45-54 
[53]. Gurgel, J. M. and Klüppel, R. P., Thermal conductivity of hydrated silicagel, The Chemical Engineering Journal and the Biochemical Engineering Journal 61 (2) (1996), pp. 133-138

[54]. Hahne, E. and Kallweit, J., Thermal conductivity of metal hydride materials for storage of hydrogen: Experimental investigation, International Journal of Hydrogen Energy 23 (2) (1998), pp. 107-114

[55]. Sandrock, G., Gross, K., and Thomas, G., Effect of Ti-catalyst content on the reversible hydrogen storage properties of the sodium alanates, Journal of Alloys and Compounds 339 (1-2) (2002), pp. 299-308

[56]. Tran, N. E., Lambrakos, S. G., and Imam, M. Ashraf, Analyses of hydrogen sorption kinetics and thermodynamics of magnesium-misch metal alloys, Journal of Alloys and Compounds 407 (1-2) (2006), pp. 240-248

[57]. Bouaricha, S., Dodelet, J. P., Guay, D., Huot, J., Boily, S., and Schulz, R., Hydriding behavior of $\mathrm{Mg}-\mathrm{Al}$ and leached $\mathrm{Mg}-\mathrm{Al}$ compounds prepared by high-energy ball-milling, Journal of Alloys and Compounds 297 (1-2) (2000), pp. 282-293

[58]. Srinivas, G., Sankaranarayanan, V., and Ramaprabhu, S., Kinetics of hydrogen absorption in Ho1-xMmxCo2 alloys, Journal of Alloys and Compounds 448 (1-2) (2008), pp. 159-165

[59]. Friedlmeier, G. and Groll, M., Experimental analysis and modelling of the hydriding kinetics of Ni-doped and pure Mg, Journal of Alloys and Compounds 253-254) (1997), pp. 550-555

[60]. Lacher, J. R., A theoretical formula for the solubility of hydrogen in palladium, Proceedings of the Royal Society of London Series AMathematical and Physical Sciences 161) (1937), pp. 525-545

[61]. Davidson, D. J., Sai Raman, S. S., Lototsky, M. V., and Srivastava, O. N., On the computer simulation of the $\mathrm{P}-\mathrm{C}$ isotherms of $\mathrm{ZrFe} 2$ type hydrogen storage materials, International Journal of Hydrogen Energy 28 (12) (2003), pp. 1425-1431

[62]. Lototsky, M. V., Yartys, V. A., Marinin, V. S., and Lototsky, N. M., Modelling of phase equilibria in metal-hydrogen systems, Journal of Alloys and Compounds 356-357) (2003), pp. 27-31

[63]. Singh, R. K., Gupta, B. K., Lototsky, M. V., and Srivastava, O. N., On the synthesis and hydrogenation behaviour of MmNi5-xFex alloys and computer simulation of their P-C-T curves, Journal of Alloys and Compounds 373 (1-2) (2004), pp. 208-213

[64]. Roy, S., Singh, B. K., Lototsky, M. V., and Srivastava, O. N., On the structural, hydrogenation behaviour and computer simulation studies of $\mathrm{P}$ C-T of Zr1-2xMmxTixFe1.4Cr0.6 ( $\mathrm{x}=0.03,0.05,0.07,0.09$ ) alloys, Journal of Alloys and Compounds 397 (1-2) (2005), pp. 140-148 
[65]. Singh, R. K., Lototsky, M. V., and Srivastava, O. N., Thermodynamical, structural, hydrogen storage properties and simulation studies of P-C isotherms of, International Journal of Hydrogen Energy 32 (14) (2007), pp. 2971-2976

[66]. Beeri, O., Cohen, D., Gavra, Z., Johnson, J. R., and Mintz, M. H., Highpressure studies of the TiCr1.8-H2 system Statistical thermodynamics above the critical temperature, Journal of Alloys and Compounds 267 (1-2) (1998), pp. 113-120

[67]. Samsun, B. M., Fukada, S., and Fujiwara, H., Hydrogen isotope absorption amount and rate of $\mathrm{Pd}-\mathrm{Al} 2 \mathrm{O} 3$ pellets, International Journal of Hydrogen Energy 26 (3) (2001), pp. 225-229

[68]. Fang, S., Zhou, Z., Zhang, J., Yao, M., Feng, F., and Northwood, D. O., Two mathematical models for the hydrogen storage properties of $A B 2$ type alloys, Journal of Alloys and Compounds 293-295) (1999), pp. 10-13

[69]. Fang, S., Zhou, Z., Zhang, J., Yao, M., Feng, F., and Northwood, D. O., The application of mathematical models to the calculation of selected hydrogen storage properties (formation enthalpy and hysteresis) of AB2type alloys, International Journal of Hydrogen Energy 25 (2) (2000), pp. 143-149

[70]. Dhaou, H., Askri, F., Ben Salah, M., Jemni, A., Nasrallah, S. B., and Lamloumi, J., Measurement and modelling of kinetics of hydrogen sorption by LaNi5 and two related pseudobinary compounds, International Journal of Hydrogen Energy 32 (5) (2007), pp. 576-587

[71]. MacDonald, Brendan D. and Rowe, Andrew M., Experimental and numerical analysis of dynamic metal hydride hydrogen storage systems, Journal of Power Sources 174 (1) (2007), pp. 282-293

[72]. Lexcellent, C. and Gondor, G., Analysis of hydride formation for hydrogen storage: Pressure-composition isotherm curves modeling, Intermetallics 15 (7) (2007), pp. 934-944

[73]. Zhou, Z., Zhang, J., Ge, J., Feng, F., and Dai, Z., Mathematical modeling of the PCT curve of hydrogen storage alloys, International Journal of Hydrogen Energy 19 (3) (1994), pp. 269-273

[74]. Feng, F., Geng, M., and Northwood, D. O., Mathematical model for the plateau region of $\mathrm{P}$-C-isotherms of hydrogen-absorbing alloys using hydrogen reaction kinetics, Computational Materials Science 23 (1-4) (2002), pp. 291-299

[75]. Muthukumar, P., Prakash Maiya, M., and Murthy, S. Srinivasa, Experiments on a metal hydride-based hydrogen storage device, International Journal of Hydrogen Energy 30 (15) (2005), pp. 1569-1581

[76]. Leela Mohana Reddy, A. and Ramaprabhu, S., Structural and hydrogen absorption kinetics studies of polymer dispersed and boron added $\mathrm{Zr}$ - 
based AB2 alloy, International Journal of Hydrogen Energy 31 (7) (2006), pp. $867-876$

[77]. Muthukumar, P., Satheesh, A., Linder, M., Mertz, R., and Groll, M., Studies on hydriding kinetics of some La-based metal hydride alloys, International Journal of Hydrogen Energy 34 (17) (2009), pp. 7253-7262

[78]. Bloch, J., The kinetics of a moving metal hydride layer, Journal of Alloys and Compounds 312 (1-2) (2000), pp. 135-153

[79]. Liu, J., Zhang, X., Li, Q., Chou, K.-C., and Xu, K.-D., Investigation on kinetics mechanism of hydrogen absorption in the La2Mg17-based composites, International Journal of Hydrogen Energy 34 (4) (2009), pp. 1951-1957

[80]. Srinivas, G., Sankaranarayanan, V., and Ramaprabhu, S., Hydrogen absorption and desorption properties of $\mathrm{Ho1}-\mathrm{xMm \times Co2}$ alloys, International Journal of Hydrogen Energy 32 (13) (2007), pp. 2480-2487

[81]. Sandrock, G., Gross, K., Thomas, G., Jensen, C., Meeker, D., and Takara, S., Engineering considerations in the use of catalyzed sodium alanates for hydrogen storage, Journal of Alloys and Compounds 330-332) (2002), pp. 696-701

[82]. Choong-Nyeon, P. and Jai-Young, L., Kinetic properties of the hydrogenation of the FeTi intermetallic compound, Journal of the Less Common Metals 91 (2) (1983), pp. 189-201

[83]. Forde, T., Maehlen, J. P., Yartys, V. A., Lototsky, M. V., and Uchida, H., Influence of intrinsic hydrogenation/dehydrogenation kinetics on the dynamic behaviour of metal hydrides: A semi-empirical model and its verification, International Journal of Hydrogen Energy 32 (8) (2007), pp. 1041-1049

[84]. Han, J. I. and Lee, J. Y., Hydriding kinetics of LaNi5 and LaNi4.7AI0.3, International Journal of Hydrogen Energy 14 (3) (1989), pp. 181-186

[85]. Ouyang, L. Z., Qin, F. X., and Zhu, M., The hydrogen storage behavior of Mg3La and Mg3LaNi0.1, Scripta Materialia 55 (12) (2006), pp. 1075-1078

[86]. Varin, R. A., Czujko, T., Wasmund, E. B., and Wronski, Z. S., Catalytic effects of various forms of nickel on the synthesis rate and hydrogen desorption properties of nanocrystalline magnesium hydride ( $\mathrm{MgH} 2)$ synthesized by controlled reactive mechanical milling (CRMM), Journal of Alloys and Compounds 432 (1-2) (2007), pp. 217-231

[87]. Mani, N. and Ramaprabhu, S., Effect of substitutional elements on hydrogen absorption properties in $\mathrm{ZrMnFe} 0.5 \mathrm{NiO} .5$ and $\mathrm{ZrMnFe} 0.5 \mathrm{Co} 0.5$, International Journal of Hydrogen Energy 30 (1) (2005), pp. 53-67

[88]. Li, Q., Chou, K.-C., Lin, Q., Jiang, L.-J., and Zhan, F., Influence of the initial hydrogen pressure on the hydriding kinetics of the Mg2-xAlxNi 
$(\mathrm{x}=0,0.1)$ alloys, International Journal of Hydrogen Energy 29 (13) (2004), pp. $1383-1388$

[89]. Li, Q., Jiang, L.-J., Chou, K.-C., Lin, Q., Zhan, F., Xu, K.-D., Lu, X.-G., and Zhang, J.-Y., Effect of hydrogen pressure on hydriding kinetics in the Mg2$\mathrm{xAgxNi-H}(\mathrm{x}=0.05,0.1)$ system, Journal of Alloys and Compounds 399 (12) (2005), pp. 101-105

[90]. Nagel, M., Komazaki, Y., Matsubara, Y., and Suda, S., Dynamic behaviour of paired metal hydrides II: Analytical survey of the experimental results, Journal of the Less Common Metals 123 (1-2) (1986), pp. 47-58

[91]. Freni, A., Cipiti, F., and Cacciola, G., Finite element-based simulation of a metal hydride-based hydrogen storage tank, International Journal of Hydrogen Energy 34 (20) (2009), pp. 8574-8582

[92]. Paya, J. and Corberan, J. M., Theoretical model of the effective thermal conductivity of sorption materials, Proceedings of the 2nd International Conference on Solar Air-Conditioning, Tarragona (2007), pp. 322-327

[93]. Paya, J., Linder, M., Laurien, E., and Corberan, J. M., Mathematical models for the P-C-T characterization of hydrogen absorbing alloys, Journal of Alloys and Compounds 484 (1-2) (2009), pp. 190-195

[94]. Paya, J., Corberan, J. M., Linder, M., and Mertz, R., Dynamical model of a metal hydride cooling system driven by waste heat, Proceedings of the 2nd International Conference on Solar Air-Conditioning, Tarragona (2007), pp. 529-534

[95]. Paya, J., Corberan, J. M., Linder, M., and Mertz, R., Thermally driven metal hydride cooling systems: Experimental and numerical results of a 400W system, 3rd International Conference on Solar Air-Conditioning (Palermo) (2009), pp. 222-229 